\title{
How Does Business Strategy Treat Cognition?
}

\author{
By \\ Alan John Mayo
}

A thesis

submitted to the Victoria University of Wellington in fulfilment of the requirements for the degree of Doctor of Philosophy

Victoria University of Wellington 2020 



\section{Table of Contents}

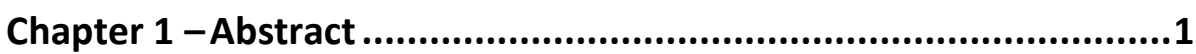

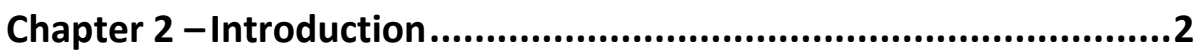

Part One - Knowledge and Cognition ............................... 8

Chapter 3 -Epistemology ..............................................................

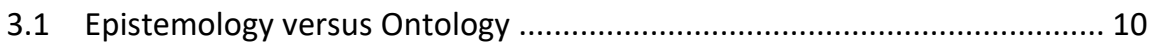

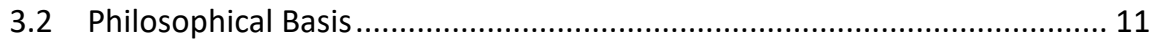

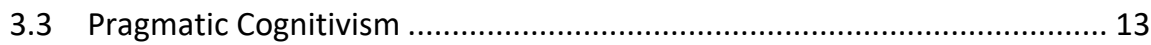

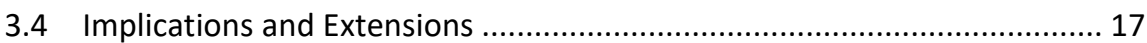

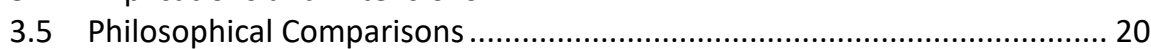

3.6 Utility of Pragmatic Cognitivism .............................................................. 22

3.7 Social Constructionism and Environmental Determinism ......................... 24

3.8 Epistemology Summarized .............................................................. 25

Chapter 4 -Methodology .........................................................26

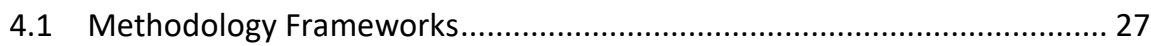

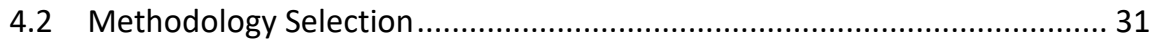

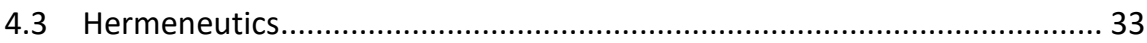

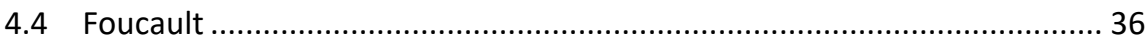

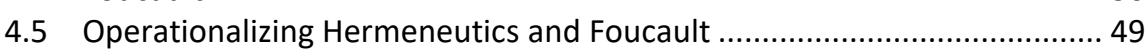

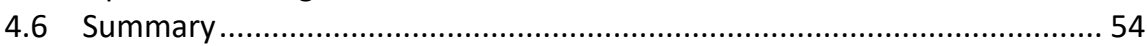

Chapter 5 -A Review of Treatments of Cognition ........................55

5.1 Treatments of Cognition ......................................................................... 56

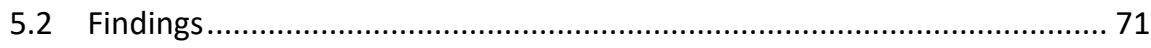

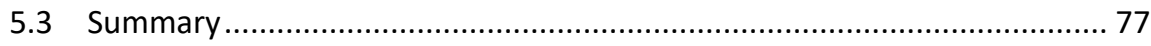

Chapter 6 -Heuristic, Insights and Cognitive Models ....................79

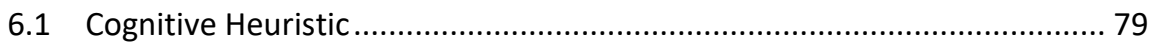

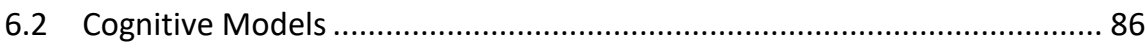

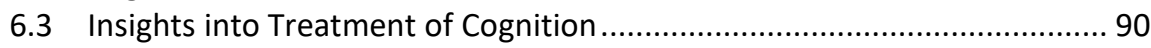

6.4 Definitions, Heuristic, and Cognitive Models.......................................... 91

Chapter 7 -Knowledge and Cognition Summary ..........................92

Part Two - Business Strategy and Cognition ................... 93

Chapter 8-Discourse Definition and Text Selection........................98

8.1 Decision Criteria........................................................................................ 99

8.2 Mainstream and Academic Strategy Discourses................................... 100

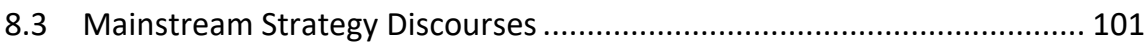

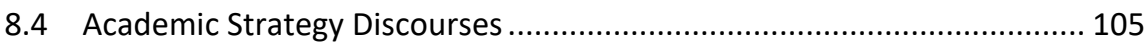

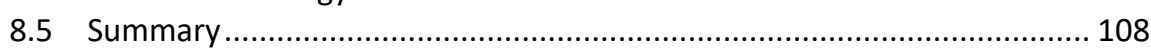

Chapter 9 -Classical ............................................................. 109

9.1 Early Pioneers ............................................................................... 112

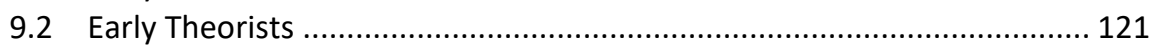

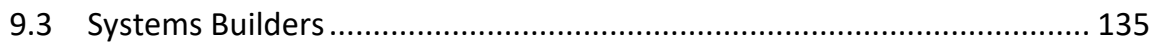

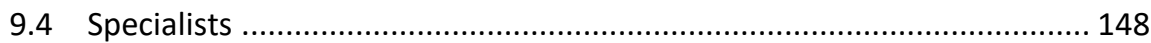

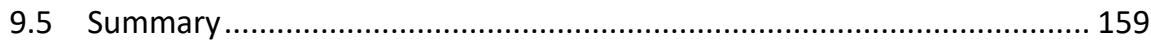


Chapter 10 - Managerial and Organizational Cognition 166

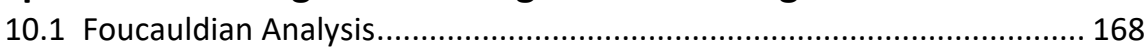

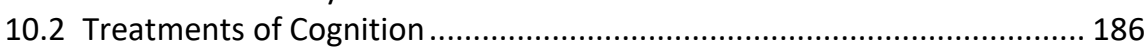

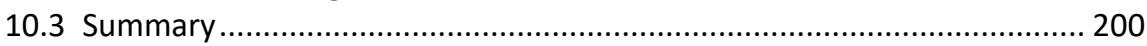

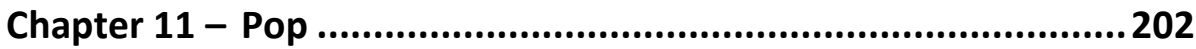

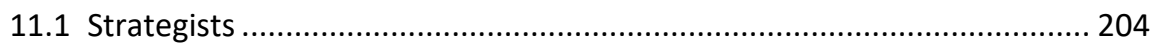

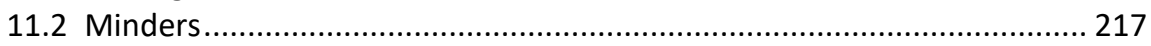

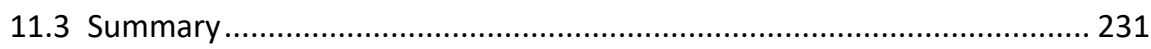

Chapter 12 - Strategy as Practice ........................................... 237

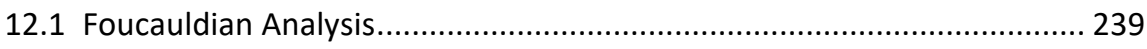

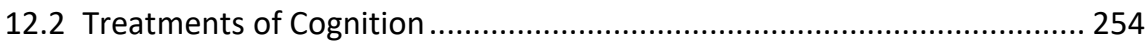

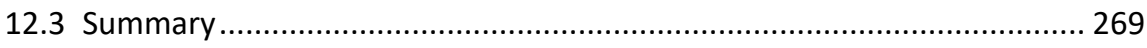

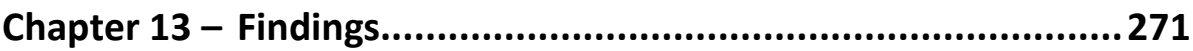

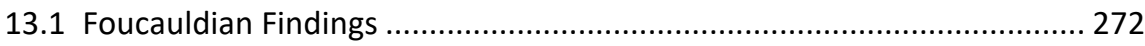

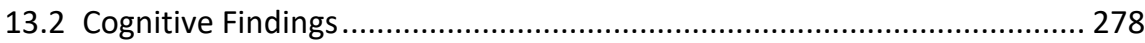

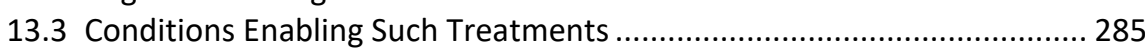

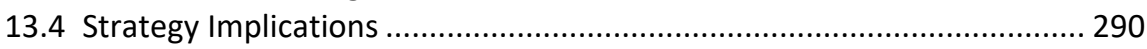

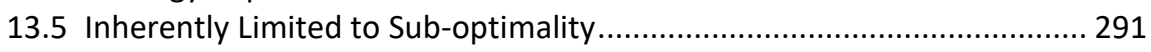

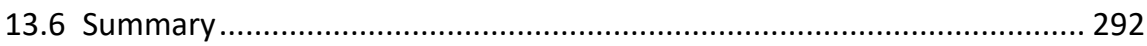

Part Three - Recommendations.................................. 294

Chapter 14 - References ..............................................................304 


\section{Table of Tables}

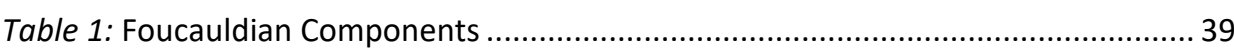

Table 2: Foucauldian Components Without 'The Other' .............................................. 48

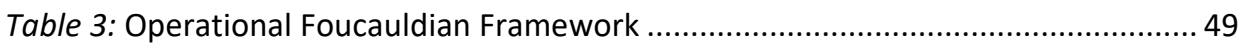

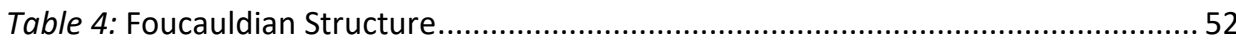

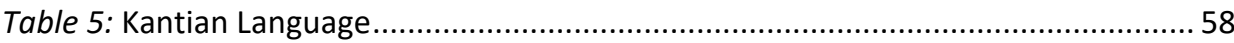

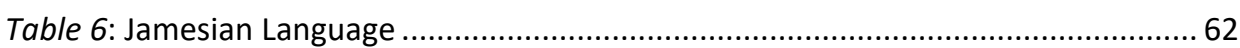

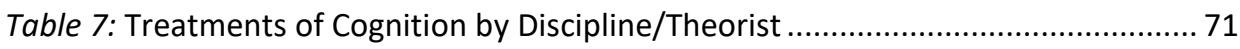

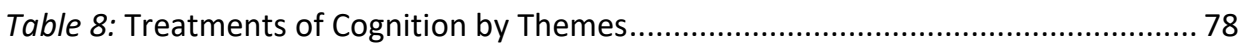

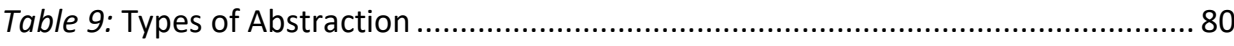

Table 10: Strategy-Cognitive Process Definitions ...................................................... 82

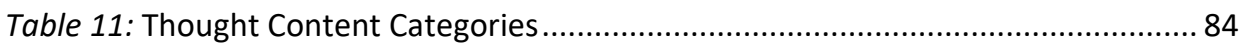

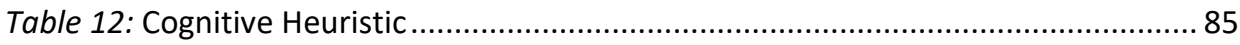

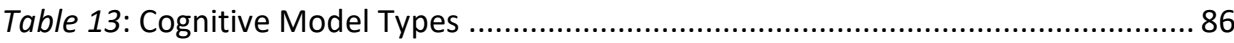

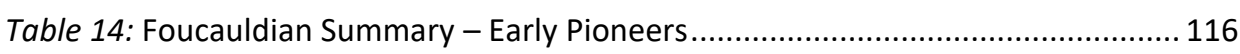

Table 15: Cognitive Summary - Early Pioneers ........................................................ 119

Table 16: Foucauldian Summary - Early Theorists .................................................... 128

Table 17: Cognitive Summary - Early Theorists ....................................................... 132

Table 18: Foucauldian Summary - Systems Builders ............................................... 140

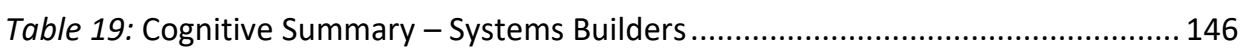

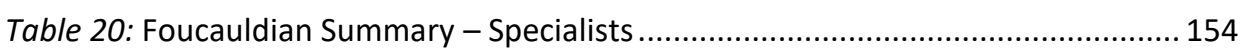

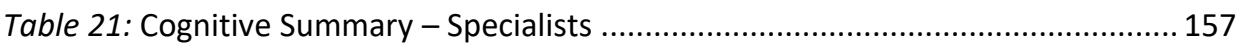

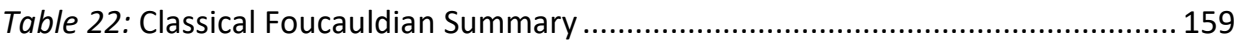

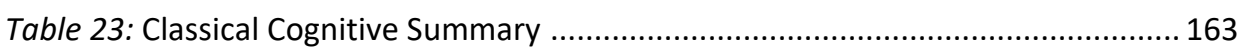

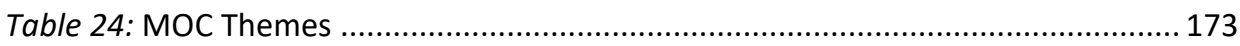

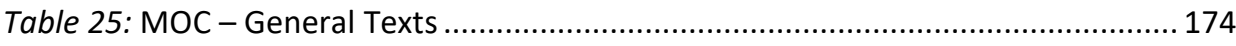

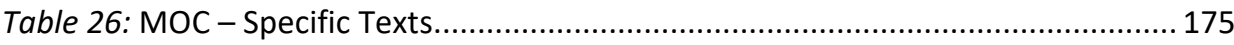

Table 27: MOC - Decision Making Texts ...................................................................... 176

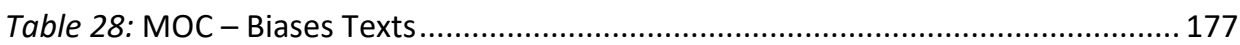

Table 29: MOC - Mental Models / Strategic Groups Texts ........................................ 178

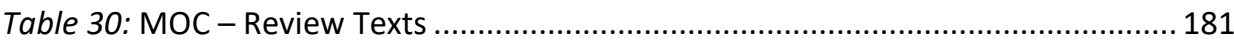

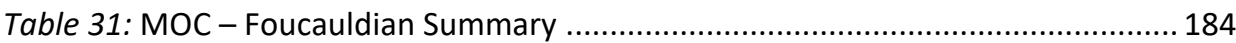

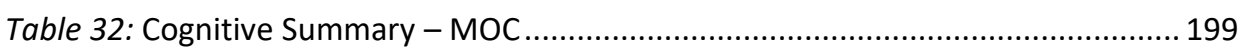

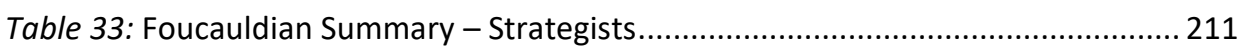

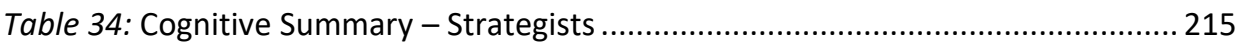

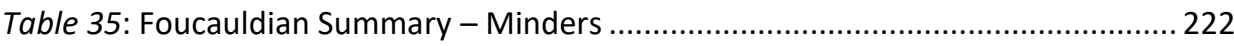

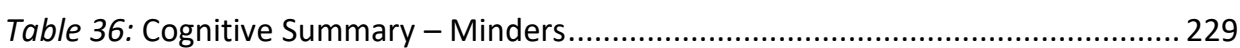

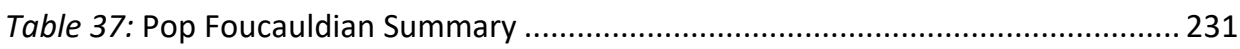

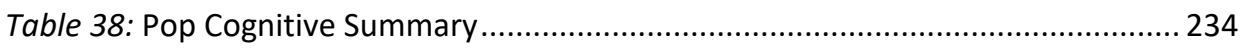


Table 39: SaP - Foundation Texts

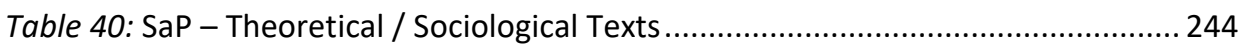

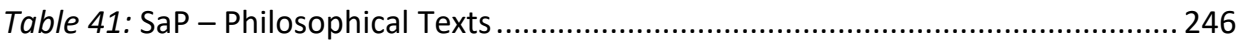

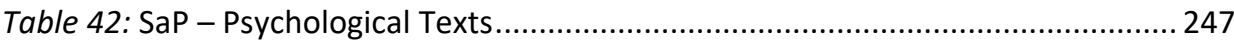

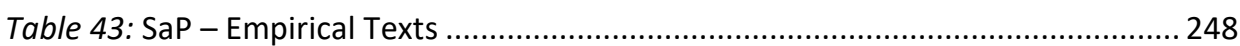

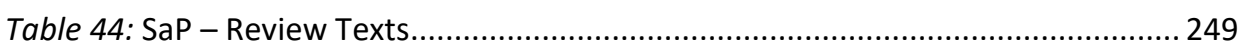

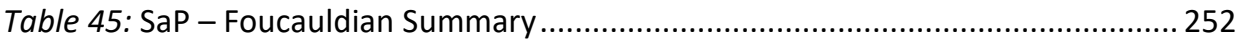

Table 46: Cognitive Summary - SaP Foundation Texts ........................................... 255

Table 47: Cognitive Summary - SaP Theoretical Texts ............................................. 260

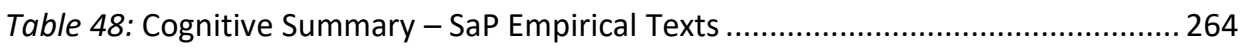

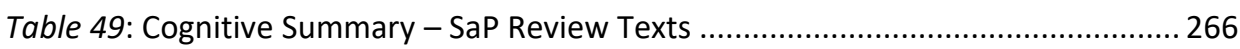

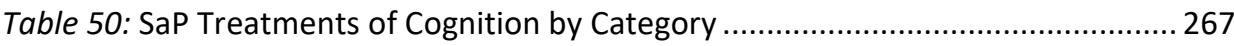

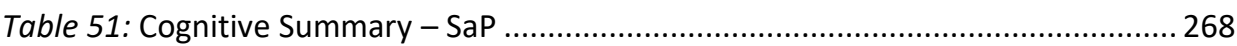

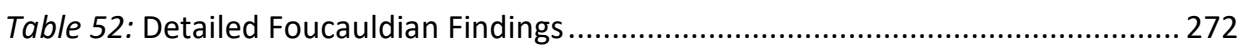

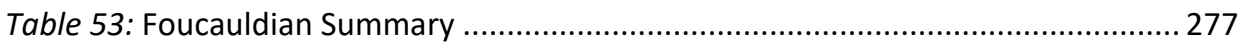

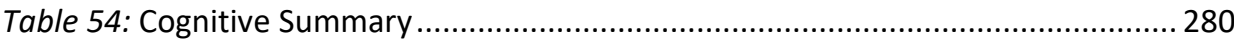

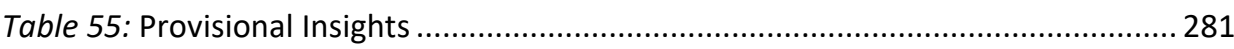

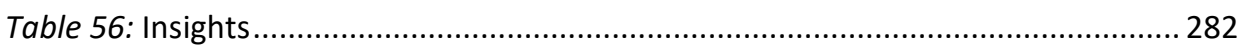




\section{Table of Figures}

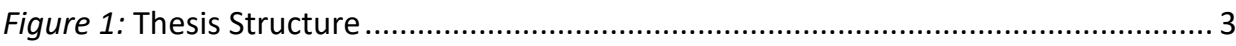

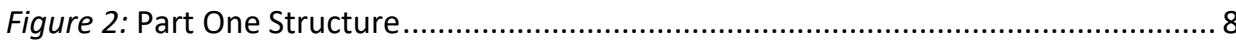

Figure 3: Burrell and Morgan Summarized. .............................................................. 28

Figure 4: Alvesson and Sköldberg Summarized ..................................................... 29

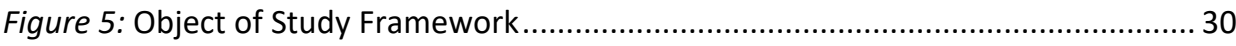

Figure 6: Categorization of Research Methods and Approaches ............................... 31

Figure 7: "Major factors affecting perceived desirability of movement." ......................67 67

Figure 8: "Some factors affecting selective attention to subgoals." .............................68

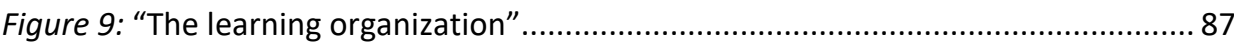

Figure 10: "Major factors affecting perceived desirability of movement" ..................... 88

Figure 11: "A cognitive model of organizational renewal" ......................................... 89

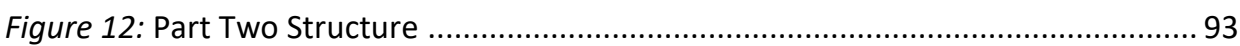

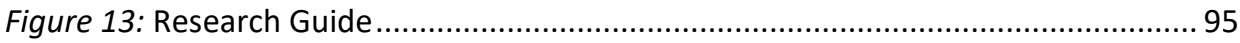

Figure 14: Foucauldian Framework Progression ..................................................... 96

Figure 15: Cognitive Heuristic Progression .......................................................... 97

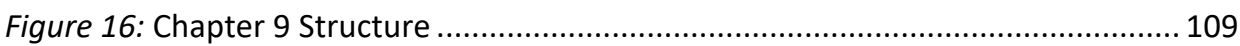

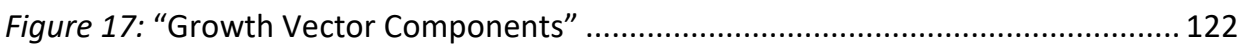

Figure 18: "Decision flow in product-market strategy formulation" .......................... 123

Figure 19: "Structure and Process of Business Companywide Planning" .................... 135

Figure 20: "How values influence company strategy" ............................................... 143

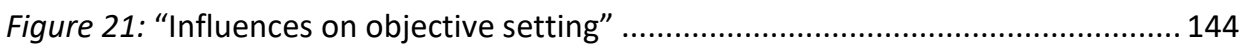

Figure 22: "A model of the strategic decision process" ............................................. 144

Figure 23: "An approach to environmental analysis" ............................................... 145

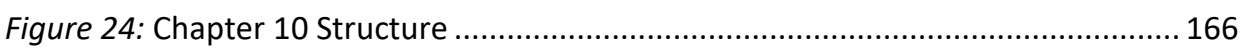

Figure 25: "Strategic problem comprehension" ...................................................... 187

Figure 26: "A cognitive model of organizational renewal" ...................................... 188

Figure 27: "A model of directors' cognitive contribution to strategic decision making"

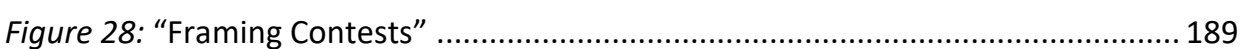

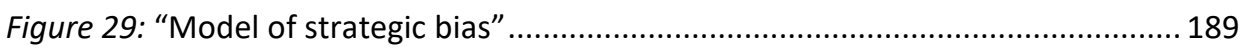

Figure 30: "Strategic sensemaking and sensegiving in practice" ............................. 190

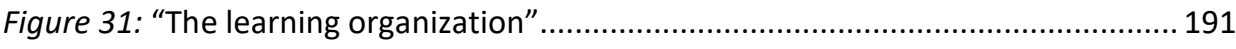

Figure 32: "Cognition and Capabilities - A Linear Model." ........................................ 191

Figure 33: "Elicited 'cognitive taxonomy' of one managing director of a Scottish

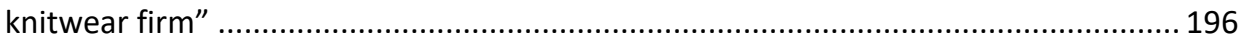

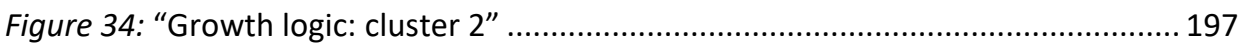

Figure 35: “Customers' causal cognitive map: pattern 1" ........................................ 198

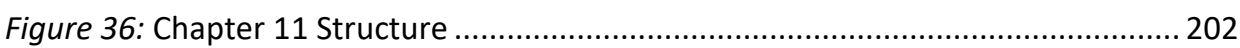


Figure 37: "Five-phase model of the organizational knowledge-creation process" .... 228

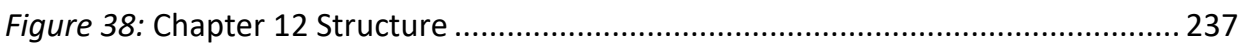

Figure 39: "Integrating Praxis, Practices and Practitioners" ...................................... 256

Figure 40: "Basic typology of contrasting cognitive strategies and style".................... 259

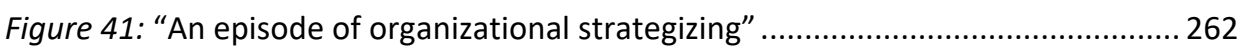

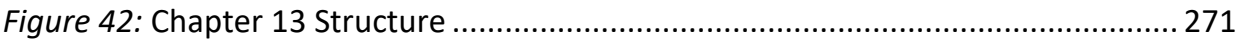

Figure 43: Conditions of Possibility Summarized .................................................. 273

Figure 44: Problematization Summarized ............................................................. 274

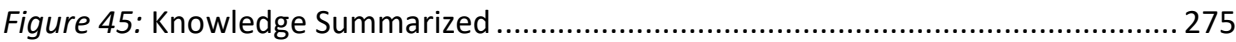

Figure 46: Social Effects/Subjectivity Summarized................................................. 276

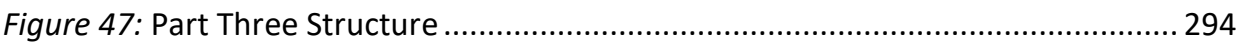




\section{Acknowledgements}

I cannot imagine completing this thesis, nor completing it in the way I desired, without the support of my wife, Catherine Mayo. Her ability to juggle her own writing career and running her violin business, while providing copious amounts of emotional support, a live-in proof reader, and sage advice on multiple topics, has been astounding. Thank you.

Thanks also to my supervisors Professor Stephen Cummings and Professor Sally Davenport. I remember how, in early stages of my thesis, my ideas were flying around in apparent disarray. Thanks for letting me keep going and your confidence I would find some landing spot. And, to Megan Key, it has been a pleasure to navigate the administrative aspects of a thesis with your direction and assistance. Thank you for your patient expertise.

And to Professor Robert Paul Wolff, thank you for your startlingly erudite and highly entertaining series of YouTube lectures on Kant. You show how philosophy can be well thought and can be fun. Thank you also for answering my emails and for your assistance.

Ron Peek and Associate-Professor Lynnette Tippett provided highly useful comments on my initial final draft. Thank you each for your input.

Les Wilson and Paul Murray have been my Wellington home away from home. Thank you for your support and encouragement over the years, and for your convivial place to stay. And to Les, a million thanks for your proof reading of my final document - your contribution has been so appreciated.

One essential ingredient of my thesis was a daily soy flat-white. Thanks to Lulu, Rachael, Donna, Donny, and Michael at Seven Loaves; Steve, Bernie, and Channon at The Governor; Hannah, Marcelo, Sean, Will, and Kash from Salta cafe; the staff at Queenies; and Lloyd, Mike, Siobhan, Frank, Melina and Rowan at the Cove Cafe. To lan Howard, who has shared many of these coffee times, thanks for your input, your encouragement, and your proof reading of my drafts. 
[This page intentionally left blank] 


\section{Chapter 1 - Abstract}

Strategizing is a human cognitive activity. While this may suggest that business strategy would focus on human cognition, this thesis finds the opposite - that business strategy overwhelmingly treats cognition superficially, and that business strategy consequently is limited and underperforms. This thesis recommends a cognitive turn that places cognition at the centre of business strategy and thereby enables the enhanced research and execution of business strategy.

To research the question "how does business strategy treat cognition?" requires an epistemology that admits cognition. Having found no such epistemology, this thesis creates its own - Pragmatic Cognitivism. A research method that is based upon the works of Michel Foucault, and which aligns with this epistemology, is adopted to analyse two mainstream business strategy discourses and two academic business strategy discourses.

This analysis finds that business strategy, driven by Enlightenment thinking and human sciences, perceives itself to be the problem and creates a large variety of approaches to strategy and strategy solutions. The development of these approaches establishes both the discipline of strategy and the role of the strategist. The analysis concludes that business strategy often ignores cognition and, when it is considered, it is treated only as a side issue. Furthermore, strategy solutions are not cognitive solutions, tasks such as learning and designing strategy are not considered, there is no consideration of knowledge of strategy and strategy intentions, and the subconscious is rarely mentioned.

Conditions that have led to this limited treatment of cognition include a scientific approach that does not easily cater for cognition and the complexities of understanding the mind. For business strategy, this has resulted in methodological approaches, a limited scope, and underperformance. Business strategy has developed in such a way that its own context is the limiting factor - business strategy cannot perform well because its core ingredient, cognition, is left untreated.

This thesis recommends a cognitive turn in business strategy that makes cognition the centre of strategy discourses. This is not to wholly reject current discourses, but it is a fundamental shift in how business strategy is conceived, researched, and executed. By placing cognition at the centre of strategy interpretations, strategy can potentially develop higher levels of performance rather than being structurally constrained.

The necessary starting point for such a cognitive turn is epistemological - to enable cognition to be well thought. Pragmatic Cognitivism is recommended as an epistemology that enables the reinstatement of the concepts of intuition and judgment, the inclusion of the subconscious as a cognitive factor, and the consideration of group cognitive dynamics. Such a cognitive turn is not an increased drawing of theory from contemporary psychology - it is a turn to concepts initially found in pre-behavioural approaches. 


\section{Chapter 2 - Introduction}

This thesis seeks to understand business strategy in the present by exploring how business strategy has treated human cognition in the past.

\subsection{The Recent Past}

Business strategy is present in the recent past in two notable and popular texts, Blue Ocean Strategy and Playing to Win. Blue Ocean Strategy (Kim \& Mauborgne, 2005) is acclaimed and quoted, but what does it say? Kim and Mauborgne state that human understanding of strategy is poor and highlight the failings of previous business authors such as Michael Porter, Tom Peters, and Jim Collins. Clearly, from their perspective, better thinking is required than the industrial economics that underpin Porter's work, and the fundamental principles Peters and Collins drew from successful companies (which then either failed or are just seen as part of successful industries). Their answer is a change to a reconstructionist approach based on a 'new growth theory' that focuses attention onto demand and the customer in order to find new untapped markets. This is all done in a systematic way with the explicit instruction to avoid intuition.

Certainly, Kim and Mauborgne momentarily consider human cognition: "industry structure ... can be reconstructed by the actions and beliefs of industry players" (p. 17). But these minds must be used systematically, and intuition is ruled out: "Nor is it a trial-and-error process of implementing wild new business ideas that happen to come across managers' minds or intuition" (pp. 79-80).

Their approach is easy to criticize, as the authors simply damn the systems of others while they promote a systematic method based on examples of ventures which never used their actual method. Essentially, the text attempts to justify a conceptual proposition based upon unrelated evidence. What problems are Kim and Mauborgne trying to solve in this unconvincing fashion? Is this a revolutionary approach to strategy as Kim and Mauborgne indicate, or is it simply a variation of past themes? Is this just another method, without humanity, competing within the United States (US) business strategy market?

Eight years later, Lafley and Martin resurrect Porter in Playing To Win (Lafley \& Martin, 2013). The two authors are fortunate to be "true thinking partners" to each other, who have solved the dilemma of "Strategy [being] a relatively young discipline" with "no single, clear, and persuasive definition of strategy and even less consensus on how to build one" (pp. 1-3). They simplify in the extreme when declaring that "Strategy is choice" (p. 3). But surely if strategy is choice then many theorists and practitioners have been missing the point for many years. More accurately, strategy is a form of choice that is preached by Lafley and Martin. This is not what we might have conceived of as strategy: vision, plan, long-term, improvement, or best practices. Lafley and Martin's conceptual frame drives their approach and includes desire, place, technique, capability, and management. These concepts are defined steps in a systematic process, beyond which the budding strategist need not be concerned. 


\subsection{The Research Question}

This brief analysis suggests that systematic methods predominate in the recent past. The authors noted above are highly successful. However, their advice about how to behave systematically is not matched by any advice about how to think.

How is it that our leading theorists can be so inhuman? Surely strategy is thinking? What has led the world of strategy to pay lip service to the minds that are the very playing field of strategy? Are they trying to improve strategy or are there other intentions driving the development of strategy?

These two examples, both from the recent past, raise the research question (also the thesis title):

"How does business strategy treat cognition?"

\subsection{Terminology}

Two key terms are business strategy and cognition. For this thesis the term business strategy is used in its everyday sense to mean the ideas and techniques commonly understood and utilized by business communities within the Western world.

Since this thesis has such a strong cognitive focus, definitions of cognition and other cognitive terms are of primary importance and are developed in detail throughout the thesis. However, for the purposes of this introduction, it is noted here that knowledge, thought, cognition, mind, and their derivatives pertain to human mental processes, and that these terms can be used somewhat interchangeably.

\subsection{The Approach of this Thesis - Three Parts}

This thesis has three distinct parts: Part One explores knowledge, especially knowledge of cognition; while Part Two explores strategy, especially strategy's treatment of cognition; and Part Three makes recommendations based on Part One and Part Two.

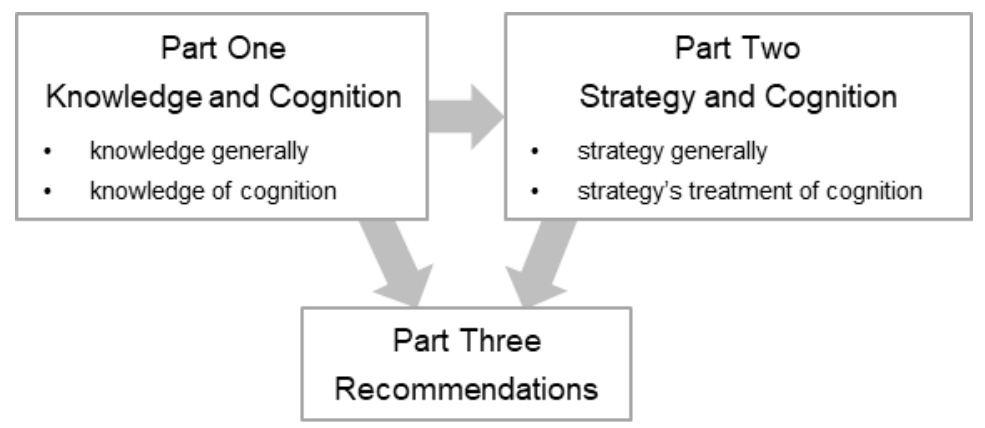

Figure 1: Thesis Structure 


\subsection{Part One - Knowledge and Cognition}

Part One considers general thinking as knowledge, which is thinking perceived as what we know; and cognition, which is the human capability to know and feel. Specifically, Part One of the thesis deals with how we can know, how we generate knowledge, what we know about knowing, and how we might apply this knowledge to Part Two.

How we can know is the topic of epistemology, and this thesis develops its own epistemology, Pragmatic Cognitivism. Cognition is added to the Kantian duality of space and time to create an a priori triad of cognition, space, and time. Since such an epistemology explicitly includes cognition, cognition can be described and considered in reasonable and sensible terms. Also explicit in this epistemology is a standard of judgement driven by a Jamesian pragmatism that seeks utility rather than truth. Further, since ontology is restricted to a simple acceptance of the triad, transcendent paradoxes and ontological dilemmas can easily be avoided.

How we generate knowledge in this thesis is a question of methodology. The knowledge we seek to generate is an answer to the research question "How does business strategy treat cognition?" This question is in the present tense - it is not an historical question. A Foucauldian approach is appropriate to this question because Foucault's work focuses on illuminating contemporary thought through study of the past. Foucault, himself, when considering why he studied history, affirmed that he did so to understand the present, "I would like to write the history of ... Why? Simply because I am interested in the past? No, if one means by that writing a history of the past in terms of the present. Yes, if one means writing the history of the present" (Foucault, 1975/1995, pp. 30-31). This thesis follows Foucault's approach of striving to identify themes and thoughts that help us understand our present.

There are many interpretations of Michel Foucault's work, and many variations on how Foucault's method can be applied. This thesis focuses on understanding the conditions of possibility and the problematizations that are inherent in the discourses studied; the knowledge that these discourses produce with respect to cognition; and how this knowledge has social effects and forms the subjectivity of the strategist.

What we now know is considered through the review of a number of cognitive contributions from philosophy, psychology, and sociology. All of these disciplines treat cognition differently, and an analysis of them yields a rich variety of interpretations.

How we apply what we know is achieved by developing a Cognitive Heuristic which is applied within a Foucauldian analysis of texts. This seeding of the research provides a useful starting point of a heuristic that can be utilized to guide interpretation of texts, rather than attempting to develop such frameworks during and throughout the whole study. 


\subsection{Part Two - Strategy and Knowledge}

To answer the research question, an historical analysis is made of business strategy from 1938 to the present day. This is undertaken using a Foucauldian method supported by a pragmatic epistemology.

Four discourses, two mainstream and two academic, are analyzed: Classical Strategy, Pop Strategy, Managerial and Organizational Cognition, and Strategy-as-Practice. The first and second, being the mainstream discourses, are studied in two overlapping periods of 1959-1997 and 1980-present day. The distinguishing quality that places texts in the Pop Strategy discourse is a tendency to be single-idea texts, with a specific message. The Classical Strategy discourse tends to be more comprehensive and addresses general shortcomings in strategy. Managerial and Organizational Cognition is the title of an academic movement that gained momentum in the 1980 s and still has adherents today. Strategy-as-Practice is often seen to have started with an article of that name in 1996 (Whittington, 1996), and continues to be a research area.

The research material is a broad collection of books and academic articles. The mainstream discourses, Classical and Pop, focus purely on books: 15 are analyzed for Classical Strategy and 11 for Pop Strategy. For Managerial and Organizational Change, 47 articles and one book (based on a PhD dissertation) are included. Strategy-as-Practice comprises 41 articles and three books.

Texts were selected based on their potential utility to illuminate general themes and specific cognitive elements of strategy discourses. To achieve this, influential well-known texts were identified, and texts with cognitive content that make specific contributions were identified. Note that there was no attempt to select texts to form a representative sample of strategy discourses, even if the selected texts may give that impression. Selection of texts is achieved through a balance of process and judgment designed for the purpose of developing insights.

Based on the literature reviewed, the general finding is that the field of business strategy has developed from the human sciences but is yet to find agreed solutions:

- Business strategy operates in a culture of Enlightenment thinking, conveyed through human sciences.

- Business strategy finds itself to be the major problem, that is, the inability to do strategy well.

- Business strategy produces a broad and extensive range of knowledge.

- Business strategy creates its own expanding field and has established a profession to practise and carry it forward.

While business strategy now has a tradition, the continual attempts to remake the field suggest that it has not yet succeeded in establishing a dominant discourse such as is found in legal and accountancy professions. 
Research into the treatment of cognition by strategy found that cognition is not central to strategy discourses in many ways:

- Strategy ignores cognition or recognizes cognition as an isolated side issue.

- Even when cognition's importance is recognized, strategy solutions are not cognitive.

- When cognition is considered, its treatment is limited, scientific, and simplistic.

- Specific cognitive elements that are rarely mentioned are:

- the subconscious

- Learning and Designing processes

- Thought Contents of Strategy and Intentions.

Conditions that contribute to strategy's limited treatment of cognition were found to be that mind is no longer the centre of our world, looking inwards is uncomfortable, understanding cognition is inherently difficult, the humanities lack a conceptual basis that admits mind, and strategy has alternatives to cognition.

In addition, there are implications from strategy's treatment of cognition: strategy is methodological, strategy has a limited scope, and strategy underperforms. Strategy, with its inherent cursory attitude towards cognition, is itself inherently limited to behaviouristic approaches and hence achieves sub-optimal performance.

Based on the literature reviewed, strategy uses predominantly scientific thinking and, while it is an established field, it has yet to find agreed solutions and finds itself to be problematic. Research into strategy's treatment of cognition reveals that cognition is peripheral to strategy. It is therefore suggested that strategy's underperformance is because business strategy discourses have developed into a state where they cannot give sufficient emphasis to the central element of the activity of business strategy, namely cognition.

\subsection{Part Three - Recommendations}

A cognitive turn for business strategy is recommended. If strategy is to progress it must make cognition its central element. In order to do so, business strategy should adopt the Pragmatic Cognitivism epistemology defined in this thesis so that mind is thought without ambiguity, and so that cognition is treated as the centre of strategy. Additionally, strategy needs to be humanized by using cognitive concepts such as the subconscious, intuition, and judgement that are currently being ruled out by the accepted scientific method. Only when business strategy becomes cognitive will business strategy have the potential to maximise performance.

Further recommendations propose a series of research ideas and frameworks for strategy. These include the use of the work of Michel Foucault, the introduction of introspection as a research tool, the development of a cognitive taxonomy, the study of argumentation, and the use of two frameworks developed in this thesis that have utility in research and in practice. 


\subsection{General Notes}

\section{Gender Imbalance}

Many early business strategy texts show a bias towards males by both male and female authors. This thesis does not attempt to remove any such bias when quoting sources nor when describing the authors' approaches. For example, Barnard (1938) ascribes almost superhuman powers to male elite business leaders, which is described in this thesis as a concept of 'supermen'; this accurately describes what Barnard stated, and to represent such as 'superhumans' would misrepresent both his position and his historical context.

\section{Citations}

All quoted text is as it appears in the original documents, with the original italics and bolding. The only exceptions are a few occasions where bolding or italicization is removed because all the text being quoted is already bold or italicized.

In-text citations and references follow the American Psychological Association Reference Style (sixth edition), with the addition that, when the publication year does not align with the first edition year, the earlier year is also given. For example, (Kant, 1781/1991) is more informative than (Kant, 1991). When a translation is being used, the publication date of the original foreign language edition is given (this is common with Foucault's texts, where an English translation is often one to two years later than the French original publication).

\section{Authors and Texts}

Texts considered in this thesis are predominantly single texts by either a single author or joint authors. When this is the case, to make the thesis easier to read, the name or names of authors will be often be used instead of the text. For example, when Michael Porter's Competitive Strategy is discussed in this thesis, it is stated as: 'Michael Porter (1985) is almost totally silent on cognition. He also rarely mentions people.'

There is a risk that this is interpreted as suggesting Michael Porter believes a certain position, or that a survey of all of Michael Porter's work suggests that he takes a certain position. This is not the intention. This thesis does not go beyond examining the texts named and therefore it simply uses authors' names to signify texts in order to improve readability.

\section{Abbreviations}

Abbreviations are not extensively used in this thesis, but two that are commonly used are:

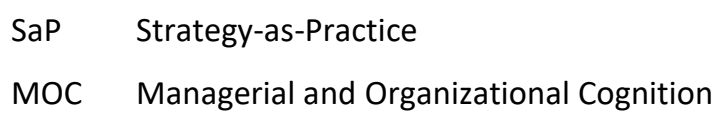




\section{Part One - Knowledge and Cognition}

This thesis is about how strategists think about cognition. There is a second cognitive player - the researcher who thinks about how strategists think about thought. Hence there are three iterations of cognition: the researcher's mind, the strategist's mind, and mind itself. Part One - Knowledge and Cognition considers this cognitive chain from four perspectives as shown in the figure below. Covered in separate chapters, these perspectives are an encompassing epistemology, a methodology for studying cognitions of cognitions, the current knowledge of cognition, and how to study strategy and cognition.

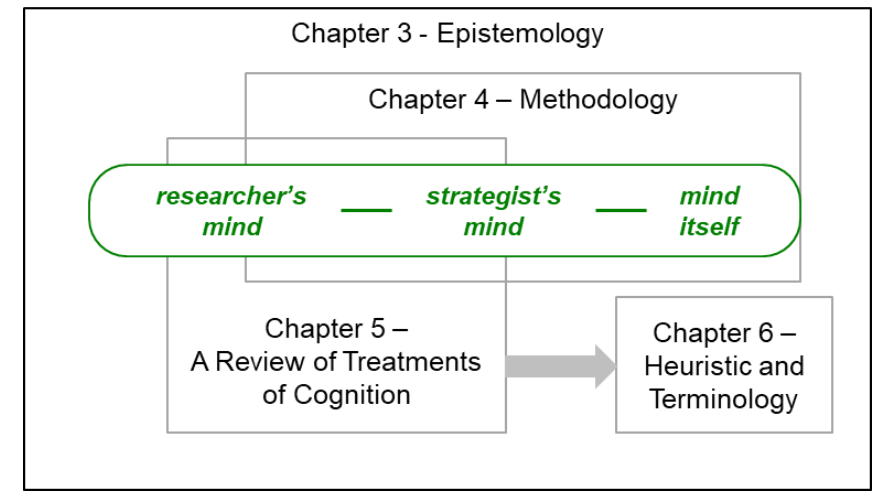

Figure 2: Part One Structure

Chapter 3 - Epistemology considers the status of knowledge, especially how researchers, including the candidate, perceive what humans can know. For this thesis, with epistemology being a cognitive concept itself, and cognition being part of the research question, it is both useful and imperative to have a clear understanding of where cognition fits in. This is achieved through the development of an epistemology of Pragmatic Cognitivism.

In Chapter 4-Methodology as a topic is how to look into the strategist's mind, and how to do so through the work of other researchers. Selecting a methodology is found to be problematic using traditional methodology categorizations, so an Object of Study Framework is developed, and then used to make selections of Michel Foucault's techniques and three hermeneutic principles as interpretative guidelines.

No thesis starts without some existing knowledge base. In Chapter 5 - A Review of Treatments of Cognition, a broad range of non-strategy literature is reviewed to create a context for further interpretation, and to also identify concepts and ideas with utility for researching treatments of cognition.

These insights are developed in Chapter 6 - Heuristic, Insights and Cognitive Models, as a Strategy Cognitive Heuristic, a cognitive vocabulary, and a taxonomy of model types suitable for the thesis' major research task developing knowledge of the treatment of cognition within business strategy.

So in Part One, mind is treated from multiple perspectives with a common thread of preparing and aligning all of the cognitive elements required to execute Part Two - the actual research of this thesis. 


\section{Chapter 3 - Epistemology}

Immanuel Kant wrote, "Now it does indeed seem natural that, as soon as we leave the ground of experience, we should, through careful inquiries, assure ourselves as to the foundations of any building that we propose to erect, not making use of any knowledge that we possess without first determining whence it has come, and not trusting to principles without knowing their origin" (Kant, 1781/1991, p. 46). In this chapter I erect a building to house my interpretative Foucauldian analysis of business strategy discourses' treatments of cognition (my Foucauldian approach is defined in the next chapter).

This is the only chapter in this thesis that I have written in the first person. These views are what I believe, and therefore it is more appropriate that I write from the first-person perspective.

My epistemology, Pragmatic Cognitivism, is based upon William James' pragmatism, Immanuel Kant's transcendental idealism, and Richard Rorty's later views of language. My position essentially aligns with a social constructionist view of society, and I do not take an ontological stance.

I define an epistemology that I believe to be radical and, more importantly, highly useful. I do this by supplementing Kant's position with my own philosophical treatment of cognition. This achieves two goals: a general contribution to epistemology is made; and key epistemological terms used in this thesis are clearly defined. Note, however, that as this thesis is not a philosophical treatise, the treatment of this epistemology is limited to providing clear definitions and examples of usage, instead of engaging in a philosophical debate.

In this chapter I establish Pragmatic Cognitivism by distinguishing between ontology and epistemology, describing the theorists drawn upon, and defining Pragmatic Cognitivism. Pragmatic Cognitivism is then more fully developed by my consideration of its implications and extensions (use of interpretation, status of language, status of texts, transcendent properties), and by comparison with other philosophies. I justify the use of Pragmatic Cognitivism based on a number of points of utility, including the ability to avoid paradoxes created through the ill-advised mixing of epistemology and ontology. Finally, I make some remarks regarding social constructionism and environmental determinism. 


\subsection{Epistemology versus Ontology}

Ontology and epistemology are relatively simple terms, but their meanings are not always well understood. As this distinction is important to this thesis, I present definitions and discuss both concepts before going further.

\section{Ontology}

The definition from dictionary.com (“Ontology," n.d.) is:

1. the branch of metaphysics that studies the nature of existence or being as such

2. (loosely) metaphysics.

So ontology is the study of all things, or understanding the very basis of reality. In The SAGE Encyclopaedia of Qualitative Research Methods (2008, p. 577), ontology, from a philosophical perspective, has a "general aim to provide reasoned, deductive accounts of the fundamental sorts of things that exist". I suggest that humanity, if it exists, is part of these things, and that ontology considers all possible things including gods and unicorns.

\section{Epistemology}

The definition from dictionary.com ("Epistemology," n.d.) is:

1. a branch of philosophy that investigates the origin, nature, methods, and limits of human knowledge. As per the definition above, epistemology is a humanistic concept - it is what humans can know, that is knowledge. The SAGE Encyclopaedia of Qualitative Research Methods (2008, p. 264) finds three questions: "The following three questions are basic to epistemology. What is knowing? What is the known? What is knowledge?"

\section{Discussion}

These two concepts are not exclusive - it is hard to imagine a knowledge without some form of existing things that can be known, and an existing knower. But even though ontology and epistemology cannot be totally separated, these are very different concepts. Topics of ontology include religion, mysticism, multiple forms of realist philosophy, alternative worlds, and the nature of time. Epistemology, when it avoids ontology, focuses on human knowledge.

This thesis focuses on epistemology for two reasons:

1. An aspect of the thesis topic is epistemological - the cognition of "how does strategy treat cognition?'

2. Ontology has the potential to, and often does, confuse and hence offers no benefit to this thesis.

These arguments are developed further and are implicit in the whole of this thesis. Initially, the focus is on defining my epistemology and then on how this definition avoids ontological difficulties. 


\subsection{Philosophical Basis}

The three philosophers that I draw extensively from are William James, Immanuel Kant, and Richard Rorty.

\section{William James}

The two components that I take from William James' pragmatism are his method and his theory of truth. James describes the pragmatic attitude: “A pragmatist turns his back resolutely and once and for all upon a lot of inveterate habits dear to professional philosophers. He turns away from abstraction and insufficiency, from verbal solutions, from bad a priori reasons, from fixed principles, closed systems, and pretended absolutes and origins. He turns towards concreteness and adequacy, towards facts, towards actions, and towards power" (James, 1907/1975, p. 31). In a wonderful Americanism, James entreats us to "bring out of each word its practical cash-value" (pp. 31-32). I do not interpret this literally as the need to quantify in dollars every item to be judged, but instead as an intent to understand the utility of an idea. For James, "Theories [are] instruments, not answers to enigmas, in which we can rest" (p. 32). My pragmatism follows this lead, searching for opportunities for useful and generative 'thinking utility'.

Following a description of how truths change over time, James states, "To a certain degree, therefore, everything here is plastic" (pp. 34-35). What James is suggesting is that truth is not an absolute but a quality of human thought. As he states, "The trail of the human serpent is thus over everything" (p. 37).

So from William James, I adopt his pragmatic approach which searches for utility, denies absolutes, and desires to find useful truths with good 'cash-values', while always understanding that these are uniquely human concepts.

\section{Immanuel Kant}

William James strives to position pragmatism between rationalism and empiricism, primarily to counter the extremes of rationalists, but perhaps also to temper empiricism against becoming a new form of dogmatism (pp. 10-26). Based upon James' definitions, Immanuel Kant is one of the first pragmatists.

In his Critique of Pure Reason (Kant, 1781/1991), Kant considers the issue in great detail, "[The critique of pure reason] will therefore decide as to the possibility or impossibility of metaphysics in general" (p. 9). Kant aims to, and believes he does, limit metaphysics to matters of faith. In Jamesian terms, he is clearly not a rationalist who deduces how we should behave from theoretical first principles, but he is interested in the practical application of our thought patterns to our daily lives. He shows this when quoting from Persius: "Tecum habita, et noris quam sit tibi curta supellex" (p. 14), which translates as "Live with yourself, get to know how poorly furnished you are". And while Kant theorizes at length, his method is empirical: "But the question is not what we ought to join in thought to the given concept, but what we actually think in it" (p. 34). Accordingly, in my view Kant shows the same intent as James, namely, to produce useful ideas for practical purposes. 
From Kant I take both his a priori space and time, and his view of consciousness. Kant explicitly defines space and time as a priori: "In the course of this investigation it will be found that there are two pure forms of sensible intuition, serving as principles of a priori knowledge, namely space and time" (p. 67). Kant also considers consciousness: "It must be possible for the 'I think' to accompany all my representations; for otherwise something would be represented in me which could not be thought at all, and that is equivalent to saying that the representation would be impossible, or at least would be nothing to me" (pp. 152-153). This shows that, for Kant, this unity of consciousness is central to his whole project.

\section{Richard Rorty}

Richard Rorty provides a useful view of language philosophy and a clear treatment of language. As detailed in The Linguistic Turn (Rorty, 1967/1992), there was an era where language was a major topic in philosophical debate and included such philosophical luminaries as Russell, Wittgenstein, Carnap, Davidson, Bergmann, Quine, Chomsky, Ryle, and Austin. While this linguistic turn had volume and effect, as Rorty (1992, p. 371) states, it does not seem to have lasted: "It now seems to me to have been little more than [one more tempest in an academic teapot]". Instead of attempting to read the leaves of Rorty's teapot, this thesis adopts Rorty's own later position on language.

In Contingency, irony, and solidarity Rorty (1989/1999, p. 73) states how language is used to express interpretations: "All human beings carry about a set of words which they employ to justify their actions, their beliefs, and their lives. These are the words in which we formulate praise of our friends and contempt for our enemies, our long-term projects, our deepest self-doubts and our highest hopes". He goes on to discuss attributes of their language which he terms a person's 'final vocabulary': “I shall define an 'ironist' as someone who fulfils three conditions: (1) She has radical and continuing doubts about the final vocabulary she currently uses, because she has been impressed by other vocabularies, vocabularies taken as final by people or books she has encountered; (2) she realizes that argument phrased in her present vocabulary can neither underwrite or dissolve these doubts; (3) insofar as she philosophizes about her situation, she does not think her vocabulary is closer to reality than others, that it is in touch with a power not herself".

Rorty finds that an individual has their own interpretation of language and therefore their own interpretations. Like both Kant and James, Rorty finds there is no universal gold standard regarding individuals' interpretation of language. 


\subsection{Pragmatic Cognitivism}

I have given my epistemological approach the appellation of Pragmatic Cognitivism. It is termed pragmatic because it is designed to have utility. It is termed cognitivism because a central differentiator of this epistemology is the explicit inclusion of cognition within the epistemology.

My definition of Pragmatic Cognitivism starts with definitions of terminology and an expression of the epistemology of Pragmatic Cognitivism. This is followed by a discussion of the implications of such an epistemology which also includes extensions to my definitions.

\section{Terminology}

I define here words that I use explicitly, and other terms which are used in a more everyday sense.

\section{Explicit Terms}

As I develop my epistemology, the word consciousness is often used. I define my use of this and other 'mind terms' here, being mindful this is far from straightforward and that the topic is reflective (i.e. the thing we describe participates in the describing and perceiving of itself). I make no claim that my use of the terms defined below is totally free from ambiguity, but I have both tried to achieve the most clarity I can, and tried to use these terms consistently throughout this thesis.

The terms I use are:

$\begin{array}{ll}\begin{array}{l}\text { Consciousness } \\ \text { Conscious }\end{array} & \begin{array}{l}\text { Overarching state of being that humans experience } \\ \text { Subconscious }\end{array} \\ \text { The part of thinking minds we are aware of } \\ \text { The our minds that we can only postulate, including emotions } \\ \text { Cognitive } & \text { The conscious and the subconscious mind } \\ \text { Introspection } & \text { The process of an individual looking into their own mind } \\ \text { Heuristic } & \text { A cognitive structure used for interpretation }\end{array}$

\section{Consciousness}

Consciousness is human awareness of existence, the human state of being. This is the apperception of Kant, and the Cogito of Descartes' Cogito Ergo Sum. It is the sometimes-mystical element of human existence that people struggle to comprehend. 


\section{Conscious}

Conscious and subconscious are used to distinguish processes and content that occur in the mind, and that are readily perceivable by the mind from those that are not. Conscious mind includes things such as thoughts and ideas, and executes processes such as reasoning and deciding. All the contents and processes that we can comprehend through introspection are part of the conscious mind.

\section{Subconscious}

Subconscious is used to include everything else which is in the mind. For this thesis, a comprehensive definition is not required (if it is even possible), as the task is to understand how others discuss and perceive such phenomena. However, to provide a consistent usage of the term throughout this thesis, the subconscious is taken to include emotions and tacit knowledge.

The term unconscious is avoided, as it can have connotations of either the subconscious or 'without any consciousness' - that is, without mind. Because of this possible confusion, the term is only used if a text being reviewed forces the contemplation of the concept of the unconscious.

\section{Cognition}

Cognition includes both the conscious and the subconscious mind. It is used as an all-inclusive term for the functioning of our minds. Cognition relies on our consciousness and is essentially the mental manifestation of being. The term is used extensively to focus attention on the actuality of mind, and to avoid drifting into the possible metaphysics of consciousness.

\section{Cognitive}

This term is used as an adjectival version of cognition.

\section{Introspection}

James (1890/1950a, p. 185) provides a useful definition of introspection that is adopted throughout this thesis: "The word introspection need hardly be defined - it means, of course, the looking into our own minds and reporting what we there discover".

\section{Heuristic}

Heuristics are often described as rules of thumb or as trial and error discovery. They are seen as something a person has and that enables them to interpret, understand, and judge. This thesis uses the term in a general way as a mental structure that people have and that can also be communicated. This thesis defines and presents its own heuristics. 


\section{Other Terms}

The following two terms are also used:
Mind
Mind is used in a general sense to indicate cognition.
Mental
Used in a similar sense to cognitive.

The following term is not used:

Unconscious This term is avoided and the term subconscious is used instead.

Additionally, everyday words that are understandable to a general readership are used. Many of these words have antecedence in philosophy, having been used by Aristotle, Descartes, Kant, and James. They are also relatively simple concepts. A sample of the vocabulary is:

$\begin{array}{ll}\text { actions } & \begin{array}{l}\text { perceiving, reasoning, understanding } \\ \text { deciding, assuming, imagining } \\ \text { intuiting, feeling }\end{array} \\ \text { general concepts } & \text { thoughts, memories, mental models } \\ \text { ideology, beliefs, traits, wants, values } \\ \text { sensations, reason, ideas, schemes } \\ \text { volitions, imagination, faith, desire }\end{array}$

The first set is a series of verbs defining specific cognitive functions that occur in minds. They are not suggested to be a set of unambiguous terms, nor are they exclusive of each other. They overlap, and all may be used at different times and in different ways. A breadth of terms is defined including both 'hard' and 'soft' terms (e.g. understanding versus feeling).

The second set contains examples of nouns used as general categories of thought. Unsurprisingly, there are many terms for describing what is perceived to be in human minds. This style of terms is used throughout this thesis to describe cognitive concepts. 


\section{Epistemology Defined}

\section{A Priori Space, Time, and Cognition}

Following Kant, I accept a priori space and time, but add cognition as an a priori. To me, it seems reasonable to accept cognition as a priori. That is, I firmly believe that I experience cognition, just as much as I experience space and time. I can think these three concepts, and I can think them in a way that I can personally verify. I tap my desk, and I experience space. I reread the sentence I have just typed, and I experience time. I check the grammar of the sentence, and I experience cognition. My world has these things, and I believe that these are common for other people.

Kant presents consciousness as being 'given', prior to his a priori space and time. My treatment of these as a triad is different. It suggests that we perceive from the inside, not the outside. That is, we are not existential gods, divining our own cognition from outside ourselves, but from within our own consciousness, we experience space, time, and cognition. A critique may be that this is circular. And it is. And it is ...

\section{Pragmatic Judgment}

When discussing philosophers, William James suggests that judgment is highly personal. He states that "his temperament really gives him a stronger bias than any of his strictly objective premises" (James, 1907/1975, p. 11). The bias James refers to is the same concept as the judgment I refer to. From my experience, to a degree we choose the basis for our judgments and, therefore I determined to explicitly make my own choice about how I wish to judge.

As previously stated, in the spirit of William James, I choose to apply pragmatism as my criteria of judgment. I apply pragmatism throughout this thesis to find utility and the cash-value of ideas. Consequently, any critique of a strategy text does not focus on its validity, but its utility. The question is not whether an author is right or wrong, it is what an author does for us, today.

This is my choice, and others make other choices. I cannot find any rule that states that my approach is more valid than any other, but I do think and believe that in a socially constructed human world there are many benefits from thinking about how things might be different and perhaps, generally, better. This is not based on any belief that the world is evolving to perfection, but instead derives from the view that humans have cognitive abilities and it might be useful to use them based upon a non-deterministic view of the planet. 


\subsection{Implications and Extensions}

These two core components of Pragmatic Cognitivism, a priori space, time, and cognition and pragmatic judgment, form the basis of my approach to knowledge. That is, they are influential and encompass how I conceive of interpretation, view language, perceive the status of texts, and understand transcendent interpretations.

\section{Interpretations}

My reality consists of a temporal series of spaces and cognitions. Space is the physical world in its various forms but also includes artefacts such as books and paintings. Cognition includes thoughts, feelings, perceptions, and memories. These temporal instances have no inherent validity or invalidity; they occur. I can perceive these elements of cognitions, both in the moment and after an interval. In a day, a week, or a year my perceptions of a previous thought vary. This is not a problem; it is how I am, and, I believe, how we are.

In dualist metaphysics, some of these elements of cognitions are called representations. I deliberately avoid this term because it suggests 're-presenting' something previously presented, and moments of cognition are clearly at a different time and are 'original' and are not 're-presented'. Instead, I adopt the term 'interpretation' meaning 'something present in space and/or cognition, at a time'. Michel Foucault uses the term and purposely denies the need for a dualist metaphysic: "If interpretation is a never-ending task, it is simply because there is nothing to interpret. There is nothing absolutely primary to interpret, because when all is said and done, underneath it all everything is already interpretation" (Foucault, 1964/1990, p. 64).

Examples of interpretations are an idea that occurs to me, the written record of the idea, a new idea that emerges after reading the old, a painting on my wall, and a bookcase of texts. They are interpretations that are quite normal, and they are our experience. I do not need to question their existence further as I accept them personally as an outcome of accepting a priori concepts of space, time, and cognition.

\section{Language}

This epistemology treats language in a similar way to Rorty (see p. 12); interpreting language as being a medium that allows interpretations to be thought, expressed, received, and recorded. Clearly, there is some organization to some of our thoughts, utterances, and writings. Like any perceptible element of our existence, cognition of these relies on previous cognitions and artefacts. For humans, cognitions are held within our conscious and our subconscious minds. As per Rorty, these interpretative processes are individualistic, without there being any general final vocabulary.

So interpretations exist and are variable through time. Our minds have and make interpretations that have some relationship with language. The interpretations on this page are expressed in language, and so it says. 


\section{Status of Texts}

Texts are specific types of interpretations in space that can be reinterpreted. Artefacts, such as the written word, obviously differ from thought: one is a material with markings, and the other exists in a mind at a point in time. Thoughts go through a human mind and can be written down. Once written, they can be read and perceived. The various interpretations by writer and reader are highly likely to vary in time. This is not a problem; it is, I believe, the way we are.

The extreme other case, of any two textual interpretations being identical - while imaginable - is only a theoretical concept. Perhaps this is possible by coincidence, but it is hard to imagine two different instances when a sentence is read with exactly the same interpretation by different humans. Such a world would be very strange, in which different moments in time were the same.

Notwithstanding these ontological arguments, it seems clear that texts are open to interpretations, or that 'there are many possibilities within the text'. In my view, interpretations are part of the human condition, and they simply 'are'. The utility of the interpretations may be debated, but the 'are-ness' of them cannot.

\section{The Transcendent}

We use language to say many things. Within space, time, and cognition, cognition is not limited. So we can think of unicorns and we can believe in gods. We can even think of a world where some interpretations are identical, even if it is painful. But, as per this epistemology, there is no concept of interpretations being valid or invalid, as they just are. One approach to this supposed issue is to simply suggest that "What we cannot speak about we must pass over in silence" (Wittgenstein, 1921/1974, p. 89). However, many other philosophers try in some way to understand and explain it.

If such a philosopher thinks that there are answers to ontological questions, the existence of such things as unicorns or culture is problematic, and one could spend much time debating the reality of such concepts. However, viewed as an epistemological question that is specifically human in nature, the answer is not so much an answer but is an observation that we make epistemological acts of judgment.

Such acts of judgement are essentially part of any interpretation, as a non-judgemental interpretation is again one of those concepts that is barely thinkable. Instead of trying to solve the riddle of the existence of unicorns, I recognize these judgements as being transcendent. So the transcendent is not really a challenge, it is simply something to recognize; and when a judgement is made that a concept or idea is transcendent, one can determine what utility may be gained by considering it further. 
And, given this judgemental capacity, we can apply some form of taxonomy to interpretations. Such an undertaking, done comprehensively, would be a thesis in its own right, but there is utility for this thesis in a basic definition. Here I define what I find to be reasonable and useful:

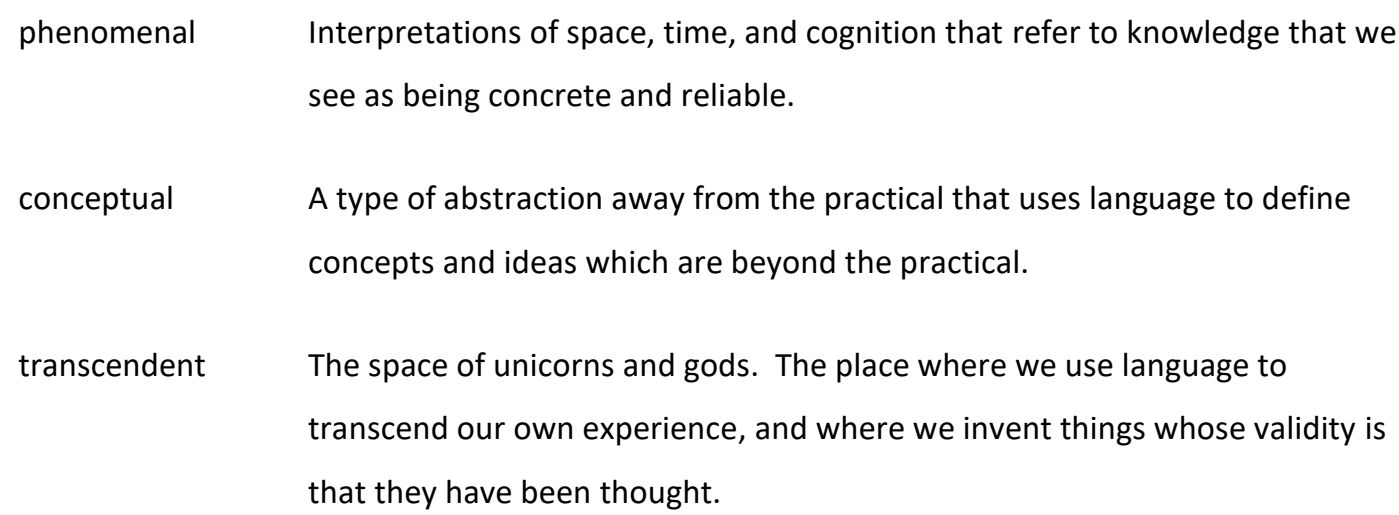
see as being concrete and reliable.

conceptual A type of abstraction away from the practical that uses language to define concepts and ideas which are beyond the practical.

transcendent The space of unicorns and gods. The place where we use language to transcend our own experience, and where we invent things whose validity is that they have been thought.

This taxonomy gives the opportunity to identify texts which go beyond the conceptual to the transcendent. 


\subsection{Philosophical Comparisons}

Pragmatic Cognitivism has alignment with James' ontology, Radical Empiricism. However, it finds little support from twentieth-century theorists whose foci are towards ontology rather than epistemology. Examples are given below to provide some context to show why Pragmatic Cognitivism is different.

\section{Radical Empiricism}

In the last decade of his life William James wrote a number of essays in which he promotes an ontology termed Radical Empiricism. Note that, as James says, Radical Empiricism and Pragmatism (as discussed above) are not co-dependent. Notwithstanding that, there are alignments between James' Radical Empiricism and my Pragmatic Cognitivism.

The introduction to Essays In Radical Empiricism (James, 1912/1996), by Ellen Suckiel, suggests that the book covers metaphysics and epistemology. While it does, it does so with a strong ontological focus that centres on consciousness and experience. James states that, "The peculiarity of our experience, that they not only are, but are known, which their 'conscious quality' is invoked to explain, is better explained by their relations these relations themselves being experiences - to one another" (p. 25). For James, there are a series of relations which are the basis of our consciousness. James finds that these cognitions coexist with space and time: "Experience is only a collective name for all these sensible natures, and save for time and space (and if you like, for 'being') there appears to be no universal element of which all things are made" (p. 27).

James goes on to discuss specific aspects of cognition. He indicates that our ability to generalise has great benefits: "Wonderful are the new cuts and short-circuits which the thought-paths make" (p. 64). But, even so, our mind is not as linear and straightforward as we might think: "[I call] our experiences, taken all together, a quasi-chaos" (p. 65). Even though our mind has such quasi-chaos, James sees mind as existing: "the universe continually grows in quantity by new experiences that graft themselves upon the older mass" (p. 90).

So James, in his Radical Philosophy, explicitly recognizes space, time and cognition, and, within his focus on cognition, he recognizes the power and variety of interpretations. My Pragmatic Cognitivism aligns with James' later psychological ontology, which is unsurprising given the centrality of mind to both.

\section{Phenomenology}

Edmund Husserl, seeking to provide a philosophical basis for mathematics, was drawn into questions of logic and epistemology. He essentially 'invented' phenomenology as his answer to these secondary questions (Husserl, 1913/2001, 1913/2014). In phenomenology, the focus is on conscious experience as a starting point for understanding actual experiences. The approach includes 'intentionality' as a driving force, and the need to 'bracket out' presuppositions to gain entry to pure experience. This type of approach conceptually appeals as it appears to avoid the transcendent. But its desire for ontological purity means that it must ignore the very 
cognition that this thesis examines. Phenomenology, bracketing out cognition, provides no assistance to this thesis.

\section{Heidegger}

Heidegger's philosophy is an ontology of being. He refuses to accept Kant's assumption of consciousness: "especially when we come to the concept of 'Being' - it is a dubious procedure to invoke self-evidence, if indeed the 'self-evident' (Kant's 'covert judgments of common reason') is to become the sole explicit and abiding theme for one's analytic - 'the business of philosophers'” (Heidegger, 1926/2008, pp. 23-24). His concept of Dasein is, "It is peculiar to this entity that with and through its Being, this Being is disclosed to it. Understanding of Being is itself a definite characteristic of Dasein's Being" (p. 32). Such transcendent ontological discussions are what my epistemology avoids. As will be seen below this is not always true of strategy as some academics invoke such metaphysics as they search for new perspectives on strategy.

\section{Existentialism}

As indicated by the title of Sartre's most famous text Being and Nothingness (Sartre, 1992/1975), Sartre's interest is metaphysical. The language confirms this supposition: "The object does not refer to being as to signification; it would be impossible, for example, to define being as a presence since absence too discloses being, since not to be there means still to be. The object does not possess being, and its existence is not a participation in being, nor any other kind of relation. It is" (p. 8). This is an example of the transcendent that I wish to avoid in my own writing.

However, because a philosopher focuses on the transcendent in one part of his works, this does not necessitate that any complementary epistemology must be valueless. But Sartre states, “Knowledge appears then as a mode of being. Knowing is neither a relation established after the event between two beings, nor is it an activity of one of these beings, nor is it a quality of a property or a virtue. It is the very being of the foritself in so far this is presence to -----------" (p. 242). Such an ontological approach to epistemology has little utility for the task of this thesis, namely to study strategy and cognition, including knowledge, in such a way that is easily communicable to readers.

\section{Critical Realism}

Roy Bhaskar was a leading proponent of Critical Realism (Bhaskar, 1993/2008), a philosophical approach that is used at times within strategy discourses. The key tenet of Critical Realism is to treat human and physical science conceptually the same by assuming there are unseen mechanisms underlying occurrences and behaviours. This is another realist philosophy in a tradition that started with Plato's ideals. Such an ontological approach of searching for truths, is not aligned in any way with the intent of my thesis; to answer the epistemological question of how strategy and cognition can be thought of differently. 


\subsection{Utility of Pragmatic Cognitivism}

There are some general benefits of Pragmatic Cognitivism that also apply to this thesis: providing clarity of interpretations, identifying the transcendent, and avoiding false paradoxes.

\section{Clarity}

It would provide useful clarity if individuals and groups had a consistent basis for what they believe, how they think, what they say, and how they act - especially in academic work. When considering functionalist sociology, Burrell and Morgan (1979, p. 105) lament that "Abstracted empiricism arises in situations where the methods used are inconsistent with the underlying theory."

For this thesis, a lack of a consistent basis would create some such general confusion. Since a core part of this thesis' topic is part of the very basis we are considering, such confusion would likely be amplified. Therefore, I have attempted to make this thesis consistent; not by following some purist ideal but because I believe the thesis gains utility through such consistency.

Thus, my epistemology drives both how I interpret texts, and what I suggest is a useful way forward for strategists. For the former, as discussed below, my methodology looks for useful ideas and insights - not for truths. This is consistent with the Foucauldian methodology I have chosen to adopt.

\section{Identify the Transcendent}

A specific benefit is to be able to identify the transcendent; that is those areas which are beyond reason. Without any distinction between types of knowledge, it is relatively easy for discussions to wander into the world of mysticism and unicorns. In addition to avoiding the transcendent in the content of this thesis, this approach usefully serves to identify the transcendent in strategy discourses.

\section{Avoid False Paradoxes}

A by-product of my epistemology is that it provides a simple way out of many self-inflicted representational paradoxes that appeared in many fields in the twentieth century. I have identified examples of such research that are wasteful and have minimal utility. I simply explain what the paradox is and then give examples.

Derrida and Wittgenstein spent their careers dismantling metaphysics, but metaphysical words (e.g. realism, empiricism, positivism, objectivism, nominalism, interpretivism) still appear in research methods textbooks (Bryman \& Bell, 2003; Easterby-Smith, Thorpe \& Jackson, 1991; O'Leary, 2014). These are important to such scholars as Burrell and Morgan (1979) who define a subjective-objective dimension as part of their core framework, and Alvesson and Sköldberg (2009) who consider philosophies of science and the challenges of representation. The issue is not the use of philosophical terms to elucidate meaning (such usages are neither valid nor invalid, but should be judged purely on utility to convey useful meanings); the issue is when texts devolve into consideration of metaphysical paradoxes and the confusion that subsequently results. 
Hernes (2014) in the preface to A Process Theory of Organization describes how the attendees at a process thinking workshop at a 2005 conference were aghast at the idea of developing a theory of processes because it would signal a framework apart from the processes themselves. This version of the paradox admits a dualist ontology but avoids the paradox of two instantiations of reality occurring simply by keeping quiet. I suggest that two theories of processes have been presented. Further, the issue that process theorists may have with such an interpretation is due to a lack of a clear theoretical basis. This issue is avoidable with my epistemology.

In their strategy textbook De Wit and Meyer (2010) use paradox as a fundamental heuristic when considering strategy topics. While suggesting that paradoxes exist, they find a convenient way to contract out of the dilemma as "a problem-solver can find a workable reconciliation to temporarily cope" (p. 16). Such artifices simply hide the inherent inconsistencies in this approach that would be better served by adopting my epistemology and considering the utility of alternative positions in context.

Alvesson and Sköldberg (2009) provide a thorough survey of qualitative research that ends with a proposal for a meta-method of reflexive interpretation that they state as being 'provisionally rational' and 'provisionally rhetorical'. But essentially, this is a created paradox. As James (1907/1975, p. 27) demonstrates, apparent contradictions can be dissolved. I suggest that my epistemology allows for the concepts espoused by Alvesson and Sköldberg and replaces potential metaphysical critiques with discussions of utility. 


\subsection{Social Constructionism and Environmental Determinism}

While these terms do not contribute to my epistemology in a philosophical sense, they are used within this thesis in discussions of aspects of theory and research. The terms are not a dichotomy, but represent two different approaches, social constructionism being a sociological epistemology, and environmental determinism being a social ontology.

My perception of social constructionism follows Berger and Luckmann (1966). They state, "Everyday life presents itself as a reality interpreted by men and subjectively meaningful to them as a coherent world" (p. 19). Such a position aligns with the interpretative flavour of my epistemology. They state further, "This object is society as part of a human world, made by men, inhabited by men, and in turn, making men, in an ongoing historical process" (p. 211). This statement, suggesting that in the human world humans play a part in creating society, may suggest that it is difficult to find societal cause and effect relationships, but as Andrews (2012, p. 40) makes clear, "This branch of constructionism is unconcerned with ontological questions or questions of causation."

Hrebiniak and Joyce (1985) provide a description of environmental determinism: "discernible features of the actual environment are also important; structural characteristics of industries or domains and various niches clearly exist, some of which are intractable to control by individuals and their organizations. At times the effects of these are peremptory" (p. 338). This clearly suggests cause and effect relationships, and the potential to discover such relationships. Since I am looking for insight rather than searching for causality, I avoid any such forms of environmental determinism. 


\subsection{Epistemology Summarized}

Throughout my career I have found many sophisticated and highly complex philosophical systems that mix ontology and epistemology. But I have not found any philosophical foundation that would comprehensively support the cognitive element of my research quest.

In my epistemology, I have avoided ontology (other than assuming existence) because I find no utility in its unending questions. I have taken an epistemological approach that fits me personally, as I have no belief in externalities or gods.

My epistemology builds on the work of three great philosophers: Immanuel Kant, William James, and Richard Rorty. Kant provides a basis for epistemology, James provides pragmatics for judgment, and Rorty provides a position on language. I add the feature of taking cognition as a priori, as Kant already finds space and time. With this addition I suffer no paradoxes regarding interpretation, language, and texts.

This epistemology is the basis of this thesis, which itself is a series of cognitions made in space and time.

At the end of this thesis, a series of recommendations are made to improve strategy and strategy research. While it was not part of the original intent, these recommendations reflect a central idea of my epistemology that cognition can be aware of itself and it can be directed. The human mind is not just an object of study, it is the active subject that 'can'. 


\section{Chapter 4-Methodology}

This chapter selects and justifies the choice of methodology of this thesis.

Traditional research methodology categorizations are of limited use as the research question of this thesis involves multiple iterations of cognitions. Because of this limitation of traditional approaches, this thesis develops its own categorization to enable a better-informed methodology selection, namely an Object of Study Framework.

Use of this framework leads to the selection of the techniques of Michel Foucault as the primary methodology, supplemented by interpretative guidelines from hermeneutics. Foucault's historical understanding of ideas aligns well with the understanding ideas about cognition, while hermeneutics provides some useful guidelines for text analysis.

Hermeneutics is reviewed at a high level and yields a subset of guidelines taken from the whole hermeneutic tradition. These are applied during the research when interpreting texts.

Foucault is analyzed more thoroughly, and his approach is viewed as research strategies and as a toolbox of techniques. These are found to be appropriate to this thesis because they are more than purely descriptive, being critical in a reasoning sense; they focus on the present as this research does; they are a useful interpretative technique; and they align with the epistemology defined in the previous chapter.

How this subset of Foucault's tools is operationalized is presented, along with the selected hermeneutic guidelines.

The chapter is structured in five distinct parts:

1. methodology frameworks are reviewed and an Object of Study Framework is crafted for this thesis

2. methodologies are reviewed and choices of hermeneutics and Foucault are made

3. hermeneutics are reviewed at a high level and specific guidelines are selected

4. the techniques of Michel Foucault are analyzed in detail and the selection of Foucault is justified

5. operationalization of the Foucauldian methodology and hermeneutic guidelines is presented. 


\subsection{Methodology Frameworks}

The research question of this thesis is challenging, as it seeks to understand cognitions of cognition.

Traditional frameworks for categorizing methodologies provide limited support when selecting a methodology for this thesis, so an alternative Object of Study Framework is presented. This framework is then used in the next section to structure the methodology selection process.

\section{A Challenging Research Question}

The research question is "How does business strategy treat cognition?" As previously stated, the subject business strategy is used in its everyday sense to mean the ideas and techniques commonly understood by the business community. The task is to understand how the strategists in this business community treat cognition. The term treat is a broad one that encompasses how strategists think of and write about cognition. Thus this is a study of strategists' views of cognition; when fully expanded it is a 'cognition of other peoples' cognitions of cognition".

While such cognitive recursivity is not abnormal, as we all have the capability to think about thinking, it does present significant opportunities for confusion in research. Such confusion can be due to ontological issues (see previous chapter) or arises simply because a methodology's taxonomy simply does not cater for the studying of ideas held by people. To avoid such confusion, this chapter defines a methodology that is suited to such a study of ideas generally and, specifically for this thesis, of cognitions of cognition. 


\section{Scan of Traditional Frameworks}

Research methods are often grouped into subjective and objective categories (or similar), as in Burrell and Morgan (1979) and Alvesson and Sköldberg (2009), and are frequently contemplated using philosophical terms such as realism, empiricism, positivism, objectivism, nominalism, and interpretivism (Bryman \& Bell, 2003; Easterby-Smith et al., 1991; O’Leary, 2014).

\section{Burrell and Morgan}

\section{Subjectivist}

\begin{tabular}{|c|c|c|}
\hline $\begin{array}{l}\text { Nominalism } \\
\text { Anti-positivism }\end{array}$ & $\begin{array}{c}\text { Radical } \\
\text { Humanism }\end{array}$ & $\begin{array}{c}\text { Radical } \\
\text { Structuralism }\end{array}$ \\
\hline $\begin{array}{l}\text { Voluntarism } \\
\text { Ideographic }\end{array}$ & Interpretive & Functionalist \\
\hline
\end{tabular}

\section{Objectivist}

Realism Positivism Determinism Nomothetic

Figure 3: Burrell and Morgan Summarized. Derived from Social Paradigms and Organizational Analysis (pp. 2137), by G. Burrell, and G. Morgan, 1979, Farnham, United Kingdom: Ashgate. Copyright 1979 by Gibson Burrell and Gareth Morgan.

One aspect of Burrell and Morgan's framework shown above, the radical layer, was important in 1979 when this text was published. This radicalism, centred around Marxian doctrines of social upheaval, is no longer a significant determinant of research methods and is therefore set aside. Burrell and Morgan's approach can then be seen as differentiating between an interpretive approach and scientific positivism, or between subjective and objective approaches.

The interpretive approach "sees the social world as an emergent social process" (Burrell \& Morgan, 1979, p. 28). This is a statement of how the researcher sees the social world, rather than a statement of what can be studied. Likewise, the functionalist paradigm that "seeks to provide essentially rational explanations of social affairs" (p. 29) presents a researchers' perspective that rational answers exist. Such perspectives provide no direction for the study of cognitions of cognitions. The focus of the words themselves draws attention to interpretations of society, not to cognition. While such interpretations of society are mental acts themselves, such cognitions are not 'of cognitions' but are of other phenomena. So while there may be value in this framework from a social studies perspective, it provides no real insight into how a method might study cognitions of cognition. 


\begin{tabular}{|l|c|l|l|l|l|}
\hline $\begin{array}{l}\text { Others: } \\
\text { Discourse Analysis } \\
\text { Feminism } \\
\text { Foucault }\end{array}$ & $\begin{array}{c}\text { Postmodern } \\
\text { Post-structural }\end{array}$ & $\begin{array}{l}\text { Critical } \\
\text { Theory }\end{array}$ & Hermeneutics & $\begin{array}{l}\text { Mainstream } \\
\text { Qualitative }\end{array}$ & Quantitative \\
\hline \multicolumn{2}{|c|}{ Interpretive } & \multicolumn{2}{|c|}{ Data Orientated } \\
\hline
\end{tabular}

Figure 4: Alvesson and Sköldberg Summarized, derived from Reflexive Methodology, by M. Alvesson and K. Sköldberg, 2009, London, United Kingdom: Sage. Copyright Mats Alvesson and Kaj Sköldberg 2009.

Alvesson and Sköldberg similarly provide a split between interpretation and science. This primary split, supported by the second level of categorization shown above, does not distinguish the object of study. There is no indication of what methodology might be more useful for considering cognition of cognitions. Essentially, this follows the same pattern as Burrell and Morgan in focusing on the mind of the researcher and how they conceive of society. So this framework does not provide any intrinsic assistance with the choice of methodology for this thesis.

\section{Summary of Traditional Methods}

The above suggests that the subjective/objective distinction has little relevance when cognition is the topic; and that this distinction is, in fact, based upon the researcher, not the topic of study.

While the subjective/objective distinction, which is the basis of the frameworks above, has utility, it is tested when the object of research concerns recursive cognitions. The very distinction, subjective or objective, does not fit with something as ethereal as mind. Contemplation of mind, or consciousness of mind, seems to be a singular human activity and one that is not easily comprehensible as: 1) a purely subjective experience which cannot be shared; or 2) an objective pursuit where the mind can be known. So subjective/objective doesn't fit and tends to lead to the philosophy of mind and endless ontological debates, which are of no utility for this thesis.

As also indicated by the scan of traditional frameworks above, the various traditional categorizations focus on the mind of the researcher, or the Subject. Within methodology texts the prevalence of the terms mentioned above (realism, empiricism, positivism, objectivism, nominalism, and interpretivism) supports this analysis. These two frameworks are primarily focused upon how the researcher thinks about the world - the researcher's ontological and epistemological position; they do not facilitate the choice of methodology for a study of cognitions of cognition.

So for this thesis an alternative is required. While it is not suggested that a researcher can or should adopt a methodology that clashes with their basic beliefs, it is suggested that understanding how a methodology aligns with the object of study is a reasonable and useful approach. 


\section{Object of Study Framework}

A useful distinction is Subject/Object, that is, who is the Subject and what is the Object. The Subject is the 'one who knows', while the Object is 'what may be known'. Seen from this perspective, the two traditional frameworks considered above focus on the mind of the Subject as the primary concern: if the researcher believes in relative qualities of the world, a subjective method may be appropriate and, conversely, if the researcher seeks eternal truths an objective method may be appropriate. This is a comfortable distinction that has been made many times and that is an accepted part of our vocabulary.

An alternative is to focus on the 'Object of knowing'. In this approach, the Subject must suspend their belief patterns and focus on what can be studied. This suspension is achieved using the Object of Study Framework below. This framework is crafted to identify methodologies that expressly support the treatment of cognition and is not presented as a general technique.

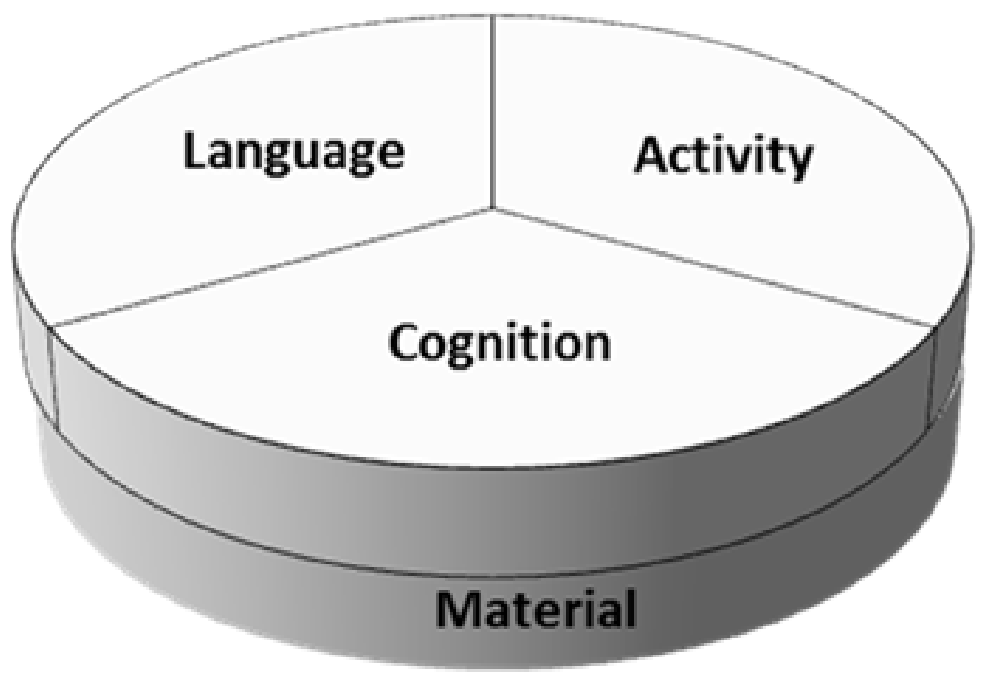

Figure 5: Object of Study Framework, by the candidate.

The four components of the framework are aligned to, and are explained by, the epistemology espoused in the previous chapter, that comprises of space, time, and cognition. The Material recognizes the realm of space and time that is researchable without any primary reference to cognition, although being researched by a cognitive entity. The other three recognize aspects of humanity: Activity occurs in space and time; Cognition occurs in time; and Language is implicit in how we consciously think. The latter three perspectives are the basis used for categorizing methods to determine what may be most appropriate for this thesis. 


\subsection{Methodology Selection}

A variety of research methods and broader approaches are categorized within this framework. Methods and approaches are taken from:

1. Burrell and Morgan (1979)

2. Alvesson and Sköldberg (2009)

3. Nicolini (2012)

4. cognitive disciplines identified and considered later in this thesis

The categorization has yielded the following results (the vertical positions, within activity and language quadrants, have no significance):

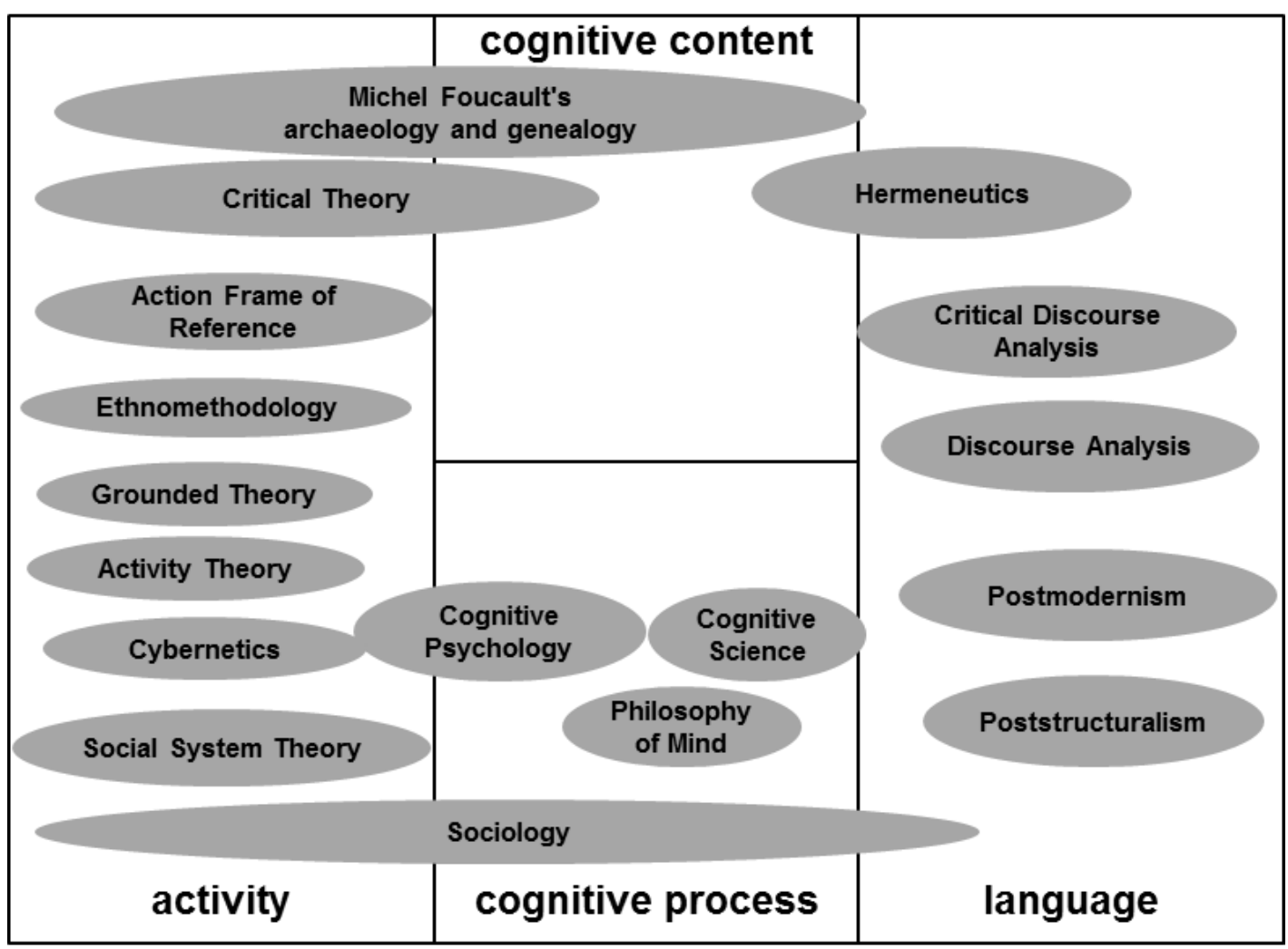

Figure 6: Categorization of Research Methods and Approaches, by the candidate.

The analysis of each object of study category is summarized below, followed by a statement of the methods the candidate identified.

\section{Activity}

Activity-based approaches tend to start with behaviour and then move to high levels of abstraction, often based upon a concept of how society operates. For example, O'Leary (2014, p. 143) states, "as a strategy of ethnomethodology, exploring how we build shared interpretations involves collecting data that captures everyday experiences." Even though ethnomethodology has a goal of understanding how human 
interpretations occur, the object of study is everyday experiences. As the object of this research is not behaviour, nor is it to produce a theory of society, an Activity approach does not align well.

\section{Language}

Within the Language perspective, Discourse Analysis delves into detailed usage of language but "empties people of psychological content in too radical a way" (Alvesson \& Sköldberg, 2009, p. 234). As Fairclough (2013) states, Critical Discourse Analysis is both concerned with language and is realist: "[Critical Discourse Analysis is] a multimodal analysis of the different semiotic modes" and "Note that this is a realist approach" (pp. 7,4). As this thesis focuses on cognition, language approaches, which tend away from the human subject and towards realism, are highly unsuitable. Postmodernism and poststructuralism, as broad fields, tend towards ontological issues which are not the topic of this thesis. This thesis is about making useful interpretations of practice, not about metaphysical debate, so language approaches also do not have utility as a primary approach.

However, the field of hermeneutics, with its methods of textual analysis and its consideration on how the 'reader knows', does have utility, and this option is developed further below.

\section{Cognition}

There are many sciences that include a focus on cognitive processes, some of which are shown in Figure 4 above (i.e. Cognitive Psychology and Cognitive Science). These are pertinent to this thesis as part of a literature review of cognitive fields, but they are not methodologies per se that can be applied to textual analysis. Further, cognitive psychology tends to focus on micro-events in a behavioural manner, while Cognitive Science looks to model the mind, instead of understanding what the mind thinks. Sociology, as a general approach, is also considered in this review, and also does not appeal as a basis for understanding historical content. Critical Theory is primarily interested in the world of power and politics. Alvesson and Sköldberg (2009, p. 144) state, “[Critical Theory poses] the idea that societal conditions are historically created and heavily influenced by the asymmetries of power and special interests, and they can be made the subject of radical change." So while Critical Theory has some applicability because it is historical, its focus on radical social change does not align with this thesis.

Michel Foucault however does have utility. His focus on historical analysis and understanding of discourses has the potential to answer the research question “How does Strategy Treat Cognition?"

\section{Options}

From this analysis, two options were identified: 1) Hermeneutics to provide guidelines for this thesis, and 2) the approach of Michel Foucault to be the methodology. These are considered in more detail below in order to understand the implications and confirm these selections. 


\subsection{Hermeneutics}

Hermeneutics is a broad field that is interpreted in multiple fashions. This section considers hermeneutics in its general sense, and summarizes six stages of hermeneutics to identify three guidelines for interpreting texts.

\section{Contemporary Approaches and Terminology}

The term hermeneutics is now often used to indicate the general challenge of interpretation of human expression, both textual and non-textual. Ramberg and Gjesdal (2005, p. 1) define hermeneutics as "both the first order art and the second order theory of understanding and interpretation of linguistic and non-linguistic actions." Mantzavinos (2016, p. 1) define hermeneutics as "the methodology of interpretation [that] is concerned with problems that arise when dealing with meaningful human actions and the product of such actions, most importantly texts." Porter and Robinson $(2011$, p. 1) see hermeneutics "as the many ways in which we theorize about the nature of human interpretation". These more recent definitions suggest a conceptual field that provides direction, rather than a methodology. This thesis follows this treatment and utilizes hermeneutics to provide useful guidelines.

Before delving into hermeneutics, the usage of this term is specifically distanced from that of a key commentary on Foucault, Michel Foucault: Beyond Structuralism and Hermeneutics (Dreyfus \& Rabinow, 1983/1983). In this text, Dreyfeus and Rabinow consider hermeneutics from a Heideggerian approach of "find[ing] the deep truth hidden by everyday practices" (Dreyfus \& Rabinow, 1983/1983, p. xxii) and, as per the title of the text, suggest that Foucault goes beyond hermeneutics as purely interpretation, to hermeneutics as ontology. In this thesis, the term hermeneutics is not used in such an ontological fashion, but, as stated above, it is used more generally as an interpretation of human expression.

\section{Hermeneutics Classifications}

To provide a structure to the analysis, classifications from Porter and Robinson (2011) are adopted with modifications. Porter and Robinson define six trends: 1) romantic hermeneutics (Schleiermacher/Dilthey); 2) phenomenological and existential hermeneutics (Husserl/Heidegger); 3) philosophical hermeneutics (Gadamer); 4) critical hermeneutics (Habermas); 5) structuralism (Saussure); and 6) post-structuralism (Derrida). These classifications are utilized, but with the fifth and sixth trends (structuralism and poststructuralism) combined, as they are similar in focus, and with an initial pre-romantic trend inserted before Schleiermacher and Dilthey, as this is identified by other authors but omitted by Porter and Robinson. 


\section{Analysis}

The six trends introduced above have much variety:

1. Pre-romantic

2. Romantic

3. Phenomenological and Existential

4. Philosophical

5. Critical

6. Structural and Post-structural
As Mantzavinos (2016) and Alvesson and Sköldberg (2009) discuss, the original hermeneutic circle identified the interpretative relationship between part and whole. The part is only understandable in the context of the whole, while the whole is understood through the parts.

Schleiermacher and Dilthey aimed to put social science on an equal footing with physical science by defining a hermeneutics that was scientific. This now seems to be a somewhat forlorn objective, but the useful idea they raise is that understanding the author's context is critical to understanding a text. This seems entirely reasonable for a study of an evolving strategy literature, as such timespecific prose could easily be misunderstood if not taken in context.

Husserl and Heidegger are less useful for this thesis, as their ontological turn to the 'nature of being' moves towards performativity. The ideas of valid knowledge being accessible only through study of phenomena and beings-in-the-world are metaphysical concepts that are more useful to a study of existentialism than a study that considers what people think.

Gadamer, a follower of Heidegger, begins with a humanist ontology that suggests hermeneutics is not a science, but how we behave. But, unlike Heidegger, Gadamer finds some useful practical implications, including the idea that a reader cannot escape her or his own context. This leads to the concept of play, between the text and the reader, and to the suggestion that a 'true' reading of a text is not possible.

Habermas's critical hermeneutics is based on his theory of communicative action, and specifically seeks to define a critical theory of society that leads to emancipation and liberation. As this thesis primarily focuses on texts, and has no such political goals, Habermas's theory has limited applicability.

Hermeneutics, as structuralism and post-structuralism, is a very wide field.

Structuralism, typified by Saussure, aims to find underlying structures that explain how we think. This thesis has no such ambition being limited in scope to what we think, and to what we have thought. Post-structuralism, in a Derridean sense, aims to break down the concept of representation. While this aligns with the stated epistemology, the desire here is to interpret language rather than to break it down.

\section{Hermeneutic Guidelines Adopted}


As this overview shows, hermeneutics supplies a number of different contributions to the discipline of interpretation. As explained above, not all of hermeneutics is applicable. Those that have general applicability and utility for the actual process of executing the research of this thesis, specifically the process of analysing documents, are the concepts of:

- part and whole, from Pre-romantic Hermeneutics

- author's context, from Romantic Hermeneutics

- play, from Philosophical Hermeneutics

The first and third concepts are essentially process guidelines. They suggest that any effective reading of a text needs to iterate and give space for interpretation to develop.

The second concept relates to the basis of interpretation. This thesis follows the position that the author's context is important. Some theorists, such as Derrida, provide another view, "There is nothing outside the text" (Derrida, 1967/1997, p. 186). Such an approach suggests that acontextual interpretation is possible and potentially the only way to interpret. This thesis does not hold with this approach but interprets texts 'in context' in line with the Foucauldian concept of 'conditions of possibility' that is developed below.

This contextual interpretation introduces a temporal dimension. Interpretations in this thesis are necessarily in a different time from that of the writing of the text and could therefore be criticised for being limited to being 'interpretations'. However, based upon the Pragmatic Cognitivism, such a criticism does not apply as there are only interpretations of interpretations. Such interpretations 'are', and there is no question of their validity. Instead, the question should be of their utility, and this is likely to be based on the reasonableness and insightfulness of the interpretations themselves. 


\subsection{Foucault}

This section focuses on Foucault's major strategies and his toolbox of techniques. His major strategies drive how his methodology is used. His toolbox is analyzed in some detail. As many others have delved deeply into Foucault's intellectual development in texts, papers, and theses, this thesis does not attempt to replicate such analyses.

\section{Michel Foucault}

Michel Foucault (born 1926, died 1984) was a French intellectual and academic. He is described both as a philosophical historian and a historical philosopher. During his career he wrote historical texts that considered madness, medicine, human sciences, discipline and punishment, and sexuality. Further, he wrote theoretically about knowledge. As elaborated on below, he had periods of archaeology and genealogy that correspond with changes of focus from knowledge, to power, to subjectivity, and also having an ethical turn.

\section{Foucault's Strategies}

Before delving into the detail of Foucault's methodology, an outline of his core approach is presented. The basis is 'social analysis through the interpretation of history' which is achieved through the core concepts of archaeology and genealogy. Foucault himself suggests that these concepts are more a toolbox of techniques, rather than a strict methodology. These strategies have implications for this thesis, both in the selection of texts and in limits to scope with respect to ethics.

\section{Interpretation of History}

In The Use of Pleasure there is a very clear explanation of Foucault's objective: "The object was to learn to what extent the effort to think one's own history can free thought from what it silently thinks, and so enable it to think differently" (Foucault, 1984/1990, p. 9). Here Foucault is very clear that he uses the past to inform the present. As Gutting $(2005$, p. 3) states, "his goal was always to suggest liberating alternatives to what seem to be inevitable conceptions and practices." Thus Foucault does not search for truthful representations of society in an ontological sense, but rather for useful descriptions and insights.

\section{Archaeology and Genealogy}

Foucault's techniques are often stated as being archaeology and genealogy. Archaeology is the "uncovering of the archive forms of the general horizon to which the description of discursive formations, the analysis of positivities, the mapping of the enunciative field belong" (Foucault, 1976/1990, p. 131). Foucault's book, The Archaeology of Knowledge, focuses on this subject and itself has many interpretations. If there is a general theme, it is that archaeology is an approach to interpreting discourses. By digging through the archive and searching for ideas, interpretations can be made. Genealogy takes archaeology further, by considering how discourses change through the use of power (as seen in Foucauldian terms - see below). This has a clear focus on change. Gutting describes the two concepts: "genealogy is a history of the present specifically concerned 
with the complex causal antecedents of the present socio-intellectual reality (in contrast to archaeology, which is concerned with the conceptual structures subtending the reality)" (Gutting, 2005, pp. 12-13). However, while these two terms, archaeology and genealogy, may suggest a defined method, the actuality is very different as O'Farrell $(2005$, p. 50) states, “Foucault continually changed and refined his concepts, not only on a major scale, but also in very minute and subtle ways, something which makes his work extremely difficult to systematize for the purposes of a methodological and wholesale application." Hence, simply adopting a 'pure' Foucauldian approach is rarely possible.

\section{Toolbox}

Instead, as he stated himself, Foucault's work can be considered as a toolbox. O'Farrell, following on from her quote above, states that Foucault's work is "a productive source of ideas for those applying specific tools piecemeal to particular domains" (p. 50). Rather than becoming a dissertation on the development of Foucault's work, this thesis moves directly to considering the tools of Foucault. As shown below, this toolbox is considered on multiple levels.

\section{Search for Rarity - Selection of Texts}

Another important Foucauldian concept has direct relevance for the selection of texts in this thesis. This is Foucault's approach to his source material. He makes it clear that he is not searching for a comprehensive truth and considers rarities: "If, by substituting the analysis of rarity for the search for totalities, the description of relations of exteriority for the theme of the transcendental foundation, the analysis of accumulations for the quest of the origin, one is a positivist, then I am quite happy to be one" (Foucault, 1969/2010, p. 125). A well-known example, in Discipline and Punishment (Foucault, 1975/1995, pp. 195-228), is the use of Bentham's Panopticon to understand attitudes towards incarceration. Bentham's Panopticon was never built, but Foucault's analysis of Bentham's text provides concepts that are useful to inform and challenge contemporary attitudes. Bentham's conceptual model highlights various attitudes that provide insights into how we might think now.

Foucault does not present lists of texts with justifications for their inclusion as his source material. While he does not state directly that he selects texts for their utility and ability to yield insights into the present, it is most unlikely that his selections were simply haphazard. This thesis follows a similar approach, selecting texts for utility and not for comprehensiveness. This approach does not mean that well-known texts are avoided as such texts are likely to be influential, but it does promote the inclusion of texts which may give insight, even if they are not the most read. 


\section{Ethics}

This thesis utilizes Foucault's methods of historical analysis, avoiding any question of ethics for two reasons. Firstly, and most obviously, the object of study is not what would generally be considered to be an ethical topic. The question of how 'strategy treats cognition' is an epistemological one rather than a question of moral or ethical judgement.

Secondly, Foucault, while a person with political interests, does not make ethical judgements in his principal texts. In Madness and Civilization (Foucault, 1961/1988, p. x) Foucault explicitly states this, "we must speak of those actions re-examined in history, leaving in abeyance all that may figure as a conclusion, a refuge in truth." When discussing Freud (Foucault, 1961/1988, p. 278), Foucault states his findings without any judgement: "[Freud] did deliver the patient from the existence of the asylum within which his "liberators " have alienated him; but he did not deliver him from what was essential in this existence." A similar example of non-judgement is, "There remains, therefore, a trace of 'torture' in the modern mechanisms of criminal justice - a trace that has not been entirely overcome, but which is enveloped, increasingly by the non-corporal nature of the penal system" (Foucault, 1975/1995, p. 16). This general approach is summarised in The Birth of the Clinic: "This book is ... an attempt to apply a method in the confused, under-structured, and ill-structured domain of the history of ideas" (Foucault, 1963/1994, p. 195). When Foucault does finally approach ethics directly, it is because his object of study - sexuality - has an ethical dimension. He does so in The Use of Pleasure (Foucault, 1984/1990), by aligning an individual's 'ascetic', or ethical position, with his concept of subjectivity, or how a person is self-constituted (see below for a definition of subjectivity). This treatment is an historical study, that is, Foucault seeks to understand how ideas of sexuality, including the concept of ethics, developed over time.

Hence, Foucault is interpreted as being 'critical' as Kant is critical, that is 'applying reason to understand'. Foucault is not interpreted as being critical in the way Horkheimer's Critical Theory aimed not only to understand society, but to also transform it. While Foucault had a significant political life, it is purely his historical method that is utilized in this thesis.

\section{Summary}

This thesis follows the core approach of Michel Foucault, because it interprets the past in order to understand the present. To follow Foucault's approach, this thesis pragmatically treats Foucault's work as a toolbox from which techniques should be selected. It further follows Foucault by selecting texts for their utility of insight, and avoids going beyond his core techniques into ethical considerations. 


\section{Foucault's Toolbox}

Based upon in-depth readings of The Archaeology of Knowledge (Foucault, 1969/2010), The History of Sexuality (Foucault, 1976/1990), The Use of Pleasure (Foucault, 1984/1990), and general readings of Foucault's other principal works, Foucault's toolbox is considered on six levels:

- 'the other'

- conceptual abstractions

- specific descriptive techniques

- descriptive techniques for active processes

- general descriptive techniques

- a non-ontological focus on practice

Within these levels, the following components are identified:

Table 1: Foucauldian Components

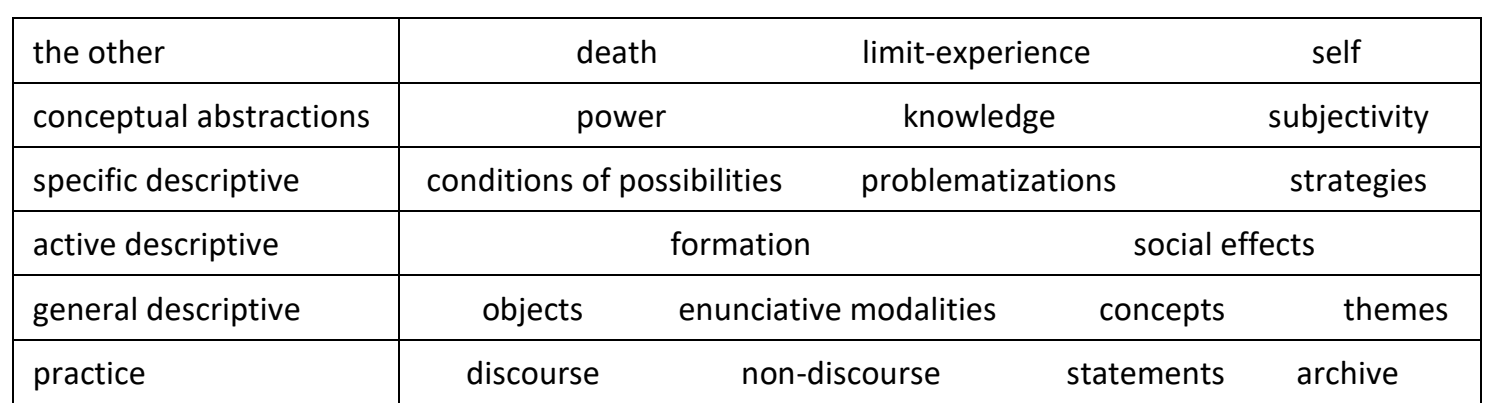

\section{Detailed Analysis}

\section{The Other}

The analysis provided here draws heavily on Miller (2000). Foucault was not purely an academic, he was also a man of his times with a fascination with death, and a man who experimented in the use of drugs and sadomasochism. While Miller's views are challenged (see Gutting (2005)), Foucault's intellectual milieu differed significantly from today. Politics and philosophy were topical for more than a narrow academic elite, and included consideration of communism, socialism, existentialism, structuralism, post-structuralism, and postmodernism. In this environment, and influenced by modernism's search for truths, there appears to have been a general drive to discover an ontology of the self which then reveals itself as a fascination with death. Miller provides enough evidence to suggest this was a preoccupation of Foucault's; and explicates how Foucault was influenced by the 'Nietzschean quest' to find oneself. That Foucault took this beyond philosophizing to experimentation with the use of drugs, limit-experiences, and sado-masochism seems likely. Within this thesis, this aspect of Foucault will not be a focus, but it is useful to take cognizance of Foucault's leanings and, particularly, to understand that he was searching for a new way of thinking and experiencing. He looked for this new way in many places, and it is his new way of looking at history and society that is now considered. 


\section{Conceptual Abstractions}

'To describe' requires a set of words, which then can be interpreted. Foucault's set of words have been interpreted as a structuralism bordering on realism, but he indicates precisely the opposite: "I would like to disengage my analysis from the privileges generally accorded ... the principles of rarefaction" (Foucault, 1976/1990, p. 12) and "There is always something ludicrous in philosophical discourse when it tries ... to tell them where truth is ... in the language of naïve positivity" (Foucault, 1984/1990, p. 9). Foucault's refutation of 'the principles of rarefaction' and condemnation of the 'search for truth' are explicitly confirmed in, "my aim is most decidedly not to use categories of cultural totalities" (Foucault, 1969/2010, p. 15). Foucault is a nominalist and, while he may use a modernist writing style where terms could be interpreted as being based upon a belief in ideals, this usage of terms is purely to support a useful conversation. This thesis uses the Foucauldian vocabulary in this sense of being useful words rather than as being a taxonomy of truths.

\section{Power/Knowledge}

Power and knowledge are considered together, as Foucault often conflates them. Note also that Foucault's use of power, as discussed below, is not the concept of domination. Foucault states, "A corpus of knowledge ... is formed ... and becomes entangled with the practices of power" (Foucault, 1975/1995, p. 23) and, "We should admit ... that power produces knowledge ... ; that power and knowledge directly imply one another; that there is no power relation without the correlative constitution of a field of knowledge" (Foucault, 1975/1995, p. 27). Similar to the above use of 'power relations' to describe power, he also uses 'force relations': power as a "multiplicity of force relations immanent in the sphere in which they operate" (Foucault, $1976 / 1990$, p. 92). Foucault sees power as a describable force; one that he wants to analyse together with knowledge, but without rarefying either; the analysis of power as relations is possible "while escaping the alternative of a power conceived of as a domination or exposed as a simulacrum" (Foucault, 1984/1990, p. 5).

Foucault (1969/2010, pp. 182-183) defines knowledge as:

- "that of which one can speak in a discursive practice"

- "the space in which the subject may take up a position and speak of objects"

- "the field of coordination and subordination in which concepts appear"

- "defined by the possibilities of use and appropriation offered by discourse"

Knowledge is specific and has human aspects. He reinforces this by stating "Between techniques of knowledge and strategies of power, there is no exteriority ... We will start therefore from what might be called "local centers" of power-knowledge" (Foucault, 1984/1990, p. 98).

Knowledge is closely related to power as, in the world of humans, it drives behaviours and is affected by behaviours. Power is not used in the traditional sense, but it is implicit in space, cognition, and time. The history we perceive can be described as driven by this power, a power conceived of a force emanating from relations within space, cognition, and time. 


\section{Subjectivity}

In the three volumes of The History of Sexuality, Foucault focuses on understanding 'subjectivities'. In the second volume, The Use of Pleasure (1984/1990), he provides a theoretical background to subjectivities by: a) defining them; b) suggesting common subjectivities and themes to the subjectivity of sexuality; c) extending to a broader concept of morality; and d) using the idea of problematization (see below) as a heuristic to investigate subjectivities.

Foucault defines subjectivities as "the forms within which individuals are able, are obliged, to recognize themselves as subjects of this sexuality" (Foucault, 1984/1990, p. 4). He goes further to describe subjectivities as "the forms of modalities of the relation to self by which the individual constitutes and recognizes himself qua subject" (Foucault, 1984/1990, p. 6) and as the "hermeneutics of the self" (Foucault, 1984/1990, p. 6). This aspect, of contemplating ourselves as subjects, is fundamental to Foucault's later work.

Foucault extends the discussion of sexuality to morality and defines values and rules, moral behaviours, and practices of the self. These practices are more than physical activities as they include a mixture of thoughts, intentions, and actions. One practice is the ethical determination of self that individuals must perform to be able to conceive of themselves as moral. Modes of subjection are how an individual submits to the rule and puts it into practice. These "modes of subjectivation", "ascetics" and "practices of self" are beyond knowledge and rules, as they consider "self-reflection, self-knowledge, self-examination, for the decipherment of the self by oneself" (Foucault, 1984/1990, p. 29).

Within this world of moving space and cognition, humans have the capacity to contemplate themselves. The joy or the curse of consciousness means we are sentient. But sentient where? Foucault sees the world as socially constructed and sees we subjects as being part of this social maelstrom. While we have the capacity to cognate, we are also within the subjectivity of self which can be described and studied over time.

\section{Specific Descriptive}

Foucault uses a series of descriptive categories for very specific purposes.

\section{Conditions of Possibility}

'Conditions of possibility' recognize the place of context. In The Archaeology of Knowledge (Foucault, 1969/2010), Foucault explains what he means: "The conditions necessary for the appearance of an object of discourse, the historical conditions required if one is to 'say anything' about it, and if several people are to say different things about it, the conditions necessary if it is to exist in relation to other objects, if it is to establish with them relations of resemblance, proximity, distance, difference, transformation - as we can see, these conditions are many and imposing" (Foucault, 1969/2010, p. 45). Later, he explicitly defines conditions for power: "Power's condition of possibility ... must not be sought in the primary existence of a central point ... ; it is the moving substrate of force relations which, by virtue of their inequality, constantly engender states of 
power" (Foucault, 1976/1990, p. 93). So Foucault finds conditions of possibility to be many and to be contextual, and he uses the concept as a descriptive categorization.

\section{Problematizations}

In The Use of Pleasure (Foucault, 1984/1990), Foucault uses problematization as a means to focus. Initially, he suggests that study should focus on problematizations: "But, after all, this was the proper task of a history of thought ... to define the conditions in which human beings "problematize" what they are, what they do, and the world in which they live" (Foucault, 1984/1990, p. 10). The first major part of this text, 'The Moral Problematization of Pleasures' (Foucault, 1984/1990, pp. 33-94), investigates four problematizations that give rise to a morality. By looking at the problematizations, he can focus his enquiry on specific parts of a discourse rather than considering the totality.

\section{Strategies}

In his early work, Foucault associates strategies with discourse: "A discursive formation will be individualized if one can define the system of formation of the different strategies that are deployed in it" (Foucault, 1969/2010, p. 68). Later, he extends this to include power: “Now, the study ... presupposes that the power exercised on the body is conceived not as a property, but as a strategy" (Foucault, 1975/1995, p. 26), and further states that it is inherent in situations: "power is ... the name that one attributes to a complex strategical situation in a particular society" (Foucault, 1976/1990, p. 93). In The Use of Pleasure, Foucault explains how strategies are a way to view power: "And the analysis of power relations and their technologies made it possible to view them as open strategies, while escaping the alternative of a power conceived of as domination" (Foucault, 1984/1990, pp. 4-5).

Foucault uses strategies as a device for describing the operation of power. He expressly disassociates strategies from any external form but sees them as being implicit in context. But, in Foucault's use, strategies could be misinterpreted as being an intention of an entity. This is not Foucault's aim; strategy is simply a way of describing the operation of power in context.

\section{Active Descriptive}

Besides these specific descriptive categories, Foucault uses two terms to describe active processes relating to discourses.

\section{Formation}

Foucault considers that discourses are not static but are always actively in a process of formation. In his early work, he adopts an almost structuralist approach to such formation: "The conditions to which the elements of this division (objects, modes of statements, concepts, thematic choices) are subjected to what we shall call the rules of formation. The rules of formation are conditions of existence (but also of coexistence, maintenance, modification, and disappearance) in a given discursive division" (Foucault, 1969/2010, p. 38). Later in his career he uses formation in a more general sense: "but it also made possible the formation of a "reverse" 
discourse, homosexuality began to speak in its own behalf" and "sexuality is a very real historical formation: it is what gave rise to the notion of sex" (Foucault, 1976/1990, pp. 101, 157).

\section{Social Effects}

Foucault uses the general concept of social effects from his early texts: "Yet what the eighteenth century first noticed about [the relegation of unreason to the distance of confinement] was not the secret interrogation, but only the social effects: the torn clothing, the arrogance in rags, the tolerated insolence whose disturbing powers were silenced by an amused indulgence" (Foucault, 1961/1988, p. 200). For Foucault, discourse is not just for the sake of discourse itself - discourse has effects on society that are worthy of enquiry: "What were the effects of power generated by what was said? What are the links between these discourses, these effects of power, and the pleasures that were invested by them?" (Foucault, 1976/1990, p. 11).

\section{General Descriptive}

Within The Archaeology of Knowledge (Foucault, 1969/2010), Foucault introduces general descriptive terms of objects, enunciative modalities, concepts and strategies. His aim is develop descriptive techniques: "instead of reconstituting chains of inference (as one often does in the history of the sciences or of philosophy), instead of drawing up tables of differences (as the linguists do), [this analysis] would describe systems of dispersion" (Foucault, 1969/2010, p. 37). Clearly, Foucault is not a Structuralist in the traditional sense, even if he defines a structure.

In The Archaeology of Knowledge, Foucault conflates strategies with themes: "I shall call these themes and theories 'strategies'“ (Foucault, 1969/2010, p. 64). He also uses the concept of themes extensively in a general sense without reference to strategies. As this latter usage is useful, Foucault's conflation of the two terms is not followed, but Foucault's general usage is.

\section{Objects}

Foucault focuses on the formation of objects, without giving a definition of objects (Foucault, 1969/2010, pp. 40-49). However, from psychopathology, he gives examples of objects: motor disturbances, hallucinations and speech disorders. He focuses on the rules of their existence, these being:

- surfaces of emergence (where ideas can emerge)

- authorities of delimitation

- grids of specification (classification)

These rules of existence align with the conditions of possibility (also termed conditions of existence) discussed above. Foucault is stating that we can think of what is thought (topics and ideas) especially by understanding how they emerge. So objects are 'of cognition' and can be described by understanding 'how they come to be formed'. 


\section{Enunciative Modalities}

Foucault (1969/2010, pp. 50-55) highlights three aspects of enunciative modalities (i.e. the way in which statements are made):

- who is speaking

- where the speaker speaks from

- the position of the speaker (questioning subject, listening subject, observing subject)

Enunciative Modalities is not a concept that is used directly within this thesis, but is included here to note the alignment with the hermeneutics of Schleiermacher and Dilthey (see Hermeneutics, page 33).

\section{Concepts}

Foucault (1969/2010, pp. 56-63) makes it very clear what concepts are not: "to analyse the formation of concepts, one must relate them neither to the horizon of ideality, nor to the empirical progress of ideas" (Foucault's italics). Foucault's example of a concept, grammar, is clearly beyond the 'thought of an individual'. He gives quite detailed descriptions of aspects of such discourses: they have forms of succession; there are coexistent statements (active, from different domains, and older statements that are now invalid); and there are various procedures for intervention. Foucault suggests that concepts can be understood from the preconceptual, this being "the group of rules that in fact operate within [discourse]" (p. 62). So concepts, having social significance, can be understood and described.

\section{Themes}

'Theme' is a term Foucault uses in all of his standard texts. He uses the term in the general sense of themes that exist through time, sometimes at a societal level, and at times at a more local level. In The Archaeology of Knowledge, he uses 'theme' generally, and explicitly describes it as part of strategies. As stated above, this latter usage is avoided in this thesis, as it is not extensively used and his general usage is more predominant. In The History of Sexuality (Foucault, 1976/1990, pp. 21-22) Foucault makes it clear that these themes are to be interpreted and are not necessarily aligned with accepted social history: "a thematic complex ... formed around ... this thematics maintained a certain constancy as time went by ... Now, it should be noted that these themes ... did not coincide with the lines of demarcation that may have been traced by great social, civil, and religious interdictions". So, for one term, Foucault's usage aligns with a common contemporary usage.

\section{Practice}

Jean-François Lyotard's postmodern view is, "the society of the future falls less within the province of a Newtonian anthropology ..., than a pragmatics of language particles. ... They only give rise to institutions in patches - local determinism" (Lyotard, 1984, p. xxiv). Foucault follows a similar postmodern approach, but goes further to interpret society through examining 'local determinism' or practice. 


\section{Practice}

Foucault looks to the local, not to universals, as he directs his attention to the statement and away from central truths: "The analysis of the discursive field is orientated in a quite different way; we must grasp the statement in the exact specificity of its occurrence" (Foucault, 1969/2010, p. 28). And, as he states, the discourse should be treated in its practical form: "Discourse must not be referred to the distant presence of the origin, but treated as and when it occurs" (Foucault, 1969/2010, p. 25).

\section{Discourse}

The term 'discourse' has many interpretations. Vaara, Kleymann and Seristö $(2004$, p. 4) suggest that "linguists understand discourse as language, pyschologists as cognitions, and sociologists as interaction." While there are many interpretations, there are very few definitions.

Fortunately, Foucault does give us a definition of discourse: "we must conceive discourse as a series of discontinuous segments whose tactical function is neither uniform nor stable. ... a multiplicity of discursive elements that can come into play in various strategies. ... discourse can be both an instrument and an effect of power ... Discourse transmits and produces power; it reinforces it, but also undermines and exposes it, renders it fragile and makes it possible to thwart it" (Foucault, 1976/1990, pp. 100-101). Alvesson and Sköldberg (2009, p. 250), in line with Foucault's words above, suggest, “[A Foucauldian] discourse is ... seen more as a framework and a logic of reasoning, that, through its penetration of social practice, systematically forms its objects, than as any use of language in a social context." Foucault's quotation primarily focuses on what discourse does, only defining discourse as "a series of discontinuous segments", whereas Alvesson and Sköldberg suggest that a Foucauldian discourse is "a framework and logic of reasoning".

Because neither of the definitions above are that practical, and because discourse is used extensively in this thesis, a definition is made here based upon Pragmatic Cognitivism: 'A discourse is an enactment of humanity over time, through thoughts and artefacts'. There is no discourse without humanity, as a subject who thinks the object of discourse is required. Further, language can be used in various ways to define discourses, these variations essentially being different epistemological frameworks. Discourses can be described hierarchically, with 'grand discourses' containing other discources.

In this thesis, strategy is treated as the grand discourse, and four discourses within it form a major categorization. Within such discourses, sub-discourses are also defined. The use of such structures should not be interpreted as a form of structuralism. It should be interpreted as a pragmatic use of language to enable conversations about complex objects of study. It should also be noted that the term discourse is also used in the general sense of the definition made above.

\section{Non-discourse}

But what of non-discursive elements? Foucault recognizes them: "Archaeology also reveals relations between discursive formations and non-discursive domains (institutions, political events, economic practices and 
processes)...; it tries to determine how the rules of formation that govern it ... may be linked to non-discursive systems: it seeks to define specific forms of articulation" (Foucault, 1969/2010, p. 162). So while Foucault focuses on discourse, he recognizes non-discursive elements. Dreyfus and Rabinow (1983/1983, p. 184) recognize that Foucault makes this connection and has more emphasis on it in his later work: “... his shift from an exclusive emphasis on discursive formations during the mid-1960s to a broadening of analytic concerns to include once again non-discursive issues: the move to cultural practices and power".

\section{Statements and Archives}

In The Archaeology of Knowledge (1969/2010), Foucault defines categorizations of discourse. Two key aspects are statements and archives: "[The statement] is not in itself a unit, but a function that cuts across a domain of structures and possible unities, and which reveals them, with concrete contents, in time and space" (p. 87), and "the archive defines a particular level: that of a practice that causes a multiplicity of statements to emerge ... ; and it does not constitute the library of all libraries. ... It is the general system of the formation and transformation of statements" (1969/2010, p. 130). So Foucault does not see statements and the archive as linguistic structures and collections, but rather as local functional instantiations.

\section{Summary}

Foucault's toolbox has a depth of topic and a breadth of concepts. This thesis interprets it as:

\begin{tabular}{|c|c|}
\hline the other & Highly personal aspects of awareness that Foucault delved into \\
\hline conceptual abstractions & Concepts that provide a language to discuss key aspects of discourse \\
\hline specific descriptive & Words that allow specific aspects of discourses to be described \\
\hline active descriptive & Words that consider active discourse processes operating in time \\
\hline general descriptive & A series of general words that allow discourse to be discussed \\
\hline practice & The object of study, and words that describe it \\
\hline
\end{tabular}




\section{Why Foucault?}

There is a clear prima facie case for using a Foucauldian approach, as his methodology is the historical analysis of documents, which is precisely what this thesis is about. The question of how well the methodology might support the purpose of this thesis is considered from perspectives of:

1. critical approach

2. history of the present

3. useful interpretative approach

4. alignment with the epistemology of this thesis

\section{Critical Approach}

Foucault does not write historically accurate histories, as he aims "to know how and to what extent it might be possible to think differently, instead of legitimating what is already known" (Foucault, 1984/1990, p. 9). Foucault rarely uses the term critical, but in The Birth of the Clinic he states: "The research that I am undertaking here therefore involves a project that is deliberately both historical and critical" (Foucault, $1963 / 1994$, p. xix). In wanting to create the possibility of thinking differently, Foucault goes beyond description for its own sake.

This criticality is aligned to the Kantian sense of reason, not to a societal sense as in Critical Theory. Foucault selects text for analysis based on the insights that they may generate and does not search for societal drivers that may align to a particular political theory or societal epistemology.

In a similar manner, this thesis adopts Kant's and Foucault's critical approaches of searching for reasoned insights.

\section{History of the Present}

Foucault's brand of history differs from traditional approaches, as he aims for a history of the present: "I would like to write the history of ... Why? Simply because I am interested in the past? No, if one means by that writing a history of the past in terms of the present. Yes, if one means writing the history of the present" (Foucault, 1975/1995, pp. 30-31). He is concerned with contemporary thought and uses historical analysis to illuminate why we might think the way we do. This thesis treats strategy in a similar manner. It asks 'how does' instead of 'how did' as it aims to understand current thought and thereby suggest how else things may be thought. Foucault, in his History of Sexuality (Foucault, 1976/1990), suggests another way of thinking about sexuality, over the then-dominating repressive hypothesis that failed to recognize multiple discourses; this thesis similarly considers how the current strategy discourse treats cognition and, depending on findings, potentially shows other possible contemplations of cognition. 


\section{Rich and Useful Interpretative Approach}

As described above and repeated here, Foucault provides a rich and useful interpretative approach. Such an approach aligns with the interpretative approach of this thesis, other than 'the other' which is not used, and which is omitted from the table below.

Table 2: Foucauldian Components Without 'The Other'

\begin{tabular}{|c|c|c|c|}
\hline conceptual abstractions & power & knowledge & subjectivity \\
\hline specific descriptive & conditions of possibilities & problematizations & strategies \\
\hline active descriptive & \multicolumn{2}{|c|}{ formation } & social effects \\
\hline general descriptive & objects & enunciative modalities & themes \\
\hline practice & discourse & non-discourse & archive \\
\hline
\end{tabular}

Further, each level of Foucault's approach has distinctive benefits:

- the abstractions are a rich way to consider change over time in a human context

- specific descriptive terms are an entry into useful lines of enquiry

- active descriptive terms provide a way to show processes

- general descriptive terms provide core and useful terminology

- Foucault's practice focus aligns with the topic of this thesis

\section{Epistemological Alignment}

Foucault's approach "examine[s] the forms of discursive practice that articulate the human sciences" (Foucault, 1984/1990, p. 6) “while escaping the dilemma of science versus ideology" (Foucault, 1984/1990, p. 4). This is the essential alignment of an interpretive approach with a practice-based epistemology. Such an examination of texts within human sciences aligns with the research topic, with the thesis goal and, more importantly, with the epistemology of this thesis. The pragmatic approach, of a priori space, cognition, and time, aligns well with Foucault's approach that 'escapes the dilemma of science versus ideology' through a focus on practice.

\section{Summary}

In summary, Foucault's approach is practice-based, focusing on discourse, but including non-discursive elements. His object of study is the statement within the archive. Foucault explicitly disavows any forms of realism with their concomitant universals, any belief in the primacy of the individual ego or consciousness, and other structures of truth that can determine behaviour. After these disavowals of all things pre-ordained, Foucault does not then propose an ontology. Instead, he provides diagnostic tools that function upon the specificity of our world.

Foucault was selected as the thesis' research method because his method has a critical approach, a focus on the present, a rich interpretative methodology, and alignment with the epistemology of this thesis. 


\subsection{Operationalizing Hermeneutics and Foucault}

How the chosen hermeneutic guidelines and Foucauldian methodology are 'operated' in the research is described below. This involves a number of choices which are made pragmatically. That is, concepts and techniques are chosen based on their applicability to the candidate and to contemporary readers of this thesis. In practice, this means adopting language that is current and avoiding what might be described as the excesses of post-modernism, as seen in Foucault himself.

\section{Application of Hermeneutic Guidelines}

The three concepts of hermeneutics adopted (see p. 34) are used as interpretative guidelines as follows:

Part and Whole A starting point is recognizing the interplay of the parts and the whole of a text. Analysis involves at least two readings of each text to avoid any errors such as taking a part to be the whole, or missing a part of the whole.

Play Gadamer's recognition of the play between reader and text is recognized by giving time for contemplation. Giving time for cognitive development inherently provides the opportunity for a 'free play' of ideas and for understanding to develop.

Author's While the author's context may be apparent, it may be necessary to go beyond texts to

Context determine contextual drivers of subjectivities. This is also a key Foucauldian concept of 'conditions of possibility.'

\section{Operationalization of Foucault}

Foucauldian concepts defined in the table below are used in two ways:

- as a guide for interpretation (all the terms in the table)

- as a specific descriptive framework when recording interpretations (the eight bolded terms)

Table 3: Operational Foucauldian Framework

\begin{tabular}{|c|c|c|c|c|c|}
\hline conceptual abstractions & \multicolumn{2}{|c|}{ power } & \multicolumn{2}{|c|}{ knowledge } & subjectivity \\
\hline specific descriptive & conditions $\mathrm{C}$ & ssibilities & problema & ions & strategies \\
\hline active descriptive & \multicolumn{3}{|c|}{ formation } & \multicolumn{2}{|c|}{ social effects } \\
\hline general descriptive & objects & \multicolumn{2}{|c|}{ enunciative modalities } & con & themes \\
\hline practice & discourse & \multicolumn{2}{|c|}{ non-discourse } & state & archive \\
\hline
\end{tabular}




\section{The Levels}

The levels of the Framework are now considered, from practice upwards, and reasoning given for the different usages of the terms defined.

\section{Practice}

The term discourse is used extensively to describe the object of study. Other terms are not used directly but, following Foucault, the focus is on the archive as represented by documents, especially practical documents: "The domain I will be analyzing is made up of texts written for the purpose of offering rules, opinions, and advice on how to behave as one should: "practical" texts, which are themselves objects of a "practice" in that they were designed to be read, learned, reflected upon, and tested out, and they were intended to constitute the eventual framework of everyday conduct" (Foucault, 1984/1990, pp. 12-13). So, in the common business archive, texts will be studied that discuss how to do strategy, and overly theoretical commentaries will be avoided. When academic fields are considered, this stricture is relaxed somewhat if 'theoretical texts' predominate over 'practical texts'.

\section{General Descriptive}

Of Foucault's general descriptive terms, those labelled as concepts and themes are used directly in their contemporary forms. Concepts are created by strategy writers, and strategy writers are subject to concepts within their discourse. Concepts are not taken to be 'realist concepts', but a convenient literary manner in which to describe aspects of discourses.

Theme is used as a general device for identifying reoccurring ideas and concepts, especially over time. Instead of looking for causality, this thesis identifies themes. This is very important to the whole approach, and is utilized throughout the research, especially in interpretations at a discourse level.

Neither of the terms enunciative modalities or objects are used directly, as they are somewhat difficult Foucauldian concepts. Aspects of enunciative modalities are included in the hermeneutic approach (see above), but the term is not used further as it is a theoretical concept about how we communicate and not a useful descriptive device. Foucault uses the term object in a very specific way (see p. 43). To follow the Foucauldian usage of the term would require constant clarification. Because of the overhead of constant clarification, the possibility of confusion, and the presence of other useful terms, object is not used in Foucauldian analysis. 


\section{Active Descriptive}

The notion of social effects is used directly, while the notion of formation is not. Social effect is a core part of this study as it pertains to what happens in society in response to strategy discourses. This is an important concept for the strategy discourse itself, in how it actually has become a discourse with influence, so it is included directly.

Foucault uses formation sparingly, and more as a general concept when considering change. It is used in this general sense to consider how specific concepts and themes form, but not as a specific concept requiring attention. Because social effects and knowledge are outcomes of formation, it is not used directly, as this would be likely to complicate this thesis without providing any significant benefit.

\section{Specific Descriptive}

Of the specific descriptive terms, conditions of possibility and problematizations are directly used in analysis and in descriptions of findings. Both terms align with common usage and indicate useful concepts. Conditions of possibility is an umbrella term that considers authors' contexts and business contexts. Problematizations introduces the very useful question of 'why' and generates some useful insights into the intent of strategy writers. However, Foucault's use of the term strategies is not a standard usage of the term and would be likely to create confusion in a thesis on strategy, so it is not used in a Foucauldian way, other than above, when discussing Foucault himself.

\section{Conceptual Abstractions}

The concept of 'knowledge' is used directly as an object to be described and as an object of analysis. It fits well with a discourse such as strategy which is full of different knowledges.

Foucauldian power is a well-known and well-used concept, but in this thesis it is not utilized for three reasons. Firstly, it is a difficult concept that is not the normal conception of power and instead describes inherent change within discourses that occurs over time. Secondly, for this thesis discourse change is important, but this is sufficiently well conveyed through descriptions of knowledge. Thirdly, Foucault recognized that knowledge and power were often the same. So, to avoid complicating the thesis for no practical reason, the term knowledge is utilized.

Subjectivity is a useful concept for how strategists think of themselves and how they came to perceive of themselves in a certain fashion. Foucault used this extensively in his three books on sexuality, and it has relevance for strategy also since the role of the strategist came into being and has changed over time. 


\section{Use of Foucauldian Concepts}

Of the eight concepts selected (see Table 3, p. 49), the terms discourse, concept, and theme are used generally within the research with the meanings described above. The other five, shown below, are used both generally and to structure Foucauldian analyses presented in Part Two - Business Strategy and Cognition.

Table 4: Foucauldian Structure

\begin{tabular}{ll}
\hline Conditions of Possibility & Underlying conditions of strategy \\
\hline Problematization & Problems that drive strategy \\
\hline Knowledge & What business strategy discourse states about strategy and cognition \\
\hline Social Effects/Subjectivity & $\begin{array}{l}\text { These two concepts are combined as they are closely related. Social effects } \\
\text { apply to society as a whole, while subjectivity applies to an individual. Both } \\
\text { have aspects of being outcomes of a discourse. }\end{array}$ \\
\hline
\end{tabular}

\section{Variations in Order}

These concepts are used as the section headings in the actual research, and two different orders are used. For academic discourses, texts often provide their sources and cite previous work, so starting the analysis with conditions of possibility and going forward is practically achievable. The section order therefore is:

1) conditions of possibility, 2) problematizations, 3) knowledge, 4) social effects/subjectivity As social effects and subjectivity are closely related, these are combined into a single section. However, for mainstream discourses, in which the texts studied are books, the conditions of possibility are more easily accessible through analysis of the knowledge of the discourse. Hence, for these discourses the order is:

1) knowledge, 2) conditions of possibility, 3) problematizations, 4) social effects / subjectivity 


\section{Research Sub-questions}

The Foucauldian structure leads to the four research sub-questions shown below. These four sub-questions treat different aspects of the strategy discourse, and answering them generates an interpretation of the strategy discourse. Within the benefit of this interpretation, the main research question, "How does business strategy treat cognition?" can then be answered.

Conditions of Possibility

Problematizations

Knowledge

Socials Effects/Subjectivity
1. Under what conditions does business strategy operate?

2. What problems does business strategy try to solve?

3. What type of knowledge does business strategy create?

4. What social effects does business strategy have and how does this make strategists feel about themselves?

\section{Summary}

The operationalization described here is 'organized hermeneutics.' A series of hermeneutic guidelines and Foucauldian concepts, used both as general concepts and to provide structure, are organized to suit the subject at hand - the question of strategy's treatment of cognition.

In accordance with Foucault's method, these techniques generate insights, rather than show causality. As is often stated throughout this thesis, the goal is not a comprehensive history showing convenient causal linkages. Instead the goal is to glean insights through critical interpretations leading to questions of how we might think differently today. 


\subsection{Summary}

This methodology aligns with Pragmatic Cognitivism, is a historical interpretative that searches for insights, and is tailored for contemporary use:

The selected methodology and guidelines align with the epistemology of Pragmatic Cognitivism. Hence, this thesis is consistent in 1) its view of the status of knowledge, and 2) its approach to gaining knowledge. This is particularly important for this thesis, as any inconsistency would be likely to make any interpretations confusing and open to significant criticism.

The methodology searches for insights through the interpretation of historical texts. It is not a search for ethical positions, nor is it a search for historical causality. These points are fundamental for the selection of texts and the scope of interpretations.

Foucault's work is treated as a toolbox of techniques which are selected for their useful contemporary usage. There is no attempt to utilize his method in some search for historical purity, but to utilize those of his techniques that are useful today for this thesis. 


\section{Chapter 5-A Review of Treatments of Cognition}

This chapter reviews treatments of cognition to provide a conceptual basis for analysis of the treatment of cognition in business strategy.

Approaches to cognition range from Buddhism to neuroscience; cognition is experienced by us all, and there are many academic disciplines that consider mind and cognition. So a comprehensive study of all treatments of cognition is beyond the scope of a single thesis. Because of this limitation, choices were made. Based upon the candidate's own knowledge, and general and academic web searches for cognitive fields, a list was made of key thinkers and cognitive disciplines. Selections were made based upon the availability of a significant literature and the likelihood of the field including useful commentary on cognition.

After a review of the chosen theorists and disciplines, this chapter summarizes treatments generally, by their philosophical approach and by their use of language, and identifies common themes in the literature.

The chapter is structured as:

- a series of analyses of treatments of cognition

- findings consolidated by theorist/field, by philosophy, by use of language, and by common themes

- a final summary of the reviews

Note that the texts are reviewed in the present tense, because they exist now and are interpreted now. Further, for ease of expression, often the name of the author(s) is used instead of the name of the specific text. This usage should be read as an interpretation of what the text means, and not a suggestion that the author(s) are in some way alive today. 


\subsection{Treatments of Cognition}

\section{Aristotle's De Anima}

Aristotle, in De Anima (Aristotle, circa 350 BC/1986), considers the soul in terms of how living entities think and move. He advances an onto-epistemological theory based on his theories of substance and form.

In what is perhaps a warning to future researchers, Aristotle notes that such enquiries are not easy to advance: "it is one of the hardest of things to gain any conviction about" (p. 126). Aristotle's scope is very broad, as indicated by the faculties he defines: "nutritive, perceptive, desiderative, locomotive, and intellective" (p. 162), but he expends considerable effort considering consciousness. Terms used frequently are cognition, reasoning, perception, thinking, knowing, imagination, and intellect. The text presents Aristotle's interpretation of these terms and the reasoning behind his interpretations, for example, "both thinking and understanding are thought to be something like perceiving" (p. 197).

In modern parlance, as described by Shields (2016), Aristotle's approach is termed 'Hylomorphism'. Hylomorphism distinguishes between matter and form. Animate beings are distinguished as having a body (matter) and a soul (form). In Aristotle's world of forms, the actual perception, which involves both receiving a sensation and subsequent thought, involves the subject taking on the form of the object.

In De Anima, Aristotle treats cognition as a serious and difficult object of study that can be known. He appeals to reason and experience to justify his assertions about cognition and the soul. And, as James (1890/1950a, pp. 1-3) notes, early thinking sought an absolutist answer to the question of cognition. Aristotle clearly believed that the soul and all its faculties were explicable.

\section{Descartes}

The modern origin of contemplation of cognition can be attributed to Rene Descartes. In Meditations on First Philosophy (Descartes, 1641/1986) he believes that he has proven "that God exists and mind is distinct from the body" (1641/1986, p. 6). The distinct mind is, of course, part of the 'Cartesian Dualism' which informs the field of Philosophy of Mind (considered below). Mind is a "pure substance" that differs from body and "is immortal by its very nature" (p. 10). Descartes establishes his principle of doubt and then, after meditating on the self, states that "I am a mind, or intelligence, or intellect, or reason" (p. 18). This is "A thing that thinks ... doubts, understands, affirms, denies, is willing, is unwilling, also imagines and has sensory perceptions." (p. 19). He goes on to define faculties of judgement, knowledge, choice, understanding, imagination, and cognition (pp. 19-50). Descartes is clear that perception and reason are separate: "the use of my senses had come first, while the use of my reason came only later" (p. 52).

Descartes' taxonomy of cognitive terms is remarkably similar to contemporary terms. While Descartes does not, in Meditations on First Philosophy, offer explicit definitions, it is clear that sensory perceptions (which Descartes terms cognition) are separate from the process of imagination, reason/judgement, 
understanding/knowledge, and memory. Volition (termed as will or choice) is conflated with these other terms, even though it appears to be a different cognitive form.

In Meditations on First Philosophy, the relationships between faculties are not analyzed in depth, other than in an ingenious argument in which Descartes reasons that human error is possible as, while humans are created by a perfect god, "the scope of the will is wider than that of the intellect" (p. 40). In similarity to Aristotle, Descartes' use of terminology - such as imagination, understanding, and knowledge - is not too dissimilar from today's common usage.

Another similarity to Aristotle is Descartes' treatment of cognition. It is a study of consciousness that relies heavily on reasoning and introspection. He also looks for absolute answers as he makes very clear (p. 3): “| have always thought that the two topics - namely God and the soul - are prime examples of subjects where demonstrable proofs ought to be given with the aid of philosophy rather than theology" (note that when Descartes writes of the soul here, he is referring to the 'whole of mind' in a general sense).

\section{Immanuel Kant}

Immanuel Kant's text, The Critique of Pure Reason, is the subject of countless analyses and discussions. In this thesis, the approach of Robert Wolff (1963) is followed (including a series of nine YouTube lectures (Wolff, 2016)). Wolff summarizes Kant's core arguments regarding pure reason, which are paraphrased here as:

1. We think, that is, we have a thing called consciousness.

2. There is some structure to our thought. The structure has some consistency, and is, in a sense, a set of rules which allow humans to predict, interpret, and judge.

3. Objectivity for us is really activities that have necessity of connection - activities are not random.

4. When we apply our rules to perceptions, we are conferring onto the objects of perception the necessity of connection.

5. So combining 1-4, given that we think, we can think about an objective world.

6. Our inner sense is time, so our thoughts are arranged in a temporal order.

7. But such a time-order is inherent in our rules of reproduction in imagination.

8. Thus, our thinking inherently presupposes a time sequence of events (necessary causal relationships).

Wolff's training in analytic philosophy is reflected in his highly structured interpretation of Kant's arguments. His intent here is to show two things: how Kant allows us to have objective thought about an empirical world of which we cannot have 'direct experience'; and how the concept of causality can be similarly justified. These two questions arose through Kant's desire to find a bridge between rationalism and empiricism, and his desire to find a place for causality, a concept that Hume had called into question.

While Kant's thinking was novel and unique, his use of language was inconsistent and complex. Hence, while the following definitions are presented in the table below as having a basis in Kant's text, it is not suggested that they form a holistic and consistent taxonomy. 
Table 5: Kantian Language

Kant uses the term in the titles of two of his critiques - The Critique of Pure Reason and
The Critique of Practical Reason. The distinction is between the process of reasoning in a
purist sense and in a practical sense.

sensibility "Objects are given to us by means of sensibility, and it alone yields us intuitions, they are thought through the understanding, and from the understanding arises concepts" (Kant, 1781/1991, p. 65). Kant starts the process from sensibility, or the use of human senses.

intuition Intuitions follow from sensibility. This is not the modern usage, of intellectual intuition, but is a process of intuiting the world. Specific intuitions include space and time.

\begin{abstract}
imagination Imagination is essential to knowledge, as "Synthesis in general ... is the mere result of the power of imagination, a blind but indispensable function of the soul” (p. 112). As for intuition, imagination is assigned a lesser role than the contemporary usage of the term.
\end{abstract}

understanding "the mind's power of producing representations of itself, the spontaneity of knowledge, should be called the understanding" (p. 93). In this and other usages, Kant uses understanding as a general term for thinking.

knowledge Knowledge is used in a general sense and then specifically as something objective and true "when the holding of a thing to be true is sufficient both subjectively and objectively, it is knowledge" (p. 646)

apperception Apperception is essentially consciousness, "unity of consciousness that precedes all data of intuitions" (p. 136).

We can see in Kant a focus on cognition in The Critique of Pure Reason, and the development of a vocabulary similar to contemporary usage. A key difference is the use of the terms 'intuition' and 'imagination' as parts of a process of perception, whereas in current usage these apply to a level of ideas and reason, rather than being limited to a more mundane level of the senses.

Further, he treats cognition as being fundamental to knowledge, and understanding cognition as being fundamental to understanding knowledge. Even allowing that Kant's scope of enquiry was wider than pure knowledge, and that he incorporated ideas of a god in some of his other works, his starting point was the primacy of cognition for the human understanding of ourselves. However, unlike earlier philosophers, Kant was not seeking to find 'the' answer, as he explicitly recognized the limits of knowledge. Thus Kant's discussion of cognition is concerned with understanding humans, not understanding an external reality. And, by understanding our own cognition, we then understand the limits and capabilities of our own knowledge. Kant's goals are not as lofty as others', but his quest is no less complex. 


\section{Philosophy of Mind}

Philosophy of mind is just that - philosophy - and specifically of the metaphysical kind. Philosophy of mind seeks to find an ontological answer to the mind/body question. It could be seen as part of cognitive science (see below), but as Heil suggests (Heil, 2013), it is specifically metaphysical and is a branch of philosophy. This analysis draws on three texts: Heil (2013), Kim (2011), and Braddon-Mitchell and Jackson (2007).

The starting point for philosophy of mind is Descartes' Cartesian dualism. This theory has been judged to be an incomplete answer, so many other theorists have proposed more advanced ontological justifications of dualism. These include parallelism that suggests mind and body operate in parallel; occasionalism with a larger role for God; idealism that sees all things being in the mind; and epiphenomenalism that sees mental activity as secondary phenomena after physical phenomena.

Twentieth-century developments in philosophy of mind include philosophical behaviourism, identity theory, and functionalism. Philosophical behaviourism (Braddon-Mitchell \& Jackson, 2007, p. 37) occurs contemporarily with psychological behaviourism (albeit they do not have a common origin). Wittgenstein and Ryle were early and key questioners of the status of the entity 'mind'. Philosophical behaviourism tends to be materialist and to reject mind-matter, replacing it with the concept of states of mind being dispositions.

In the 1950s, in the United States and Australia, the Identity Theory arose (Heil, 2013, p. 74). This postulates that what we experience cognitively is correlated to our physical brains. Thought is actively aligned with brain activity. Again, this is a theory that focuses on how cognition functions at an ontological level.

This theory was superseded in the late 1960s by functionalism (Kim, 2011, p. 130), though this is not related to the functionalism of sociology. Now, based on a computer model, minds are conceived as inputs, a program, and outputs. Such a program runs in a machine, has functional states, and functional properties. This new abstraction still holds sway and has spawned a number of new theories. Such theories are not uniformly accepted and the field seems to be becoming more detailed and to be evolving along multiple paths.

While there are significant metaphysical discussions of consciousness, cognition is rarely mentioned. The Glossary in Braddon-Mitchell and Jackson (2007), a text titled Philosophy of Mind and Cognition, contains 127 definitions but omits to provide definitions for the terms cognition, consciousness, perception, and reason. While terms such as senses, mental states, feelings, volitions, traits, and abilities are used when Philosophy of Mind considers metaphysical theories of the mind, they are used for creating context for theoretical discussions and are not the core topic of study.

Philosophy of Mind focuses on ontological matters of mind at a high level of abstraction. While it conceptualizes general categories of thought, it is very much a focus on a metaphysical problem of being. Cognition is treated as the puzzle to be solved, not an object to be described in useful terms, and hence does not yield a taxonomy of cognition. Instead, as it treats cognition as an ethereal problem it creates new languages of its own. Philosophy of Mind ignores Kant's stricture not to go beyond the limits of reason, but instead invents new artefacts and taxonomies. 


\section{Wilhelm Wundt}

Pure psychology (as distinct from clinical psychology) can be interpreted as having three phases: introspection, behaviourism, and cognitive (Baars, 1986). Within the introspective phase, Wilhelm Wundt and William James (see below) were key contributors, although Wundt's treatment varies from James'.

Wundt, a German psychologist, in the preface to the first edition of Principles of Physiological Psychology writes, "The work which I present to the public is an attempt to mark out a new domain of science" (Wundt, 1874/1910, p. v). He is recognized "as the founder of the science of psychology" (Benjamin Jr, 2014, p. 38), especially by introducing laboratory research. As indicated by the title of his text, his aim was to include a physiological element within psychology, where previously there had been none: "Psychologists, it is true, have been apt to take a different attitude towards physiology. They have tended to regard as superfluous any reference to the physical organism; they have supposed that nothing more is required for a science of mind that the direct apprehension of processes themselves" (Wundt, 1874/1910, p. 2). Notwithstanding this consideration of the physical, Wundt also proposed an experimental approach: "The aim of the experimental procedure is to substitute for this subjective method [self-observation which obtains direct access to exact characteristics of mental facts], whose sole resource is an accurate inner perception, a true and reliable introspection, and to this end it brings consciousness under accurately adjustable objective conditions" (p. 7).

According to Baars, Wundt was misrepresented as being solely focused on such experimental self-observation, as he aimed to determine the components of conscious experience (apperception) and believed "in the effects of context on perception, thought, and action" (Baars, 1986, p. 31). He also developed a völkerpsychologie that Benjamin Jr (2014, pp. 46-47) suggests is best translated as cultural or ethnic psychology. Wundt maintained that his psychology required other approaches than self-observation, however it is not prominent in English-speaking countries due to a lack of translation.

Wundt treated cognition as a subject of science. While he did not focus solely on laboratory self-observation, the scientific treatment of cognition gained huge popularity in academic circles. This treatment inherently believes that cognition is knowable and explicable, and can be studied through scientific methods, rather than through philosophical investigations. As Baars (1986, pp. 30,39-40) suggests, perceived flaws in the approach of laboratory self-investigation were a justification for a new scientific approach that would develop in the early twentieth-century, namely behaviourism. 


\section{William James}

James was a philosopher and a psychologist. According to Benjamin Jr (2014), James' psychological treatise The Principles of Psychology has "no rival for importance in the history of American psychology" (p. 61).

James is a strong believer in introspection as a method: "Introspective Observation is what we hope to rely on first and foremost and always" (James, 1890/1950b, p. 185). James (p. 299) provides a personal account of what thinking is: "I am aware of a constant play of furtherances and hindrances in my thinking, of checks and releases, tendencies which run with desire, and tendencies which run the other way. Among the matters I think of, some range themselves on the inside of thought's interest, whilst others play an unfriendly part thereto. The mutual inconsistencies and agreements, reinforcements and obstructions, which obtain between these objective matters reverberate backwards and produce what seems to be incessant reactions of my spontaneity upon them, welcoming or opposing, appropriating or disowning, striving with or against, saying yes or no. This palpitating inward life is, in me, that central nucleus which I have tried to describe in terms that all men might use". Here James demonstrates the technique of introspection in his own rich literary style. James recognizes that introspections are individualistic and, hence, in some ways introspection is problematic as a method for generating a common understanding of how the mind operates, but he still maintains that the introspective method is fundamental to psychology. Here James explicitly recognizes our ability to "think ourselves as thinkers" (p. 296).

While James stood by introspection, he recognizes the challenge of making abstractions about cognition (his major psychology text, The Principles of Psychology, is of course filled with such abstractions) and the need for conceptions. He notes that, with respect to cognition, abstractions are challenging due to manifold perspectives: "There is an abstract way of dealing with consciousness, in which, as it actually presents itself, a plurality of faculties are always to be simultaneously found" (p. 296). Notwithstanding James' concept of 'conception', while denying realist and nominalist approaches, he recognizes the need to summarize. He recognizes "this sense of sameness is the very keel and backbone of our thinking" (p. 459).

But, while we may come to understand we have states of consciousness through introspection and we can create conceptions of cognition, James laments the lack of development of a taxonomy of cognition as: 1) there is a lack of specific cognitive vocabulary (instead, common words are used); 2) the lack of a cognitive word is often interpreted as the supposition of no entity; and 3) often ideas are seen as permanent and immutable, as "The continual flow of the mental stream is sacrificed" (pp. 197-198).

Notwithstanding these issues, and perhaps because of these issues, James goes on to provide a clear and useful framework. As a precursor to his considerations of cognitive functions, James: 1) provides a framework of self; 2) highlights the issue of selective attention that he sees as being previously ignored, especially by British empiricists; 3) discusses how we can form conceptions; 4) extends this to consideration of discrimination and comparison, and association; and 5) considers 'internal perceptions' of time and memory. 
He then defines various cognitive functions:

Table 6: Jamesian Language

\begin{tabular}{ll}
\hline sensation & Sensation follows the standard approach of that being received from our senses. \\
\hline imagination & $\begin{array}{l}\text { Imagination, following Locke, is the ability to reproduce representations of previous } \\
\text { sensations (this is similar to Kant's intuition). }\end{array}$ \\
\hline perception & Perception is the recognition of things, space, and reality. \\
\hline reasoning & James gives no definition of reason, but, through examples and comparisons with \\
animal reason, demonstrates a view of reason that aligns with contemporary usage. & James lists a number of human instincts including jealousy, love, acquisitiveness, play, \\
and curiosity. & Emotion is used in its normal way, and an overlap with instinct is recognized. \\
\hline emotions & $\begin{array}{l}\text { Will is described as being: "Desire, wish, will, are states of mind which everyone knows" } \\
\text { (James, 1890/1950b, p. 486). }\end{array}$ \\
\hline will &
\end{tabular}

James, although not being definitive, brings together a host of cognitive terms and concepts in his writings. His treatment of cognition follows that of both Aristotle and Descartes: cognition is something that can be studied through introspection. But, as he makes clear, there is no absolute, but cognition operates in context: "the faculty [of memory] does not exist absolutely, but works under conditions; and the quest of those conditions becomes the psychologist's most interesting task" (James, 1890/1950a, p. 3). James may be a pioneer of the science of psychology, but he is also a pragmatist, not a realist. He seeks to discover useful knowledge, not universal knowledge.

\section{Behaviourism}

Behaviourism is now considered, not for what it says, but for what it disallows. Following the analyses of Benjamin Jr (2014), Gardner (2008), and Baars (1986), psychological behaviourism became the principal doctrine of psychology, replacing the psychological introspection of Wundt and James that had held sway until the end of the $19^{\text {th }}$ century. This behavioural movement, led by John B. Watson and B. F. Skinner, aimed for a truly scientific understanding of psychology. As Watson states, "Psychology as the behaviorist views it is a purely objective experimental branch of natural science. Its theoretical goal is the prediction and control of behavior" (Watson, 1913, p. 158). Behaviourism excludes consciousness: "The time seems to have come when psychology must discard all reference to consciousness; when it need no longer delude itself into thinking that it is making mental states the object of observation" (p. 163). 
The method stressed behaviour as being 'observable and measurable' phenomena, whereas introspection was not 'measurable'. Behaviourism suggests that, through analysis, mental states can be 'translated' into behavioural descriptions. As Baars $(1986$, p. 7) states, “Behaviorism utterly rejected the idea that psychology was the study of the contents of consciousness, claiming instead that psychology was the science of observable behavior". Hence, a major branch of psychology, for a period of approximately 50 years after William James, aimed not to approach cognition directly, but to approach behaviour.

Cognition is treated as being something totally controllable, even if not explicable. The behaviourists believed that through control of environment, not only the operation of the mind could be controlled, but its development could also be controlled. Mind as a malleable substance!

\section{Psychoanalysis}

Sigmund Freud (1856-1939) and Karl Jung were key developers of psychoanalysis. Freud developed several new concepts and defined numerous vocabularies including: the mental apparatus (id, ego, superego); defence mechanisms (repression, denial, projection, displacement, rationalization, reaction formation); and psychosexual stages (oral, anal, phallic, latency, genital). Jung (1875-1961) was also prolific in creating terms including: personal unconscious/collective unconscious, archetypes, extravert/introvert (Benjamin Jr, 2014, pp. 118-138).

Jung describes the Freudian approach as being somewhat negative: "At first the concept of the unconscious was limited to denoting the state of repressed or forgotten contents. Even with Freud, who makes the unconscious - at least metaphorically - take the stage as the acting subject, it is really nothing but the gathering place of forgotten and repressed contents, and has a functional significance thanks only to these" (Jung, 1968, p. 3). Jung, in his own work, describes both a personal unconscious and a collective unconscious: "A more or less superficial layer of the unconscious is undoubtedly personal. I call it the personal unconscious. But this personal unconscious rests on a deeper layer, which does not derive from personal experience and is not a personal acquisition, but is inborn. This deeper layer I call the collective unconscious" (p. 3). Both focused on the subconscious and developed methods to open the conscious mind to resolve subconscious issues. The language of psychoanalysis is markedly different from the language used by Aristotle, Kant, and James.

The conscious mind is treated as an outcome of the subconscious mind. While we do think, and we are conscious of our thinking, it is other deep cognitive elements that really are the controlling element in our minds. The deeper truth in the individual can be and needs to be discovered! 


\section{Cognitive Psychology}

Cognitive psychology recognizes human cognitive capabilities that can be described in "a metatheory that encourages one to infer unobservable theoretical constructs from empirical observations" (Baars, 1986, p. 158). This contemporary form of theoretical psychology, the foundation for cognitive thinking in a number of disciplines, focuses on process over content. Baars places the 'cognitive revolution in psychology', that supplants behaviourism, as occurring from 1955 to 1965, and perceives it as a significant move away from positivistic behaviourism.

Ulric Neisser was a leading proponent. In Cognitive Psychology (Neisser, 1967/2014), he contrasts Freud's view of motivation based on 'instincts', with the 'stimulus information' that is central to cognitive science, and goes on to describe the field: "'cognition' refers to all the processes by which sensory input is transformed, reduced, elaborated, stored, recovered, and used. It is concerned with these processes even when they operate in absence of relevant stimulation, as in images and hallucinations. Such terms as sensation, perception, imagery, retention, recall, problem-solving, and thinking, among many others, refer to hypothetical stages or aspects of cognition" (p. 4). While these terms suggest a focus on both perceptive and reasoning levels of cognitive functions, the first 262 of 290 pages within Cognitive Psychology focus on a purely perceptive level of visual and auditory cognition.

According to Baars (1986), cognitive psychology was opened to theoretical debate and development. Unobservable constructs such as purpose, knowledge, meaning, and imagery could be used to explain behaviour. Baars describes a science that uses a computer metaphor to focus on memory and information processing. These views suggest that the focus of cognitive psychology is to understand how the mind works that is, how cognitive processes function.

Daniel Kahneman's Thinking, Fast and Slow (Kahneman, 2013) describes mental life using the metaphor of System 1 and System 2. Kahneman's focus is on System 1, thinking fast, and not on System 2, slow thinking. As such, Kahneman and much of cognitive psychology appear not to focus on the 'higher mental processes' such as understanding and reason, but to focus at the level of micro-events. Hence the object of study seems to mimic behaviourism's focus on micro-events, even if the method and underlying beliefs are very different.

This treatment of cognition is first to isolate the complex processes, and then to focus on those processes for empirical scientific analysis. The mind is essentially inferred, as introspection is not used, and structures of the mind can be estimated. 


\section{Social Psychology}

Aronson, Wilson, Akert and Sommers (2013), in the ninth edition of the introductory text Social Psychology, give a broad general definition of the task of the psychologist: "The task of the psychologist is to try to understand and predict human behaviour" (p. 3), and then focus social psychology on social situations: "Social psychology is the scientific study of the way in which people's thoughts, feelings, and behaviours are influenced by the real or imagined presence of other people: parents, friends ... indeed by the whole social situation" (p. 3).

A chapter dedicated to 'social cognition' summarizes concepts developed by multiple theorists in other areas of psychology, especially cognitive psychology (pp. 51-83). These concepts include automatic thinking, schemas, priming, heuristics, analytical thinking, and holistic thinking. These concepts do not flow over into the consideration of group processes (pp. 269-302), as other concepts, such as groupthink, transactive memory, and polarization, are introduced. This particular text suggests that social psychology draws on many other areas of psychology.

Similarly to cognitive psychology, social psychology treats cognition as being central to behaviour, and endeavours to model the operation of cognition through inferred structures that are often expressed at a social level and not at an individual level.

\section{Psychometrics}

Dictionary.com defines psychometrics as "the measurement of mental traits, abilities, and processes". Rust and Golombok (1999) describe a history of psychometrics beginning in the late nineteen century, developing through Alfred Binet's intelligence tests in the early twentieth century, and becoming a sophisticated science.

One aspect, considered here, is the distinction between convergent and divergent thinking. While Rust and Golombok's text, Modern Psychometrics, does not mention either concept, there is a literature that suggests that these terms may have developed out of psychometrics. Guilford (1959) describes a three-dimensional model of the intellect, with axes of contents, products, and operations. With operations, convergent thinking and divergent thinking are defined and tests made to measure such capabilities. McCrae (1987) researches the relationship between creativity and divergent thinking, focusing on the accuracy of measurement tests. Cropley (2006), in a theoretical paper, suggests that convergent thinking has been misrepresented and is a necessary process, alongside divergent thinking, for creativity.

So while the concepts of convergent and divergent thinking may have now been superseded in psychometrics, it may also be that these ideas have become more mainstream psychology concepts, and that they are also in common usage. 


\section{Karl Weick}

Weick (1995), a social scientist, produced a classic text, Sensemaking in Organizations. It is highly cited (over 15,000 times) and summarizes many previous research streams and suggests future research possibilities. Weick initially defines sensemaking in cognitive terms: "The sensemaking perspective is a frame of mind about frames of mind that is best treated as a set of heuristics rather than as an algorithm" (p. xii). Weick confirms his acceptance of previous work and the deductive method, describing sensemaking theory as being "grounded as much in deductions from well-articulated theories as it is in inductions from specific cases" (p. 13). Hence his view is that the study of sensemaking has a strong theoretical basis.

Weick structures his discussion around, "[sensemaking] understood as a process that is: 1. Grounded in identity construction, 2. Retrospective, 3. Enactive of sensible environments, 4. Social, 5. Ongoing, 6. Focused on and by extracted cues, 7. Driven by plausibility rather than accuracy" (p. 17). These seven elements of sensemaking are presented as a system but have no clear common basis - perhaps because they are derived from a number of theorists and were not originally designed as a holistic framework. Individual sensemaking and organizational sensemaking are distinguished from each other but are treated in a similar fashion.

In this text Weick treats sensemaking as a specific instance of cognition that involves making sense over relatively long periods (i.e. days rather than seconds). His treatment is to summarize a number of perspectives or heuristics to understand this complex behaviour. Given the eclectic nature of his sources and the lack of any robust criticism or integration of the various techniques found, the text is more a summary of previous work than a significant addition to knowledge of cognition.

\section{March and Simon}

March and Simon, two social scientists (their description), in their 1958 classic Organization, focus on organization theory. The authors were early proponents of the computer model of cognition: "the human organism can be regarded as a complex information-processing system" (March \& Simon, 1958, p. 9).

As the authors state (p. 28), their approach aligns with the work of Edward Tolman. While a behaviourist, Tolman went beyond the limitations of the radical behaviourism of Watson and Skinner, allowing for recognition of cognitive processes in scientific terms through the use of 'intervening variables'. This is clearly reflected in March and Simon's work through their use of such variables (Baars, 1986, pp. 61-62; Benjamin Jr, 2014, pp. 150-152).

Barnard (1938) raises a question of the employee 'decision to participate' that March and Simon consider. One depiction, shown below, considers the 'desirability of movement' or the desire to leave the company. This is, of course, not a process model. It is a model of factors that influence individuals. This is termed a 'Cognitive Influence Model' as it primarily shows lines of cognition influence. This and other such definitions are developed later in this thesis (see page 86). 


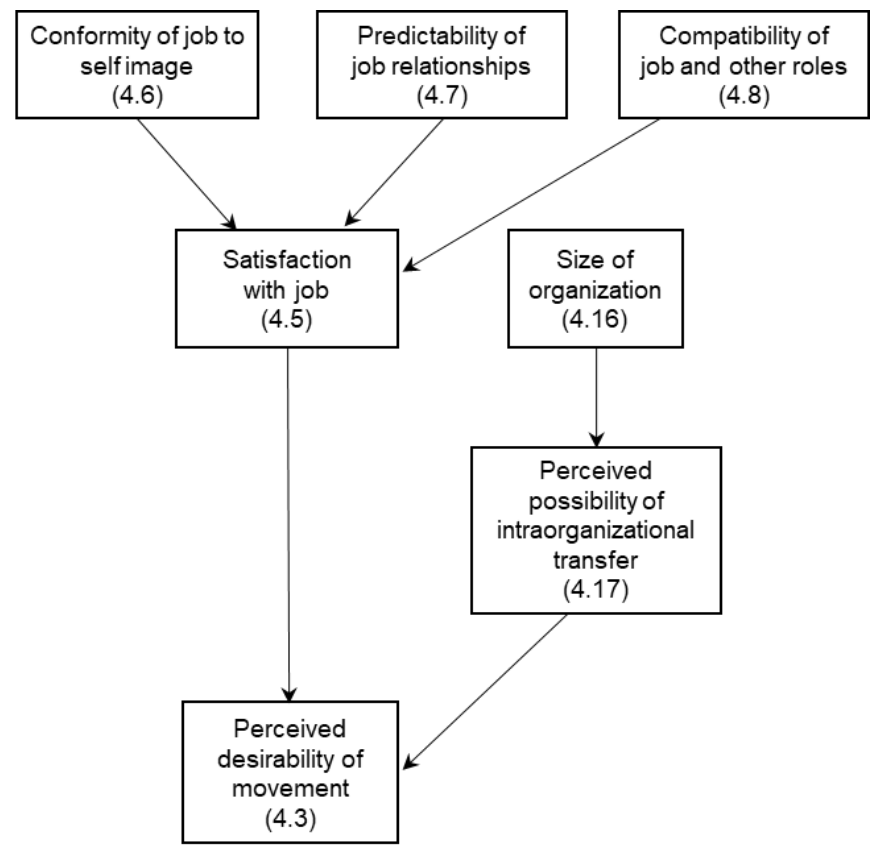

Figure 7: "Major factors affecting perceived desirability of movement.", reproduced from Organizations (p. 99), by J. G. March, \& H. A. Simon, 1958, New York, NY: John Willey \& Sons. Copyright 1958 by John Wiley \& Sons.

However, notwithstanding the regard in which this text is held, it is difficult to conceive of peoples' minds actually operating in such a fashion. Firstly, it is not a process model, so should not be interpreted as showing steps in time. Secondly, as an influence model, it shows only one possible 'reasoning'. There is no reason given why all would follow such reasoning. This model borders on the transcendent, as it is not presented as a simple example of what a person may think, but as a model that may be unperceivable.

March and Simon also consider "[a person's] characteristics as a rational [being]" (pp. 136-171). Traditional models of rationality (from economics and statistical studies) are seen as being valid only in situations of certainty, and have "failed to make explicit [the] subjective and relative character of rationality" (p. 139). The authors proceed to build their own models that include cognitive elements. Specifically cognitive terms, such as knowledge, perception, and attention, are used in scene setting, but a behaviourist approach dominates, as reflected in the analysis and definition of rational processes as programs involving variables such as "division of labour", "focus of information", and "focus of attention", as seen in the diagram below. 


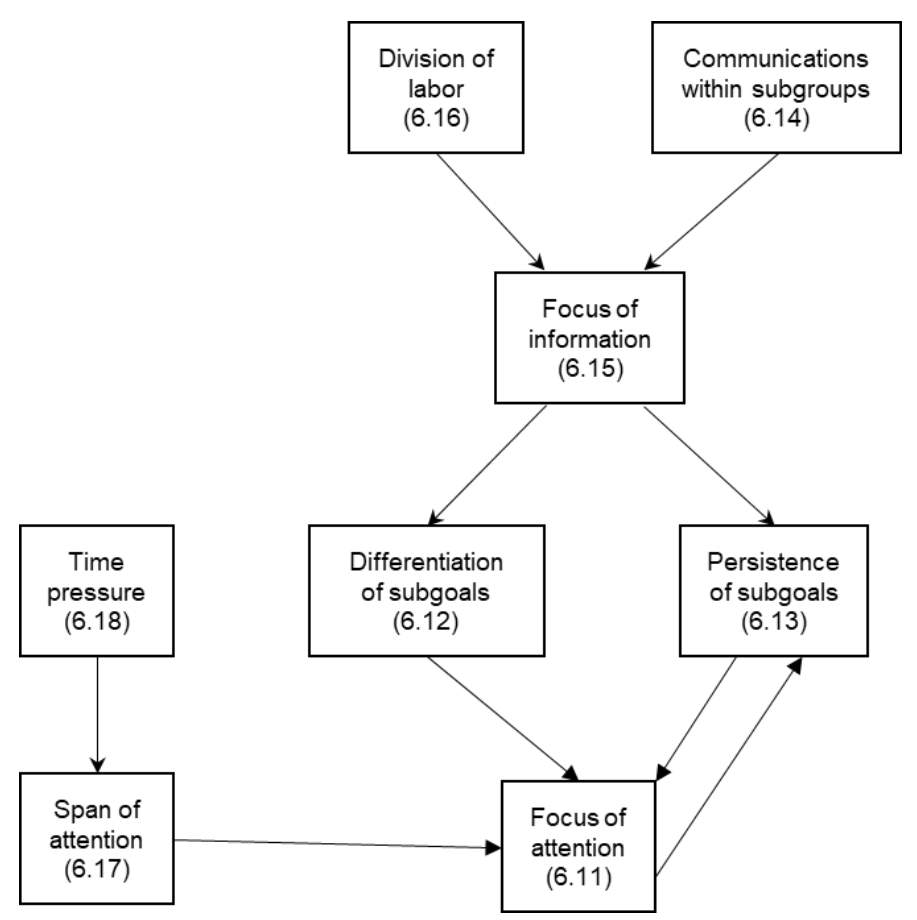

Figure 8: "Some factors affecting selective attention to subgoals.", reproduced from Organizations (p. 154), by

J. G. March, \& H. A. Simon, 1958, New York, NY: John Willey \& Sons. Copyright 1958 by John Wiley \& Sons.

This is categorized as a Cognitive Hybrid Model as three of the eight variables are not cognitive (division of labour, communications within subgroups, time pressure), while the other five could be considered cognitive. Note also that the model is not clear whether the subject is an organization or an individual, although the authors explicitly recognize that they consider both: "Individuals and organizations develop repertories of programs of action suited to different situations" (p. 155).

The reason for the fame of March and Simons' Organizations may be because it rejects homo economicus in favour of homo sociologicus, and has compelling ideas of selective attention, bounded rationality, and satisficing (being content with 'satisfactory' options, and not being compelled to find 'optimal' solutions). It is hard to imagine that the behavioural diagrams above, with their limited applicability to actual experience, would have gathered much of a following outside academia.

Cognition is treated as something that can be expressed in a variable and can then be used as part of a behavioural explanation. Cognition is a cog in behavioural description. It is somewhat ironic, after such a limited approach to cognition, that the authors themselves note: "The cognitive aspects of organizational behaviour are to date almost unexplored terrain" (p. 211). 


\section{Cognitive Science}

Cognitive science is largely based on a computer analogy of the mind, and evolved into an interdisciplinary field that covers philosophy, psychology, linguistics, artificial intelligence, neuroscience, and anthropology (Bermúdez, 2010). It developed out of the cognitive revolution in psychology (Baars, 1986) spurred on by the computer age. March and Simon, discussed above, were early proponents. Gardner (2008) defines five features of paramount importance including a) understanding the mind through a computer analogy; and b) de-emphasizing certain factors, including historical factors, cultural factors, and background context. Bermúdez (2010), in his introductory text, suggests that "Almost all cognitive scientists agree that cognition is information processing" (p. 46).

He sees cognitive science as being a return to the brain as developed by neuroscience during the 1980s and being based on a computer analogy. This allows both top-down and bottom-up efforts to understand cognition in this multidisciplinary field. Much of the development of cognitive models had an end goal of then being able to build cognitive engines, or artificial intelligence.

Cognitive science treats cognition as being significant, as it is the topic at the heart of the field. It is treated as being real, able to be modelled, and reproduced (even if this has never been achieved at anywhere near the level of general human capability). There is no subconscious cognition to be found - all is there to be revealed and replicated.

\section{Cybernetics}

C Ross Ashby, an early proponent of cybernetics, noted the interest from other disciplines "Many workers in the biological sciences - physiologists, psychologists, sociologists - are interested in cybernetics and would like to apply its methods and techniques to their own speciality" (Ashby, 1956, p. v). As Ashby describes,

"[Cybernetics] offers a method of scientific treatment of the system in which complexity is outstanding and too important to be ignored. Such systems are, as we well know, only too common in the biological world" (p. 5).

Norbert Wiener coined the term 'cybernetics'. He conceives of cybernetics in a world where the certainty of Newtonian physics has been superseded by a world of entropy, but where local control can occur: "the characteristic tendency of entropy is to increase" and "there are local enclaves whose direction seems opposed to that of the universe at large and in which there is a limited and temporary tendency for organization to increase" (Wiener, 1954, p. 12). He states that the purpose of cybernetics is to be able to understand these enclaves: "to develop a language and techniques that will enable us indeed to attack the problem of control and communication in general, but also to find the proper repertory of ideas and techniques to classify their particular manifestations under certain concepts" (p. 17). This is based, somewhat, on 'smart' machines that he has observed, such as "the controlled missile, the proximity fuse, the automatic door opener, the control apparatus for a chemical factory" (p. 22). These machines reverse entropy through 
communications and control, much as a human does when driving a car. For Wiener, the machine and the human are precisely parallel: "It is my thesis that the physical functioning of the living individual and the operation of some of the newer communications machines are precisely parallel in their analogous attempts to control entropy through feedback" (p. 26).

Maturana (2002) takes the biological world as the matter of his system, and defines cognition as a biological phenomenon: "the capacity that a living system exhibits of operating in a dynamic structural congruence with the medium in which it exists" (p. 26). Or, that cognition is constitutive in the 'structural coupling' of a living being and its environment. Maturana's starting point is a molecular ontology: living things exist as and within molecules through autopoiesis, this being the manner in which they maintain their being and their adaptive abilities. Issues of cognition, language, and self-consciousness are defined as being within this biological system. From this, he infers that an attempt to consider cognition as an aspect of the nervous system alone is doomed.

Cybernetics provides a theory for modelling complex systems, be they human or mechanical. As Maturana shows, cognition can be treated as an outcome of a biological system. In this approach, people can be regarded as complex machines. 


\subsection{Findings}

The texts are summarised below, and then analysed in three ways: philosophical approach, their use of language, and the common themes identified.

\section{Summary by Discipline/Theorists}

The table below shows that cognition has been treated in many different ways.

Table 7: Treatments of Cognition by Discipline/Theorist

\begin{tabular}{|c|c|}
\hline Discipline/Theorist & Treats cognition as... \\
\hline Aristotle & something that can be known through experience and understood \\
\hline Descartes & core to human understanding of existence and aligned to God \\
\hline Immanuel Kant & knowable, limited, but definable; the key to understanding knowledge \\
\hline Philosophy of Mind & a metaphysical puzzle that can be debated for eternity \\
\hline Wilhelm Wundt & a science that includes laboratory self-observation as a research technique \\
\hline William James & a topic that can be investigated through introspection \\
\hline Behaviourism & something to be avoided \\
\hline Psychoanalysis & having a subconscious layer that may need specialist treatment \\
\hline Cognitive Psychology & inferable from behaviour \\
\hline Social Psychology & inferable from behaviour at a social level \\
\hline Psychometrics & convergent and divergent thinking \\
\hline March and Simon & a computer, and definable in a quasi-logical manner \\
\hline Karl Weick & contributing to sensemaking \\
\hline Cognitive Science & information processing that can be modelled and reproduced \\
\hline Cybernetics & an output of a system. \\
\hline
\end{tabular}




\section{Philosophical Approaches}

The reviewed treatments of cognition vary significantly depending on whether cognition is approached as a philosophical question or as a matter of science.

\section{As an Ontological Question}

Aristotle, philosophy of mind, and behaviourism treat cognition ontologically, that is, as a question to understand what cognition 'is'. Aristotle does this from a substance/form perspective to find what cognition is and how we can have it. For philosophy of mind, cognition is part of a broader puzzle concerning 'how things are.' Therefore, for philosophy of mind, cognition is the subject of much conjecture and debate. For behaviourism, cognition is an unknowable and therefore to be avoided. This is for ontological reasons - it cannot be reliably known.

\section{As an Onto-Epistemological Question}

Descartes and Kant focus on both how things are and what we know. Descartes' Cartesian dualism is a position about 'the way things are,' and it sets up the metaphysical debate that consumes philosophy of mind. But Descartes also considers how an individual knows. Kant focuses on this latter aspect, aiming to understand the limits of our cognition. He also considers the question of 'how things are' using consciousness as the basis of thought, and thereby seeks to obviate the study of metaphysics.

\section{As a Matter of Science}

James, Wundt, psychoanalysis, cognitive psychology, social psychology, Karl Weick, psychometrics, March and Simon, cognitive science, and cybernetics all treat cognition as a matter for scientific exploration, albeit with significant variations in how such exploration should be performed.

James and Wundt, the forefathers of psychology, treat cognition as knowable and discoverable through introspection. The advent of behaviourism effectively halted such approaches. Psychoanalysis is significantly different from the others, being based in the subconscious. But the same underlying belief in science is apparent - based on behaviours, inferences can be made and this can lead to the prediction of future behaviours.

Cognitive psychology, social psychology, and Karl Weick all provide interpretations of how humans operate, and they derive much of their propositions from observed behaviour. Cognitive psychology appears to focus on more basic processes of the mind, while social psychology focuses on social aspects. Weick, in Sensemaking, focuses on one particular cognitive process - sensemaking.

March and Simon and cognitive science tend to follow the same research path but have larger descriptions of behaviour. They can be based on systems theory and are more likely to build grand schemes of how the human world works. Cybernetics appears to be theoretically derived, rather than a theory induced from observations. As such, it is still scientific, albeit in a different manner. 


\section{Language}

What is now 'contemporary terminology' is used in many early texts. While modern translations of early Greek and Latin texts may tend to find alignments with a contemporary vocabulary, still some basic cognitive concepts are evident. Of the philosophers, Aristotle, as he focuses on the soul as the source of being and thinking, uses concepts of thinking, understanding, and perceiving; Descartes considers senses, reason, imagination, and understanding; and Kant uses ideas of perception, understanding, reason, and intuition. While this is a limited literature review, it shows that much current cognitive language was used by early texts and it is quite plausible that philosophy has furnished us with a cognitive vocabulary. The alter psychologists, building on the philosophers, use a similar cognitive vocabulary. Wundt writes of emotions, volitions, sensations, and ideas. James' considerations include feelings, desires, cognitions, reasonings, and decisions.

Philosophy of mind, a highly metaphysical subject with multiple theories, builds its own technical vocabulary to enable one theory to be distinguished from another. Psychoanalysts are another group who create their own vocabulary with their discoveries and definitions of the subconscious. From philosophy of mind we have words and phrases such as common-sense functionalism and identity theory of mind, and from the psychoanalysts we have extrovert, introvert, and superego.

For the more recent sciences reviewed (cognitive psychology, social psychology, Karl Weick, March and Simon, cognitive science, and cybernetics), language also becomes more technical. Cognitive psychology has focal attention, the word-apprehension effect, and echoic memory. Cognitive science has dichotic listening experiment and multiple realizability. Cybernetics has coupling systems, feedback, and homomorphic machines. Social psychology is less technical, but includes normative social influence, and frustration and aggression, while Weick and March and Simon, with little focus on cognition, rarely use cognitive terms.

Within the texts reviewed, one can observe the development of cognitive language within philosophy and early psychology up to around 1900, followed by more elaboration of language as new disciplines and fields have developed. The early vocabulary is still in everyday use, as are many elaborations. 


\section{By Themes}

The analysis also revealed variations in some common themes that may assist in understanding treatments of cognition in business strategy. Because of behaviourism's avoidance of cognition, it is omitted from the analysis below.

\section{Types of Abstraction}

Cognition can be treated in many ways, from a personal phenomenon to a metaphysical discussion. The philosophers and psychologists discuss the metaphysical, consider cognition conceptually, and often, when using introspection, consider operational processes and personal micro-activities. Similarly, the psychoanalysts operate at multiple levels. Cognitive psychology and cognitive science operate at all levels, but with more of a focus on operational processes.

The other scientific approaches discuss cognition conceptually, model cognition operationally, and study cognition phenomenally to support operational propositions. Social psychology considers operational behaviour, supported by phenomenal cognitive examples. Similarly, Karl Weick and March and Simon focus on operational behaviours, such as decision making and sense making, supported by phenomenal cognitive examples. Cybernetics, as a general theory, operates at multiple levels.

The examples show cognition behaviour treated conceptually, operationally, and phenomenally.

\section{Subject}

Cognition, as defined in this thesis, is individual, but processes clearly exist that involve multiple people using their cognitive faculties in a group setting or as a part of a process over time.

The three philosophers reviewed, Aristotle, Descartes, and Kant, treat cognition and consciousness as the conceptual subject, and refer to examples of themselves: "I saw that the ideas which I formed myself were less vivid..." (Descartes, 1641/1986, p. 52) and "I am conscious of myself, not as I appear to myself..." (Kant, $1781 / 1991$, p. 168). Through this latter usage, the subject of cognition is clearly the individual. Given the metaphysical breadth of the Philosophy of Mind field, generalization about how the subject is treated is not possible, although the analysis suggests that a significant number of theories concern the individual.

For the theorists and disciplines with a strong basis in psychology (Wundt, James, cognitive psychology, and cognitive science), the subject is clearly the individual, as their discussions and methods focus on the person. For the psychoanalysts, the subject is the individual with both a conscious and subconscious mind. Jung goes further to suggest a collective mind. This latter usage is very definite: "[The collective unconscious is] identical in all men and thus constitutes a common psychic substrate of a suprapersonal nature which is present in every one of us" (Jung, 1968, p. 4). This definitive creation of a new cognitive subject concept stands out in the texts reviewed. 
For the social disciplines, the individual remains the subject but the surroundings take on more importance. Weick finds the subject to be the individual, but recognizes an underlying social layer: "Those who forget that sensemaking is a social practice miss a constant substrate that shapes interpretations and interpreting" (Weick, 1995, p. 39). In the text reviewed, social psychology covers individual and group processes, but when considering cognition directly, focuses on the individual, except for one example of groupthink (Aronson et al., 2013, pp. 285-287).

March and Simon and cybernetics, the two builders of models, rarely treat cognition directly, given that their focus on behavioural issues. March and Simon recognize that the individual has emotions, values, knowledge, and perception, but this treatment is minor compared to the behavioural models created at both an individual and an organizational level. For cybernetics, the focus is the system which can model humanity (either as an individual or as society), and not humanity directly.

The analyses of the selected literature primarily show cognition treated at an individual and, occasionally, at a group level. Philosophy and mainstream psychology tend to treat the subject as the individual, while sociology and social psychology can treat group processes, and Jung finds a 'collective unconscious'.

\section{Mind}

The philosophers Aristotle, Descartes, and Kant rarely consider the subconscious, as they attempt solely to unravel the mysteries of the conscious mind. Wundt and James focus strongly on the conscious mind, but both discuss emotions - part of the subconscious. Social psychology, cognitive philosophy, and cognitive science follow a similar path of recognizing emotion, but not recognizing a broader subconscious. March and Simon recognise emotion and values, but as an underlying basis, not as an object of study. Cybernetics focuses on knowns, not on the unknowns of the subconscious. The psychoanalysts are clearly different, as they perceive that the subconscious mind definitely exists and is central to understanding humanity.

This analysis finds: 1) a number of disciplines and theorists who focus on the conscious mind, and consider the subconscious only as emotion, and 2) the psychoanalysts who make the subconscious the mainstay of their field.

\section{Thinking Processes}

Many of the theorists reviewed approach the functioning of the mind from the process of thinking. The philosophers conceptually consider the thinking process, while the psychologists, Wundt and James, are similarly highly interested, but with a more practical focus. The psychoanalysts have a focus on the process of how the subconscious directs conscious thought. Cognitive psychology and cognitive science have a primary focus on determined how the mind 'works'. March and Simon create abstract process models.

How we think is a common object of study in the texts reviewed. 


\section{Thought Contents}

Thought contents here means ideas and concepts that people think. For the philosophers and the psychologists, such thought contents are simply support material for conjecturing about how thought processes work. The reviewed texts of social psychology and sociology contain descriptions of thought contents as they aimed to represent real-world social situations. Psychoanalysis delves into specific contents of the subconscious, to understand how it directs the conscious mind.

Cognitive psychology and cognitive science are concerned with what we think, when trying to understand how we think. For them, the process and content are intrinsically connected and hence process cannot be considered without content. Similarly, Karl Weick when making sense of sensemaking, considers the contents of the sense to be made. March and Simon recognize cognitive contents in some of their models (along with contextual factors). Of all the texts reviewed, cybernetics pays the least attention to thought contents, as it focuses on processes.

Within the texts reviewed, thought contents are considered important, but often simply as the context within which thought processes operate, not as an independent topic. 


\subsection{Summary}

This brief review of treatments of cognition is merely illustrative and is not indicative of any causality between disciplines, or of historical justified trends. However, within the multiple approaches and treatments, there are themes of treating the subject as the individual, treating the mind as the conscious mind, and focusing on thinking processes over thought content. In summary:

- there are many treatments of cognition

- philosophical approaches include ontological/onto-epistemological and scientific

- the language of cognition includes everyday language supplemented by technical terms

- common themes are present:

- cognition is treated conceptually, operationally, and phenomenally

- the subject is often the individual, but can be groups

- mind is treated as conscious mind, except for the psychoanalysts for focus on the subconscious

- thinking processes are a common focus

- thought content is mostly considered when analyzing thinking processes (the exception being the psychoanalysts who see thought content as being highly significant)

\section{Multiple Treatments}

Most startling is the sheer variety of different treatments. While some of the treatments have common themes, there is no one fundamental approach within these multiple disciplines and theorists, and some of the variations are large. A comparison of philosophy of mind and cybernetics shows a vastly different approach to treating mind. Humanity has, over time, produced quite an array of thinking about thinking.

Therefore, there is no reason to assume that a consistent approach will be found in business strategy. The starting point is therefore to expect variation and allow for the interpretation of it.

\section{Philosophical Approaches}

In the selected literature, mind can be seen as being approached broadly as a philosophical question, seen as ontology or onto-epistemology, or as a scientific discipline. It is noted that there are literatures and approaches not reviewed (e.g. Buddhism) that would broaden these philosophical approaches; notwithstanding this, the variation between the approaches of philosophy and science are clear and show that humanity has found that mind can be approached cognitively through thought and can be approached scientifically through scientific method.

\section{Everyday and Technical Language}

Much of our everyday language of cognition derives from early philosophy and psychology. This has been supplemented with more technical language as more approaches to mind have developed. 


\section{Themes}

The analysis of the texts has produced a series of topics and shown treatment themes within those topical areas. The hermeneutic process of reading and rereading texts, going from single text to all texts, and considering the author's context has produced the following interpretation of topics and themes:

Table 8: Treatments of Cognition by Themes

Topic Themes

Types of Philosophy and psychology treat cognition phenomenally, operationally, and

Abstraction conceptually, while other scientific approaches focus on operational process abstractions supported by phenomenal cognitive examples.

Subject Philosophy and psychology treat the individual. A less common approach is to treat the subject as a group, and consider the individual for supporting examples.

Mind The mind is treated as the conscious mind and, at times, as emotion. It is only the psychoanalysts who explicitly treat the subconscious.

Thinking Process All of the texts consider thinking processes, and for many it is the prime object of study.

Thought Content Thought content is, at best, a secondary consideration for most texts, with the exception being the psychoanalysts, who interpret content deeply.

\section{Use of These Findings}

The themes above are the basis of the Cognitive Heuristic developed fully in the next chapter. Treatments, philosophical approaches, and language are all part of the object of research but are categorized under Foucauldian concepts of conditions of possibility and knowledge. 


\section{Chapter 6 - Heuristic, Insights and Cognitive Models}

The primary structure for this thesis is a Foucauldian framework, as described in Chapter 4 - Methodology (p. 26). Within this framework, a 'Cognitive Heuristic', the concept of insights, and standard definition of cognitive models are utilized when considering cognition.

\subsection{Cognitive Heuristic}

This heuristic, based upon themes developed in the previous chapter, asks the following questions of business strategy discourses:

$\begin{aligned} \text { Topic } & \text { Question } \\ \text { types of abstraction } & \text { What types of abstraction describe business strategy's treatment of cognition? } \\ \text { subject } & \text { What does business strategy perceive as the cognizing subject? } \\ \text { mind } & \text { Does business strategy perceive cognition as conscious and/or subconscious? } \\ \text { thinking process } & \text { What thinking processes does business strategy focus upon? } \\ \text { thought content } & \text { What does business strategy perceive of as strategy thought content? }\end{aligned}$

Each of the topics of the Cognitive Heuristic is developed below. For each topic, a series of possible options is described. While the topics and initial options were discerned during the research described in Chapter 5 - A Review of Treatments of Cognition, additional options were added in the initial creation of the heuristic and also when the actual research was performed. In the latter process, as new information was found, it was used both to document results and to update the initial heuristic.

Note that this heuristic might be better described as a Cognitive Strategy Heuristic, as it is specifically designed to analyse treatments of cognition within strategy. However, such a title is somewhat unwieldy, so the shorter version is used. 


\section{Types of Abstraction}

Any interpretation involves abstraction away from the interpreted object. For this thesis, four types of abstraction are defined to describe both popular and academic strategy discourses. These combine the types found in the previous chapter and the core epistemology in this thesis (p. 15):

Table 9: Types of Abstraction

Phenomenal A phenomenal type considers actual events. It includes empirical research that focuses

Operational Operational refers to discussions that consider actual strategy processes and content. For example, if a discussion considers, in some detail, the various steps that make up a decision process, this would be considered operational.

Conceptual Where discussions are theoretical, and possibly contain epistemological positions, they are labelled conceptual. Typically, academic texts have a degree of Conceptual content, either as an epistemological starting position or as some output of the text. However, mainstream texts also promote ideas at high levels of abstraction.

Transcendent The occasion when interpretations become so esoteric that they belong in a different world of dreams or faith.

These distinctions are most subtle. Most texts operate on at least two levels and it is relatively easy to mix the levels in the same sentence. That is, to consider operational activity with phenomenal examples, to take a conceptual view of phenomenal examples, and to discuss operational activity conceptually. With these challenges, interpretation can be problematic. To achieve some consistency, a general approach is taken that recognizes the highest-level in a section of text (with transcendent being the highest).

Some examples of levels follow. Direct or indirect references to phenomenal treatments of cognition are rare within the discourses analyzed. In an empirical paper, Beech and Johnson (2005) study identities in the practice of strategic change. They quote directly from interviews: "I sometimes feel that I do not have enough power" (p. 38) and "I think you will find a great deal of sympathy and loss of eye-contact" (p. 39). These are somewhat phenomenal, but not as direct as William James' first-person perspective: "When I try to remember or reflect, the movements in question, instead of being directed towards the periphery, seem to come from the periphery inwards and feel like a sort of withdrawal from the outer world" (James, 1890/1950a, p. 300). An operational treatment is Steiner (1979, p. 46): "Planning involves a different type of mental process from that generally employed in dealing with day-to-day operations." Here Steiner considers the planning process as a mental process, even if the treatment is superficial. Barnard (1938, p. 302) gives a useful example of conceptual macro musing, as he considers fundamentals of thought: “... mental processes consist of two groups which I shall call 'logical' and 'non-logical.'” 


\section{Subject}

What do strategy discourses perceive as the cognizing subject? Walsh (1995), in his review of Managerial and Organizational Cognition, develops a set of subject classifications: individual, group, firm, and industry. This thesis develops the list further and is especially concerned to identify treatments beyond the individual. However, given that generalisation is a valid way of discussing conceptual issues, it is important not to overrecognize such literary devices as reifications, collective nouns, and cognition used as the subject. How such risks are resolved is defined below.

\section{Reifications}

Goold and Campbell (1987, pp. 55,67) project conscious thought and emotions onto the central part of the firm: "The centre determines what strategies..." and "If the centre feels that a business...". Levitt (1962, p. 15) states, "The inability or refusal of companies to see the opportunities...". In both cases, the authors are reifying the company and ascribing cognitive abilities to it (the term 'reify' is used to mean 'to consider or make an abstract idea or concept real or concrete'). But as such reifications are common when we use collective nouns and ascribe attributes and capabilities to them, a text is not automatically interpreted as treating the company as the thinking subject simply because of a single or a few instances of such usage. Instead, the text is interpreted as a whole to determine what the predominant treatments of subjects are (in fact, in Levitt's case, in the reviewed text he is interpreted as treating the cognizer as an individual manager, not as a company).

\section{Collective Nouns}

Note that the simple usage of a collective term does not denote a collective subject. For example, Barnard (1938, p. xxviii) states, "executives are able to understand each other with very few words when discussing essential problems of organization." The subject here is not a group, as Barnard is suggesting that there is a number of individuals who share the same capability.

\section{Cognition as the Subject}

Similarly, when some form of cognition is the subject of a statement, this is not inferred to be anything other than pertaining to individuals. For example the statement of Henderson (1979, p. 42) that, "Intuition disguised as status, seniority, and rank is the underlying normative mode of all business decisions", is interpreted as being a general statement regarding individuals, and not any type of reification. 


\section{Mind}

Is strategy treated as a conscious process or a subconscious process by business strategy? As discussed previously in Terminology (p. 13), this thesis considers cognition as the conscious mind and the subconscious mind. The theorists and disciplines surveyed in the previous chapter treat both these aspects of the mind, and the distinction is carried forward into the research of business strategy in the next part of this thesis.

\section{Thinking Processes}

What thinking processes does business strategy engage with? In this study, thinking processes are defined as Strategy-Cognitive Processes, which include Learning, Designing, Strategizing, and Performing (throughout this thesis, when used, these categories are capitalized). Note that these are deliberately not defined as 'strategic' cognitive categories, as this can often be misinterpreted as 'important' cognitive categories. They are 'Strategy'-Cognitive Processes, as they pertain to strategy:

Table 10: Strategy-Cognitive Process Definitions

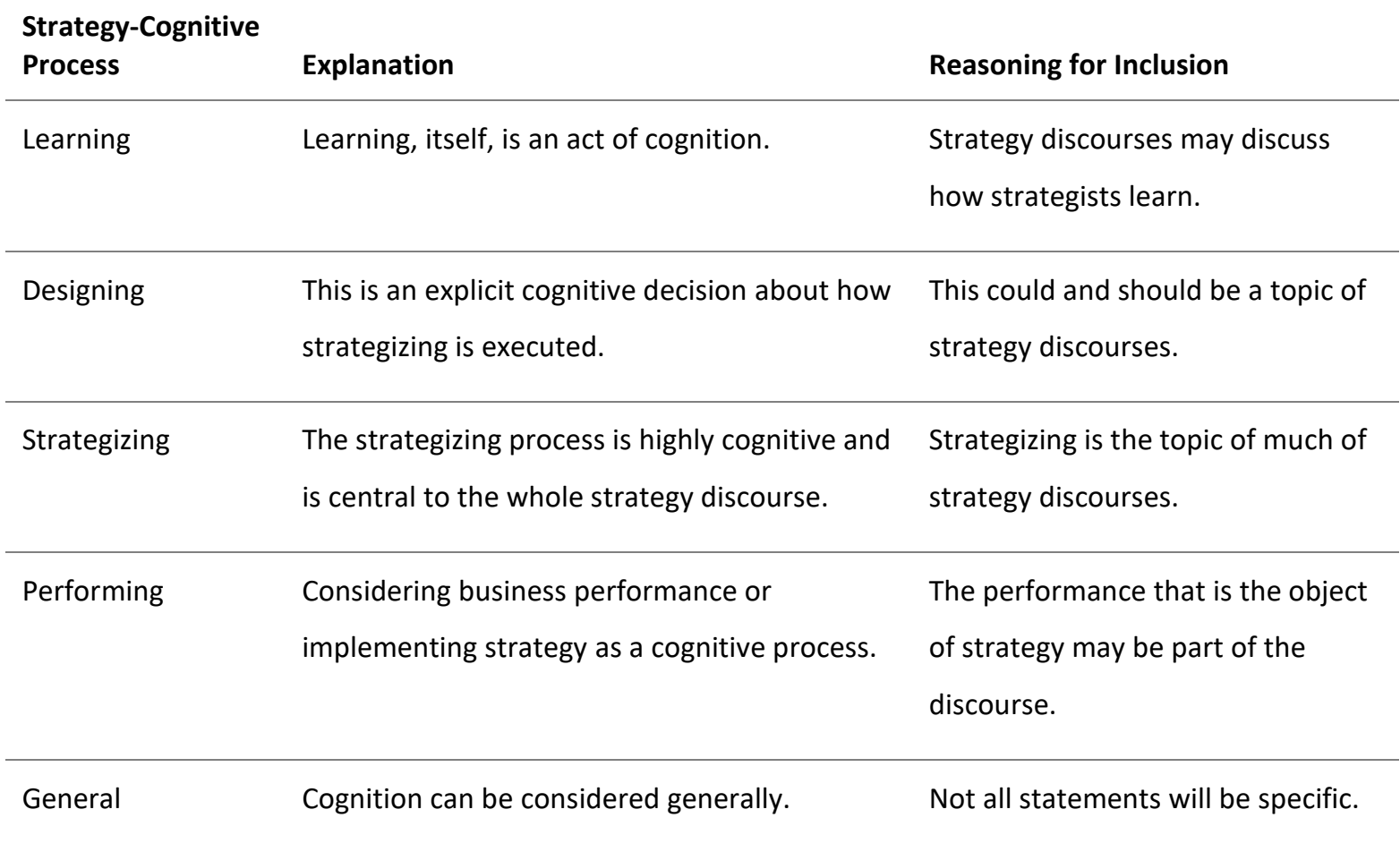

It should be noted that these processes are defined for their analytical utility. It is not suggested that this approach has any inherent primacy over another approach, although it has had utility for this thesis and does have a basis in cognitive recursiveness.

Such cognitive recursiveness is relatively easily approachable by individuals through introspection. Simply by thinking about how your mind just thought provides a single iteration, while doing so again (i.e. thinking about 
how you thought about your thinking) provides a second iteration. The concept of recursiveness has been recognized many times:

- Descartes recognizes consciousness of self: "I am beginning to achieve a better knowledge of myself" (p. 53).

- Kant aims to explain what such consciousness is: "I have no knowledge of myself as I am but merely as I appear to myself. The consciousness of self is thus very far from being a knowledge of the self" (Kant, 1781/1991, p. 169).

- William James devotes a chapter to self-consciousness (James, 1890/1950a, pp. 291-401).

- March and Simon (1958, p. 161) explicitly recognize a second level of process: "Thus, we may distinguish substantive planning - developing new performance programs - from procedural planning developing programs for the problem-solving process itself."

- The reflective approaches above have been used by other theorists: 'double-loop learning' (Argyris, 2005); and quadri-hermeneutics (Alvesson \& Sköldberg, 2009).

The Strategy-Cognitive Processes incorporate such recursiveness. Essentially, Strategizing is thinking about Performing, Designing is thinking about Strategizing, and Learning is to think about Designing in a broad sense.

Examples of the Strategy-Cognitive Processes in use are:

"The evaluation of alternative courses of action is a preoccupation of many planners. Unfortunately, this preoccupation frequently precludes their involvement in what is often a more fruitful activity: inventing, designing, or otherwise creating new alternative courses of actions or policies" (Ackoff, 1970, p. 43).

"Coöperation is a social aspect of the total situation and social factors arise from it. These factors may be in turn the limiting factor of any situation. This arises from two considerations: (a) the process of interaction must be discovered or invented, just as a physical operation must be discovered or invented; (b) the interaction changes the motives and interest of those participation in coöperation"(Barnard, 1938, p. 60).

"The ideal process of decision is to discriminate the strategic factors and to redefine or change purpose on the basis the estimate of future results of action in the
Ackoff reflects on Learning benefits which he suggests are often not achieved.

Here Barnard invokes two categories: Designing and Strategizing. He recognizes that the process must be designed (i.e. discovered), and he focuses on the process of Strategizing (i.e. the changing motives).

Strategizing is central as Barnard discusses the process using current knowledge. 
existing situation, in the light of history, experience,

knowledge of the past" (Barnard, 1938, p. 209).

"Extensive planning requires the co-operation of many

Chandler explicitly discusses Strategizing. individuals who have confidence in each other, and this, in general, requires knowledge of each other" (Chandler, 1962, p. 47).

"Consumers are unpredictable, varied, fickle, shortLevitt focuses on the actual market, or the sighted, stubborn, and generally bothersome" (Levitt, process of Performing in an environment. 1962, p. 66).

\section{Thought Content}

Strategists think and, in this thesis, what they think is termed 'Thought Contents'. The question is 'how does the business strategy discourse perceive strategy Thought Content?' Based upon the candidate's own experiences and reading of strategy, three categories are defined (like the processes above, these are capitalized throughout the thesis):

Table 11: Thought Content Categories

Strategy Knowledge of strategy itself is clearly essential to executing strategy processes. Such Strategy knowledge is what Learning creates and Designing utilizes. The question this asks is 'Do strategy texts consider what practitioners think about strategy?' or 'Do strategy texts consider what is known about strategy?'

Context The Context is knowledge of the company and the environment. Such perceptions are often created through analysis techniques such as SWOT (strengths, weaknesses, opportunities, and threats) and PESTEL (political, economic, social, technological, environmental, and legal).

Intention Strategy, if it is to be successful, requires some intentionality. This category asks 'How do texts consider intentionality?' Clearly intentionality can be present in artefacts such as documents, and in the minds of practitioners.

It is not suggested that these three Thought Content categories are comprehensive, but they are presented as a starting point for interpretation within a complex conceptual space. They support the asking of illuminating questions about how strategy treats Thought Content - they are not intended to be a complete categorization of everything ever thought about strategy. 
There are difficulties in determining whether a text treats cognition as Context or Process. If the question is applied in a purist sense, the only statements qualifying as concerning Context would be limited to the empirical research of practitioners' cognitions. That is, limited to subjects such as frames and mental models. However, texts do consider cognition, both as generic processes of decision making, understanding, and judgment, and when applied to specific areas of Context. When texts do the latter, it is recognized as Context in the analyses that follow. For example, when Andrews (1971, p. 100) states, "To identify the less obvious or by-product strengths of an organization ... one might well begin by examining the organization's current product line and by defining the functions it serves in its markets", he talks of the cognitive process of discovery, but clearly is concerned with the Context within which a firm is performing. He is not considering knowledge of Strategy, nor is he considering statements of Intention.

\section{Cognitive Heuristic Summarized}

The Cognitive Heuristic and options identified above are shown below. As indicated above, these options were not all preset, but the options and the heuristic have evolved through the process of doing the research for this thesis.

Table 12: Cognitive Heuristic

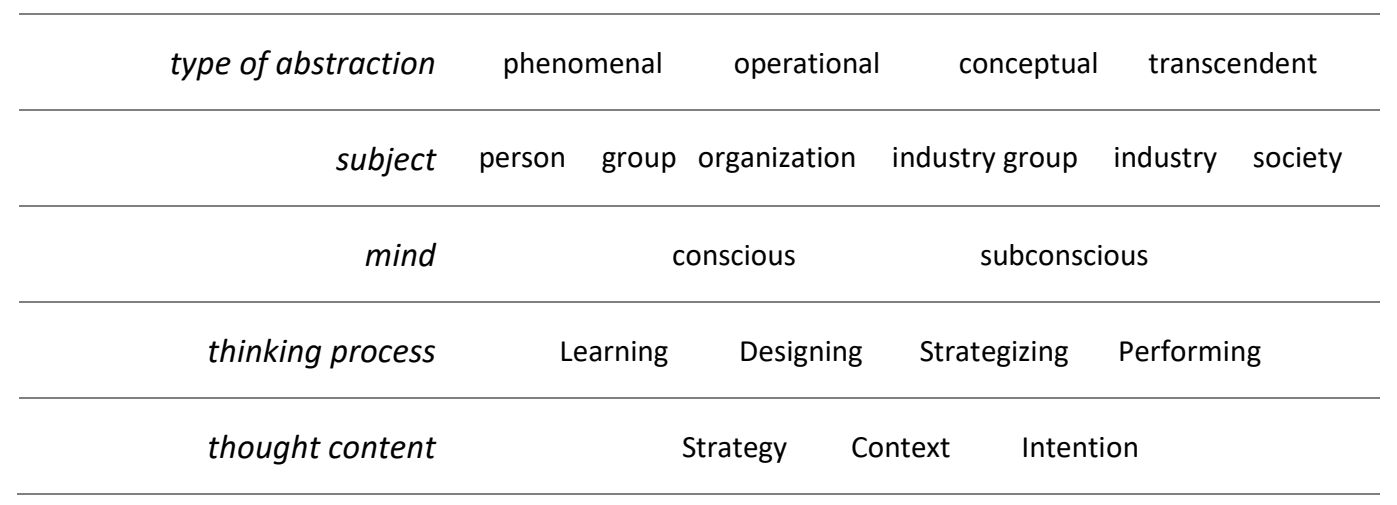

\section{Warning - a Heuristic Applied to Treatments of Cognition}

Please note that this heuristic is applied to treatments of cognition, not to texts in general. For example, a research paper that includes highly phenomenal empirical research, but treat cognition conceptually, is categorized as a conceptual treatment of cognition. Similarly, a text that focuses on deciphering strategy Context, but purely defines methodology without reference to cognition, will not show up in this analysis. The key is to understand how business strategy treats cognition, not how business strategy treats business. 


\subsection{Cognitive Models}

Strategy abounds with models that are graphically drawn and that contain cognitive elements. These models, already seen in Chapter 4-A Review of Treatments of Cognition, show key aspects of strategy and relationships between diverse elements of strategy. This section categorizes these models into cognitive model types, and these types are used in the next thesis part when analysing texts.

Many of the models studied have antecedents in sociology and psychology. The models tend to have both objects (often in boxes) and relationships (expressed as lines). The objects can be:

- cognitive elements (e.g. perception, action, disposition)

- an event

- a structure

- a quality or quantity

- part of an environment.

Relationships are also varied:

- influence (from incidental to causal)

- process steps (showing steps in time)

The model types are:

Table 13: Cognitive Model Types

\begin{tabular}{ll} 
Model Type & Description \\
\hline Cognitive Model & $\begin{array}{l}\text { A general term to refer to any model that describes aspects of } \\
\text { cognition (but may also include non-cognitive elements) }\end{array}$ \\
\hline Cognitive Process Model & $\begin{array}{l}\text { A model that primarily shows process between cognitive } \\
\text { elements }\end{array}$ \\
\hline Cognitive Influence Model & $\begin{array}{l}\text { A model that primarily shows influence between cognitive } \\
\text { elements }\end{array}$ \\
\hline Cognitive Hybrid Model & $\begin{array}{l}\text { A model that shows both influence and process between } \\
\text { cognitive elements }\end{array}$ \\
\hline
\end{tabular}

Applying the model types is an act of interpretation of the intent of the model. For example, if the intent is interpreted as being primarily to show influences, the model will be termed a Cognitive Influence Model. To illustrate how the terms are used in this thesis, examples are given below. 


\section{Cognitive Process Model Example}

Within van der Heijden and Eden (1998), Eden and Spender present a model of a cognitive process. Each step involves people thinking (i.e. cognition) and its overall purpose is to indicate how organizations learn.

In the graphic below, there is a clear sequence to this learning, so the graphic is interpreted as modelling a process. Further, three of the four activities (experiences, observation and reflection, and formation of abstract concepts and theory) are cognitive activities. Hence, in this thesis, such graphics are interpreted as being Cognitive Process Models or CPMs.
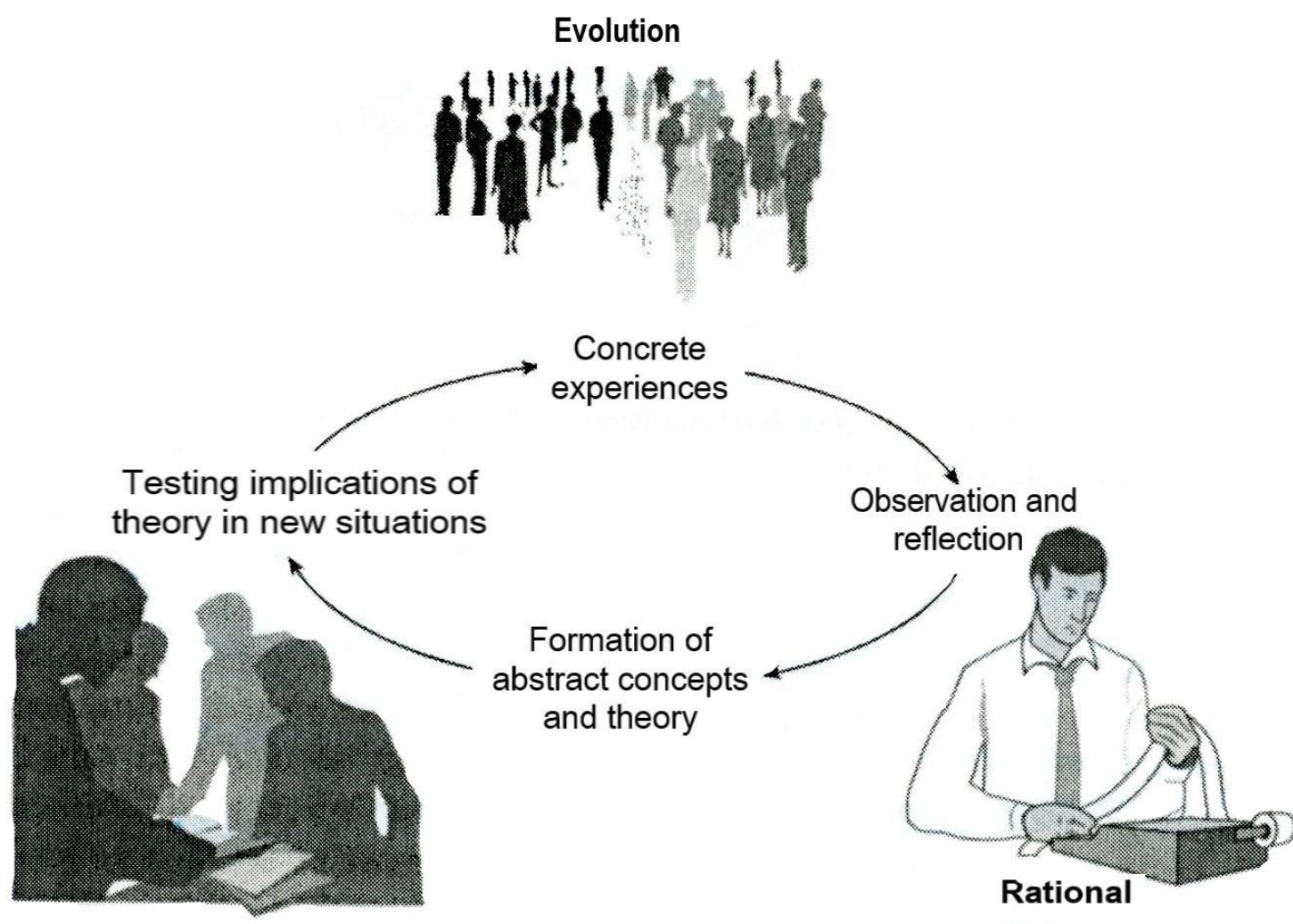

Figure 9: "The learning organization", Reproduced from Managerial and organizational cognition: Theory, methods and research (p. 63), edited by K. Van der Heijden, and C. Eden, (1998), The theory and praxis of reflective learning in strategy making (pp. 58-75), by C. Eden \& J.C. Spender, London, United Kingdom: Sage.

Copyright Kees van der Heijden and Colin Eden 1998. 


\section{Cognitive Influence Model Example}

March and Simon (1958) present a variety of models for how people feel and perceive, including the one below. The model below contains cognition elements, satisfaction and perceptions, and shows influence between these and other non-cognitive elements. It does not present a process operating in time.

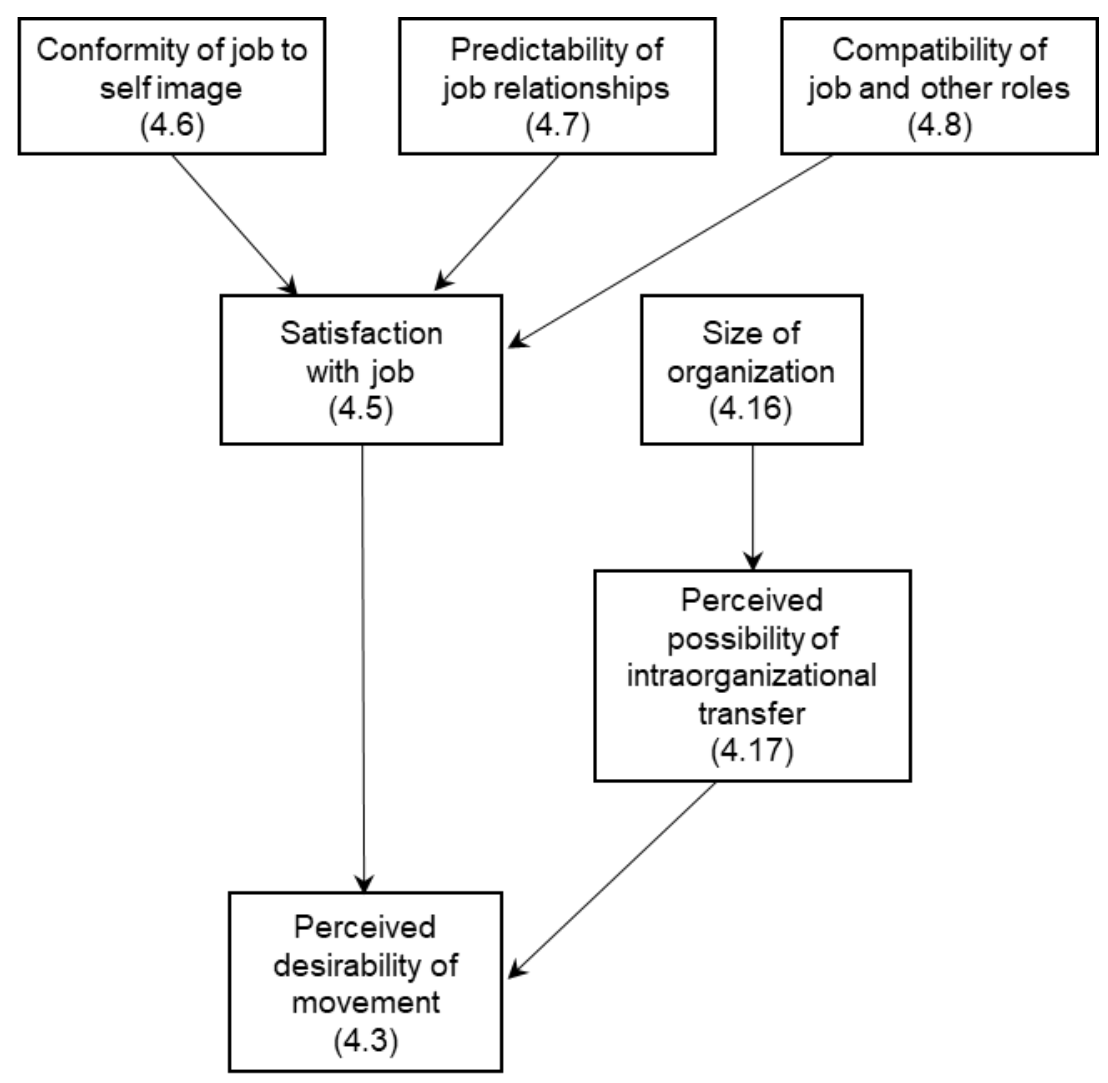

Figure 10: "Major factors affecting perceived desirability of movement", reproduced from Organizations (p. 99), by J. G. March, \& H. A. Simon, 1958, New York, NY: John Willey \& Sons. Copyright 1958 by John Wiley \& Sons.

While this model has elements of a Cognitive Hybrid Model, the primary intent is to show factors affecting 'perception' and many of those factors are cognitive. Therefore, it is categorized as a Cognitive Influence Model in this thesis. 


\section{Cognitive Hybrid Model Example}

Barr, Stimpert and Huff (1992) define the model below that has both influence and process, and hence is termed a Cognitive Hybrid Model. Cognitions that influence processes and other cognitions are shown, while there is a sequence to the right that suggests mental models changing over time and driving other processes.

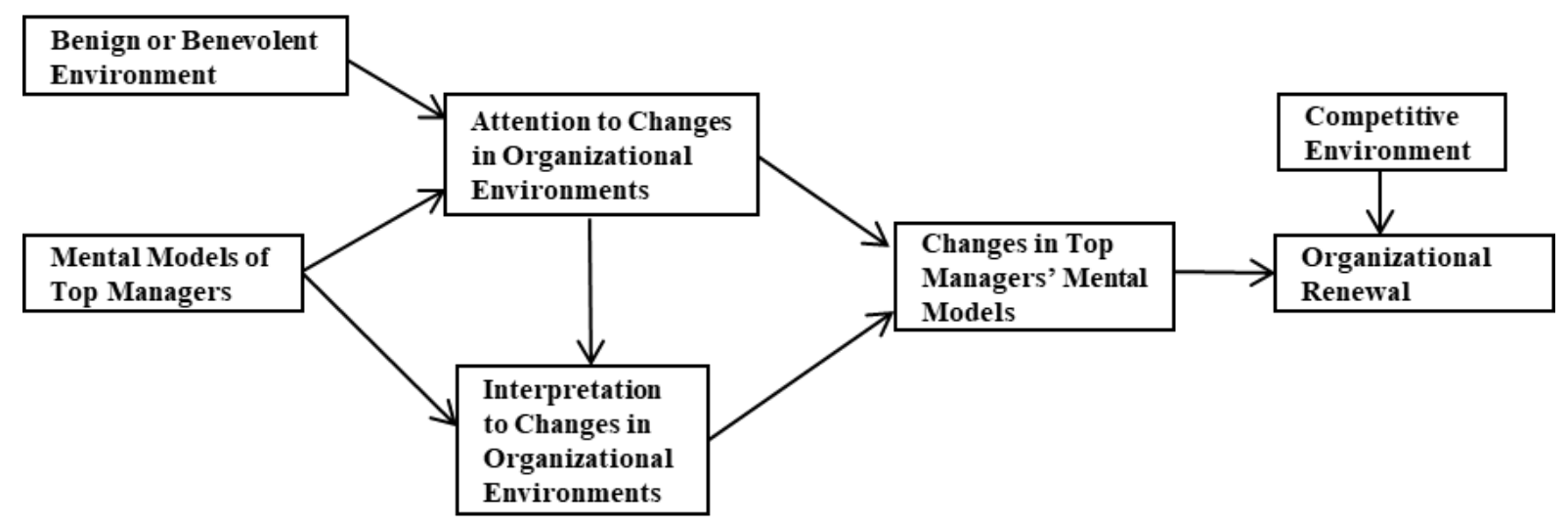

Figure 11: "A cognitive model of organizational renewal”, reproduced from Cognitive change, strategic action, and organizational renewal (p. 18), P. S. Barr, J. L. Stimpert, \& A. S. Huff, Strategic Management Journal, 13(S1), 1992 (pp. 15-36), Copyright 1992 by John Wiley \& Sons. 


\subsection{Insights into Treatment of Cognition}

The concept of insights, developed extensive in Chapter 4 - Methodology, is used explicitly in Part Two analyses of strategy discourses and applied to treatments of cognitions.

Within each discourse analysis, a series of 'provisional insights' are described and collated based on the interpretation of each discourse. These insights are developed for sub-discourses where applicable and collated at a discourse level. As they are specific to particular discourses, they are termed provisional and are synthesized later in the thesis.

This synthesis occurs in Chapter 13 - Findings. Together with the Cognitive Heuristic, the use of insights provides the context for describing the treatments of cognition found and contributing insights into these treatments of cognition. 


\subsection{Definitions, Heuristic, and Cognitive Models}

Key outcomes from Part One, to be used in Part Two, are definitions from Epistemology, and the Cognitive Heuristic and Cognitive Model Types defined in this chapter:

Consciousness Overarching state of being that humans experience.

Conscious The part of thinking minds we are aware of.

Subconscious The part of our minds that we can only postulate, including emotions.

Cognition The conscious and the subconscious mind.

Cognitive Pertaining to cognition.

Introspection The process of an individual looking into their own mind.

Mind $\quad$ Mind is used in a general sense to indicate cognition.

Mental Used in a similar sense to cognitive.

Unconscious This term is avoided, with the term subconscious being used instead.

Discourse A discourse is an enactment of humanity over time, through thoughts and artefacts.

Table 12 (p. 85) repeated: Cognitive Heuristic

\begin{tabular}{|c|c|c|c|c|}
\hline type of abstraction & phenomenal & operational & conceptual & transcendent \\
\hline subject & person group & organization & industry group & industry society \\
\hline mind & \multicolumn{2}{|r|}{ conscious } & \multicolumn{2}{|c|}{ subconscious } \\
\hline thinking process & Learning & Designing & Strategizing & Performing \\
\hline thought content & \multicolumn{2}{|r|}{ Strategy } & Intent & ion \\
\hline
\end{tabular}

Table 13 (p. 86) repeated: Cognitive Model Types

Model Type Description

\begin{tabular}{ll}
\hline Cognitive Model & $\begin{array}{l}\text { A general term to refer to any model that describes aspects of } \\
\text { cognition (but may also include non-cognitive elements) }\end{array}$ \\
\hline Cognitive Process Model & $\begin{array}{l}\text { A model that primarily shows process between cognitive } \\
\text { elements }\end{array}$ \\
\hline Cognitive Influence Model & $\begin{array}{l}\text { A model that primarily shows influence between cognitive } \\
\text { elements }\end{array}$ \\
\hline Cognitive Hybrid Model & $\begin{array}{l}\text { A model that shows both influence and process between } \\
\text { cognitive elements }\end{array}$ \\
\hline
\end{tabular}




\section{Chapter 7 - Knowledge and Cognition Summary}

Part One - Knowledge and Cognition addresses epistemology, methodology, knowledge of cognition, and a heuristic and terminology for Part Two.

As no epistemology was found with cognition at the core, Pragmatic Cognitivism was invented. This merges elements of the philosophers Kant, James, and Rorty with the concept of treating cognition as a priori, in a triad of space, time, and cognition. The expansion of Kant's space and time, the inclusion of James pragmatism, and the use of Rorty's position on language, provide an epistemological basis that both explicitly allows for cognition, and can easily distinguish ontological-based discussions that are often best avoided.

Additionally, the concept of interpretation is an outcome of this epistemology. Interpretation has the utility that it avoids 'representation' which has realist overtones, and because it inherently avoids metaphysics and invented issues of paradoxes and dilemmas.

A methodology is selected that aligns with the epistemology of Pragmatic Cognitivism. An Object of Study Framework is developed that explicitly distinguishes methods for studying how others think. Michel Foucault is the selected theorist based on his theoretical techniques which he used to understand how humanity has thought about a range of topics including prisons, health, and sexuality. For this thesis, this topic is thought itself, but limited to the world of strategy. Additionally, hermeneutic guidelines are selected that direct effective interpretation.

Importantly, the techniques of Michel Foucault align with the epistemology of Pragmatic Cognitivism. Both recognize the implicitness of 'interpretations of interpretations' in human existence.

With these two bases of epistemology and method secure, the next step taken is to review treatments of cognition in other fields and use those outcomes to seed a heuristic for the actual research undertaken. The review finds a broad range of approaches to mind, and mind considered from multiple perspectives. These perspectives and additional knowledge structures are tailored into a Cognitive Heuristic and terminology that facilitates an efficacious study of treatments of cognition.

This part has both established the ground rules for this thesis (epistemology and methodology) and established knowledge structures, as shown on the previous page, for the research to follow (the review of knowledge leading to knowledge structures).

"Tell me the thoughts that surround you,

I want to look inside your head, yes I do"

Lyrics from Where Do You Go to My Lovely by Peter Sarsted, copyright Sony/ATV Music Publishing LLC 


\section{Part Two - Business Strategy and Cognition}

As Part One - Knowledge and Cognition has defined the conceptual basis for Part Two - Business Strategy and Cognition, these introductory words simply show the structure of Part Two, reconfirm key concepts from Part One that are particularly relevant in Part Two, offer some reading guidelines to Part Two, and outline how the research proceeded in practice.

\section{Part Two Chapters}

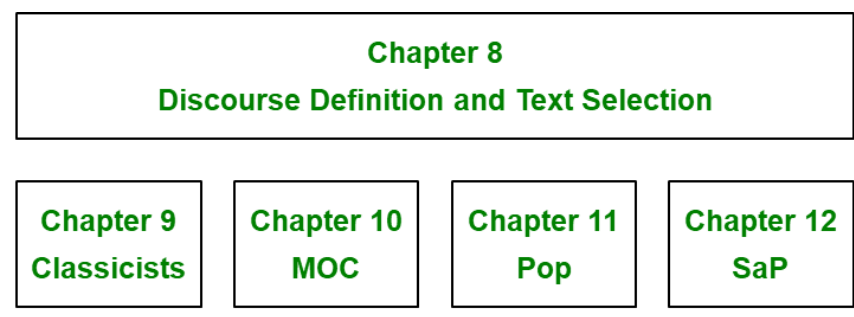

\section{Chapter 13}

Findings

Figure 12: Part Two

Structure

Part Two:

1. describes the selection of discourses and texts within business strategy (Chapter 8)

2. presents the research results for the four selected discourses (chapters 9-12)

3. presents summarized findings (Chapter 13).

\section{Part One Concepts}

Key concepts from Part One pertinent to Part Two are:

Epistemology

Methodology

Terminology and

Cognitive Heuristic
The epistemology of Pragmatic Cognitivism promotes the basis for selection of texts and definition of discourses. As there are, in general, only interpretations of interpretations, selection decisions can be made, and they should be made to provide clear and insight interpretations.

The Foucauldian method utilized introduces key terminology and a structure for the research chapters (see Use of Foucauldian Concepts, p. 52).

As summarized on p. 91, Part One provides a number of definitions, the Cognitive Heuristic, and definitions of cognitive model types. 


\section{Reading Guidelines}

The research techniques used in this thesis produce text that, at times, needs some explanation. Specifically, this is to ensure that the reader does not misread examples of cognition as being representative of a strong focus on cognition, and to ensure that the reader does not misinterpret specific terms used in different ways.

\section{Foucauldian Analysis vs Cognition Analysis}

There is a marked difference of approach to these two analyses which the reader should be cognizant of:

Foucauldian The Foucauldian analysis of strategy texts highlights the major and most pertinent analysis elements of each text. The intent is to provide a clear and comprehensive description of the broad knowledge structures within which cognition is treated.

Cognition Analyses of treatments of cognition are different from the Foucauldian analyses, as they analysis often highlight the infrequent. Often texts will have minimal references to cognition. In these cases, the text is often quoted to show how cognition was treated, even if the text itself is almost silent on cognition. For these instances, the text will be recognized as having minimal or brief treatments of cognition, and the quotes are given simply to highlight the types of these minimal treatments; when the analysis highlights cognitive comments it should not be assumed to be an indication that a text is cognitively oriented.

\section{Cognitive Heuristic Terms}

Throughout the analyses of discourses, references are made to the Cognitive Heuristic. Repeating the full terminology whenever an element is mentioned would make this manuscript somewhat difficult to read. Therefore, some terms are used in an abbreviated manner, and some are augmented to avoid ambiguity:

- Thinking Processes (Learning, Designing, Strategizing, Operating) are always capitalized to distinguish their specific usage from a general usage, and at times the word 'process' is dropped (e.g. simply use 'Strategizing' instead of 'Strategizing process').

- Thought Contents (Strategy, Context, Intentions) are always capitalized. Often 'Strategy' is termed 'Strategy knowledge' to avoid ambiguity with 'strategy' which is used generically, but 'Context' and 'Intentions' are used as single words as their meaning is clear when used in this fashion, and no ambiguity would result. 


\section{The Research in Practice}

The research was executed in a structured manner and evolved during the thesis.

\section{Process}

Research was discourse by discourse, in the order they are presented in this thesis. The research was structured around five research areas (the Foucauldian concepts of conditions of possibility, problematization, knowledge, and subjectivity/social effects) and around cognition. These two structures were represented on a two-sided card with the Foucauldian Framework and Cognitive Heuristic that was used as a Research Guide:

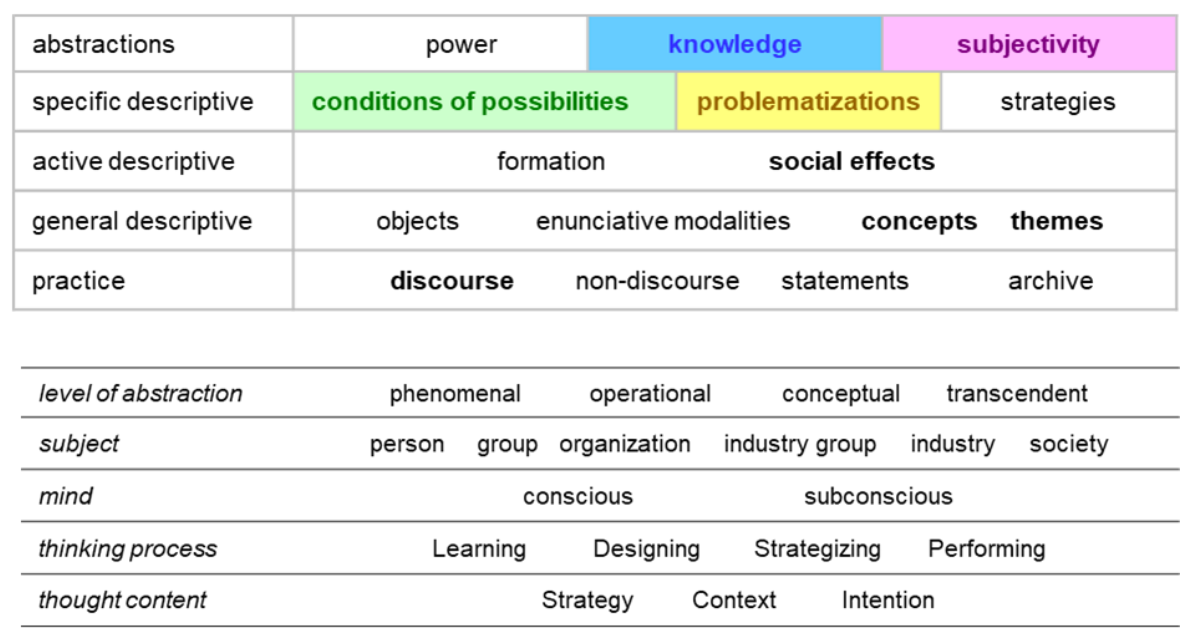

Figure 13: Research Guide

Slightly different approaches were taken for the mainstream and academic discourses. For mainstream discourses, the texts studied were mostly books:

1. the texts were read and marked up in two fashions:

a. Statements were colour coded to highlight incidents of the Foucauldian concepts that structure the Foucauldian part of the research chapters (purple also applied to social effects).

b. Cognitive elements will be identified and the text written on to highlight the relevant point, using the Research Guide as a quick reminder.

2. a quote document was maintained that recorded for each text and for each of the five research areas:

a. key quotes
i. the quote itself
ii. a comment on the quote
iii. a classification of Thinking Process found (if relevant)
iv. cognitive elements found (if relevant)

b. a summary of the key treatments found

3. a master summary was maintained that recorded for each text: 
a. a brief summary of the text

b. for each of the five research areas:
i. a list of quotes
ii. a brief summary of treatments

For academic discourses, the texts studied were mostly articles:

1. texts were marked up as described for mainstream discourses texts above

2. a master spreadsheet was maintained that recorded for each text:
a. text summary
b. a brief summary for each of the five research areas
c. key quotes
d. categorization of the text in cognitive terms

The research results of this thesis were written up using these research materials and the texts themselves.

\section{Evolutions}

The use of the Foucauldian Framework was very consistent throughout the project, while the Cognitive Heuristic evolved significantly and especially during the researching of the first two discourses.

\section{Foucauldian Framework}

The Foucauldian framework only changed once:

\begin{tabular}{|c|c|c|c|c|c|}
\hline abstractions & \multicolumn{3}{|c|}{ knowledge } & \multicolumn{2}{|c|}{ subjectivity } \\
\hline specific descriptive & conditions of pos & sibilities & probleme & ations & strategies \\
\hline active descriptive & \multicolumn{3}{|c|}{ formation } & \multicolumn{2}{|c|}{ social effects } \\
\hline general descriptive & objects & \multicolumn{2}{|c|}{ enunciative modalities } & \multicolumn{2}{|c|}{ concepts } \\
\hline practice & discourse & \multicolumn{2}{|c|}{ non-discourse } & ents & archive \\
\hline abstractions & \multicolumn{2}{|l|}{ power } & nowledge & \multicolumn{2}{|c|}{ subjectivity } \\
\hline specific descriptive & \multicolumn{2}{|c|}{ conditions of possibilities } & \multicolumn{2}{|c|}{ problematizations } & strategies \\
\hline active descriptive & \multicolumn{3}{|c|}{ formation } & \multicolumn{2}{|c|}{ social effects } \\
\hline general descriptive & objects & \multicolumn{2}{|c|}{ enunciative modalities } & concepts & themes \\
\hline practice & discourse & non-di & ourse & nents & archive \\
\hline
\end{tabular}

Figure 14: Foucauldian Framework Progression

Formation was initially one of the key concepts used, while discourse was not. Formation was found to be essentially covered between the interactions of conditions of problematization and knowledge. Therefore, treating it as a separate concept only confused the presentation of results. Discourse is a key concept in this thesis and therefore given higher priority. 


\section{Cognitive Heuristic}

The Research Guide includes the Cognitive Heuristic and other cognitive terms combined on one side. The actual Cognitive Heuristic changed very little during the course of the thesis, but the main change being levels of abstraction:

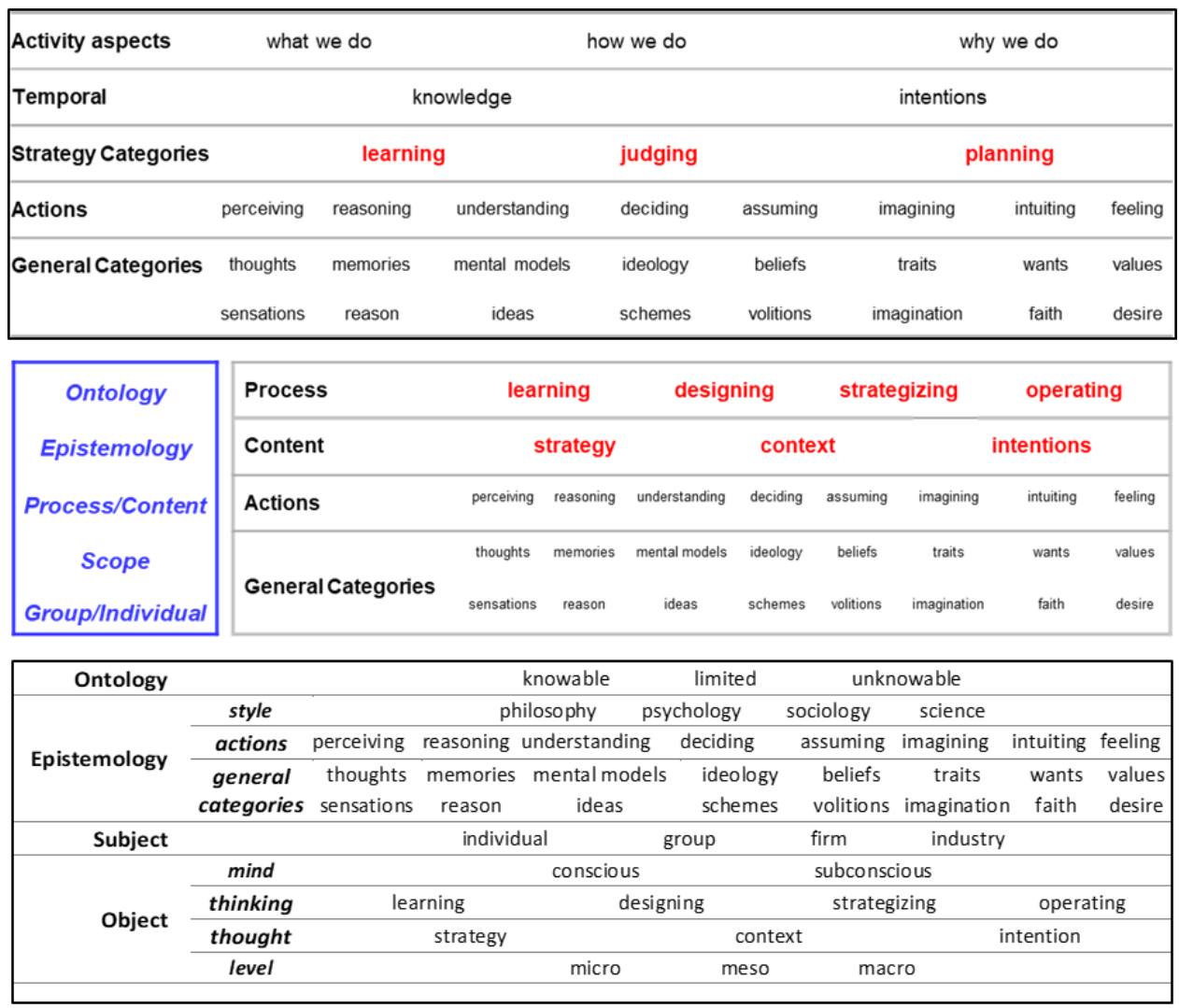

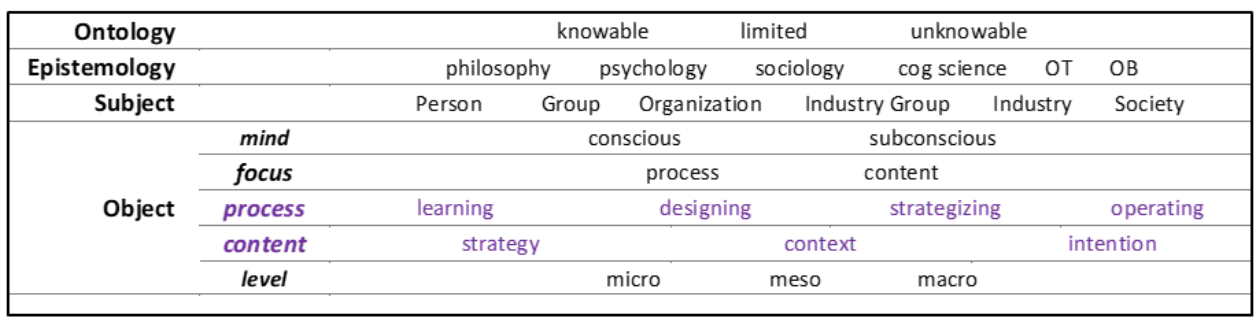

\begin{tabular}{|c|c|c|c|c|c|}
\hline level of abstraction & phenomenal & operational & conceptual & trans & endent \\
\hline subject & person & organization & industry group & industry & society \\
\hline mind & \multicolumn{2}{|c|}{ conscious } & \multicolumn{2}{|c|}{ subconscious } & \\
\hline thinking process & Learning & Designing & Strategizing & \multicolumn{2}{|c|}{ Performing } \\
\hline thought content & & Strategy & Intent & ion & \\
\hline
\end{tabular}

Figure 15: Cognitive Heuristic Progression

\section{Rework}

As shown above, many of the changes are naming changes, either as labels or as actual names of concepts. These types of changes were relatively easy to achieve. The removal of formation required more work, and the change of levels of abstraction required more extensive rework including reworking content in Part One. 


\section{Chapter 8 - Discourse Definition and Text Selection}

This initial chapter of Part Two - Business Strategy and Cognition defines the discourses to be studied by this thesis and describes the text selection and grouping processes.

Note that the topic of this thesis, business strategy, is specifically 'western, English-language business strategy' and this therefore excludes eastern business strategy, non-English-language strategy, and military strategy. Note also that the term 'text' is used here to indicate written material, and two forms of texts are distinguished: 'books' and 'articles'.

The chapter is structured in four sections:

1. the adoption of decision criteria based on the epistemology and methodology defined in Part One Knowledge and Cognition

2. a decision to study both mainstream strategy and academic strategy discourses

3. the definition of mainstream strategy discourses and book selection processes

4. the definition of academic strategy discourses and text selection processes

As elaborated on, in 8.1 Decision Criteria, decisions are made based upon the epistemology defined and the methodology selected in Part One. These starting points stress the Foucauldian aim of finding insights to inform the present, rather than attempting to find comprehensive and 'representative' knowledge. This concept, of 'utility to provide insights', is the basis of the decision processes used to define discourses and select texts.

An important initial decision was to study both mainstream and academic literatures. As both are influential, as described in 8.2 Mainstream and Academic Strategy Discourses, it was decided to study both.

As mainstream and academic strategy discourses are different, they are treated differently when defining discourses. In 8.3 Mainstream Strategy Discourses, a survey and categorization of books is compared with two other theorists' discourse categorizations leading to the selection of the discourses of Classicists and Pop.

In 8.4 Academic Strategy Discourses, a slightly different approach is taken; specific academic fields are identified leading to a selection of Managerial and Organizational Cognition and Strategy-as-Practice as the discourses.

Sections 8.3 and 8.4 describe the process of text selection and rationales for grouping texts, but do not list the texts or show the groupings. These are defined in each of the relevant later chapters. 


\subsection{Decision Criteria}

This thesis explicitly rejects the concept of a 'true' categorization of discourses and a 'true' selection of texts, and makes determinations based on utility to provide insights into the research question.

In 3.4 Implications and Extensions (p. 17), the epistemological approaches of this thesis to interpretation and to the status of texts are defined. These are that interpretations are just that - interpretations made at a point of time. In such an epistemology, the concept of a representative or comprehensive sample of texts does not apply. The concept of a useful sample of texts, however, does apply.

In 4.4 Foucault (p. 36), Foucault's strategies are presented, including his approach to history and selection of texts. Foucault does not aim for an accurate description of the past, he aims for the utility of developing insights into the present. He does this by searching for rarity, rather than by searching for the common or the average view.

This thesis, in being consistent with its own epistemology, follows an approach based upon Foucault's strategies to develop insights. The decision criteria adopted are:

1. to define discourses and to group texts in ways that will aid the development of insights

2. to select:

a. 'well-known' texts, indicated by citations and/or recognition in the field, that are likely to be influential on how we think today

b. 'outlying' texts, indicated by title and identifiable through their introductions, as they can provide useful input that will counter-balance the risk of only sampling the status quo and well-promoted literature.

Insights can be developed through these techniques. By utilizing well-understood discourses and groupings, general comprehension will be enhanced. By a well-directed search for texts, the identification of insights will be enhanced.

As shown below, these processes are executed through a balance of process and judgment. This, of course, is simply interpretation in action, but an interpretation designed with a purpose to develop insights. 


\subsection{Mainstream and Academic Strategy Discourses}

An important distinction is made between mainstream and academic strategy discourses, and an important approach this thesis takes is to study both.

The label 'mainstream strategy' is used to denote the business strategy literature in common usage (and often found in strategy texts sold in bookshops), and the label 'academic strategy' denotes university-based research into business strategy that is found in academic texts and articles. Even though authors may cross the divide, this distinction is still useful as it provides a focus on the audience of strategy texts.

From this perspective it could be proposed that understanding the treatment of cognition by business strategy should be confined to considering mainstream strategy texts, as these are the influential texts for the business world. An alternative view, taken by this thesis, is that while it is unlikely that academic strategy texts are widely read by the general business community, academic strategy discourses are the source of much mainstream strategy thinking. Therefore, this thesis researches both mainstream and academic strategy discourses on the basis that both discourse types will yield insights that are pertinent to how we think of strategy today. 


\subsection{Mainstream Strategy Discourses}

This chapter describes the process of discourse selection and the discourses selected, and the book selection and grouping processes used. These processes, a mixture of categorizations, ranking, and judgements, are based upon the design criteria defined in the first section of this chapter.

The sections of this chapter are:

1. an initial decision to focus on books

2. definition and selection of two discourses, Classical and Pop

3. identification of mainstream books

4. selection processes for books and grouping processes for each discourse.

\section{Books, Not Articles}

Mainstream texts include both articles and books. Articles from journals, such as the Harvard Business Review, and from magazines, such as BusinessWeek, were rejected for two reasons:

- Such articles have editorial oversight and, even though their content would vary over time, there was a significant chance that the articles would exhibit standard themes and not the rarity that a Foucauldian technique seeks in order to provide insights.

- The books identified provide a sufficient literature with significant variety for the research.

For these two reasons, and also to simplify the research process to a single style of text, only books are considered in the research of mainstream strategy.

\section{Discourse Selection}

Discourse selection was achieved by surveying mainstream strategy books and by considering known categorizations of business strategy. This process overlapped with the process described in the next section covering the selection of texts, as that process created the master list of texts utilized here. Three possibilities for determining discourses to study were considered:

1. discourses suggested by the master list of 116 books themselves (see section immediately below)

2. Mintzberg, Ahlstrand and Lampel (1988) categories from Strategy Safari

3. a split suggested by Kiechel (2010) in The Lords of Strategy

The master list of books suggested no natural classification. No doubt, once fully analyzed, themes would be discernible, but doing such an initial analysis would essentially mean that all texts would be researched as a single discourse.

The ten schools of Strategy Safari are design, planning, positioning, entrepreneurial, cognitive, learning, power, cultural, environment, and configuration. Such a categorization has challenges: texts cover multiple 
schools, some schools are primarily academic, and some schools have minimal strategy texts. Rather than bend this thesis to fit into this categorization, other approaches were considered.

Kiechel (2010), in a more recent review, created a distinction between what are here described as Classical and Pop business strategy. In The Lords of Strategy he provides a useful distinction in strategy, focusing on people: "The shadow, as postulated by the Swiss psychotherapist [Jung], consists of that part of oneself - energies, desires, ambitions that we repress as we become the individuals we are, 'rejected aspects of ourselves and undeveloped potential,' as one expert defines it. What got repressed - sometimes viciously repressed - by the strategy-concept makers, consultants, and data gatherers was a consciousness of people and their importance in the creation and execution of any strategy. Not that there weren't voices in the corporate wilderness crying up the centrality of the human. Indeed, sometimes they were spitting and shouting voices, like that of Tom Peters"(Kiechel, 2010, p. 7).

Such a distinction was useful for Kiechel's high-level analysis of strategy, but for this thesis, a slightly different approach is taken, since post the publishing of In Search of Excellence, some texts have been published that are not people focused, but strive more for a popular audience, and other texts are published that could more appropriately be described as Classical. Hence a split has been made between Classical Strategy and Pop Strategy, with Classical extending to the present, and Pop starting in 1982.

When checked against the list of books, this distinction gave a useful split of 65 Classical texts and 51 Pop texts. Further, it provided the opportunity to test whether Pop texts would, as one might assume, be more focused on cognition than Classical texts. Hence these were chosen as the two mainstream strategy discourses.

\section{Identification of Mainstream Books}

This section describes how a master list of 116 mainstream strategy books was derived. The strategy adopted was to create a broad initial list of texts, apply some structured analysis to these texts, and cull those texts that did not provide any utility. This section describes three steps:

1. an identification of an initial list of books with possible strategy perspectives

2. categorization and ranking of books

3. a cull to remove non-strategy books, multiple books by the same author, and repeated books

\section{Initial List}

The initial list contained 449 books from 'best-book' books, internet lists, suggested readings from texts, and bibliographies. All books were included from 'best book' books and internet lists, while the suggested readings and bibliography book entries were only included if they pertained to strategy. The sources were:

- 'best books' books:

1) 50 Success Classics (Butler-Bowdon, 2010)

2) The 100 Best Business Books of All Time (Covert \& Sattersten, 2011) 
3) The Best Business Books Ever (The best business books ever, 2012)

- 'top book' lists on the Internet, specifically:

4) Time Magazine Top 25 Business Books of all Time ("The 25 most influential business management books," 2016)

5) Goodreads Popular Strategy Books (“Popular Business Strategy Books,” 2016)

6) Amazon Best Sellers - Strategy \& Competition ("Strategy \& Competition," 2016)

- suggested readings and bibliographies from texts:

7) The Economist Guide to Management Ideas and Gurus (Hindle, 2008)

8) Handbook of Strategy and Management (Pettigrew, Thomas \& Whittington, 2002)

9) The Lords of Strategy (Kiechel, 2010)

10) The Oxford Handbook of Strategy (Faulkner \& Campbell, 2003)

11) Strategy: Process, Content, Context (De Wit \& Meyer, 2010)

12) Strategy (Freedman, 2013)

13) The Strategy Process (Lampel, Ghoshal, Mintzberg \& Quinn, 2014)

14) Exploring Corporate Strategy (Johnson \& Scholes, 1984)

\section{Categorization and Ranking}

To provide some indication of the types of books present in the master list, all texts were categorized based on the book's introduction/preface and/or reviews of the book (Amazon, Google, and Good Reads websites). The categories found in the books were:

- Administration

- Business

- Compendium

- Digital

- Economics

- Environment

- General

- Global trade

- History/Biography

- HRM
- Industrial Organization

- Innovation

- IT

- Leadership

- Learning

- Management Marketing

- Organizational Theory

- People

- Personal Skills

- Positioning
- Production

- Psychology

- Restructuring

- Single Idea

- Sociology

- Strategy

- Strategy Textbook

- Technology

- Tools

- War

The books were ranked based on:

- the number of times the book was referenced in the 14 sources above

- the number of Google Scholar citations.

The rankings are calculated by <references in the above sources $>+<$ number of citations $>/ 5000$. This yields rankings from 1 to 19 . Books ranked 1, indicating a book recommended just by a single source, were likely to be omitted unless compelling reasons for inclusion were found. 


\section{Culling}

The culling strategy was designed to focus on texts that have strategy and cognitive content, to eliminate books that are included simply based on a single recommendation, to consider only one edition of a book, and to include only one book from any author(s). The 449 books were culled back to 116 books in four stages. These stages were:

1. Cull books with limited support and non-strategy books (reduced to 163) Books with a ranking of 1 were culled, unless they had a specific cognitive aspect or were judged to be influential. Further, any higher ranking books which were clearly not strategy oriented were culled.

2. Cull different editions of a book (reduced to 157)

3. Cull multiple books by the same author(s) (reduced to 131)

4. Final cull of off-topic books (reduced to 116)

\section{Book Selection and Grouping}

\section{Selection}

The final selection of books was primarily based upon the candidate's judgement. As indicated above, all book reviews or the introductions in the books had been read. Based upon this, books were categorized as probable, possible, or unlikely for inclusion. A number of probable and possible books were purchased, primarily through second-hand outlets, aiming for first or early editions.

As described above in 8.1 Decision Criteria, selections were made based upon the perceived degree of influence the book has and the useful cognitive content it contains. As the lists in the relevant chapters show, the Classical books selected do not have cognition in their titles, but they do have significant cognitive content. For the Pop books, as described in Chapter 11 - Pop, some texts are specifically cognitive, while others also include cognitive content.

\section{Grouping}

A further level of categorization is the grouping of books. These groupings were made to allow comparison between books of a particular era and/or type, and because a Foucauldian analysis of 10-12 books en masse would be unwieldy to execute and likely difficult to read. As shown in the relevant chapters, grouping texts is possible, and proved to be a useful structure for presenting results.

The rationales for the particular groupings within Classical and Pop are covered in the relevant chapters. 


\subsection{Academic Strategy Discourses}

This section describes the selection of academic strategy discourses and the processes for text selection and grouping. The selection processes follow the decision criteria defined above for mainstream strategy discourses, but the selection of discourses is different as it is based upon current and well-known academic schools.

The sections of this chapter are:

1. the decision to include both articles and books

2. selection of Managerial and Organization Cognition and Strategy-as-Practice discourses

3. an introduction to selection processes and group processes for articles and books

\section{Articles and Books}

As journal articles are the most common academic text, they were the obvious starting point. These are at times published in edited books, and academics also do publish academic books. Therefore it was determined not to limit the texts to articles only, but to include books also.

\section{Discourse Selection}

Academia within management and strategy tends to be organized into schools, often with specific organizational bodies providing a central focal point. These distinctions are well-known and were taken as a natural starting point for discourse selection, as it would add little value to attempt to redefine what is already well-defined. Four alternatives are discussed below, followed by the selection and justification of two discourses.

\section{Managerial and Organizational Cognition}

As described by Walsh (1995), interest in Managerial and Organisational Cognition (MOC) occurred after "an explosion of things cognitive in social psychology" (p. 280). Walsh applies the MOC title to this movement, that includes special issues of the Journal of Management Studies (July 1989, May 1992), a special issue of Organizational Science, (August 1994), and various texts. He gives a starting date of around 1985 and, in his review of MOC, lists a substantial literature and confirms the forming of an Interest Group within the Academy of Management in 1989.

Kaplan (2011) provides another review of the MOC, primarily focusing on the effects of a seminal article Competitive groups as cognitive communities: the case of Scottish knitwear manufacturers (Porac, Thomas \& Baden-Fuller, 1989). She recognizes the significant influence of the article, and that cognition has been diffused into many managerial fields. The breadth of the Domain Statement of the Academy Of Management MOC Interest Group bears this out ("Managerial and Organizational Cognition Division - Domain Statement," 2018). 
This stream of academia has a literature and a common theme of cognition. However, as the name suggests, MOC has a broader scope of management and is not limited to purely strategy. Notwithstanding that, the literature has a focus on decision making and business strategy. So while MOC is not in name a strategy discourse, in substance it has significant strategy material, and therefore it was judged to be a discourse worthy of study.

\section{Microstrategy}

Microstrategy has had a Special Issue of Journal of Management Studies (January 2003), so it is a candidate for study. As described by the guest editors for the Special Issue, (Johnson, Melin \& Whittington, 2003), Microstrategy is a turn towards practice over macro-level process. It is an activity-based view of strategy.

Nicolini (2012) focuses on this 'practice turn'. He suggests that "Practice-based approaches consider cognition and sense-making as emerging from practices" (p. 7) and that they are not drivers of actions. This suggests that Microstrategy could be an area of study, but literature using the description is almost non-existent after 2003. Of those texts that cite Microstrategy articles, the majority are Strategy-as-Practice. Because of the dearth of texts, Microstrategy is not a feasible discourse and, as indicated below, Strategy-as-Practice has many of the same core concepts and is a better option.

\section{Resource-Based View}

Google Scholar returns 324,000 articles for a search for Resource-Based View. A brief review of highly-cited articles (Barney, 2001; Peteraf, 1993; Wernerfelt, 1984) suggests that the Resource-Based View has an economic focus that has been maintained through the life of the discourse. The discourse is based on an alternative economic approach to the Structure Conduct Performance model made famous by Michael Porter. Instead of focusing on the industry itself, the focus is upon the resources of the firm. It has potential as a candidate for research given its size and its focus on resources including humanity, which is classed as "human capital'.

\section{Strategy-as-Practice}

Strategy-as-Practice (SaP) is an established field with its own Academy of Management Interest Group called Strategizing Activities and Practice. As the group was formed in 2009 by three SaP pioneers (Julia Balogun, Paula Jarzabkowski and Richard Whittington), and as the domain statement aligns with SaP objects, a linkage between SaP and the Interest Group is inferred. Further, a SaP International Network exists with reportedly 3,000 scholars registered. SaP is smaller than Resource-Based View, but still has sufficient size to be a candidate for research (7,000 Google Scholar results).

Paula Jarzabkowski (2005) in strategy as practice explains that the focus is on activity, with the three focal points of practice, practitioners, and practices (the first practice being actual behaviour, and practices being routines and processes). She draws attention to the statement of Johnson et al. (2003): "An activity-based view of strategy allows for, but does not commit to, managerial agency" (p. 15). In this manner, SaP allows for cognition within a broader scope. Because of its cognitive aspects and its size, SaP is a potential discourse. 


\section{Academic Discourses Selected}

Because Microstrategy was not feasible, the choice was between the other three discourses. The ResourceBased View is the least cognitive of all, being economically-focused. Therefore, it was not selected. Both MOC and SaP appear to have cognitive elements. Additionally, MOC started earlier (1985) than SaP which gained momentum in the 2000s. Therefore, as the discourses have cognitive elements, have distinctive approaches to cognition, and cover different time periods, both were selected as discourses for this thesis.

\section{Text Selection and Group}

As the processes for selection of texts and grouping are specific to each discourse, they are documented in the relevant chapter. However, there are important commonalities of approach.

\section{Text Selection}

Common selection themes are to use existing academic structures to identify and select texts:

- Texts are identified using searches for keywords of the discourse and for keywords of cognition (both in Google Scholar and library searches).

- Highly-cited texts are identified, given they are likely to be influential.

- Texts are reviewed based on readings of their abstracts, introductions, or reviews, to determine their utility.

\section{Text Grouping}

In the academic strategy discourse analysis chapters, grouping is only done when presenting the articles within the Foucauldian knowledge analysis. This differs from the mainstream strategy analyses which use groupings as a primary structure under which Foucauldian analyses are executed.

While a similar approach for academic strategy discourse texts is possible, an initial scan of the texts showed that a broad grouping by themes is possible, but that academic scholars often combine and present ideas and concepts from multiple sources in single articles. Therefore, with the analyses of academic strategy discourses, text groupings are only used when considering Foucauldian knowledge, while the remainder of the analysis treats the texts as a single discourse. 


\subsection{Summary}

This chapter is a bridge between the epistemology and methodology discussions of the previous part, as it makes clear that the criteria for discourse definition and text selection are based upon a search for utility, and the specification of useful texts to generate insights into how business strategy treats cognition.

Application of these criteria led to the identification of four discourses:

- Classical

- Pop

- Managerial and Organizational Cognition

- Strategy-as-Practice

For the two mainstream strategy discourses, Classical and Pop, a master list of 116 books was derived and provided the context for the discourse selections of Classical and Pop. This chapter describes the process for the selection and grouping of texts with these discourses, which are then detailed in Chapter 9 - Classical and Chapter 11 - Pop. For the two academic strategy discourses, the text selection and grouping process are defined in this chapter and detailed in Chapter 10 - Managerial and Organizational Cognition and Chapter 12 Strategy as Practice.

The use of the grouping of texts varies between the two pairs of discourses. For the mainstream strategy discourses, Foucauldian analysis is done on each of the groups defined, whereas for academic strategy discourses, this grouping is only pertinent to the knowledge analysis within the Foucauldian analysis of the total discourse. 


\section{Chapter 9 - Classical}

This chapter is the first research chapter and considers one of the two mainstream strategy discourses Classical. The structure defined here is also applied to the second mainstream strategy discourse described in Chapter 11 - Pop.

The analysis is structured around four groups of books (described in the next section). The diagram below shows how the analysis of the four groups (9.1 to 9.4) is split into two, with the first being a Foucauldian analysis of the books in order to give a Foucauldian perspective to support the second analysis - Treatments of Cognition.

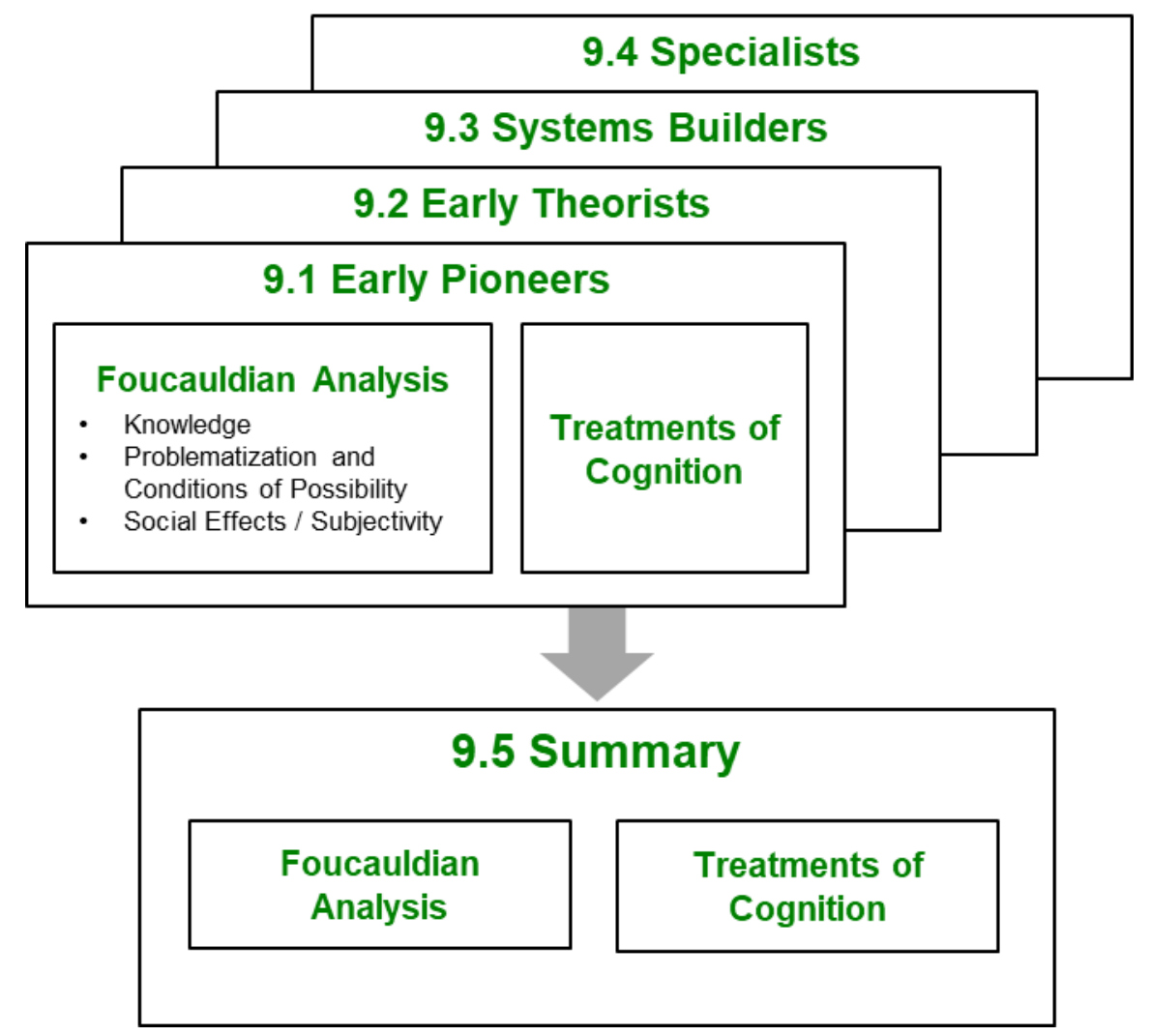

Figure 16: Chapter 9 Structure

As shown immediately above, the four groups of texts are then summarised using the same split of Foucauldian Analysis and Treatments of Cognition. 


\section{Texts and Grouping}

The Classicist texts and groupings are:

1. Early Pioneers

\author{
Barnard (1938) \\ Levitt (1955) \\ Penrose (1962)
}

2. Early Theorists

$$
\begin{aligned}
& \text { Chandler (1962) } \\
& \text { Ansoff (1965) } \\
& \text { Ackoff (1970) }
\end{aligned}
$$$$
\text { Andrews (1971) }
$$

3. Systems Builders

4. Specialists

\author{
Steiner (1979) \\ Porter (1985) \\ Goold \& Campbell (1987) \\ Johnson \& Scholes (1984)
Henderson (1979)
Kanter (1983)
van der Heijden (1996)
Christensen (1997)

\author{
The Functions of the Executive \\ Innovation in Marketing \\ The Theory of the Growth of the Firm
}

\author{
Strategy and Structure \\ Corporate Strategy \\ A Concept of Corporate Planning \\ The Concept of Corporate Strategy
}

Strategic Planning

Competitive Strategy

Strategies and Styles

Exploring Corporate Strategy

\author{
Henderson on Corporate Strategy \\ The Change Masters \\ Scenarios \\ The Innovator's Dilemma
}

\section{Texts}

Eleven of the 15 books selected were within the initial top 24 rankings (see p. 103 for a description of how the books were ranked). The four texts excluded were judged either to be too far off topic (Cultures Consequences (Hofstede, 2001) and Reengineering the Corporation (Hammer \& Champy, 2001)) or without potential to add many insights over the other books already selected (Strategy Formulation (Hofer \& Schendel, 1980) and Strategies for Change (Quinn, 1980)).

A judgment call was made to include four additional books: Innovation in Marketing (Levitt, 1962), A Concept of Corporate Planning (Ackoff, 1970), and Strategic Planning (Steiner, 1979), as these authors have a degree of fame and the books held promise; and Scenarios (van der Heijden, 1996) as it considers cognition. 


\section{Groups}

Based upon an initial reading of each text, the books were grouped for the following reasons:

Group

1. Early

Pioneers

Theorists

Key authors who form

the initial strategy

discourse

3. Systems Those who establish

Builders

specific strains of

strategy such as planning

and positioning

4. Specialists Theorists that make a

speciality out of one

aspect of strategy

\section{Reasoning}

These books establish a starting point for three different perspectives - executive ability, marketing, and economics that reoccur in later strategy authors. As initial texts, they come without precedence and hence have a certain openness.

While these authors also have an open field, they have very specific theoretical approaches that they apply to strategy.

These theorists build complete systems. They tend to present their solutions as being holistic and broader than some earlier writers.

These authors swing back to considering specific topics or techniques. They isolate particular aspects of strategy and focus on those. 


\subsection{Early Pioneers}

Before specialized strategy texts became common, three general management texts stood out as being highly recommended and well cited. These pre-1963 canonical business texts introduce important strategy constructs and are the subject of this sub-chapter. They are Chester Barnard's Functions of the Executive (Barnard, 1938), Theodore Levitt's Innovation in Marketing (Levitt, 1962), and Edith Penrose's The Theory of the Growth of the Firm (Penrose, 1959/1966).

\section{Foucauldian Analysis}

\section{Knowledge}

Chester Barnard - Functions of the Executive (1938)

Barnard, following a long career as an executive in the telecommunications industry, aims to fill a gap in the management literature based upon his own career. While he is not an academic, he is aware of the work of Vilfredo Pareto (Pareto, 1935) and Talcott Parsons (Parsons, 1951). Despite such influences, the text is primarily a summary of Barnard's thinking, developed over a number of years.

In his own idiosyncratic style, he develops his own theory of formal organizations to provide the essential context he needs to then specify the functions of executives. This context starts with consideration of individual humans from physical, biological, psychological and social perspectives, before outlining a theory of formal organization, defining the elements of formal organization, and then enumerating executive functions within this broad context.

Barnard proposes a theory of incentives, which is possibly his most well-known and principal contribution to management literature. He highlights the importance of incentives: "the subject of incentives is fundamental in formal organizations and in conscious efforts to organize" (Barnard, 1938, p. 139), and splits incentives into objective and subjective components: "We call the process of offering objective incentives 'the method of incentives' and the process of changing subjective attitudes 'the method of persuasion'" (p. 141). The second method, persuasion, would likely in today's terminology be determined unacceptable social engineering: "Persuasion in the broad sense ... includes (a) the creation of coercive conditions; (b) the rationalization of opportunity; (c) the inculcation of motives" (p. 149). Inculcation includes both the education of the young and propaganda for adults.

Levitt - Innovation in Marketing (1959)

Levitt was a Harvard professor with a quest to establish marketing as the leading management technique. Without directly stating it, Levitt builds a case for marketing to be the main plank of strategy. His treatise is not the result of empirical research, but he does support his own propositions with examples gleaned from his career. 
His delivery is prone to aphorisms, which give his assertions a somewhat provocative nature. For example: "Every statement addresses itself to a customer" (Levitt, 1962, p. 1), and "Selling is as basic to our society as metabolism is to life"(p. 2). He makes it clear that a problem exists with executives not really 'knowing' and suggests that the answer to this dilemma is marketing, which involves seeing things more clearly.

His definition of organization and process is conventional: "In order to determine where a company should be going, the following points need to be considered: (1) the company's competence ... (2) its history ... (3) its competition ... (4) the customer ..." (p. 78); but he makes it very clear that a marketing focus must override all other considerations: "The view that an industry is a customer-satisfying process, not a goods-processing process, is vital for all businessmen to understand" (p. 69). This assertion of the importance of marketing is justified through a variety of examples of successful and failed industries and/or companies. He also gives examples of a range of new technologies that would make industries obsolete in the short term, but even today, these have either not eventuated; are only just coming into fruition; or have failed to gain any traction (e.g. the replacement of the internal combustion engine with a battery-powered motor, and the introduction of negative ion machines to influence behaviour positively).

\section{Edith Penrose - The Theory of the Growth of the Firm (1962)}

Penrose was an economist living in a time when 'the theory of the firm' was unsophisticated and did not easily allow for growth. Her text aims to further develop economic theory of firm growth but, somewhat strangely, there is no interest in firms that do not grow: "Many firms do not grow ... I am not concerned with such firms" (Penrose, 1959/1966, p. 7). Further, she focuses on developing good predictive theory instead of well-justified theory (p. 3) as she considers growth in scenarios of merger, expansion, diversification and acquisition.

Penrose recognizes that firms are human and dynamic: "a firm is more than an administrative unit, it is also a collection of productive resources the disposal of which between different uses and over time is determined by administrative decision" (p. 24). While the effect of the limited cognitive ability of management is recognized, "the capabilities of the existing managerial personnel of the firm necessarily set a limit to the expansion of that firm in any given period of time" (pp. 45-46), in the end it is economic drivers of growth that are important: "It seems reasonable therefore, to assume that in general the financial and investment decisions of firms are controlled by a desire to increase long-run profits" (p. 29). 


\section{Problematization}

All three texts recognize either a gap in knowledge or a lack of human performance. Barnard and Penrose are particularly concerned with the lack of theory, while Barnard and Levitt are concerned that managers cannot do their jobs. These human concerns relate to a lack of perception and a lack of knowledge.

Barnard laments the lack of practical direction provided by sciences that, "are as a whole difficult to apply to more than a few aspects of personal experience in everyday affairs" (Barnard, 1938, p. 301). Additionally, there is a dearth of management literature, and Barnard is also concerned with sub-optimal organizational and human performance. He sees organizational failure as being normal: "successful coöperation in or by formal organization is the abnormal, not the normal condition" $(1938$, p. 5). He sees human performance as needing improvement: "One can hardly contemplate the passing scene of civilized society without a sense that the need of balanced minds is real and that a superlative task is how socially to make mind more effective" (p. 322). Barnard identifies specific issues throughout the text, including a lack of focus on organization, a lack of understanding of authority, and confusion between morality and responsibility.

Barnard raises these questions in (as he notes) a time that debated social and philosophical issues such as fascism, liberty, free-will, and collectivism. He adopts at times a functionalist approach, that he may have taken from his knowledge of Parsons, and displays a belief in the ability to control behaviour through manipulation, a belief that is aligned to the psychological behaviourism dominant at the time. He sees a 'right way' of doing things, that can be known.

But then, in a total about face, Barnard invokes 'forces unseen': "So among those who coöperate the things that are seen are moved by things unseen. Out of the void comes the spirit that shapes the ends of men" ( $p$. 284). Barnard seems caught between worlds of science and religion. Perhaps in 1938 this was a dilemma facing many people.

Levitt is more direct in identifying the failure of managers to think 'correctly': "It is that all too often neither the researchers nor the corporate bosses really know what they are trying to do" (Levitt, 1962, p. 9). Levitt suggests that the (then) contemporary malaise was a recent phenomenon: "[Expertness] is what old-time business entrepreneurs did before the advent of professional commercial research and the fetishes of scientific management" (p. 188). However, while Levitt may lament the foibles of scientific management, his belief in science borders on faith if taken literally. Such 'Enlightenment Thinking' or the belief that humans can control the world, is also reflected in Levitt's assertion that managers can see correctly: "All of them got into trouble ... because of their myopia" (p. 40).

Penrose takes a less critical stance, aiming instead to provide some theory of growth. However, she also shows a strong belief in the possibility of proper process: "In the ideal case, once an administrative framework has been created within which the 'bureaucracy' functions smoothly, ..." (Penrose, 1959/1966, p. 16). As one may expect with an economist, she believes in the ability to model behaviour and predict results. 
The problematizations show that the three authors believe in the possibility of rational solutions. This inference is supported through the authors' explicit recognition of scientific process, behaviourism, and functionalism.

\section{Conditions of Possibility}

The texts do not significantly rely on previous work, but are the authors' own work. This suggests that the strategy world was not yet defined and the authors had an open field. In their texts, the authors question the efficacy of contemporary knowledge, and their underlying mode is still 'Enlightenment Thinking' that will deliver correct solutions. As will be shown in analyses that follow, this is a common theme within the Classicists. It is also noted that Barnard had an extensive business background, while Levitt and Penrose were academics, with Penrose being an economist.

\section{Social Effects / Subjectivity}

All three authors believe, to some degree, in the ability of science to understand and control humanity. As highly influential texts, these texts would both strengthen beliefs in a scientific approach and promote its use. For Penrose, her science is specifically in the areas of economics, but for Barnard and Levitt, it is more a general view.

Additionally, in Barnard and Levitt, the 'superman manager' is posited. These treatments serve two purposes: 1) to increase belief in the need for and possibility of such men; and 2) to show the need for guidance from such supermen.

So what does this mean for the executive strategist? From Barnard and Levitt's texts, the strategist (if not already a superman) is needing to reach a higher level of performance and is suffering from a number of afflictions (poor sight, lack of mental ability). The executive is in need of salvation and perhaps some special treatment! 


\section{Foucauldian Summary}

Table 14: Foucauldian Summary - Early Pioneers

\begin{tabular}{l|l|l|l|} 
& Barnard & Levitt & Penrose \\
\hline Knowledge & executive abilities & marketing methods & economic models \\
\hline $\begin{array}{l}\text { Problematization } \\
\text { lack of theory }\end{array}$ & performance & lack of theory \\
\hline $\begin{array}{l}\text { Ponditions of } \\
\text { Possibility }\end{array}$ & business experience & academic experience & economics \\
\hline Social Effects & Broadens the field and lays the groundwork for multiple strategy discourses. \\
\hline Subjectivity & need to be superman & need salvation & - \\
\hline
\end{tabular}

The three early pioneers approach strategy differently, but share common themes of Enlightenment Thinking, lack of theory and performance problems, and the need to establish a strategy discipline and the role of strategists.

None of the early pioneers explicitly state a philosophical position, but they share the Enlightenment Thinking assumption that, through science, humanity can be understood and controlled, leading to better outcomes.

The problems they aim to solve are related to people performance and the absence of theory. Barnard, the experienced executive, shares his thoughts on formal organisation and how it can be made to be effective; Levitt suggests that business strategy is marketing, and should follow his mode of understanding customers; and Penrose introduces the concept of business strategy operating within an economic realm - an approach that was later even more developed by luminaries such as Michael Porter (see below). That authors expressed such new ideas without any significant justification is perhaps indicative of the nascent nature of their respective fields. While contemporaneous with developing social science and psychology literatures, the epistemology is one of everyday language as essentially were inventing their fields.

These texts provide multiple approaches to business strategy and are likely to have increased the possibility for a strategy discourse. They also open the space for a thinking strategist, even though for Barnard such a person is a superman, and for Levitt, such a person is a marketer. These texts are the beginning of the emergence of the strategist, but such a strategist will need expertise. 


\section{Cognition}

Chester Barnard - Functions of the Executive (1938)

Cognition is treated conceptually by all the texts, and also found to be important. Barnard discusses cognition conceptually as an aspect of general management, but not specifically with respect to strategy itself. Within this discussion, he recognizes the subconscious, logical/non-logical reasoning, and group cognition processes, but the ideal solution he promotes is simply stated as 'executives with intuition'.

Barnard explicitly recognizes the psychological concepts of the conscious and subconscious: "The acts of individuals may be distinguished in principle as those which are the result of deliberation, calculation, thought, and those which are unconscious, automatic, responsive ..." (Barnard, 1938, p. 185). These mental processes are conceptually split into logical and non-logical groups, but the ability of humans to be logical is limited: "The most interesting and astounding contradiction in life is to me the constant insistence by almost all people upon 'logic,' 'logical reasoning,' 'sound reasoning' on the one hand, and on the other their inability to display it, and their unwillingness to accept it when displayed by others" (p. 303).

Barnard, recognizing a social aspect of group processes through his consideration of organization, implicitly recognizes the thinking process of Designing, and postulates a constructionist view both of process and ideas: "Coöperation is a social aspect of the total situation and social factors arise from it. These factors may be in turn the limiting factor of any situation. This arises from two considerations: $(a)$ the process of interaction must be discovered or invented, just as a physical operation must be discovered or invented; $(b)$ the interaction changes the motives and interest of those participating in coöperation" (p. 60). However, Barnard does not go beyond this recognition to delve deeply into Design processes.

In his analyses, Barnard predominantly focuses on Strategizing, using concepts of types of reason; generating understanding; and intentions. What Barnard does not do is to link these concepts in any way to the innate ideas, or intuition, that he presents as being the epitome of goodness: “... executives are able to understand each other with very few words when discussing essential problems of organization, ..." (p. xxvii) and "Yet ... men of widely diversified businesses ... have seemed to show an understanding - or better, a sense - that is quite similar. To me it has long seemed probable that there are universal characteristics of organization that are active understandings, evaluations, concepts, of men skilled in organizing" (p. xxviii). While Barnard postulates a number of processes that organizations should follow (e.g. incentives, decision processes), how an executive becomes a great intuitive strategist is not described. But Barnard makes it clear that men of Barnard's standing have this ability, and it is good. Barnard covers many cognitive topics from a general management perspective. He does not try to relate the importance of cognition implicit in his comments to the development of highly effective intuitive managers that he sees as fundamental to success. 
Levitt - Innovation in Marketing (1959)

Levitt follows a similar dichotomy, but on very different terms. His key problem with the business world is lack of judgement, and specifically of 'perceiving', as clearly articulated in his concept of 'marketing myopia' and when he challenges the reader with statements such as: "But do you recognize ..." (p. 33). He considers cognition conceptually: "If thinking is an intellectual response to a problem, then the absence of a problem leads to the absence of thinking" (p. 47), and he finds that perception is not easily obtained: "All this is very complicated, and it obviously requires people of unique capabilities" (p. 133). There is a strong realist inference that perfect vision is possible and that things can be seen 'properly'.

This inability to perceive is especially important in Strategizing: "The inability or refusal of companies to see the opportunities..." (p. 15). This perceiving theme reoccurs throughout the text, but Levitt has no process for developing such skills, relying instead on innate capabilities: "and probably the best method of proceeding is to appoint a task force of carefully selected people who are known for their imaginativeness, audacity, and their rather cosmopolitan interests and competence ..." (p. 126). So Levitt, like Barnard, sees a problem and has a solution, but these are not connected.

Edith Penrose - The Theory of the Growth of the Firm (1962)

Penrose presents a picture of organizations and people within organizations. She treats cognition conceptually: "Knowledge comes to people in two ways. One kind can be formally taught ... the second form in which knowledge appears ... I have called experience" (Penrose, 1959/1966, p. 53); and identifies general cognitive concepts concerning learning and judgement: vision, perception, human reason, knowledge, experience and imagination. Examples are: "[The firm] is a complex institution ... generally directed in the light of human reason" (Penrose, 1959/1966, p. 9) and "It is clear that this opportunity will be restricted to the extent to which a firm does not see opportunities" (Penrose, 1959/1966, p. 32). These ideas are presented in early chapters of the text, and then abandoned in the more serious matter of economic analysis. Cognition is recognized, but only when establishing organizational Context. 


\section{Cognition Summary}

Table 15: Cognitive Summary - Early Pioneers

\begin{tabular}{l|l|l|l|} 
& Barnard & Levitt & Penrose \\
\hline Summary & innate abilities & need vision & important \\
\hline Type of Abstraction & conceptual & conceptual & conceptual \\
\hline Subject & managers & managers & managers \\
\hline Mind & conscious \& subconscious & conscious & conscious \\
\hline Thinking Process & Strategizing & Strategizing & Strategizing \\
\hline Thought Content & - & - & - \\
\hline
\end{tabular}

While the three authors recognize important aspects of cognition, cognition is only conceptually discussed in everyday language, and that is where it ends - solutions are not cognitive.

All three authors recognize thinking as being important. Barnard sees the innate thinking qualities of leaders as being core to solving the challenges of business. Levitt laments the lack of good perception as the problem, and proposes good perception as being necessary for good outcomes. Penrose firmly recognizes cognition as being important, and recognizes rational minds in her economic theory.

When treated, cognition is treated conceptually, the subject is the manager, the mind considered is almost always the conscious mind, and the process considered is Strategizing. Thought Content is rarely considered.

Treatments of cognition are conceptual, not phenomenal or operational. Barnard considers concepts of logical/non-logical reasoning, and suggests that good performance is based on the 'innate capabilities' of executives. Levitt infers the desired outcome in terms of perception. Penrose understands cognitive capability as an enabler/constraint, and recognizes the importance of cognition. All use everyday terms to discuss cognition as a concept.

Most considerations of cognition centre on the subject of the executive, although Barnard certainly recognizes the cooperative nature of organizations. However, this is simply a recognition of the existence of group processes and he does not propose any solutions or give any advice on how to improve cooperation in firms. So the subject of cognition, or the cognifier, is the manager. None of the authors reify the company when discussing cognition, although Penrose - the economist - reifies the company as an economic unit in her theories.

Throughout the three texts, the mind considered is the manager's conscious mind, with only one isolated mention of the subconscious by Barnard. 
In all texts, the Strategizing process has a greater focus than Thought Content. This focus includes how to incentivise the staff, how to drive marketing, and how to understand growth. While there are some mentions of Context knowledge, Strategy knowledge and Intentions are not mentioned.

The formation of the views described above follows what may well be a normal human approach to thinking: we are aware of thought, but we do not actively engage in thinking about thought. The authors are aware of cognition, and the importance of cognition, but without any other theories presenting themselves the authors go no further, simply thinking as any person, when reflecting upon cognition, might think about cognition.

Beyond the recognition of cognition, these three authors see people as either requiring instruction or as economic units. Cognitive approaches are not developed to provide the salvation to the problems of business; instead methods such as use of management techniques, prediction of economic outcomes, and marketing are presented. Like the subject of B F Skinner's behaviourism (see Benjamin Jr, 2014, pp. 155-159), the executive mind is only incidental to the action. While cognition is recognized, it plays no part in any solution.

\section{Early Pioneers Summary and Provisional Insights}

The authors share an Enlightenment attitude of being able to understand and control the world. They assume problems in Strategy knowledge for which they propose various methodological solutions. This helps to establish the field of Strategy and the role of Strategists.

Within these discussions, cognition is recognized and highlighted, but never approached directly or intimately. Instead of delving into the workings of the mind, the authors respectively retreat to simple innate ideas, propose a methodology, or define business theories. Cognition is treated as being important, but is not approached directly, nor is it seen as a potential medium for any solution. It is implicit in context, but not explicit as a way forward. Therefore, a provisional insight is:

C1 Cognition, even when recognized as important, is not part of strategy solutions.

This provisional insight is reconsidered later in the summary of this chapter. 


\subsection{Early Theorists}

The authors of the initial canons of Classical strategy are well-known names. These highly-cited texts represent some of the starting points of the Classical strategy discourse. They are Alfred D. Chandler Jr's Structure and Strategy (Chandler, 1962), H. Igor Ansoff's Corporate Strategy (Ansoff, 1965), Russell L. Ackoff's A Concept of Corporate Planning (Ackoff, 1970), and Kenneth R. Andrews The Concept of Corporate Strategy (Andrews, 1971).

\section{Foucauldian Analysis}

Knowledge

Alfred D. Chandler Jr. - Structure and Strategy (1962)

Chandler presents, in a comprehensive style, an insightful and empirical historical study of the development of American multi-divisional enterprises, which is both compelling and useful, as well as adding to the theory of strategy. The text is a history. It defines four eras: the initial empire building before 1900; an adaptive response to create central, functionally departmentalized organisations; a growth phase driven by technology and population expansion that resulted in diversification and geographical expansion; and a so-called creative innovation that created the multi-divisional organisation. The focus of the text is primarily upon the fourth era and the creation of multi-divisional organizations.

The relationship between Structure and Strategy is the central theme of the text. He starts with the thesis that structure follows strategy: "The thesis deduced from these several propositions is then that structure follows strategy" (Chandler, 1962, p. 14). But through the detailed analysis of the history of four large enterprises (du Pont, General Motors, Standard Oil, Sears and Roebuck), Chandler concludes that, based on these companies, structure can follow strategy, but often is significantly delayed. He further adds to this position to suggest the strategy and structure have a common driver in market demand: "The comparison [of the four companies studied] emphasizes that a company's strategy in time determines its structure and that the common denominator of structure and strategy has been the application of the enterprise's resources to market demand" (p. 383). 
H Igor Ansoff - Corporate Strategy (1965)

$\mathrm{H}$ Igor Ansoff, a mathematician by training, presents an intricate and complex method for developing corporate strategy. In Ansoff's era, a general question was how a firm should grow. Ansoff assumes that diversification is almost mandatory: "If the problem cannot be solved within the limit of the present productmarket position, presumption is strong that the firm has to diversify" (Ansoff, 1965, p. 140). For Ansoff, the key strategy question is 'the decision': "In summary, this book provides a practical method for strategic decision making in a business firm" (p. ix).

Ansoff creates two structures, the Product-Market Scope and Growth Vector Components. The former is essentially just a definition of present markets and products, but the latter, shown below, is his well-known $2 \times 2$ matrix. Ansoff utilizes these structures when building a process that allows firms to determine, within myriad different market opportunities, how a firm should grow.

\begin{tabular}{|c|c|c|}
\hline Mission & Present & New \\
\hline Present & $\begin{array}{l}\text { Market } \\
\text { penetration }\end{array}$ & $\begin{array}{l}\text { Product } \\
\text { development }\end{array}$ \\
\hline New & $\begin{array}{l}\text { Market } \\
\text { development }\end{array}$ & Diversification \\
\hline
\end{tabular}

Figure 17: "Growth Vector Components", reproduced from Corporate strategy: An analytic approach to business policy for growth and expansion (p. 99), by H. I. Ansoff, 1965, New York, NY: McGraw-Hill Book Company. Copyright McGraw Hill, 1965, 1968.

He does this using an iterative method, similar to a linear-programming approach he would know well as a mathematician: "the adaptive search method ... [formulates] a product market strategy for a firm. Its salient characteristics are (1) a "cascade" procedure of successive narrowing and refining the decision rules (2) feedback between stages in the cascade, (3) a gap-reduction process within each stage, and (4) adaption of both objectives and the starting-point evaluation" (p. 24). While this may seem relatively straightforward, the actual implementation is somewhat startling when displayed as below. 


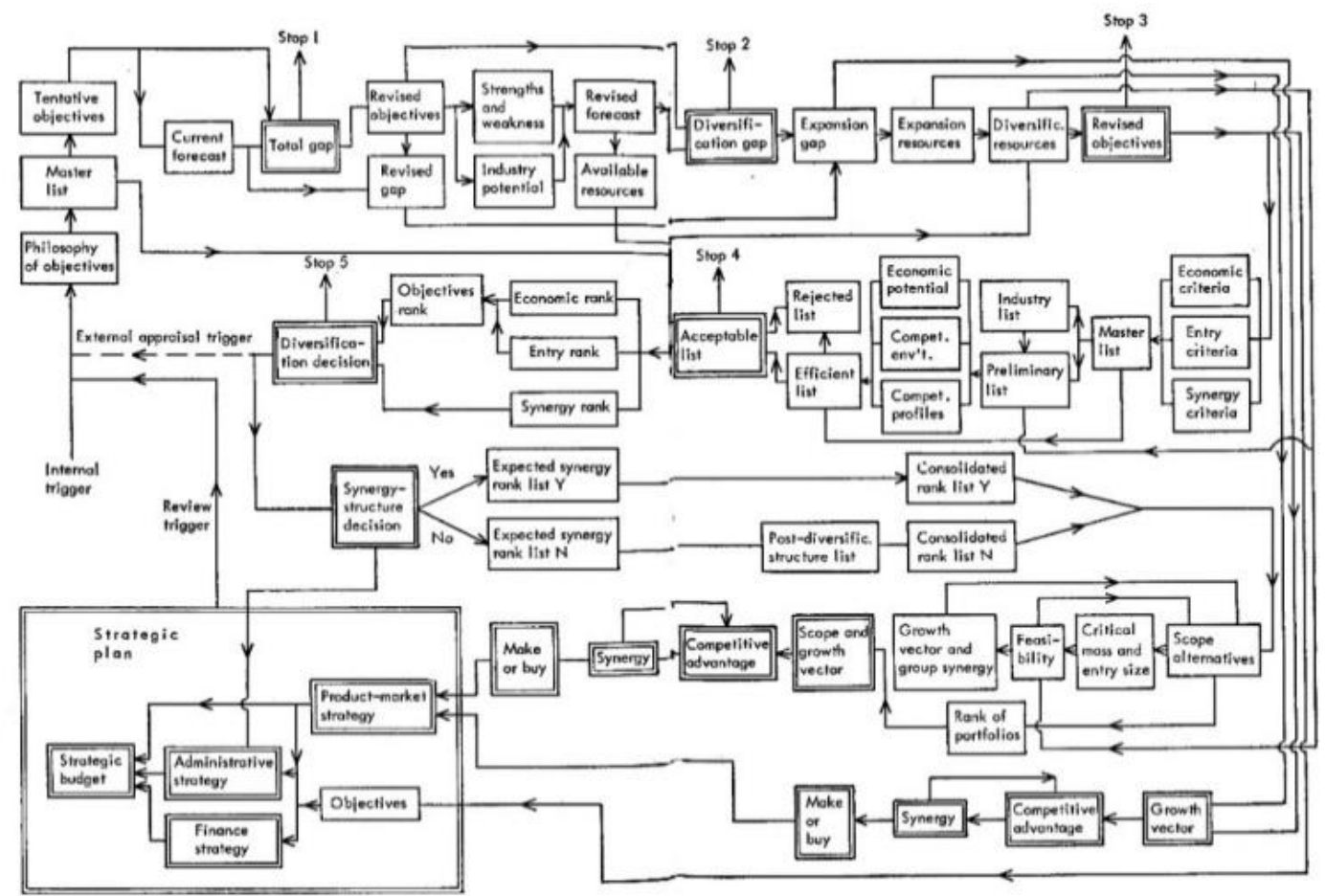

Figure 18: "Decision flow in product-market strategy formulation", reprinted from Corporate strategy: An analytic approach to business policy for growth and expansion (pp. 202-203), by H. I. Ansoff, 1965, New York, NY: McGraw-Hill Book Company. Copyright McGraw Hill, 1965, 1968.

Ansoff also covers and refines a broad spectrum of strategy concepts. These include strengths and weaknesses, synergy, fit, competencies, competitive advantage, partial ignorance, vertical integration, and horizontal diversification.

\section{Russell L. Ackoff - Concept of Corporate Planning (1970)}

Russell Ackoff was one of the founding fathers of operations research. His corporate planning text is an eclectic mix of a standard planning approach, philosophical approaches, and the modelling of solutions for all problems. His starting point is standard: "The parts are ... 1. Ends: specification of objectives and goals. 2. Means: selections of policies, programs, procedures, ... 3. Resources ... 4. Implementation ... 5. Control" (Ackoff, 1970, p. 6). Ackoff then takes a philosophical slant: "There appears to be three dominant philosophies. ... which I shall call satisficing, optimizing, and adaptivizing" (p. 6). These philosophies are not full-blown philosophies but are limited to defining the level to which a strategist wants to aim for better performance. Satisficing, deriving from Simon (1997), is simply being limited to a satisfactory solution, optimizing to go further with performance, while adaptivizing is to consider new ways for a firm to function.

Modelling is the answer in multiple scenarios. Modelling approaches, with an operations research flavour, are suggested for the second two philosophies and the planning parts 1-5 above. For optimizing, simulation can be used. Adaptivizing essentially looks for alternatives beyond current processes but uses numerical analysis to consider proposals. Ends, or goals, can be modelled to provide accurate measures. Means can be selected if the strategist first knows how 'the system functions'. Such knowledge comes through modelling. Resources, 
such as personnel, can be modelled (e.g. call volumes). Implementation can be preceded by modelling of the organization. Control systems can be modelled and lead to 'correct information' for managers.

In a somewhat bizarre twist, Ackoff leaves it to the second to last paragraph to recognize the need for contextual knowledge: “Executives and managers on planning review boards are usually quite aware of deficiencies in their knowledge and understanding of aspects of the business and its environment. In such cases I have found it useful to arrange seminars and discussion sessions..." (p. 137). This almost complete lack of focus on gaining contextual knowledge is not apparent in Ansoff, who does specify internal and external appraisals as parts of his strategy process.

Kenneth R. Andrews - The Concept of Corporate Strategy (1971)

Kenneth Andrews' text draws much of its substance from Business Policy: Text and Cases (Learned, Christensen, Andrews \& Guth, 1965) and its revised 1969 edition. As three of the four authors were professors within the Graduate School of Business Administration at Harvard University, The Concept of Corporate Strategy (Andrews, 1971) can be taken as a reliable source of the Harvard model.

The view of strategy presented includes many of the structures and concepts of strategy that one might expect, but also a surprising ethical stance. Strategy is part of Business Policy that aims to resolve four wellknown problems: "[The problems of Business Policy studied include] the choice of objectives, the moulding of organizational capability and character, the definition of what needs to be done, and the mobilization of resources for the attainment of goals" (p. viii). Strategy has elements of formulation/implementation, competence, strategy/structure, management by objectives, resources, and leadership (pp.

$37,97,181,205,219,238)$. Strategy is the driver behind all decision making in these conceptual topics, as it drives what a company is or becomes: "corporate strategy is the pattern of major objectives, purposes, or goals and essential policies and plans for achieving those goals, stated in such a way as to define what business the company is in or is to be in and the kind of company it is or is to be" (p. 28).

Andrews suggests that Strategy has four components: "the four components of strategy - (1) market opportunity, (2) corporate competence and resources, (3) personal values and aspirations, and (4) acknowledged obligations to sections of society other than stockholders" (p. 38).

The fourth component, obligation to society, is the subject of the largest section of the book "The Company and Its Social Responsibilities: Relating Corporate Strategy to the Needs of Society" (pp. 118-179). In an era when corporate responsibility was a matter of some debate, Andrews quotes a view from economist Milton Friedman: "that the doctrine of social responsibility is a 'fundamentally subversive doctrine' in a free society" (p. 123). Andrews explicitly disagrees: "praise by Milton Friedman of classical capitalism cannot justify either company or town behaviour in their destruction of priceless public property" (p. 129), as he sees the scope of corporate responsibility to extend beyond the company to society. 


\section{Problematization}

For Chandler, the problem is a lack of data and a lack of theory to make the obvious apparent: "Yet the historians have provided social scientists with little empirical data on which to base generalizations or hypotheses concerning the administration of great enterprises. Nor have the historians formulated many theories or generalizations of their own" (Chandler, 1962, pp. 1-2). Chandler's text aims to create the required theory, based upon empirical research. This is not just for theory's sake, but to avoid economic inefficiency: "One important corollary to this proposition is that growth without structural adjustment can lead to economic inefficiency" (p. 16).

Chandler does not explicitly describe the basis of his approach, other than using Schumpeter's concept of 'innovation vs adaptive response' to suggest that proactive strategy is better than simply reactive behaviour. He is primarily a historian and empiricist. He takes no fixed positions, nor does he reveal any deep influences.

Ansoff suggests that the time is right to develop a comprehensive approach: "In summary, both the conceptual foundation and the tools of methodology are now at hand for an attempt at a comprehensive 'strategic decision theory of the firm'”' (p. 21). The foundations and tools include US military doctrine, business world developments (Andersen, Ansoff, Drucker, Gilmore and Brandenburg, Kline, Levitt, Novick, Staudt, Steiner, Tilles, Weston, and Fayol), and cognitive science (H. A. Simon and A. Newell). The problem is that such a synthesis has not yet been done: "The purpose of this book is to synthesize and unify these into an overall analytical approach to solving the total strategic problem of the firm" (p. viii).

Ansoff's solution is based upon scientific knowledge, especially mathematics. He specifically invokes game theory: "The bridge to business usage [from strategy's historical origin in military arts] was provided in 1948 by Von Neumann and Morgenstern in their now-famous theory of games" (p. 118). He also recognizes behaviourism, and concludes that, "If our strategic decision theory were to be compared with others, we suggest that it is a behavioural theory" (p. 206).

Ackoff believes in scientific method, and sees a future in which science-based approaches solve complex problems: "As yet we cannot optimize complex structures relative to complex problems" (p. 13). He maintains special places for management science, operations research, and behaviouralism: "In my concept of the management sciences and operations research, the behavioural sciences play a major role. Without the participation of behavioural scientists many of the procedures discussed cannot be carried out effectively" ( $p$. viii). However, within these sciences, planning is in confusion: "There is also confusion over what a plan should contain, how planning should be conducted and organized, and what values can be derived from it" (p. vii).

Andrews sees large problems of performance that are created by a lack of good managers and a lack of good support. He is clear that the United States of America (USA) can do better: "a clear majority of businesses, in even the most sophisticated economy in the world, are mismanaged in some obvious and preventable ways" (p. 7). Part of the problem is the lack of good managers: "a scarcity of requisite management ability is felt in all 
earnest and honest organizations" (p. 7). Industry support is seen as problematic, as its conventional wisdom is hardly that at all: "The advice [the general manager] will be offered most persistently by his seniors will be the conventional wisdom of the industry" (p. 12). The support from management science and other disciplines is also problematic: "[the general manager] may well encounter management scientists who will claim or imply that operations research, simulation, mathematical modeling, statistical decision theory, and such other approaches made possible by the computer can make important improvements in operating efficiency and a more orderly consideration of alternative future courses of actions" (p. 13), and "The conceptual apparatus of special disciplines - economics, anthropology, psychology, sociology, and the like - do not produce balanced appraisals, understandably enough, of environmental developments relevant to business decisions" (p. 69).

At the time, economies were experiencing strong growth, as highlighted by Chandler's history. Within this period of growth, the four authors agree broadly that company performance is far from optimal, strategy is far from complete, and new developments are required. Chandler highlights the challenges of supporting diversification, and Ansoff aims to solve this. Andrews is quite clear that he does not recognize the central issue to be diversification: "Diversification is often an illusory diversion from the opportunities a company is best able to capitalize" (Andrews, 1971, p. 40). Ansoff and Ackoff propose scientific solutions, which Andrews rejects, as highlighted in a comment that may have been directed at Ansoff's use of decision rules: "A man contemplating strategic decision must be willing to make it without the guidance of decision rules. He must have confidence in his own judgment, which will have been deepened and seasoned by repeated analysis of similar questions" (Andrews, 1971, pp. 175-176).

Ansoff, Ackoff, and Andrews aim to fill that 'strategy gap' with approaches aligned to their own personal philosophies (Chandler does not promote any solution). While they agree on the general problem, they also seem to see each other's approaches as potentially being part of the problem, with Andrews rejecting the scientific approach of Ansoff and Ackoff, and these two belittling the cognitive relevance of both Chandler's and Andrew's strategist.

\section{Conditions of Possibility}

In similarity with the Early Pioneers, the Early Theorists have academic backgrounds and share Enlightenment thinking. That they can promote quite different approaches highlights the absence of an accepted orthodoxy, and highlights the opportunity for promotion of new and distinctive approaches. 


\section{Social Effects / Subjectivity}

The Early Theorists established concepts and techniques that are live today. They provide a basis for strategists to exist, but without a singular view of the strategist's role.

Chandler does not suggest any revolutionary approaches to strategy and management. His purpose is to understand the historical relationship between structure and strategy, and to provide better knowledge so that mistakes can be avoided. He sees managers in the same light as managers in the preceding 50 years. For him, the great machine of industrial enterprise continues on, and managers merely need to become somewhat more aware of the past in order to gain better futures.

For Ansoff, in the text reviewed, the future lies in the use of mathematics to understand business better. Strategists simply need to follow the method to make good decisions. While Ansoff recognizes 'partial ignorance', he sees that mathematical methods can be used to avoid or minimize the risks of poor decisions. After he has dismissed the mind as an object of research he further limits the mind to being a processor of instructions.

Ackoff see strategists as both 'scientific processors of methods', and as 'cognitive beings with judgment and intuition'. But he indicates that, over time, we should evolve to become fully scientific processors. For the strategist, the future is to engage in science and methods.

By contrast, Andrews seeks to explicitly address the strategist. While there is a defined strategy process, he sees the mind of the strategist as the arena for strategy development. He firstly suggests that strategists have judgment: "The process described thus far assumes that the strategist is analytically objective in estimating the relative capacity of his company and the opportunity he sees or anticipates in developing markets" (Andrews, 1971, p. 47). He then goes on to look at how we might develop our own psyches: "The object of this selfexamination [of our own values] is not necessarily to endow us with the ability to persuade others to accept the strategic recommendations we consider best: it is to acquire insight into the problems of determining purpose and skills in the process of resolving them" (p. 116). This is almost Zen in character - by understanding one's own values one can better understand the process of defining purpose better, and also develop skills to do it better. This is a focus on Learning and on stepping back to widen the strategist's perspective to consider more than the process of Strategizing.

So strategy, in these texts, has some beacons of light. For the strategy world, there are more methods and ways to proceed. Thus, the field can expand and become more embedded. But a strategist in the early 1970s could easily be confused. What should one do? Perhaps follow a methodology, work with mathematic formulae, model everything, and/or train one's mind? The early classical strategy discourse offered many alternatives. 


\section{Foucauldian Summary}

Table 16: Foucauldian Summary - Early Theorists

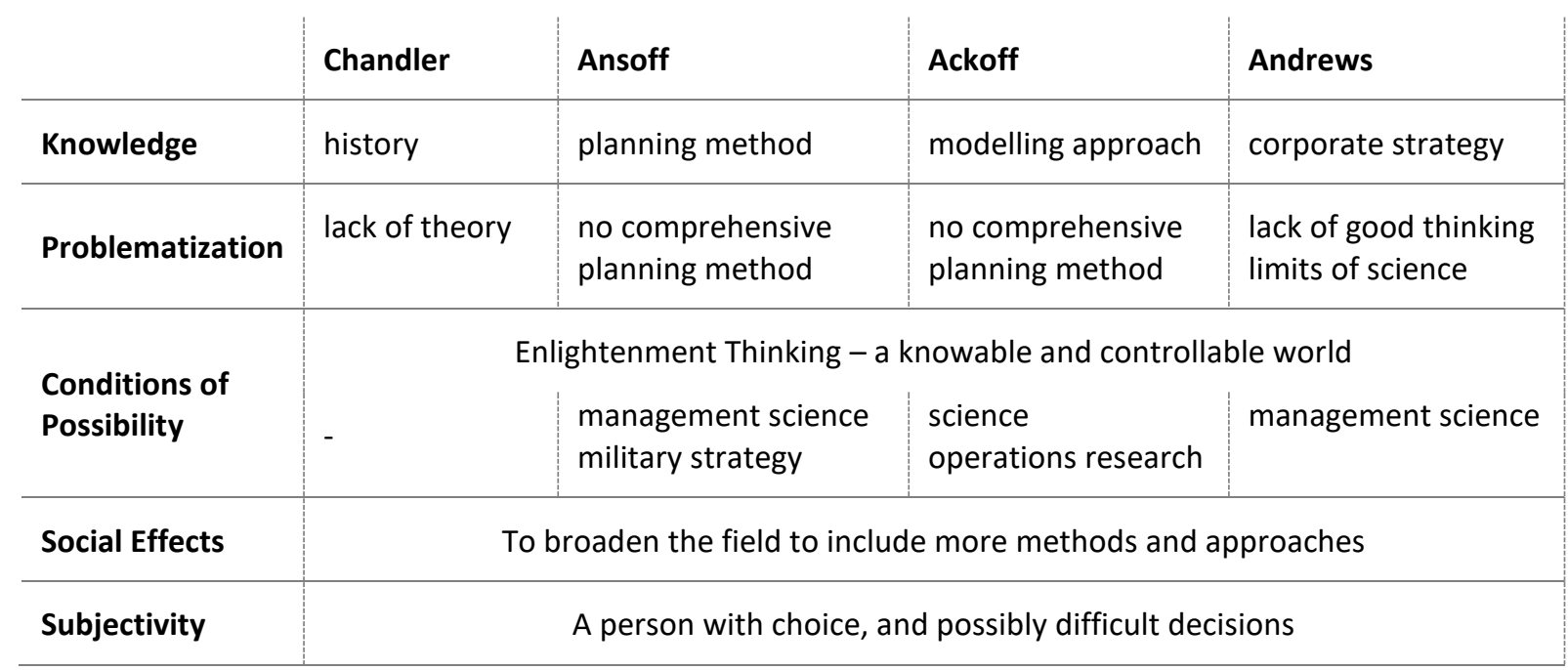

The Early Theorists share the same confidence as the Early Pioneers in the ability to understand and control. However, they recognize a broader background of scientific approaches including management science, military strategy, and operations research.

Even with a large theoretical base to call upon, when compared with the Early Pioneers they perceived a vacuum of strategy. All authors agree that companies should be better, and that more theory is required. All confirm an environment of economic growth and, with the exception of Chandler, aim to provide answers as to how companies should do better. But they are different: Chandler, the historian, finds insights into the relationship of structure and strategy; Ansoff, based upon an iterative evaluation process, focuses on the problem of diversification; Ackoff, the operations research guru, finds operations research solutions in many areas of the strategy process; and Andrews, the Harvard professor, promotes a traditional process of strategy, but one reliant on the judgment of seasoned professional managers. However, they have two very different approaches, depending on the author's belief in the applicability of scientific method to business. Chandler and Andrews focus on executive capability over science (Andrews explicitly questions the value of science), whereas Ansoff and Ackoff assume that science will prevail.

Thus, these Early Theorists' texts legitimize both scientific and judgement-based approaches to business strategy, and contribute to a broadening of the business strategy discourse. Aligned with these dual approaches, how a strategist might be perceived varies widely, from an open mind to a processor of scientific method. The strategist is left to choose between following the science lead or learning to think better, or to do both. The historian, the mathematician, the operations researcher, and the Harvard professor all elaborated business strategy, and opened up different strategy paths and careers for strategists. 


\section{Cognition}

In these four texts, treatments of cognition vary from 'avoid', to 'necessary', to 'assumed', and to 'central'.

\section{Alfred D. Chandler Jr. - Structure and Strategy (1962)}

Chandler pays little attention to cognition, but when he does he focuses on Strategizing operational issues, and recognizes the breadth and importance of managers' cognitive abilities. He takes a conventional operational approach to the scope of managers: "Just what, then, are the functions of the executive ... They coordinate, appraise, and plan" (Chandler, 1962, p. 8). But Learning is also mentioned, beyond the Strategizing represented in the above statement, through the ways that executives learn to operate in new ways: "[studies in organizational organization] trace the way in which executives worked out, often slowly and painfully, new methods and means for coordinating, appraising, and planning the effective use of vast, and varied assortments of money, men, and materials" (p. 4). So Chandler recognizes cognition somewhat, but the major focus is on describing the historical development of four companies. His position on cognition appears to be limited to and aligned with that of a du Pont report from March 1912 that he quotes: "The answer is that the controlling individual need not know every detail of the business, but require [sic] only a good mind, sound judgment, and knowledge of general business principles'” (p. 71).

\section{H Igor Ansoff - Corporate Strategy (1965)}

Ansoff explicitly contracts out of any consideration of cognition: "[One approach], and by far the more ambitious one, is to discover how people in general, and executives in particular, make decisions individually or in groups. ... This direction which goes under the general name of decision theory, has received much attention for many years from diverse scientific disciplines: philosophy, psychology, mathematics, and economics. It is a testimony to the difficultly of the problem that all of these efforts have produced very few results. ... Instead of exploring the mind of the manager, this [text] explores the business firm" (p. 2). So while he makes a few fleeting references to cognition when considering Strategizing, the focus is on methods and techniques, not on minds.

\section{Russell L. Ackoff - Concept of Corporate Planning (1970)}

Ackoff's view of cognition, from operational and conceptual perspectives, is an odd mix of general recognition, a scientific basis to Strategizing, a few mentions of Designing and Learning, and a view on understanding Context. He recognizes the concept of wisdom in operational planning for the future: "Wisdom is the ability to see the long-run consequences of current actions, the willingness to sacrifice short-term gains for long-run benefits, and the ability to control what is controllable and not to fret about what is not" (Ackoff, 1970, p. 1). He also conceptually considers the need for judgment and intuition when scientific knowledge cannot make a decision: "Judgment and intuition must be used to support the rest" (p. 64).

Notwithstanding Ackoff's recognition of cognition, it is clear that he sees that the future of Strategizing is found in processes of scientific thinking: "[Advancing planning] is not the only place that scientific methods and common sense, and technology and judgement, are required to share the same bed. The more corporate 
planning is pushed from satisficing to adaptivizing, the greater the requirement for scientific methods, techniques, and tools" (p. 21). This is because, conceptually, science gives better understanding: "Understanding is most effectively captured in explanatory models of the system involved" (p. 63).

Ackoff briefly recognizes the opportunity to Design and sees it as being scientific: "A procedure for making group decisions can be completely specified..." (p. 99). He also briefly acknowledges Learning, when lamenting that strategists are transfixed by evaluative processes and not the creative processes that yield insights: "The evaluation of alternative courses of action is a preoccupation of many planners. Unfortunately, this preoccupation frequently precludes their involvement in what is often a more fruitful activity: inventing, designing, or otherwise creating new alternative courses of actions or policies" (p. 43). This is somewhat ironic, given that Ackoff proposes his own evaluative procedure.

Also, commensurate with his belief in method, is a desire to understand strategy Context: "The key to both creating and evaluating courses of action and policies lies in understanding the system involved: that is, in the ability to explain its behavior" (pp. 43-44). A key part in understanding Context is to understand constraints: "Policy innovation depends critically on our ability to bring these self-imposed constraints into question. The most effective way of which I am aware for systematically reviewing such constraints..." (p. 59).

\section{Kenneth R. Andrews - The Concept of Corporate Strategy (1971)}

Andrews, more than the other three authors analyzed in this sub-chapter, stresses cognition as a fundamental aspect of strategy, from conceptual and operational perspectives. He primarily does this in a general sense invoking various cognitive capabilities. He also discusses Learning of insight and applies general cognitive capability to Strategizing, and specifically to Context.

Conceptually, he favours individual experience over academic or science approaches: "[W]e prescribe the point of view of the practitioner rather than that of the scholar or scientist - the thinking, intelligent, and learning practitioner, it should be said at once - not the complacent and obsolescent intuitionist" (Andrews, 1971, p. xi). Here Andrews calls out the old intuitionists pedalling conventional wisdom, and he promotes the thinking practitioner. This ability is more important that entrepreneurship and knowledge of process: "We admire quick response to opportunity and entrepreneurial energy, but we intend to apply mind and judgment to such elemental gifts" (p. xii), and "The ability to identify the four components of strategy ... is nothing compared to the art of reconciling their implications in a final choice of purpose" (p. 38). The conceptual cognition that Andrews promotes is multi-faceted. It includes creativeness: "changing patterns in work and leisure mean ... work which emphasizes slide-rule efficiency less and initiative, creativeness, and variety more" (p. 65). It includes judgment and perception: "The evaluation of strategy is as much an act of judgment as is the original perception" (p. 53). It is conscious: "conscious strategy can be consciously implemented through skills primarily administrative in nature" (p. 181). Reasoning is important: "But with the assignment of sufficient analytical brainpower to the [assessment of opportunity] a degree of order can be imposed upon the range of alternatives available" (p. 84). 
Along with these mind skills, Andrews also allows for the creation of frameworks: "to offer a conceptual framework for thinking about the problems that confront the general manager" (p. 2). However, given that these skills and models do not guarantee success, as cognition is limited, he recognizes challenges of process: "When the range of what must be known exceeds the capacity ... of a single mind, and when the range of a company's activities spans many industries and technologies, the problems of formulating a coherent strategy get out of hand" (p. 86).

Andrews does not consider knowledge about Strategy or the statement and maintenance of Intentions, but instead he applies cognition within processes to understanding Context, even if this is very superficial compared to later theorists: "To identify the less obvious or by-product strengths of an organization ... one might well begin by examining the organization's current product line and by defining the functions it serves in its markets", and "The way, then, to narrow the range of alternatives is to match opportunity to competence, once each has been accurately identified and its future significance estimated" (p. 100).

As Andrews summarizes, mind skills are fundamental: "Far more important than the intelligence, integrity, energy, and courage which their assignments require and which are hard enough to find are the skills of mind and action which convert these qualities in quite individualistic ways into impressive performance" (p. 15).

Andrews also believes that good thinking can be learnt: "The limitations of the concept of strategy consist principally then of the inherent difficulties of conceiving an original pattern of goals and policies and implementing them wisely. Dealing with these limitations effectively means not abandoning the concept, but learning to use it successfully with reasonable perspective on what is possible" (p. 47). Andrews does not develop the idea further, possibly due to a limited epistemological basis for cognition at the time. As he lists no sources, it is likely that the source for the cognitive terms he uses was his own introspection (e.g. reason, perception, etc.), and he questioned such introspection: "Despite the well-known problems of introspection" (p. 116). This perceived epistemological weakness may have prevented him from delving further, even if this was desired.

In a similar vein, when Andrews discusses Strategizing, it is purely to apply thought to it: "But with the assignment of sufficient analytical brainpower to the [assessment of opportunity] a degree of order can be imposed upon the range of alternatives available" (p. 84). Cognition, as analytical brainpower, is applied, but no more detail is entered into. 


\section{Cognition Summary}

Table 17: Cognitive Summary - Early Theorists

\begin{tabular}{l|l|l|l|l|} 
& Chandler & Ansoff & Ackoff & Andrews \\
\hline Summary & assumes & rejects & recognizes & fundamental \\
\hline Type of Abstraction & operational & - & $\begin{array}{l}\text { conceptual } \\
\text { operational }\end{array}$ & conceptual \\
operational
\end{tabular}

Here there are four authors and four different treatments of cognition, but the texts have a common focus on Strategizing, and a consistent lack of deep engagement with cognition.

Ackoff and Andrews offer some high-level conceptual views discussing wisdom, judgment, intuition, reason, and perception. All authors, with the exception of Ansoff who avoids cognition, consider operational aspects of cognition. Such considerations are about decision making in periods of days or weeks and not a phenomenal view of cognition work in situ.

The focus is primarily on the individual decision-maker. Chandler focuses on the executive; Ackoff, in the few moments when he ventures beyond method, concentrates on the individual planner; and Andrews, like Chandler, focuses on the executive. The focus is on the conscious mind, although Andrews discusses cognitive processes in depth, and gets close to the subconscious without ever venturing into tacit knowledge or similar topics.

What is common is that cognition is recognized as an important component of Strategizing, albeit from two different perspectives. Ansoff and Ackoff clearly promote scientific thinking, whereas Chandler assumes, and Andrews implicitly recognizes, the utility of the thinking strategist. While they are mentioned, Designing and Learning are not significant topics for any of the authors.

All the authors, to some extent, promote the understanding of Context knowledge, whether this be by scientific method or through intuition. It seems to be a principle preoccupation, while knowledge of Strategy is hardly ever touched upon, as if it should be second-nature. Perhaps the authors, especially Ansoff and Ackoff, simply assume that their texts supply the required Strategy knowledge. The other Thought Content element, Intentions, are assumed; the focus is on formulating them, not on how they exist, evolve, or are implemented. 
These Early Theorists appear to have formed their views of cognition in different manners. Chandler, the historian, takes his chosen companies as a guide to cognitive knowledge. Ansoff and Ackoff are science driven, even though it takes them into different places. For Ansoff, it is to reject cognition in his quest for method, but for Ackoff it is to accept cognition, but to focus on scientific thinking. Andrews' ideas appear to form through his own observations and cognitive abilities. He rarely ascribes his ideas to others and, presumably, within his role as an academic, he had the opportunity, desire, and responsibility to state his own thoughts as he perceived them.

So there are four treatments of cognition: Ansoff dismisses cognition as something not to study; Chandler assumes its efficacy; Ackoff sees it as necessary when science cannot prevail; and Andrews goes much farther in seeing it as central to strategy and describing the use of specific cognitive faculties when strategizing. All authors focus on Strategizing and, with little focus on Learning or Design, there is no indication of how a strategist might utilize or develop cognitive ability beyond the methodologies described. The primary goal is to enable individuals to better comprehend Context, but how they perceive Strategy or how Intentions operate are not topics of consideration. Unlike the Early Pioneers, the Early Theorists treat cognition both conceptually and operationally.

The major differences in treatments of cognition reflect a distinction between scientific thinking and judgment. While all four authors recognize the existence and importance of cognition in some form, their epistemological approaches vary; Ansoff and Ackoff stress scientific method, whereas Andrews stresses mind and judgment, and Chandler recognizes judgment.

Like the Early Pioneers, the Early Theorists go no further than commentary on thought; cognition is an adjunct to method and process, which become their major concern. 


\section{Early Theorists Summary and Provisional Insights}

In contrast to the Early Pioneers, the Early Theorists introduce scientific thinking as a legitimate approach, and consider cognition operationally and not just conceptually. But like the Early Pioneers, the Early Theorists find cognition important, and then go no further - cognition is not part of their solutions.

An easy assumption to make is that the Early Theorists would promote a consistent view of strategy and the strategist, and to a certain extent that is correct - there is a core progression of purpose, opportunities, competencies, and plans that all authors adhere to in some degree. But business strategy is perceived differently as thinking executives (Chandler, Andrews) and scientific method (Ansoff, Ackoff). Business strategy develops based on different principles and often borrowing from other fields. The discipline of business strategy has more alternatives and the strategist's role becomes more secure - if also more complex.

Within these treatments of strategy, cognition is treated differently. Ansoff simply ignores cognition, Ackoff and Andrews respect cognition, and Chandler assumes cognition. Chandler and Andrews follow a similar approach to Barnard, seeing the judgement of executives as being of primary importance. While cognition is occasionally treated operationally, the predominant approach is to discuss cognition conceptually. For Thinking Processes, the focus is on Strategizing and, for Thought Content, the focus is on Context.

No relationship is discernible between the two approaches to strategy, thinking executives and scientific method, and corresponding treatments of cognition. Of the thinking executive approach, Chandler simply assumes cognition while Andrews embraces it as being fundamental. Of the two scientific method approaches, Ansoff ignores cognition while Ackoff embraces it. This suggests another provisional insight:

C2 Treatment, or non-treatment, of cognition is independent of strategy approach. 


\subsection{Systems Builders}

The System Builders are highly recognized names who institutionalized many practices of business strategy.

The texts are George Steiner's Strategic Planning (Steiner, 1979), Michael Porter's Competitive Strategy

(Porter, 1985), Michael Goold and Andrew Campbell's Strategies and Styles (Goold \& Campbell, 1987), and

Gerry Johnson and Kevan Scholes' Exploring Corporate Strategy (Johnson \& Scholes, 1984)

\section{Foucauldian Analysis}

\section{Knowledge}

George Steiner - Strategic Planning (1979)

The sub-title of Strategic Planning (Steiner, 1979) is "What Every Manager Must Know". This aptly summarizes Steiner's view of the planning process which Steiner helped develop in his career as an academic and as a business consultant. For Steiner, planning is central to management, and "superior management knows how to develop planning systems to suit their needs" (p. 43). According to Steiner, planning had reached maturity: "I believe that our knowledge of formal strategic planning is sufficient to permit every manager to develop and implement a system appropriate to his circumstances" (p. 341). Steiner presents his own view of planning in the figure below (p. 17):

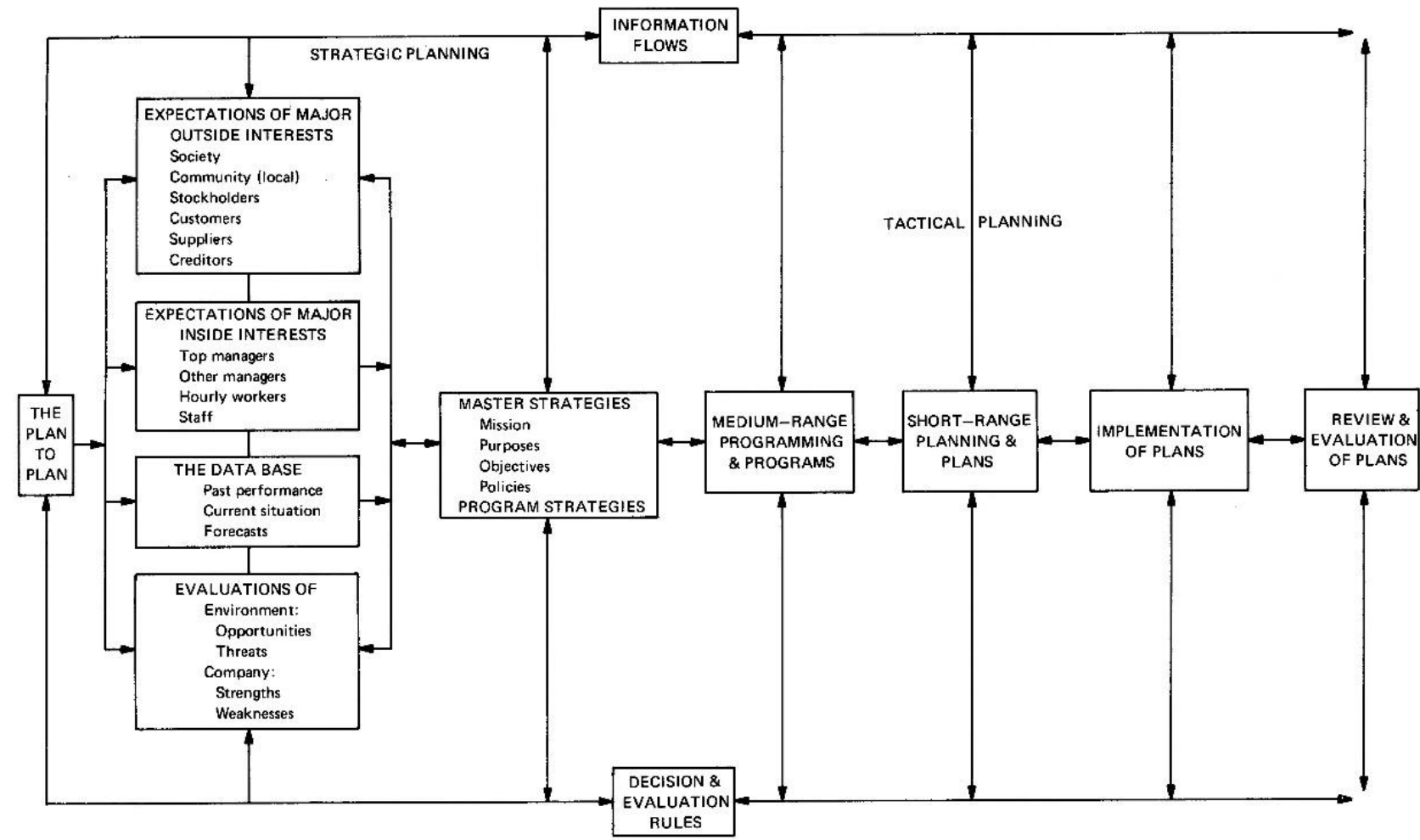

Figure 19: "Structure and Process of Business Companywide Planning", reprinted from Strategic Planning, by G. A. Steiner, 1979, New York, NY: The Free Press. Copyright 1979 by The Free Press. 
He lists his and five other methods: "there are fundamentally a number of different planning patterns. ... intuitive-anticipatory, formal strategic planning, day-to-day reactive planning, entrepreneurial opportunistic planning, incremental muddling through, and the adaptive approach" (p. 120). Steiner sees all these as having applicability at different times, but his focus is purely on strategic planning. He describes, in-depth, multiple aspects of strategic planning, from the situation audit to contingency planning.

But such strategic planning is not a fixed formula, and Steiner goes to some length to indicate that planning must be tailored to individual organizations: "there is no single planning model for all organizations" (p. 34), and "Companies go through life cycles and the planning system will vary depending upon the stage in the life cycle" (p. 78). This necessitates planning the plan, which is explicitly recognized: "Once managers have decided what they wish to get from their planning system it is crucial that the details be carefully thought through. This is the plan to plan" (p. 59).

\section{Michael Porter - Competitive Strategy (1985)}

Like George Steiner's subtitle discussed above, the subtitle of Michael Porter's Competitive Strategy (Porter, 1985) is illuminating. It is "Techniques for Analyzing Industries and Competitors". Porter, a Harvard academic, created strategy analysis techniques based on his PhD thesis in industrial economics.

He defines the goal of competitive strategy in terms of the position of a company in an industry: "The goal of competitive strategy for a business unit in an industry is to find a position in the industry where the company can best defend itself against these competitive forces or can influence them in its favour" (p. 4). Mintzberg et al. (1988, pp. 81-85) placed Porter as a prime proponent of 'The Positioning School', although this moniker somewhat understates Porter's provision of multiple frameworks, tools, and processes for in-depth and detailed analysis.

The frameworks include the five forces model and three generic strategy types known throughout the Western business world (Porter, 1985, pp. 3,6,35). These are far from the only structures defined, with further structures for barriers to entry, competitor diagnostics, industry environments, and decision types (pp. $7,48,189,299)$. As presented, the whole text is a series of lists, as Porter describes industry types and strategy decision types in deeper detail. These series of descriptions are more than pure economics, as Porter provides justifications and examples based upon his own perceptions and experiences doing industry analysis. The frameworks themselves are to be used in combination for analysis of industries: "The full range of analytical techniques and concepts presented elsewhere in this book should be combined with the concepts in this chapter [Competitive Strategy in Fragmented Industries] to draw conclusions about competitive strategy in any particular industry" (p. 192).

\section{Michael Goold and Andrew Campbell - Strategies and Styles (1987)}

Michael Goold and Andrew Campbell are both academics and business consultants who have worked in large businesses and in government in the United Kingdom. Through an empirical study of 16 large companies 
(interviews with executives, information gathering, attending meetings), they aim to contribute to knowledge of how the centre of multidivisional companies 'contribute to company performance', and how this may be proactively driven in the future.

In Strategies and Styles (Goold \& Campbell, 1987), eight styles of management approach are defined for large companies, that essentially describe how the central administration interfaces with business units and/or subsidiaries: "We have found our classification both clarifies the options for the centre and describes the main differences in approach that companies take" (p. 293). Three styles are found to be predominant: "We have identified eight different management styles. Three of these, Strategic Planning, Strategic Control and Financial Control, are the most popular amongst large UK companies today" (p. 293). The text focuses on these three styles, producing many examples from the 16 companies studied, and concluding that matching strategies to management styles is essential: "Understanding what strategies fit most comfortably with each style is therefore essential in making strategic choices" (p. 295).

\section{Gerry Johnson and Kevan Scholes - Exploring Corporate Strategy (1984)}

These two British authors created a textbook for use in strategy courses in educational institutions (Johnson \& Scholes, 1984). In 2017, the $11^{\text {th }}$ edition was published.

The presentation of strategy in Exploring Corporate Strategy focuses on what strategy is, strategy decisions, and formulation of strategy (p. xi). Characteristics of strategy are scope of an organization's activities, matching organisation to environment, matching activities to resources, resourcing, values, long-term, and complexity (pp. 6-9). Three levels of strategy are defined: corporate, competitive or business, and operating levels (pp. 9-10), and three main levels of strategy are defined: strategic analysis, strategic choice, and strategic implementation (p. 10). These are extensively developed as methods and structures.

While the content described above constitutes the bulk of the text, the importance of people is stressed many times: "to understand how strategy comes about, it is essential to understand organisational culture and managerial values and attitudes" (p. 25), and "The 'economic' analysis of organisations fails to recognize the important role which people play in the evolution of strategy" (p. 116).

\section{Problematization}

As the Systems Builders texts fill out the strategy discipline, identification of problems occurs but is not a high priority.

George Steiner finds no real problem with strategy, but sees it more as an opportunity created since so many companies were using planning: "Since [the mid-50s] formal planning has matured until virtually all large companies around the world have some form of system and an increasing number of smaller companies are following the example" (Steiner, 1979, p. vii). But while many companies were using planning, a formalization of planning was necessary to counter a changing environment and clarify the role of the CEO: "Changing 
environment is a major factor influencing the introduction of formal planning in many countries" (p. 36) and "the proper role of the chief executive officer in strategic planning is far from clear" (p. 80).

In his text, Michael Porter only once states the problem: "the emphasis in formal strategic planning processes has been on asking these [strategic] questions in an organized and disciplined way rather than on answering them" (Porter, 1985, p. xiv). The problem is in 'solving these strategic questions' and Porter assumes that industrial economics is the solution. Other possible methods, such as the product life cycle, are found to be of questionable utility as they lack any underlying rationale: "And except for industry growth rate, there is no underlying rationale for why the competitive changes associated with life cycle will happen" (p. 162).

Porter provides no justification for his claims. It is assumed that industrial organizational economics is correct and the book is simply an outcome of Porter's own work in the area: "This book ... grows out of my research and teaching in industrial organization economics" (p. ix). Porter's recognition game theory (p. 68) shows that he has a belief in scientific method and the ability to model the world with some accuracy.

For Goold and Campbell (1987) there is a lack of theory. Multidivisional companies are highly complex and, within that context, the authors wish to "to seek an improved understanding of the reality of corporate decision making" (p. 5). The basis for this is a belief in the power of empirical research. While the authors are careful not to claim any innate rightness to their theories, there is the sense of a belief in an underlying rationality: "Some styles are unsatisfactory" (p. 294) and "Different styles follow from different assumptions about the nature of the successful company" (p. 296). The authors do not claim to have the truth, but they give the impression that it exists, and that they have the ability to shed some light upon it.

Johnson and Scholes (1984) briefly cite the problem as being, "the inability of managers to think strategically" (p. xi). Thus, in one small sentence in a short preface to the textbook, the authors situate the problem in the realm of cognition. However, as described above, the bulk of the textbook concerns processes and structures.

So Steiner sees the problem as an opportunity to synthesize planning approaches, while Porter sees a need for an analytical tool based on industrial economics. For Goold and Campbell, the issue is a lack of managerial understanding, and Johnson and Scholes simply assume that a comprehensive view of strategy is required.

\section{Conditions of Possibility}

The conditions of possibility within which these books were written is a strategy field ripe for development and that seemingly does not require justification of a need. These conditions include a number of scientific fields that can be borrowed from, which include organizational studies, psychology, Industrial economics, and management science. As strategy developed, it also developed a penchant for borrowing from other disciplines, although a consistent and underlying theme of Enlightenment Thinking is always present. 


\section{Social Effects / Subjectivity}

The four texts reinforce strategy in different ways, but all add to the establishment of strategy as a discipline.

Steiner promotes planning. In his 1979 text he brings together a number of strands of planning and was, as Mintzberg (1994, p. 47) suggests, "less a ground breaker than a populizer of generally accepted views of planning." The very act of producing such a comprehensive volume serves to reinforce the validity of planning. For the strategists, the role is to be part of a large strategy planning team working to create plans. This is not the world of an entrepreneur; it is the world of systematic practitioners working to methodologies such as those Steiner defines.

Michael Porter (1985) promotes economic and scientific views of the business world. The strategist/economist sits outside the firm/industry with the capability to understand the world in economic and organizational terms, and to make sound decisions.

The influence of Goold and Campbell (1987) is more subtle. Their detailed study suggests that the world can be handled at a macro level and that good strategic outcomes originate from enlightened leaders. Their subject matter is large 'ships of enterprise', and the message is that major decisions of strategic style can be made and are fundamental to success. Within such a business world, the strategist stands at the helm, working with the captain to keep the enterprise on course.

Johnson and Scholes (1984) stress the role of the strategist, but predominantly promote a series of processes and techniques for doing strategy. A strategist's thinking is fundamental, and the answer is a series of techniques.

Planning and industry analysis are established by Steiner and Porter respectively. These are part of a broader package, as promoted by Johnson and Scholes, while Goold and Campbell suggest how the enterprise can be managed from the top. The texts show how the strategy discourse expanded with many more options.

The strategist now has much to learn, but discipline is elaborated, entrenched and validated. 


\section{Foucauldian Summary}

The texts of the System Builders consolidate and extend business strategy.

Table 18: Foucauldian Summary - Systems Builders

\begin{tabular}{|c|c|c|c|c|}
\hline & Steiner & Porter & $\begin{array}{l}\text { Goold \& } \\
\text { Campbell }\end{array}$ & Johnson \& Scholes \\
\hline Knowledge & planning & analytical tools & multi-divisional & general approach \\
\hline Problematization & $\begin{array}{l}\text { need for } \\
\text { comprehensiveness }\end{array}$ & lack of tools & lack of theory & $\begin{array}{l}\text { lack of strategic } \\
\text { thinking }\end{array}$ \\
\hline \multirow{2}{*}{$\begin{array}{l}\text { Conditions of } \\
\text { Possibility }\end{array}$} & \multicolumn{4}{|c|}{ Enlightenment Thinking - a knowable and controllable world } \\
\hline & $\begin{array}{l}\text { organizational studies } \\
\text { psychology }\end{array}$ & $\begin{array}{l}\text { industrial } \\
\text { economics }\end{array}$ & - & $\begin{array}{l}\text { management science } \\
\text { sociology } \\
\text { psychology } \\
\text { organizational studies }\end{array}$ \\
\hline Social Effects & \multicolumn{4}{|c|}{ To further entrench and systematize strategy as a legitimate field } \\
\hline Subjectivity & \multicolumn{4}{|c|}{ To professionalize strategists, with accompanying requirements for expertise } \\
\hline
\end{tabular}

Steiner (1979), the planner, consolidates his and others' planning approach into a single volume. Johnson and Scholes (1984) take a generalist approach to strategy. Porter (1985) presents a tool set for evaluating industries, based upon economics. Goold and Campbell (1987) look at large multi-divisional organisations, in a similar manner to Chandler (1962), searching for insights into how to how such structures can be made effective. The strategy field finds room for more approaches: there is space for texts that focus on planning, positioning, and multi-divisional strategies, and on strategy in general.

None of the authors state a compelling real-world business problem that needs a strategy solution; they see the need to consolidate and develop further the business strategy field instead. Porter is the most radical, introducing a new wave of thinking about industries, but only to avoid limitations of previous techniques such as the Product Life Cycle.

The conditions of possibility remain consistent with the two previous analyses, in a general Enlightenment approach. There are no post-modern excursions, but instead there is more expansion into the use of other science-based approaches. These enable the strategy discipline to grow and provide more tools for the strategist. 


\section{Cognition}

Treatments of cognition vary from Steiner's conceptual recognition, to Porter's silence, to Goold and Campbell's cursory approach, and finally to Johnson and Scholes' modelling.

\section{George Steiner - Strategic Planning (1979)}

Steiner considers cognition conceptually, with input from a number of other theorists, and as Learning and Strategizing. At a conceptual level, intuition is at the forefront of planning: "there is no superior approach to strategy identification than a brilliant intuitive mind" (Steiner, 1979, p. 188). Steiner presents a conceptual cognitive framework developed by McKenny and Keen (1974) that shows varieties of styles: "managers have preferred cognitive styles for collecting and evaluating data. ... systematic perceptive, systematic receptive, intuitive perceptive, and intuitive-receptive modes" (p. 120). He also quotes a number of organizational theorists and psychologists regarding their views on the issue of authority, what inhibits performance, groupthink, psychological forces, and resistance.

Steiner records a number of such observations regarding Strategy knowledge and Learning. He finds that firms need to learn about strategy, especially the process of planning: "every manager should be able to identify those major elements, methods, and practices of disciplines that affect his or her area of planning and should have at least a conceptual understanding ... of [the strategic planning process]" (p. viii) and "an executive planning system can be designed and introduced only after top management has a clear understanding of strategic planning" (p. 78). While Steiner presents many views on how people behave based upon the work of other experts, the solution he finds for developing Strategy knowledge is his planning method, which is not a cognitively-focused solution but a procedural solution.

Even though cognition is not part of his solutions, Steiner still stresses the role of cognition in Strategizing: "However, formal planning cannot be done without management intuition" (p. 11) and "strategic planning is more of a thought process, an intellectual exercise, than a prescribed set of processes, procedures, structures, or techniques" (p. 14). Further, this type of thinking is different to everyday thinking: "Planning involves a different type of mental process from that generally employed in dealing with day-to-day operations" (p. 46). But while it is critical to generate understanding and use good judgment, again Steiner offers no method of achieving such better results.

\section{Michael Porter - Competitive Strategy (1985)}

Michael Porter (1985) is almost totally silent on cognition. He also rarely mentions people. Those few quotes that he makes are to simply recognize cognitive processes, such as perceiving, in Strategizing processes. His techniques for analysing industries and companies exist within his own models of the business world, and he does not consider the mind of the strategist, and seldom the mind of the manager. 


\section{Michael Goold and Andrew Campbell - Strategies and Styles (1987)}

While Goold and Campbell (1987) recognize the conceptual importance of cognition sparingly throughout the text, the importance of cognition is highlighted in many quotes from managers interviewed and, in a strange twist, business organizations are personified.

Their treatment of Strategizing is conceptual and brief: "four ideals that distinguish companies whose strategic decision making is successful. These are: 1 Matching style to business circumstances, 2 Understanding the business, 3 Openness and mutual respect, 4 Energy and common purpose" (p. 12). While the authors recognize the importance of understanding, the extent of the authors' cognitive recommendations is the introduction of fresh ideas: "the tendency for managers to fall into habits of mind ... The most effective way of dealing with the "habits of mind' pitfall is to introduce fresh ideas and opinions continuously" (p. 183).

While Goold and Campbell's own words have minimal reference to cognition, the quotes included from interviews often highlight the cognitive element of strategy: "Basically it comes back to backing your market judgment", "to think more broadly from time to time", "You get far more out of people if they can see and understand", and "If they had known more about the business,..." (pp. 3, 90, 114, 170). These and other comments reflect concerns with how people think, or don't think, in various ways.

It is therefore somewhat surprising that the authors do not discuss these concerns further, but then go beyond such phenomenal examples to the world of high conceptual abstractions as they personify companies and business units: "The centre determines what strategies", "the extent to which the centre feels it understands a proposal", "If the centre feels that a business ...", and "management perceives that control objectives are now tightly enforced" (pp. 55, 62, 67, 99). The first and last of these quotes, while suggesting that there is a thinking central thing, could be interpreted as a group of individuals working together who develop agreements over time. However, the second and third quotes attribute feelings to such an entity. It is highly unlikely that everyone of a management team has common feelings, and more unlikely that these could easily be shared with researchers.

Gerry Johnson and Kevan Scholes - Exploring Corporate Strategy (1984)

In Exploring Corporate Strategy Johnson and Scholes (1984), drawing upon a number of other theorists, conceptually consider the individual who understands strategy Context, and operationally consider and model Strategizing processes (various models are shown - see Cognitive Models, p. 86, for definitions of these model types).

Johnson and Scholes stress the importance of the individual and recognize many conceptual cognitive capabilities that pertain to understanding Context: "it is much more to do with developing a sensitivity both to an increasingly turbulent environment and the expectations of those involved in organizations", "Strategic analysis is concerned with understanding", and "The awareness of a strategic problem usually occurs at an individual level" (pp. xii,12,33). 
They also recognize the influence of environment in determining individual values: "There are three major sources of influence on an individual's values; external influences, the nature of the business and the company culture" (p. 118).

In the figure below, a Cognitive Influence Model depicts values of individuals and other factors influencing company strategy. The defined arrows of the model suggest causality. The overriding impression is that cognition by individuals, as values, is only one of many influences upon strategy.

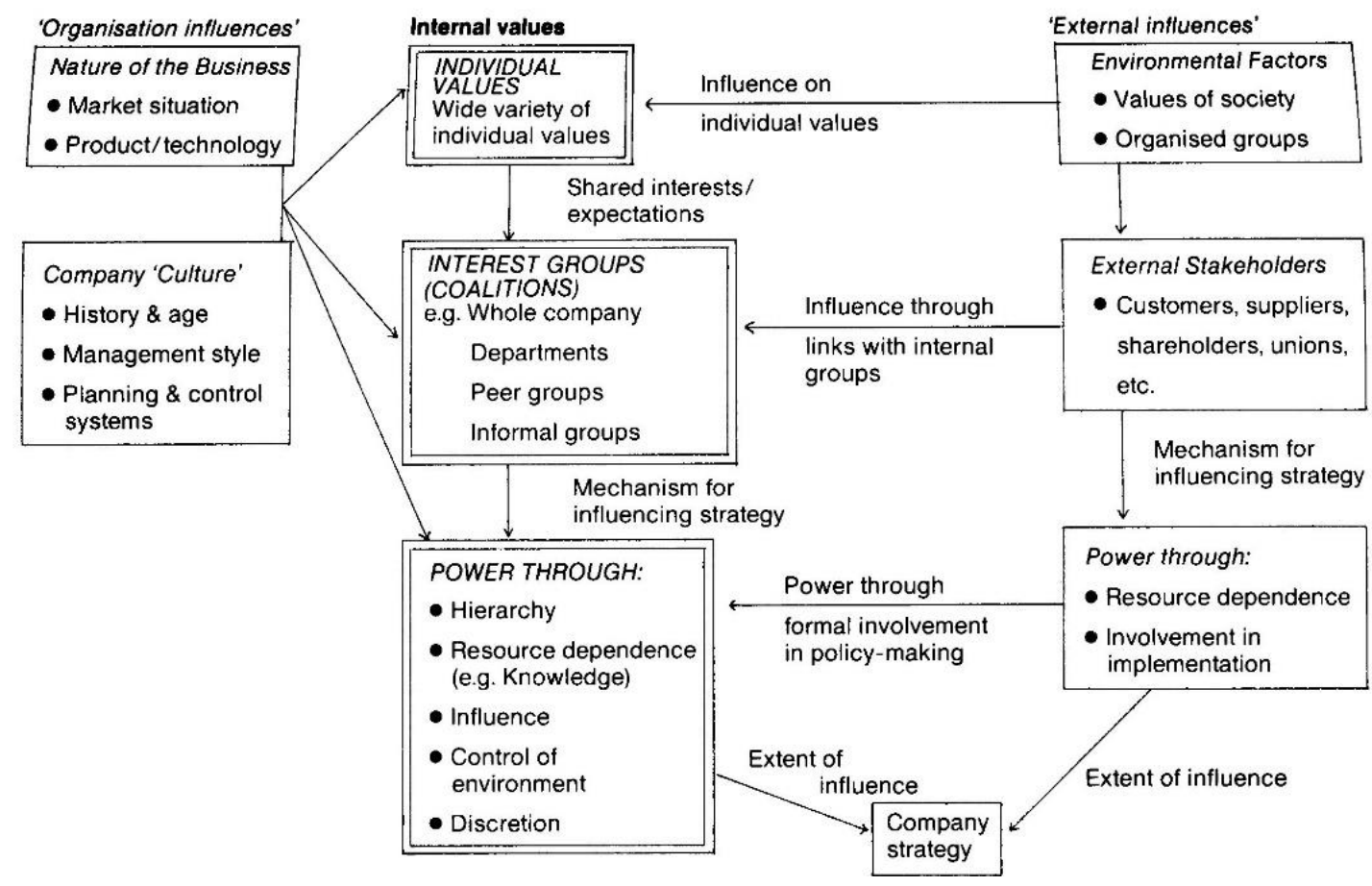

Figure 20: "How values influence company strategy", reprinted from Exploring corporate strategy (p. 117), by G. Johnson, \& K. Scholes, 1984, Englewood Cliffs, NJ: Prentice/Hall International. Copyright 1984 by Gerry Johnson and Kevan Scholes. 
In the figure below, a simple Cognitive Influence Model shows "what is likely to influence objective-setting" ( $p$. 145). This model includes strategists' perceptions and expectations amongst a number of other aspects. Again, individuals are part of the process, but driven by other influences. These two Cognitive Influence Models, above and below, show that cognition, even if recognized as being critical, is primarily viewed as just another conceptual factor.

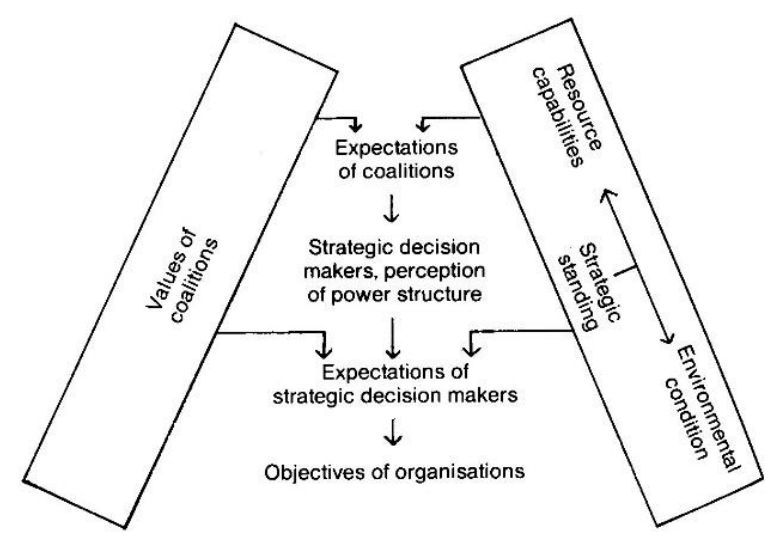

Figure 21: "Influences on objective setting", reprinted from Exploring corporate strategy (p. 146), by G. Johnson, \& K. Scholes, 1984, Englewood Cliffs, NJ: Prentice/Hall International. Copyright 1984 by Gerry Johnson and Kevan Scholes.

Cognition is also treated operationally, as Strategizing. Johnson and Scholes rely on a number of theorists when considering decision making (Mintzberg, Quinn, Cyert and March, Miles and Snow, and Spender). Based on much of these theorists' research, the cognitive process of decision making is seen as systematic: "the evaluation process should provide managers with a sound understanding ... to discuss the various steps which a systematic evaluation can follow" (p. 204). Such processes are modelled by the authors.

For example, in the Cognitive Process Model below, Johnson and Scholes depict Strategizing decision processes based on "research evidence which exists to help provide an answer to this question [of how decisions are taken]" (p. 32).

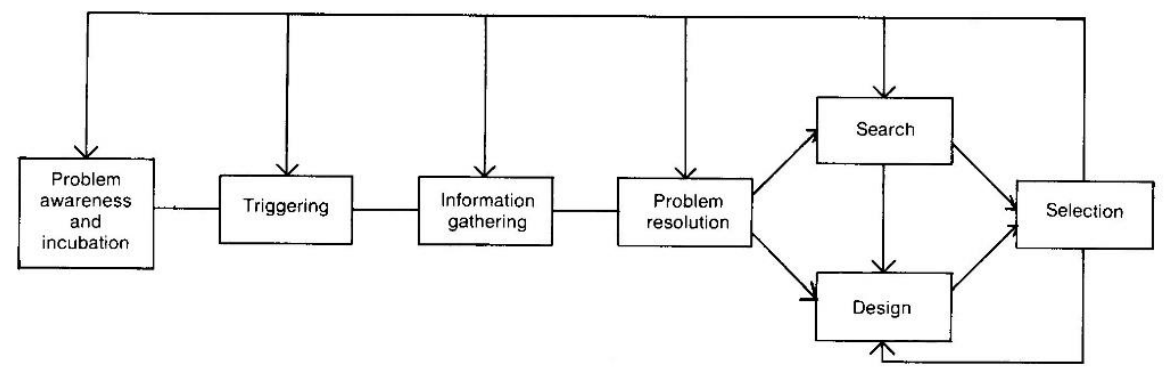

Figure 22: "A model of the strategic decision process", reprinted from Exploring corporate strategy (p. 34), by G. Johnson, \& K. Scholes, 1984, Englewood Cliffs, NJ: Prentice/Hall International. Copyright 1984 by Gerry Johnson and Kevan Scholes. 
And, in the Cognitive Process Model below, simple cognitive terms of 'assess' and 'identify' are included in this model of environmental analysis.

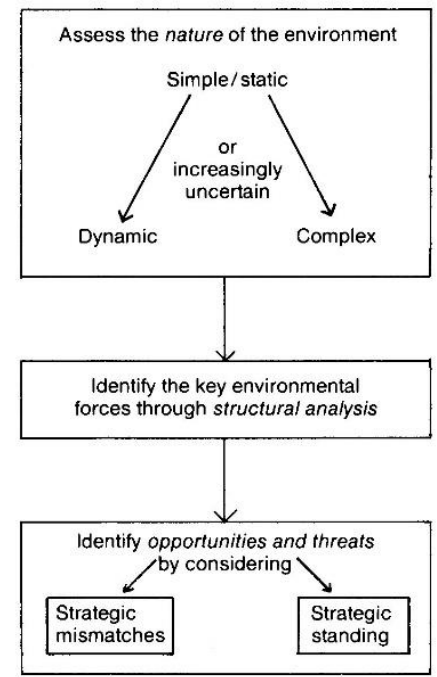

Figure 23: "An approach to environmental analysis", reprinted from Exploring corporate strategy (p. 57), by G. Johnson, \& K. Scholes, 1984, Englewood Cliffs, NJ: Prentice/Hall International. Copyright 1984 by Gerry Johnson and Kevan Scholes.

Three points stand out in Johnson and Scholes. Firstly, cognition is one factor among many. Secondly, the previous Cognitive Process Models suggest that the cognitive processes are linear processes that are discoverable. At a minimum, the authors believe that treating the individual as a cog is appropriate and that there is utility in presenting strategy process in these ways. Thirdly, while the models provide frameworks for structuring much of the text itself and for promoting abstract conceptual reflection, this is the limited extent to which cognition is treated. 


\section{Cognitive Summary}

Table 19: Cognitive Summary - Systems Builders

\begin{tabular}{|c|c|c|c|c|}
\hline & Steiner & Porter & Goold \& Campbell & Johnson \& Scholes \\
\hline Summary & essential & hardly mentioned & a sidebar & essential \\
\hline Type of Abstraction & conceptual & - & conceptual & $\begin{array}{l}\text { conceptual } \\
\text { operational }\end{array}$ \\
\hline Subject & managers & - & $\begin{array}{l}\text { managers } \\
\text { firms }\end{array}$ & managers \\
\hline Mind & $\begin{array}{l}\text { conscious } \\
\text { subconscious }\end{array}$ & - & conscious & conscious \\
\hline Thinking Process & $\begin{array}{l}\text { Strategizing } \\
\text { Learning }\end{array}$ & - & Strategizing & Strategizing \\
\hline Thought Content & Strategy & - & - & Context \\
\hline
\end{tabular}

In the System Builders, treatments of cognition vary. Three of the authors treat cognition conceptually, with two, Steiner and Johnson and Scholes, quoting theorists from disciplines with cognitive focus (psychologists, organizational theorists), treat cognition with some reverence and find it essential to strategy. Steiner focuses on understanding and intuition, and touches on the possibility of the subconscious, while Johnson and Scholes discuss the need for individual understanding when discovering Context, but see cognition as only one factor among others. Goold and Campbell only provide brief conceptual comments.

Johnson and Scholes further provide a series of Cognitive Models that suggest what Strategizing actually is. These models have some utility by suggesting possible relationships between activities and ideas, but the models are essentially gross generalizations without any critique or justification. It is noteworthy that in the sixth edition of the Johnson and Scholes' text (Johnson \& Scholes, 2002), these models are not present, or are only presented in a highly simplified form.

Two minor anomalies stand out from the treatments reviewed up to this point. Steiner is the first theorist to explicitly consider Learning processes that develop Strategy knowledge. While this is only treated in a few sentences, no other theorist has yet even mentioned the issue. Secondly, Goold and Campbell are the first to reify the company as a thinking thing. To this point, cognition has been of individuals, not of the firm.

All of these treatments form in a similar time period, but the background knowledge structures vary considerably. Those theorists who have generally taken from the humanities, Steiner and Johnson and Scholes, specifically provide some commentary on cognition. Porter, coming from economics, ignores cognition, whereas Goold and Campbell, without any defined theoretical basis, simply treat cognition in everyday terms. 


\section{The Systems Builders Summary and Provisional Insights}

Within these four systems builder texts, strategy tools are consolidated and, fuelled by an expansion of other disciplines into business strategy, new tools and ideas are added to the strategy discourse. The underlying belief system is still scientific method, based upon Enlightenment Thinking, and strategy is expanded. The System Builders further establish business strategy as a field of techniques and approaches.

Cognition now gets more focus. Steiner is clear, like Barnard and Andrews, that the mind of the manager is allimportant. He even manages to allow some human theories into a book that is filled with planning techniques. Johnson and Scholes likewise quote many theorists and even develop their own models. Porter is mostly silent on cognition, and Goold and Campbell are brief. And when treated, cognition is treated narrowly and conceptually as Strategizing, in some alignment with the Early Pioneers and the Early Theorists. And, uniformly, strategy solutions are primarily methodological without any specific in-depth cognitive elements.

In the previous two sub-discourse analyses, provisional insights were made. Here, for the System Builders, no new provisional insights are discerned and, hence, none are presented. 


\subsection{Specialists}

Four authors are considered under the rubric 'Specialists' as they focus on either a specific problem or a specific technique: Bruce Henderson, in Henderson on Strategy, focuses on tools developed for the consulting industry; the topic for Rosabeth Moss Kanter, in The Change Masters (Kanter, 1983), is change relating to structure; Kees van der Heijden, in Scenarios: The Art of Strategic Conversation (van der Heijden, 1996) considers the use of scenario planning; and Clay Christensen, in The Innovator's Dilemma (Christensen, 1997) is concerned with disruption.

\section{Foucauldian Analysis}

\section{Knowledge}

Bruce D Henderson - Henderson on Strategy (1979)

Bruce Dolin Henderson founded the Boston Consulting Group in 1963. This text (Henderson, 1979) is a series of articles that were mailed to clients over a ten year period. Henderson clearly has a wide-ranging mind, as he covers general business issues, strategy, and economics. Much of his writing, devoid of supporting material in such brief articles, comes across as a series of aphorisms, but notwithstanding this limitation, the ideas are often compelling.

While Henderson utilizes concepts of equilibrium and fit, he firmly focuses on strategy as an ongoing process: "the military analogy has only a limited application to business because business is a continuing process, not just a battle, a campaign, or even a war to be won and finished" (p. 3). Henderson's strategy focus is on competitive strategy, and he defines markets in terms of segments and sectors. He promotes the uses of economic tools to understand business: "But [strategy] does not need to be so implicit. There are ways of equating risk, return, and the cost of capital" (p. 37). The Experience Curve is a key tool: "Experience Curve Theory provides a full integration of the relationships among growth, market share, cost price, and competitive stability", as is Product Portfolio with its well-known $2 \times 2$ matrix comprising of stars, cash cows, problem children, and dogs: "To be successful, a company should have a portfolio of products with different growth rates and different market shares" (p. 163).

\section{Rosabeth Moss Kanter - The Change Masters (1983)}

The Change Masters (Kanter, 1983) provides an analysis of, and recommendations for, corporate America. Based upon years of empirical study of US corporates, specific study of ten corporates, and other data gathering, Rosabeth Moss Kanter maintains that she was able to develop a deep understanding of how business operates: "I could understand the human reality of how work life was lived" (p. 27). While the title of the book suggests a 'change' focus, Kanter actually seeks to improve corporate America's competitiveness through enhanced innovation. Her definition of innovation, "Innovation refers to the process of bringing any new, problem-solving ideas into use" (p. 20), directs her attention to process and structural issues that enable or inhibit corporations when pursuing strategy ends. 
At a broad level, her solution is about providing the right conditions for entrepreneurs: "[This book] describes the environments that stimulate people to act and give them power to do so: how some companies systematically encourage innovation by the design of their systems and the treatment of their people, while others stifle or ignore it" (p. 18). Her designs aim to avoid silos and promote integration. She aligns integration in thinking to structure: "Integrative thinking that actively embraces change is more likely in companies whose cultures and structures are also integrative" (p. 28). Specific skills are also required: "Three new sets of skills are required to manage effectively in such integrative, innovation stimulating environments... "power skills" - skills in persuading ... the ability to manage the problems associated with the greater use of teams and employee participation ... an understanding of how change is designed and constructed" (p. 36).

A variety of other approaches and techniques are proposed, including culture, empowerment, participation, and change mastery. These skills are not necessarily new: "I argue that tools already exist to 'save the American corporation'” (p. 64). The challenge is for managers to understand and implement what Kanter promotes: "Whether the promise of this corporate Renaissance is fulfilled depends on how fully corporate leaders understand this need and decide to act upon it" (p. 370).

Kees van der Heijden - Scenarios: The Art of Strategic Conversation (1996)

Kees van der Heijden (van der Heijden, 1996), based upon his 35 years of experience at Shell, provides an overview of strategy and promotes the use of scenario planning. He identifies three schools of strategy: "Over the years, three schools of thought have arisen to interpret the way managers and entrepreneurs think about their daily business. These can be characterized as rationalist, evolutionary, and processual" (p. 23). Without providing any evidence, he proposes that the rationalist school has limitations: "The rationalist school codifies thought and action separately. The tacit underlying assumption is that there is one best solution" (p. 23). He suggests that the evolutionary school, primarily attributed to Mintzberg, essentially gives up on strategy as it is only emergent: "The evolutionary school emphasizes the complex nature of organizational behaviour, beyond the realms of rational thinking" (p. 24).

Faced with the inflexibility of the rationalist school and the lack of executive involvement in the evolutionary school, he proposes the processual school which, when utilizing scenario planning, creates learning loops. The processual school "takes a middle position. It suggests ... managers can create processes in organizations that will make it more flexible and adaptable, and capable of learning from its mistakes" (p. 24). Scenario planning is the technique for implementing the processual school approach: "The processual approach to strategy is concerned with improving the fitness of organizations by creating processes that can tap the resources available. Scenario planning is such a process. It looks at multiple futures which are treated as equally plausible, reflecting the inherent uncertainty" (p. 41). This usage essentially creates a large corporate learning loop that drives strategy development: "We have presented scenario planning as a complete approach to institutional management based on an integrated philosophy of management around organisational learning" (p. 132). 


\section{Clayton M Christensen - The Innovator's Dilemma (1997)}

In The Innovator's Dilemma (Christensen, 1997), Clayton Christensen, a Harvard professor, presents an economist's view of a rules-based world and suggests how companies may avoid some of the pitfalls he has identified.

Christensen's rules are primarily derived from study of the computer disk drive market: "This book derives a set of rules, from carefully designed research and analysis of innovative successes and failures in the disk drive and other industries, that managers can use to judge when the widely accepted principles of good management should be followed and when alternative principles are appropriate" (pp. xii-xiii). These rules can also be called innovations, and they concern Christensen's principal interest, that of disruption of the markets of large corporates: "These rules, which I call principles of disruptive innovation, show that when good companies fail, it often has been because their managers either ignored these principles or choose to fight them" (p. xiii).

The rules/principles, some initial findings, and some final insights contain a number of contextual observations that may be responsible for much of the fame of the book. One such observation is that, in technology markets, often customer needs are exceeded by technology offerings: "the pace of progress that markets demand or can absorb may be different from the progress offered by technologies. ... Recognizing this, we cannot expect customers to lead us towards innovations that they now do not need" (p. 208); decision making is driven by customer demand and the financial processes of organisations: "customers and financial structures of successful companies color heavily the sorts of investments that appear to be attractive to them, relative to certain types of entering firms" (p. xv); and analysis of markets for disruptive technologies is hard or impossible: "in many instances, the information required to make large and decisive investments in the face of disruptive technology simply does not exist" (p. 209).

In a somewhat loose usage of the concept of 'laws of behaviour', Christensen suggests that large companies can circumvent the laws that condemn them to be disrupted by smaller and nimbler players. The solution has a strong organisational component: "With few exceptions, the only way instances in which mainstream firms have successfully established a timely position in a disruptive technology were those in which the firms' managers set up an autonomous organization [to address the threat]" (p. xix). But it also has aspects of new planning processes and taking appropriate care: "a different approach to strategy and planning that recognizes the law that the right markets, and the right strategy for exploiting [disruptive technology opportunities], cannot be known in advance. Called discovery-based planning, it assumes forecasts are wrong, rather than right, and that the strategy they have chosen to pursue may likewise be wrong" (p. xxii); and "Only those companies that carefully measure trends in how their mainstream customers use their products can catch the points at which the basis of competition will change in the markets they serve" (p. xxiii). 


\section{Problematization}

The authors approach a similar problem from different perspectives. Henderson and van der Heijden see a lack of good strategy tools to deal with dynamic times, while Kanter and Christensen see major operational problems being structural in nature.

Bruce Henderson finds a business world dominated by intuition: "Since the beginning of business ... the plans and the strategy have been intuitive or traditional" (Henderson, 1979, p. 3). But he regards this as inadequate: "But intuitive and experience-based management philosophies are grossly inadequate when decisions are strategic and have major irreversible consequences" (p. 6). Partly this is a result of new dynamics of business: "The conclusion seems inescapable that the combination of dynamic business concepts, growth potential, and computers requires a basically different management style for competitive success than the traditional approaches of the past" (p. 24). This style includes analysis: "Neither experience nor intuition is of much help in strategy formulation even if both are vital to implementation. Systematic analysis of competitive equilibrium is the only technique that works" (p. 25).

But now mathematics is contributing and new methods are emerging: "Mathematics has made a contribution to strategy, particularly in terms of decision theory and risk evaluation" (p. 3) and "One prediction seems safe: explicit and sophisticated approaches to strategy are emerging" (p. 7). These open up the possibilities of new approaches: "Some of the frustrations we have mentioned may account for the fact that many corporate strategies are traditional and intuitive rather than logical and tightly reasoned. But there are concepts and techniques which are of great value in approximating the opportunities of a corporation and speeding up the process of strategy development" (p. 4).

For Kanter (1983), the challenge is to innovate as the USA is on the brink of losing control of the economic world: "American companies are at a critical watershed" (p. 35), and "What has slipped away for many managers and executives is not just a sense of supremacy ("America as \#2") but a sense of control" (p. 62). That the US should expect to have global leadership is not supported in any way but is simply assumed. The problem manifests itself as a need for innovation: "I have been struck by an even-louder echo of the same question: how to stimulate innovation, enterprise, and initiative from people" (p. 17). The core problem is structural, which Kanter calls segmentation: "The contrasting style of thought is anti-change-oriented and prevents innovation. I call it 'segmentation'”' (p. 28).

Kees van der Heijden (van der Heijden, 1996) found issues in strategy, a reliance on emergent strategy, and risks for companies. Strategy is full of fads and fashions: "People often get exasperated by what they read about strategy. It's a highly dynamic area, full of fads and fashions, where ideas come and go" (van der Heijden, 1996, p. vii). Van de Heijden wants a more holistic approach to strategy: "What is needed is a more complete philosophy mobilizing the cognition, culture, structure and process throughout the organisation" (p. 9). But this is not just because of a lack of good strategy texts; there are real-world problems in strategy execution: "Most of our organisational models are quite inadequate to make reliable predictions of 
[behaviour]. Much of the pattern of reactions to events that organizations display can be interpreted only after the event, in terms of "'emergent strategy"” (p. 291) and risk in times of change: "in times of rapid change the large, well-run companies are in particular danger of suffering from strategic failure, caused by a crisis of perception" (p. 31).

Clayton Christensen (Christensen, 1997) sees the problem to be seemingly successful companies being disrupted by smaller players. The problem is not that they do things wrong, but that they do things in a conventional manner that is limited: "Precisely because these firms listened to their customers, invested aggressively in new technologies that would provide their customers more and better products of the sort they wanted, and because they carefully studied market trends and systematically allocated investment capital that promised the best returns, they lost their positions of leadership" (p. xii). However, even though people are involved, the problem is not people-based: (p. 207). Managers are instead overpowered by the laws of organizational nature: "there are, in fact, sensible ways to deal with [the challenge of disruptive technologies]. ... Managers faced with disruptive technologies fail their companies when [laws of organizational nature] overpower them" (p. xviii).

The four authors all see a problem. Henderson sees a lack of tools in an increasingly dynamic business environment. For van der Heijden, 35 years of experience at Shell has highlighted the folly of rational and evolutionary strategy approaches. Kanter laments how businesses cannot innovate due to segmentation, and wants the United States to retain its economic dominance. Christensen sees major problems with how American corporates can respond to disruption, and that such problems are often caused by structural issues.

\section{Conditions of Possibility}

Like the previous sub-discourse, the Specialists share Enlightenment thinking, that is, the belief that behaviours, including strategy, can be understood and, at times, controlled. While the intellectual milieu from the times these texts were written would be influential on the authors, it is noteworthy that these four texts, from two practitioners and two academics, are built upon the authors' own experiences and don't draw directly from other theorists.

\section{Social Effects / Subjectivity}

The problem seems to have got larger, and the solutions more numerous. How will the strategist cope?

Henderson (1979) created tool sets to perform large scale analysis of corporate businesses in growth economies. The tools established strategists as legitimate practitioners, and were core to the establishment of large scale strategy consultancies. As Kiechel (2010, p. ix) states, a profession was born: "What [Bruce Henderson] and his consulting firm did was to launch the corporate-strategy revolution."

Kanter (1983) would be a bitter pill for many strategists. For them, the tools were always there, and the strategists had simply failed to achieve the right results because they were 'unaware'. However, with the salvation of now knowing what Kanter provided, strategists had a way forward. Of course, those chosen few 
in the successful companies would find great reassurance from the confirmation of their own abilities from Kanter's book.

van der Heijden (1996) turns the strategist into a facilitator and one of many strategy thinkers in an organization. Following van der Heijden, there is even more strategy work to be done, and the strategist now has the task of facilitating the moving of many minds. The strategist is now more important and needs more resources. Strategy is now bigger and more important. If companies are to avoid regressing, a great deal must be done.

Christensen (1997) sees the strategist as a simple methodologist, engulfed in the dilemma of being caught up by the laws of organisation nature. These laws have taken the strategist hostage and the strategist needs salvation through organizational structure change. Such an organizational focus will tend to lessen the effect of the strategist and make strategy less important.

Together, the authors' descriptions of problems would seem to strengthen the need for strategists.

Henderson and van der Heijden promote strategy methods which would strengthen the role of the strategist. Being conceptually clear, they would be, and were, a boon for many strategists. Kanter and Christensen promote organizational change - both structural and cultural. Such approaches may involve strategists or, potentially, may be seen as human resources activities. 


\section{Foucauldian Summary}

Table 20: Foucauldian Summary - Specialists

\begin{tabular}{|c|c|c|c|c|}
\hline Texts & Henderson & Kanter & $\begin{array}{l}\text { van der } \\
\text { Heijden }\end{array}$ & Christensen \\
\hline & \multicolumn{4}{|c|}{ Enlightenment Thinking - a knowable and controllable world } \\
\hline $\begin{array}{l}\text { Conditions of } \\
\text { Possibility }\end{array}$ & $\begin{array}{l}\text { experience } \\
\text { mathematics }\end{array}$ & experience & experience & experience \\
\hline Problematization & lack of tools & $\begin{array}{l}\text { US performance } \\
\text { traditional segmentation }\end{array}$ & lack of tools & small disrupters \\
\hline Knowledge & techniques & change management & scenarios & structure \\
\hline Social Effects & \multicolumn{4}{|c|}{ More concepts, more tools, and a larger discipline. Possible competition. } \\
\hline Subjectivity & \multicolumn{4}{|c|}{ More confusion, but more work. Expert knowledge is required! } \\
\hline
\end{tabular}

The practitioners, Henderson and van der Heijden, propose specific business strategy tools. Henderson, a broad thinker, offers opinions about a wide range of topics, including those that he and the Boston Consulting Group are famous for (i.e. Portfolio Matrix and the Experience Curve). van der Heijden focuses on scenario planning that was invented in Shell, where he worked for 35 years. Kanter, from a broad research agenda, finds received behaviour patterns that are not optimal. Christensen, in a similar vein, finds corporate America to be constrained by laws of organisational nature that are difficult to break out from. So the two practitioners, based on experience, propose tools to respond to problems. The two academics, based on research, see that changes in organizational structure will create the organization adaptivity that is needed.

These authors exhibit the same Enlightenment thinking as authors within previous discourse analyses, but none relies on outside theorists. As opposed to the System Builders, who take more holistic approaches, the Specialists are experts in their fields and require limited outside assistance. For the researchers, Kanter and Christensen, the problem is lack of USA competitiveness and market disruption, both caused by a lack of organisational adaptiveness due to inflexible structures and cultures. For Henderson and van der Heijden the problem is a lack of quality tools.

These texts, which are spread over 18 years at the end of the Millennium, create more specialities. There are many choices for the strategists. The tools of the Boston Consulting Group, even if they are not suited to today's environment, are available and are used. Scenario planning is an option and can be used as a core strategy platform or as a tool. Structure and culture become strategic issues, although this will not necessarily be the domain of the strategist, as other corporate functions, such as human resources, may take responsibility. Notwithstanding that possibility, strategists need education if they are to be fully conversant with the field. 


\section{Cognition}

The distinction between the two pairs of authors, recognized above, is much more profound when considering cognition. For Henderson and van der Heijden cognition is crucial; in Kanter and Christensen it is hardly mentioned.

\section{Bruce D Henderson - Henderson on Strategy(1979)}

For Bruce Henderson (Henderson, 1979), cognition, especially intuition, is a fundamental aspect of Strategizing. For him, this intuition may not always be logical, but it is the basis of all strategy, and it can function effectively with analysis. He recognizes cognition conceptually, mentioning general cognitive categories of perception, conception, insight, knowledge, and emotion. But it is his focus on intuition that is greatest, providing a definition and describing its non-logical aspects: "Intuition is in fact the subconscious integration of all the experiences, conditioning, and knowledge of a lifetime, including the emotional and cultural biases of that lifetime" (p. 40), "It is interesting to observe that many companies make intuitive decisions which are often correct, even though they are in direct contradiction to the logic of the policies they state" (p. 5), and "Characteristically, intuitive insights can tolerate great inconsistencies and ambiguities no matter how brilliant or important" (p. 38).

Henderson, as described above, provides analytical tools that can be utilized systematically to get beyond the limitations of intuition. But, notwithstanding this approach, intuition still holds sway: "Business thinking starts with an intuitive choice of assumptions. Its progress as analysis is intertwined with intuition. The final choice is always intuitive. If that were not true, all problems of almost any kind would be solved by mathematicians with non-quantitative data" (p. 40), and "analysis, by its very nature, requires initial oversimplification and an intuitive choice of initial assumptions, as well as exclusion of certain data. All these choices are intuitive. A mistake in any one can be fatal to analysis" (p. 40).

But, in a further twist, Henderson sees the potential in disagreements between data and intuition to expand knowledge: "When the results of analysis and intuition coincide, there is little gained except confidence. When the analysis reaches conclusions that are counterintuitive, then more rigorous analysis and reexamination of underlying assumptions are always called for. The expansion of the frame of reference and the increased rigor of analysis may be fruitful” (p. 41).

\section{Rosabeth Moss Kanter - The Change Masters (1983)}

Rosabeth Moss Kanter (Kanter, 1983) is almost silent on cognition in general. For her, cognition is important to understanding her own bigger picture and putting it into effect: "The ultimate skill for change mastery works on just that larger context surrounding the innovation process. It consists of the ability to conceive, construct, and convert into behavior a new view of organizational reality" (p. 279). She also makes reference to systems thinking, using her concept of integrative thinking: "I found the entrepreneurial spirit producing innovation is associated with a particular way of approaching problems that I call "integrative" ... To see problems integratively is to see them as wholes, related to larger wholes, and thus establishing accepted 
practices" (p. 27). Beyond this, there is an occasional reification of the firm as a thinking entity: "American business organizations will need to learn to operate in a wholly new mode" (p. 38).

However, for Kanter, cognition is primarily an assumed faculty that can be simply directed onto the right content and simply needs to be broadened somewhat. If the correct structures, skills, and environments are created, it is assumed that the mind will simply follow along correctly.

Kees van der Heijden - Scenarios: The Art of Strategic Conversation (1996)

van der Heijden (1996) takes cognition seriously. Not only is cognition worth consideration, he sees it also as capable of being improved when combined with scenario planning, and it has organisational aspects. General concepts such as awareness, mental models and inductive/deductive thinking are considered by van der Heijden. It is notable that an author is thinking about reasoning: "The difference between the inductive and deductive methods is between letting the framework emerge in the process of building stories from the data upwards, or deducing a framework from the data as a first step" (p. 196).

Scenario planning includes crucial cognitive aspects: "Crucial elements of [scenario-based strategic thinking] include: the aim of changing the mental models of decision makers; the need to understand predictability and uncertainty; the need to take existing mental models of the decision makers as the starting point; creating a reframing of the issues involved, through the introduction of new perspectives" (p. x), and "Scenarios contribute to the learning process in a number of important ways: at the individual level ... As a cognitive device ... As a perception device ... As a cognitive reflection tool ... At the group level ... As a ready-made language provider ... As a conversational facilitation vehicle ... As a vehicle for mental model alignment ..." (p. 51). For van der Heijden, the art of Strategizing can best be operationalized through strategic conversations that are enabled by scenario planning techniques, and that promote the development of mental models. But, such mental model development is limited to this one technique: "It is my experience that scenarios are the best available language for the strategic conversation" (p. ix).

van der Heijden considers both individual and group cognition: "Perception is in the first place an individual activity, but having discussed how individuals perceive we need also to talk about how these perceptions are internalized by the group through interaction and discussion. Specifically we will discuss scenarios as perception devices" (p. 116). The organization, perceived as a system, has greater knowledge than individuals. While van der Heijden does personalize the firm, he makes it clear that individuals are the thinking entities: "The ability to read signals must be institutional: enough people must have jointly acquired the mental model if any action is to result" (p. 19). 
Clayton M Christensen - The Innovator's Dilemma (1997)

Clayton Christensen (Christensen, 1997), hardly mentions cognition. On the final page of the text, he recognizes that understanding is required by managers: "Managers must first understand what these intrinsic conflicts are" (p. 210). Processes of the mind are of little import compared to laws of organisation.

\section{Cognitive Summary}

Table 21: Cognitive Summary - Specialists

\begin{tabular}{l|l|l|l|l|} 
& Henderson & Kanter & van der Heijden & Christensen \\
\hline Summary & fundamental & almost silent & core process & almost silent \\
\hline Type of Abstraction & conceptual & - & conceptual & - \\
\hline Subject & managers & - & managers & - \\
\hline Mind & $\begin{array}{l}\text { conscious } \\
\text { subconscious }\end{array}$ & - & conscious & - \\
\hline Thinking Process & Strategizing & - & & \\
\hline Thought Content & - & - & - & - \\
\hline
\end{tabular}

Henderson and van der Heijden find that cognition is vital to business strategy and consider cognition conceptually. They recognize the need to improve cognitive effectiveness when Strategizing, but cognition is not the basis of the tools they recommend. Henderson notes the importance and centrality of intuition in all strategy processes, and the opportunity for intuition and analytical tools to interact and produce useful learning. With this focus on intuition, Henderson, like Steiner, implicitly recognizes the subconscious without directly mentioning it. van der Heijden treats cognition and scenario planning together: he sees scenarios as providing a useful and necessary aid to understanding. Although he notes the group benefits of scenario planning, cognition is treated as an individual capability, as it is also for Henderson.

Henderson presents his solutions in isolation from cognition. van Der Hayden does so similarly, but links his method to better cognitive understanding outcomes.

Kanter and Christensen mostly ignore cognition. Their focus is on describing what their research has shown them and drawing conclusions to demonstrate underlying patterns of behaviour. 


\section{Specialists Summary and Provisional Insights}

In the Specialists there are two practitioners and two academics. The two practitioners, based on perceived weaknesses in strategy itself, offer science-based tools for strategy. The two academics, seeing problems in performance, find organisational structure and culture to be the points where change can be effected to improve results.

The two practitioners find cognition crucial, but they fail to include any specifically cognitive elements in their solutions. Their focus is on Strategizing at a conceptual level, including stressing the criticality of intuition to success. But, even so, their tools are methods without cognitive features. Such treatments are aligned with previous treatments analyzed.

While the two practitioners recognize cognition, the two academics however essentially ignore cognition. This suggests a further provisional insight:

C3 Practitioners are more likely to treat cognition seriously than academics. 


\subsection{Summary}

This summary shows themes, commonalities, and differences that may shed some light on the way we think now. It does not show, nor should it be interpreted as showing, a progression or causality.

Following the approach taken for each sub-discourse summary, an overall Foucauldian analysis is done, followed by a consideration of treatments of cognition over the whole discourse, and completed by consideration of the questions raised by previous analyses of sub-discourses.

\section{Foucauldian Analysis}

Table 22: Classical Foucauldian Summary

\begin{tabular}{|c|c|c|c|c|}
\hline & Early Pioneers & Early Theorists & Systems Builders & Specialists \\
\hline & $\begin{array}{l}\text { Barnard (1938) } \\
\text { Levitt (1955) } \\
\text { Penrose (1962) }\end{array}$ & $\begin{array}{l}\text { Chandler (1962) } \\
\text { Ansoff (1965) } \\
\text { Ackoff (1970) } \\
\text { Andrews (1971) }\end{array}$ & $\begin{array}{l}\text { Steiner (1979) } \\
\text { Porter (1985) } \\
\text { Goold \& Campbell (1987) } \\
\text { Johnson \& Scholes (1984) }\end{array}$ & $\begin{array}{l}\text { Henderson (1979) } \\
\text { Kanter (1983) } \\
\text { van der Heijden (1996) } \\
\text { Christensen (1997) }\end{array}$ \\
\hline Knowledge & $\begin{array}{l}\text { executive abilities } \\
\text { marketing } \\
\text { economic models }\end{array}$ & $\begin{array}{l}\text { history } \\
\text { planning } \\
\text { modelling } \\
\text { corporate strategy }\end{array}$ & $\begin{array}{l}\text { planning tools } \\
\text { analytical tools } \\
\text { multi-divisional } \\
\text { generalist }\end{array}$ & $\begin{array}{l}\text { strategy techniques } \\
\text { change management } \\
\text { scenario planning } \\
\text { structure }\end{array}$ \\
\hline Problematization & $\begin{array}{l}\text { lack of theory } \\
\text { performance }\end{array}$ & $\begin{array}{l}\text { lack of theory } \\
\text { lack of planning } \\
\text { limits of science }\end{array}$ & $\begin{array}{l}\text { lack of theory } \\
\text { lack of tools }\end{array}$ & $\begin{array}{l}\text { lack of tools } \\
\text { performance }\end{array}$ \\
\hline & \multicolumn{4}{|c|}{ Enlightenment Thinking - a knowable and controllable world } \\
\hline $\begin{array}{l}\text { Conditions of } \\
\text { Possibility }\end{array}$ & $\begin{array}{l}\text { business, } \\
\text { academia }\end{array}$ & $\begin{array}{l}\text { management science } \\
\text { operations research }\end{array}$ & $\begin{array}{l}\text { human sciences } \\
\text { industrial economics }\end{array}$ & $\begin{array}{l}\text { human sciences } \\
\text { business } \\
\text { mathematics }\end{array}$ \\
\hline Social Effects & \multicolumn{4}{|c|}{ A discipline with multiple options. Finally spilling over into human resources. } \\
\hline Subjectivity & \multicolumn{4}{|c|}{ The strategist is created, with a broad job and some prestige. } \\
\hline
\end{tabular}

\section{Knowledge}

Each group contributes different aspects of knowledge: the Early Pioneers create topics; the early Theorists introduce science and consider strategy operationally; the Systems Builders consolidate and add tools; and the Specialists add more approaches and tools.

In an open field, the Early Pioneers (Barnard, Levitt, Penrose) were free to roam and created grand ideas.

Barnard finds power and virtue in the supermen of business. Levitt says 'marketing is the answer'. Penrose 
considered management and economics jointly. The chance of doing better is established and starting points are defined.

The Early Theorists are various. Chandler, the historian, makes apparent a dichotomy of strategy and structure; Ansoff and Ackoff, using mathematics, employ scientific method to problems of diversification and general strategy; and Andrews, the Harvard professor, promotes good judgment. They show the field of strategy expanding with new techniques. And they show the field of strategy having widely different techniques. Andrews' approach to promoting good judgment through experience and awareness is the antipathy of Ansoff's decision making by formula. Of course, both 'recognize' the other approach to some degree, but the underlying rationales are quite different.

The Systems Builders instantiate business strategy methods. Steiner consolidates planning. Porter, the industrial economist, invents a way to analyse industries. Goold and Campbell extend considerations of structure in large multi-divisional companies. Johnson and Scholes consolidate everything. Through the consolidations, strategy is both reinforced and validated; it has a literature.

The Specialists add to this. Henderson introduces new tools, van der Heijden scenarios, Kanter innovation, and Christensen disruption. The practitioners, Henderson and van der Heijden, base their work on experience. The theorists, Kanter and Christensen, base theirs on research. The practitioners come up with methods of doing strategy, whereas the theorists highlight conceptual challenges without specific operational solutions.

Through the Classicists, a broad range of knowledge is created, showing how open strategy is to interpretation and to the application of multiple approaches.

\section{Problematization}

Problematization shows a common theme, the lack of sufficient theory or method to drive strategy. In some periods, this response is also tied to concerns about the performance of firms: for the Pioneers, such performance is due to the lack of theory, and for the Specialists, this performance is due to the rise of global competition. But while there are some concerns about such performance, the dominant theme is the lack of new methods.

Not surprisingly, given that the issues are a lack of theory and at times performance, the problematizations are rarely stated as being cognitive. Levitt, with his focus on vision, is one author who sees cognitive issues: "[The trouble is] that all too often neither the researchers nor the corporate bosses really know what they are trying to do" (Levitt, 1962, p. 9), and Johnson and Scholes : "The problem is the inability of managers to think strategically" (Johnson \& Scholes, 1984, p. xi). Even so, the overwhelming problem is a lack of theory and tools. 


\section{Conditions of Possibility}

All of the texts show the influence of Enlightenment Thinking, as defined by Palmer, Colton and Kramer (2007, p. 297): "The leading ideas of the Enlightenment - optimistic belief in the historical advance of reason, science, education, social reform, ... have been constant themes in the modern world". Even those theorists who do not specifically recognize science-based approaches implicitly adopt a rationalistic approach that suggests the world can be understood and controlled.

Beyond this consistency of Enlightenment Thinking, conditions of possibility are a mixture of business experience, academic experience, human sciences (this includes psychology), and mathematics. No theorist's conditions are singular, but some themes are apparent.

Three authors, Barnard, Henderson, and van der Heijden, draw extensively on their own experiences of the business world, which drive how they present their beliefs and solutions. Early Theorists and System Builders explicitly draw on various forms of human science, including management science, operations research, sociology, psychology, organisational studies, and industrial economics. The Specialist texts see no need to explicitly define what theorists or schools they draw on, except specifying mathematics in one case.

The conditions of possibility are broad, with many alternatives.

\section{Social Effects and Subjectivity}

The social effect of these various texts is considerable. The texts cover enough time, 1939 to 1997 , to be influential - and they are. Strategy has gone from a notion to a field. Businesses have a 'need' for business strategy and there is a queue of authors ready to fulfil the need for methods and approaches. The practitioners justify their approaches through shared experiences, whereas the theorists both call on research and simply assume their work has validity. Together, they create a field of strategy, rather than just a single discipline based on a single philosophy.

The strategist is created. The strategist has an identity and has prestige. The strategist has options, and thus has many things to learn. With no one way, strategists' positions may become somewhat political, as they need to balance varying views of what strategy is! Together, these texts create many ways to think about business strategy and multiple methods of doing business strategy.

Two of the Specialist texts, Kanter (1983) and Christensen (1997), break with this theme somewhat, as the strategist is no longer central. They present strategy approaches that are no longer necessarily carried out by a strategy function, but potentially by another corporate function such as human resources. 


\section{Foucauldian Summary}

Strategy is created by the Classicists using Enlightenment thinking and a variety of theoretical foundations to yield multiple approaches and opportunities for strategists. Major themes discerned are:

Conditions of Possibility

Problematization

Knowledge

Social Effects

Subjectivity
Enlightenment Thinking, business experience, academic experience, human sciences, and mathematics

Lack of theory, poor performance

Multiple approaches

A discipline with multiple options

The strategist is created, with a broad job and some prestige 


\section{Cognition}

\section{By Cognitive Heuristic}

Table 23: Classical Cognitive Summary

\begin{tabular}{|c|c|c|c|c|}
\hline & Early Pioneers & Early Theorists & Systems Builders & Specialists \\
\hline Texts & $\begin{array}{l}\text { Barnard (1938) } \\
\text { Levitt (1955) } \\
\text { Penrose (1962) }\end{array}$ & $\begin{array}{l}\text { Chandler (1962) } \\
\text { Ansoff (1965) } \\
\text { Ackoff (1970) } \\
\text { Andrews (1971) }\end{array}$ & $\begin{array}{l}\text { Steiner (1979) } \\
\text { Porter (1985) } \\
\text { Goold \& Campbell (1987) } \\
\text { Johnson \& Scholes (1984) }\end{array}$ & $\begin{array}{l}\text { Henderson (1979) } \\
\text { Kanter (1983) } \\
\text { van der Heijden (1996) } \\
\text { Christensen (1997) }\end{array}$ \\
\hline $\begin{array}{l}\text { Cognition } \\
\text { Summary } \\
\text { by } \\
\text { Text }\end{array}$ & $\begin{array}{l}\text { innate abilities } \\
\text { problematic } \\
\text { just there }\end{array}$ & $\begin{array}{l}\text { just there } \\
\text { to be avoided } \\
\text { useful } \\
\text { fundamental }\end{array}$ & $\begin{array}{l}\text { essential } \\
\text { hardly mentioned } \\
\text { a sidebar } \\
\text { essential }\end{array}$ & $\begin{array}{l}\text { fundamental } \\
\text { almost silent } \\
\text { core process } \\
\text { almost silent }\end{array}$ \\
\hline $\begin{array}{l}\text { Type of } \\
\text { Abstraction }\end{array}$ & conceptual & $\begin{array}{l}\text { conceptual } \\
\text { operational }\end{array}$ & $\begin{array}{l}\text { conceptual } \\
\text { operational }\end{array}$ & conceptual \\
\hline Subject & \multicolumn{4}{|c|}{ managers } \\
\hline Mind & \multicolumn{4}{|c|}{ conscious } \\
\hline Thinking Process & \multicolumn{4}{|c|}{ Strategizing } \\
\hline Thought Content & \multicolumn{4}{|c|}{ Mostly ignored, but if considered, then Context } \\
\hline
\end{tabular}

As shown above, when cognition is treated there is remarkable consistency in the bottom four levels.

The subject is the manager, and the object is the conscious mind, and only occasionally the subconscious mind. For the latter, intuition is recognized only by Barnard, Steiner, and Henderson, and not in any depth. The primary focus is on Strategizing, with Learning or Designing occasioning only the odd comment. The focus is primarily on Thinking Processes, with Thought Content of Context being occasionally mentioned as part of considering processes of analysis, but what practitioners know of Strategy is mentioned only once and the cognization of their Intentions is not approached at all.

Types of abstraction have some variety, but one consistency is that cognition, when discussed, is discussed in everyday terms of perception, reason, understanding, imagination and intuition. These words are used often in conceptual considerations of cognition, when theorists have a need to show the importance of cognition.

Some theorists consider cognition in operation: Ackoff focuses on his own approach while Andrews, Steiner, and Johnson and Scholes focus on contemporary strategy processes. Such operational descriptions are generally high-level abstractions, a long way from the functioning of the individual mind. 


\section{Provisional Insights}

A series of provisional insights were gained in the sub-discourse analyses. These, summarized below, will be considered with other discourses in Chapter 13 - Findings (p. 271):

C1 Cognition, even when recognized as important, is not part of strategy solutions.

C2 Treatment, or non-treatment, of cognition is independent of strategy approach.

C3 Practitioners are more likely to treat cognition seriously than academics.

\section{Cognition is Not Part of Solutions}

This provisional finding was recognized when analyzing the Early Pioneers, and the theme continues for all of the theorists. Of the nine theorists who recognize cognition, none propose a cognitive solution. While this may be unsurprising for those theorists who have strong methodological approaches (Ackoff, 1970; Henderson, 1979; Penrose, 1959/1966), and be less surprising for those with a process approach (Johnson \& Scholes, 1984; Steiner, 1979), it is revealing that even those with a strong focus on the manager and cognition (Andrews, 1971; Barnard, 1938) do not include cognition in solutions. That is, even those with the highest humanistic leanings cannot find a place for cognition in the actual execution of strategy.

\section{Independent of Approach}

The Early Pioneers showed how treatment or non-treatment of cognition seemed to be independent of approach: Ansoff (1965) and Ackoff (1970) have similar rationale approaches, but one treats cognition as critical while the other ignores it. The other two other theorists from the Early Pioneers (Henderson, 1979; Porter, 1979) have similar approaches to strategy tools, and exhibit the same type of variance in treatments of cognition.

This theme is supported by other theorists from human sciences approaches who have strong cognition treatments varying from critical to ignore (Andrews, 1971; Christensen, 1997; Johnson \& Scholes, 2002; Kanter, 1983; Levitt, 1962; Steiner, 1979). Such variations confirm a theme, within the Classicists, of no connection between approach and treatment, or non-treatment, of cognition.

\section{Treating Cognition Seriously}

Three practitioners (Barnard, 1938; Henderson, 1979; van der Heijden, 1996) treat cognition seriously. The more humanistic theorists (Andrews, 1971; Christensen, 1997; Johnson \& Scholes, 2002; Kanter, 1983; Levitt, 1962; Steiner, 1979) are split with four for treatment and two not. The more rationally minded academics (Ackoff, 1970; Ansoff, 1965; Penrose, 1959/1966; Porter, 1985) are evenly split between treatment and nontreatment of cognition. From this analysis no preliminary finding is made regarding academics' treatment of cognition, but the theme of practitioners treating cognition seriously is recognized. 


\title{
Summary
}

In summary, the common treatment of cognition is the conceptual consideration of managers' conscious minds when used in Strategizing processes.

Additional findings, that are at this stage preliminary, are these themes:

C1 Cognition, even when recognized as important, is not part of strategy solutions.

C2 Treatment, or non-treatment, of cognition is independent of strategy approach.

C3 Practitioners are more likely to treat cognition seriously than academics.

\author{
"Call out the instigators \\ Because there's something in the air \\ We've got to get together sooner or later \\ Because the revolution's here, and you know it's right \\ And you know that it's right"
}

Lyrics from Something in the Air by John Keen, copyright T.R.O. Inc., Abkco Music Inc., Spirit Music Group 


\section{Chapter 10 - Managerial and Organizational Cognition}

"Theorists, writers, researchers and teachers of management know perfectly well that managers make an

$$
\text { impact" }
$$

(Spender, 1989, p. 5).

"At present there is virtually no high-quality scientific evidence to support the use of cognitive mapping procedures as a basis for intervening in the strategy process"

(Hodgkinson \& Maule, 2002, p. 212)

"I highlight the challenges associated with establishing cognition as a legitimate factor in strategic

$$
\text { management" }
$$

(Kaplan, 2011, p. 665)

"[cognition and strategy are] still in a "pre-paradigmatic phase”“

(Gavetti \& Ocasio, 2015, p. xi)

The title Managerial and Organizational Cognition (MOC) is an academic movement that started in the 1980s and is still functioning. As the title suggests, the movement considers 'cognition' within the broad contexts of 'management' and 'organization'.

As demonstrated by the citations, above, perceptions of the status of cognition vary considerably within MOC. This chapter presents a Foucauldian analysis of selected MOC texts, followed by an analysis of treatments of cognition.

Note that the Knowledge section within 10.1 Foucauldian Analysis necessarily considers cognition, because the texts selected have a cognition focus. Section 10.2 Treatments of Cognition then uses the Cognitive Heuristic to delve more deeply into specific aspects of cognition.

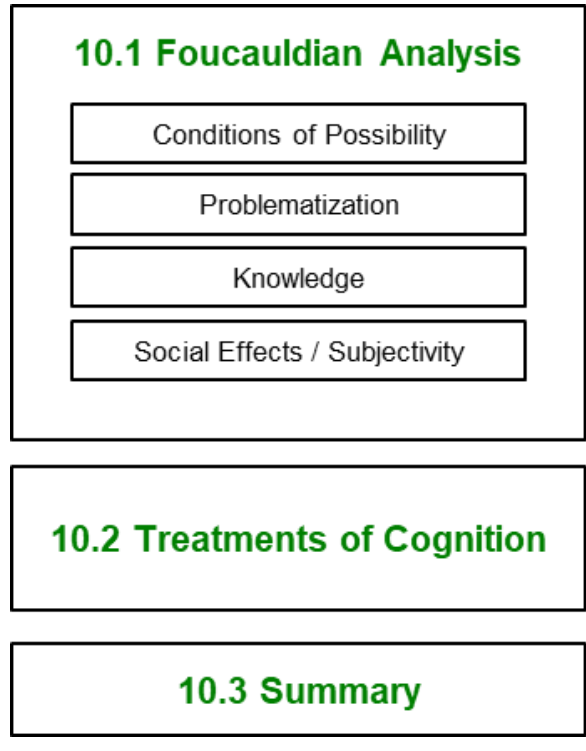

Figure 24: Chapter 10 Structure 


\section{Articles and Books}

For the analysis of MOC, 59 texts, predominantly journal articles, are reviewed. An initial search yielded 87 texts which were checked for relevance, leading to the 59 texts chosen.

An initial decision was made to focus on journal articles as these are the standard publication in academic fields, and only to include other types of texts if they had relevant content.

The search strategy was to identify likely texts using search engines and then use the candidate's judgment to make final selections.

As $\mathrm{MOC}$ is an academic field, Google Scholar and the Victoria University of Wellington library search engines were used to find texts. The initial list of 87 texts were found by:

- searching for highly quoted articles that referenced 'managerial and organizational cognition', 'strategy', and 'cognition'

- searching for highly cited authors

- scanning bibliographies, especially from reviews of MOC, for 'strategy' and for 'cognition' articles.

During the searches, three compendia (Eden \& Spender, 1998; Huff, 1990; Huff \& Jenkins, 2002) and one book (Spender, 1989) were identified. From these compendia 13 articles were included for review. The initial list was reduced to 59 texts, once texts without mention of strategy and cognition were eliminated.

While no claim is made that this list is representative of MOC, the texts cover 33 years of scholarship, a variety of approaches, and authors from different countries. Therefore, the list has variety and the potential for different insights to be gained. 


\subsection{Foucauldian Analysis}

Within the reviewed literature, this Foucauldian analysis finds that that MOC's conditions of possibility are science-based, finds that the MOC problem to be solved is often MOC itself, summarizes the broad knowledge of $\mathrm{MOC}$, and suggests that $\mathrm{MOC}$ has minimal social effects and minimal influence on strategists.

\section{Conditions of Possibility}

MOC, with a scientific approach to cognition, finds cognition can be both represented and measured. MOC borrows from the human sciences, especially sociology and psychology.

\section{Scientific Method}

The scientific method is the basis of MOC, with the assumption being that cognition can be studied in a structured and logical manner. Symptomatically, this adoption of science is shown throughout almost every statement made in the literature surveyed, and is highlighted by the representation and measurement of cognition itself. For some, the theory becomes more real than the practice.

\section{Inferred Approach}

The articles reviewed rarely define any epistemological basis, but a scientific approach can be inferred from the texts. The MOC reviews illustrate the relatively minimal consideration of MOC's epistemological basis. Walsh (1995), in a major review, could have been expected to start at this point, but it is only in one quotation from Robert W Zmud that MOC is recognized as a science-based field: "This cogent view of the managerial and organizational literature nicely 'pulls together' the important ideas and developments in one of the more promising and exciting fields of inquiry in organizational sciences" (p. 280). Spender and Eden (1998) look into fundamental aspects of managerial and organizational cognition, as they ask "is the field distinctive, necessary or appropriate?" (p. 1), but they do not go further to consider the theoretical basis of MOC. Porac and Thomas (2002), in their review, acknowledge that MOC includes social science (e.g. the Carnegie School, Weick) and psychology (e.g. Kahneman), but they offer no critique. In their review, Gavetti and Ocasio (2015) find the field still in a pre-paradigmatic phase (see quote at the beginning of this chapter) but still do not question the scientific bias of MOC. So, in the few occasions identified in the literature when the basis of MOC is considered, a scientific basis is named but not critiqued. As is also apparent in the discussions of Knowledge below, the scientific method is assumed beyond these review articles.

\section{Representation of Cognition}

The science-based approach is also visible in the assumption that knowledge can be 'represented'. Huff's early research, aiming to show changes in strategic concepts over time, is predicated on the belief that such cognitive concepts can be represented on a page (Huff, 1982). Later she explicitly states that "I believe that mental maps can also be more than a methodological tool: we can hope to capture something that has the same essential characteristics as thought itself" (Huff, 1990, p. 14). Ireland, Hitt, Bettis and De Porras (1987, p. 
475) state that "The result is a quantitative representation of the person's cognitive model". Fiol and Huff (1992, p. 267) modify this position, but still perceive knowledge as being representable in some way: “Cognitive maps are of potential interest to managers because they are a means of displaying graphically the firm's current strategic position." While not explicitly stated by all authors, there is a prevailing theme that cognition can be represented in some form.

\section{Measurement of Cognition}

As befitting a scientific approach, cognition is, at times, seen as essentially 'measurable'. A number of the studies reviewed measure different aspects of cognition. Ireland et al. (1987) measure managers' SWOT thinking by assigning weights to decision-influencing cues, and find discernible differences between management levels. Barr et al. (1992) track mental maps through quantitative analysis of 25 years of letters to shareholders. Grønhaug and Falkenberg $(1998$, p. 99) in one of their hypotheses, show their underlying belief that cognition is measurable: "Degree of consensus on success criteria among managerial team members will correlate positively with organizational performance outcomes." Kaplan, Murray and Henderson (2003) analyse 23 years of corporate data to measure the recognition levels of senior managers. They state that "The key explanatory variable $\mathrm{Xj}, \mathrm{t}-\mathrm{n}$ is a measure of the importance that the top management of a particular firm places on biotechnology in a prior year" (p. 206). So, for some authors, cognition is a thing that can be measured.

\section{Realism}

Some authors go further than simply assuming that cognition can be represented, and move to a more realist position where the theory is the reality. For example, Bougon (1992, p. 369) states that he is looking for the inner truth: "while different-looking, special-purpose expressions of the underlying collective structure of a social system are possible, there exists only one underlying collective cognitive structure." Lyles and Schwenk (1992, p. 160) similarly suggest there are underlying structures: "firms are characterized by core elements of a generalized knowledge framework about which there is widespread agreement. The core facilitates understanding about the firm's general purpose, mission, and competitors."

\section{Human Sciences}

MOC frequently utilizes techniques and approaches, from psychology, sociology, and organization theory, within its own research but only rarely uses philosophy. Like many academic subjects, it also draws on its own previous work.

\section{Psychology, Cognitive Science, Sociology, and Organization Theory}

Human sciences are frequently drawn upon and researchers quoted. Of the 59 texts reviewed, 88 percent contain a citation to one or more of: a leading sociologist, Karl Weick; two leaders in cognitive psychology, Daniel Kahneman and Amos Tversky (either jointly or with others); and the Carnegie school (Richard Cyert, James March, Herbert Simon). The social psychology of organizing (Weick, 1979) is cited 22 times, and 
'Judgment under uncertainty: Heuristics and biases' (Tversky \& Kahneman, 1974) in Science is cited 12 times. Reliance on these academic subjects goes beyond simply citing, as these disciplines are core techniques that are operationalized: "Cognitive scientists and behavioural decisions theorists ... have identified a wide range of cognitive processes" (Schwenk, 1984, p. 111), and "In this paper we link the competitive characteristics of hypercompetitive environments to the sensemaking challenges they represent" (Bogner \& Barr, 2000, p. 213).

Philosophy

Fletcher and Huff (1990) are the only authors reviewed who consider strategy from a philosophical perspective, when they suggest argument mapping based upon an English philosopher Steven Toulmin. The philosophy of mind, as initiated by Descartes and developed by Kant, does not form any part of the expressed conditions of possibility underlying MOC. MOC takes no philosophical position on what we can know.

\section{Strategy Frameworks}

Like any academic subject, MOC creates and reuses its own frameworks. For example, Lyles and Thomas (1988) develop their own taxonomy of: rational, avoidance, adapting, political, and decisive; Schendel and Hofer's strategic management process (environmental analysis, strategy formulation, evaluation, implementation, control) is used (Stubbart, 1989); and van der Heijden and Eden (1998) integrate three strategy schools.

\section{Conditions of Possibility Summary}

None of the MOC articles surveyed starts with a statement of its underlying ontology or epistemology. They generally describe some theoretical foundations, most commonly based on human sciences. These are mostly sociology and forms of psychology. Although the object of MOC is cognition, a human attribute, the predominant conditions of possibility are scientific. This imbues the articles with an aura of the potential for rational explanations of human cognition. 


\section{Problematization}

The stated MOC object of study is activities, ideas, behaviours, and artefacts within management and organizations. At times, MOC focuses directly on such aspects of everyday life, but there is also MOC itself, as an object of study when researchers discuss each other's ideas and analyses. This analysis suggests that MOC has little focus on everyday business issues, but has a leaning towards perceived problems in MOC itself.

\section{Problems in the Business World}

Only two theorists highlight the challenges in business:

Barnes (1984, p. 135) gives a broad description of the problem: "For strategic planners, the findings reported here pose what may be a difficult challenge: to recognize their own cognitive limitations, to temper their assessments of strategy risk with the important qualitative aspects that influence the response of managers, and somehow to create ways in which these considerations can find expression in strategic plans, without, in the process, creating more heat than light on the subject." Bukszar (1999, p. 105) takes a similarly direct approach to defining the problem: "Retrospective sense-making produces the perception of a world more orderly than it is. Outcomes are recalled as more predictable that they seemed in retrospect. This inflated perception of order may bias strategic management...".

These are the only two articles found with a clear statement of the problem for the 'end-user'. While there is much focus on the behaviour within business, the problem is not stated that way. This leads to the question 'what problems are MOC researchers trying to solve?'

\section{Problems in MOC}

The problems identified in MOC itself are grouped into themes of initial gap, limited scope, limited approaches, and lack of integration of approaches. These are purely thematic categorizations and should not be read as being exclusive as many articles refer to multiple problem themes.

\section{Initial Gap}

In the earlier MOC texts analyzed, cognition was seen as being critically missing from strategy discourses:

"definitions of strategy which concentrate only on the fit between organization and environment cannot answer all the questions" (Huff, 1982, p. 120).

“Even though managerial cognition must figure prominently in strategy-making, top managers' thinking is seldom explicitly mentioned in the academic or business literature on strategic management" and "Cognitive aspects of strategy are implied but passed over in silence" (Stubbart, 1989, pp. 326, 328).

The absence of cognition in these early texts is also considered as a lack of understanding of strategic problem formulation (Lyles \& Thomas, 1988), and not accounting for creativity (Spender, 1989). This initial gap is 
identified in the earlier articles studied, and it may well be that once the problem was established no subsequent theorist found it necessary to identify the problem anew.

\section{Limited Research Scope}

MOC often finds that previous research is limited, and the scope needs to be expanded. Some researchers focus on expanding the specific business roles studied: directors (Rindova, 1999), CEOs (Eggers \& Kaplan, 2009), and entrepreneurs (Palich \& Bagby, 1995; Porac, Mishina \& Pollock, 2002). Others consider relationships with specific topics: politics (Kaplan, 2008), environment (Bukszar, 1999; Kaplan et al., 2003), and competitive groups (Porac et al., 1989). There is consideration of processes such as capability development (Eggers \& Kaplan, 2013; Laamanen \& Wallin, 2009) and connecting cognition to performance (Barr et al., 1992; Thomas, Clark \& Gioia, 1993). This small sample shows a broad expansion, over time, of MOC scope.

\section{Limited Approaches}

Many of the articles imply that cognition can be approached in a better way, and present alternatives. These include: more use of psychology (Haley \& Stumpf, 1989), going beyond behaviourism to introspection (Bougon, Baird, Komocar \& Ross, 1990), more use of behaviourism (Powell, Lovallo \& Fox, 2011), use of argument analysis (Fletcher \& Huff, 1990), a focus on attention (Cho \& Hambrick, 2006), and a focus on adaption processes (Bogner \& Barr, 2000; Tripsas \& Gavetti, 2000).

\section{Lack of Integration of Approaches}

Integration is considered in two ways. Firstly, some scholars suggest integrating different strands of MOC at different levels: consolidated models (Schwenk, 1988; Walsh, 1995), mental maps (Bougon, 1992; Fiol \& Huff, 1992), and mental maps and biases (Hodgkinson \& Maule, 2002). Secondly, aspects of cognition can be integrated with other knowledge structures: strategic perspectives (Das \& Teng, 1999; Schwenk, 1989; van der Heijden \& Eden, 1998), resource-based views (Ginsberg, 1989), strategic groups (Bogner \& Thomas, 1993; Reger \& Huff, 1993), business models (Tikkanen, Lamberg, Parvinen \& Kallunki, 2005), and industry structure (Nadkarni \& Barr, 2008).

\section{Problematization Summary}

The MOC discourse is primarily concerned with $\mathrm{MOC}$ itself and the outside world is assumed. As befitting an established academic field, problems are often perceived as limitations of scope, approach, and integration. These problems seem to stem from a need to describe the world accurately. When treatments of cognition are considered below, one aspect that will become clear is that a number of researchers believe that cognitions can be 'right'. That is, strategists can be 'right'. While not explicitly stated in any of the articles, there is an underlying theme that researchers also can be, or should aim to be, 'right'. The problematizations, described above, aim to find this rightness. 


\section{Knowledge}

The structure to this section is provided through a series of themes. Texts are reviewed within these themes, and a summary provided at the end of the section.

\section{Themes}

The academic texts reviewed follow a common structure of an initial theoretical development that may then be followed by empirical research. The texts are categorized within broad themes below. Clearly, the very nature of academic work is to differentiate and integrate topics, so these are not hard categorizations, but give a broad indication of the knowledge of the MOC texts reviewed. The themes are:

Table 24: MOC Themes

\begin{tabular}{|c|c|}
\hline General & Papers that consider MOC in a broad context \\
\hline Other Topics & $\begin{array}{l}\text { Those papers that consider a specific aspect of MOC not covered in the } \\
\text { themes below }\end{array}$ \\
\hline Decision Making & Articles that have a specific focus on decision making processes in strategy \\
\hline Biases & $\begin{array}{l}\text { Drawing from psychology, theorists study why managers are biased and } \\
\text { therefore make incorrect decisions. }\end{array}$ \\
\hline Mental Models & $\begin{array}{l}\text { Many theorists approach } \mathrm{MOC} \text { with the goal of understanding what mental } \\
\text { maps are behind managers' thinking. These mental maps may also be } \\
\text { termed frames. This type of analysis can go further towards understanding } \\
\text { strategic groups based on their shared mental maps. }\end{array}$ \\
\hline Reviews & These papers look at the history and development of MOC. \\
\hline
\end{tabular}

\section{Texts}

\section{General}

These texts take a holistic view of an area of MOC and often aim to explain or suggest systemic approaches as to how MOC should be structured to better understand behaviour. Authors suggest variously that MOC should utilize multiple perspectives (Eggers \& Kaplan, 2013; Powell et al., 2011; Schwenk, 1989; Stubbart, 1989; van der Heijden \& Eden, 1998); consider knowledge structures (Lyles \& Schwenk, 1992; Spender, 1998); and consider cognition with respect to action (Thomas et al., 1993; Tikkanen et al., 2005). 
Table 25: MOC - General Texts

\begin{tabular}{|c|c|c|}
\hline Author(s) & Article Title & Article Content \\
\hline Schwenk (1989) & $\begin{array}{l}\text { Linking Cognitive, Organizational and } \\
\text { Political Factors in Explaining Cognitive } \\
\text { Change. }\end{array}$ & $\begin{array}{l}\text { Theorizes on how three perspectives on strategy } \\
\text { (cognitive, process, political) can be integrated to form a } \\
\text { schema-based model of strategy process. }\end{array}$ \\
\hline Stubbart (1989) & Managerial Cognition & $\begin{array}{l}\text { Suggests that cognition has been ignored and the time } \\
\text { has come to use Cognitive Science: categories } \\
\text { (language), semantic networks (cognitive mapping, } \\
\text { frames etc.), managerial inferences (heuristics, biases). }\end{array}$ \\
\hline $\begin{array}{l}\text { Lyles and Schwenk } \\
\text { (1992) }\end{array}$ & $\begin{array}{l}\text { Top Management, Strategy, and } \\
\text { Organizational Knowledge Structures }\end{array}$ & $\begin{array}{l}\text { Proposes ten macro-level hypotheses of organizational } \\
\text { knowledge structures supported by interviews with two } \\
\text { executives. }\end{array}$ \\
\hline $\begin{array}{l}\text { Thomas et al. } \\
\text { (1993) }\end{array}$ & $\begin{array}{l}\text { Strategic Sensemaking and } \\
\text { Organizational Performance }\end{array}$ & $\begin{array}{l}\text { Hypothesizes relationships between cognitive and } \\
\text { performance variables, performs an empirical study } \\
\text { (analyses survey answers) to show that cognition drives } \\
\text { performance. }\end{array}$ \\
\hline Spender (1998) & $\begin{array}{l}\text { The Dynamics of Individual and } \\
\text { Organizational Knowledge }\end{array}$ & $\begin{array}{l}\text { Proposes a } 2 \times 2 \text { matrix of individual/social vs } \\
\text { explicit/implicit, based on a variety of theorists, to } \\
\text { remedy many of the problems of MOC. }\end{array}$ \\
\hline $\begin{array}{l}\text { van der Heijden } \\
\text { and Eden (1998) }\end{array}$ & $\begin{array}{l}\text { The Theory and Praxis of Reflective } \\
\text { Learning in Strategy Making }\end{array}$ & $\begin{array}{l}\text { Based on a merger of three strategy schools } \\
\text { (rationalistic, evolutionary, processual), suggests } \\
\text { research methods to eliciting strategy knowledge based } \\
\text { on symbolic interactionism, semiotics, and } \\
\text { ethnomethodology. }\end{array}$ \\
\hline $\begin{array}{l}\text { Tikkanen et al. } \\
\text { (2005) }\end{array}$ & $\begin{array}{l}\text { Managerial Cognition, Action and the } \\
\text { Business Model of the Firm }\end{array}$ & $\begin{array}{l}\text { Develops a theory of business models and proposes } \\
\text { various links between cognition and actions. }\end{array}$ \\
\hline Powell et al. (2011) & Behavioral Strategy & $\begin{array}{l}\text { Defines behavioural strategy as behavioural decision } \\
\text { making, social psychology, strategic management, and } \\
\text { practice. Entreats researchers to work together and to } \\
\text { include a behavioural focus. }\end{array}$ \\
\hline $\begin{array}{l}\text { Eggers and Kaplan } \\
\text { (2013) }\end{array}$ & Cognition and Capabilities & $\begin{array}{l}\text { Proposes a multi-level focus on cognitive processes of } \\
\text { build routines, assemble to capabilities, and match to } \\
\text { need, to thereby integrate cognition and a resource- } \\
\text { based view, but with a microfoundations focus. }\end{array}$ \\
\hline
\end{tabular}

These nine texts present a variety of overarching structures that aim to improve MOC, especially with respect to cognition. They highlight how it is possible to think in many ways about strategy and cognition. 


\section{Other Topics}

These papers, focusing on a specific theory or a specific behavioural pattern, cover argument mapping, entrepreneurial risk-taking, attribution theory, board involvement, hyper-competitive environments, middlemanager sensemaking, heuristics/thought, industry velocity, capability development, and CEO attention.

Table 26: MOC - Specific Texts

\begin{tabular}{ll} 
Author(s) & Article Title \\
\hline $\begin{array}{l}\text { Fletcher and Huff } \\
\text { (1990) }\end{array}$ & Argument mapping \\
& \\
\hline $\begin{array}{l}\text { Palich and Bagby } \\
\text { (1995) }\end{array}$ & Using Cognitive Theory to Explain \\
\end{tabular}

\section{Article Content}

Presents a method of argument mapping based on the philosophy of Stephen Toulmin, an English philosopher, who sees argument as not being logical, but to be a rhetorical device with its own structure.

Based on Categorization Theory, hypothesizes that entrepreneurs differ in cognitive processes. Presents research through 92 questionnaires to show this is so and suggests it may be possible to train people to cognitively get it 'right'.

\begin{tabular}{|c|c|c|}
\hline $\begin{array}{l}\text { Grønhaug and } \\
\text { Falkenberg (1998) }\end{array}$ & $\begin{array}{l}\text { Success Attributions Within and Across } \\
\text { Organizations }\end{array}$ & $\begin{array}{l}\text { Uses attribution theory to hypothesize how perceptions } \\
\text { drive outcomes. Shows some basis for these } \\
\text { hypotheses via a study of Norwegian newspaper } \\
\text { industry. }\end{array}$ \\
\hline Rindova (1999) & $\begin{array}{l}\text { What Corporate Boards Have to do } \\
\text { with Strategy }\end{array}$ & $\begin{array}{l}\text { Suggests a series of probabilistic hypothesizes of how } \\
\text { boards involve themselves cognitively in strategy. }\end{array}$ \\
\hline $\begin{array}{l}\text { Bogner and Barr } \\
\text { (2000) }\end{array}$ & $\begin{array}{l}\text { Making Sense in Hypercompetitive } \\
\text { Environments }\end{array}$ & $\begin{array}{l}\text { Proposes that managerial cognition is different in } \\
\text { hypercompetitive markets, as it is adaptive (cognitive } \\
\text { diversity, rapid decision making, experiments), and it } \\
\text { remains, even when competition stabilizes. }\end{array}$ \\
\hline $\begin{array}{l}\text { Tripsas and Gavetti } \\
\text { (2000) }\end{array}$ & Capabilities, Cognition, and Inertia & $\begin{array}{l}\text { Demonstrates that cognition contributes to managerial } \\
\text { inertia as it affects how organizations adapt, through an } \\
\text { inductive and longitudinal case study of Polaroid. }\end{array}$ \\
\hline $\begin{array}{l}\text { Hodgkinson and } \\
\text { Maule (2002) }\end{array}$ & The Individual in the Strategy Process & $\begin{array}{l}\text { Defines two types of cognition: heuristics and thought. } \\
\text { Shows that mapping can change the use of heuristics. } \\
\text { Suggests the cognitive perspective is still in its infancy } \\
\text { and not that practical. }\end{array}$ \\
\hline Rouleau (2005) & $\begin{array}{l}\text { Micro-practices of Strategic } \\
\text { Sensemaking and Sensegiving }\end{array}$ & $\begin{array}{l}\text { Through ethnographic research, shows how middle } \\
\text { managers' sensemaking and sensegiving draws on tacit }\end{array}$ \\
\hline
\end{tabular}


knowledge, and identifies micro-processes of translating, overcoding, discipline, and justifying.

\begin{tabular}{lll}
\hline $\begin{array}{l}\text { Nadkarni and Barr } \\
\text { (2008) }\end{array}$ & $\begin{array}{l}\text { Environmental Context, Managerial } \\
\text { Cognition, and Strategic Action }\end{array}$ & $\begin{array}{l}\text { Hypothesizes that industry velocity drives attention } \\
\text { focus and causal logics, which jointly drive speed of } \\
\text { strategic response. Analysis of letters to shareholders } \\
\text { supports this hypothesis. }\end{array}$ \\
\hline $\begin{array}{ll}\text { Laamanen and } & \text { Cognitive Dynamics of Capability } \\
\text { Development Paths } & \text { Presents a longitudinal case study and finds that } \\
& \text { instrumental cognition, shifts in managerial attention, } \\
\text { and management foresight drive capability }\end{array}$ \\
$\begin{array}{ll}\text { Eggers and Kaplan } \\
\text { (2009) }\end{array}$ & $\begin{array}{l}\text { Cognition and Renewal } \\
\text { development. }\end{array}$ \\
& $\begin{array}{l}\text { Hypothesizes that CEO attention has organizational } \\
\text { effects, and confirms this through research of patent } \\
\text { data and letters to shareholders. }\end{array}$
\end{tabular}

As with the previous groups of texts, there is a broad variety of approaches to strategy and cognition.

\section{Decision Making}

These papers see decision making as a fundamental process of strategy. Specific approaches are understanding problem formulation, multiple perspectives on decision-making, modelling decision-making, causality, and sensemaking.

Table 27: MOC - Decision Making Texts

\begin{tabular}{|c|c|c|}
\hline Author(s) & Article Title & Article Content \\
\hline $\begin{array}{l}\text { Lyles and Thomas } \\
\text { (1988) }\end{array}$ & Strategic Problem Formulation & $\begin{array}{l}\text { Sees cognition as important and focuses on defining five } \\
\text { strategic problem formulation processes which are } \\
\text { proposed as a basis for research. }\end{array}$ \\
\hline Schwenk (1988) & $\begin{array}{l}\text { The Cognitive Perspective on Strategic } \\
\text { Decision Making }\end{array}$ & $\begin{array}{l}\text { Summarizes four topics (cognitive heuristics and biases, } \\
\text { cognitive frames, strategic assumptions, analogy and } \\
\text { metaphor), and proposes an integrated cognitive } \\
\text { decision-making model. }\end{array}$ \\
\hline $\begin{array}{l}\text { El Sawy and } \\
\text { Pauchant (1988) }\end{array}$ & $\begin{array}{l}\text { Triggers, Templates, and Twitches in } \\
\text { the Tracking of Emerging Strategic } \\
\text { Issues }\end{array}$ & $\begin{array}{l}\text { Proposes a macro-level process model of strategy } \\
\text { (Triggers, Templates, and Twitches) and supports this } \\
\text { through a repertory grid survey of } 17 \text { managers. }\end{array}$ \\
\hline Hall (2002) & $\begin{array}{l}\text { Gaining Understanding in a Complex } \\
\text { Cause-effect Policy Domain }\end{array}$ & $\begin{array}{l}\text { Researches causality of decision-making using artificial } \\
\text { intelligence in place of human subjects. }\end{array}$ \\
\hline
\end{tabular}




$\begin{array}{ll}\text { McKenzie, Woolf, } \quad \text { Cognition in Strategic Decision Making } & \text { Sees conventional thinking as limited. Proposes an } \\ \text { van Winkelen and } & \text { approach of fluid sense-making, delaying closure, and } \\ \text { Morgan (2009) } & \text { going beyond contradictions, that is supported by } \\ & \text { interviews with successful CEOs. }\end{array}$

All these texts find decision making to be explicable and capable of being modelled.

\section{Biases}

Many researchers consider biases (as defined in behavioural decision theory), and some researchers extend the concept of bias to mean that cognition is 'at fault'. Schwenk (1984), investigating biases in decisionmaking, finds cognitive heuristics to be not 'totally harmful': "[cognitive simplification processes] should not be regarded as universally harmful in organizations" (pp. 123-124). Barnes (1984, p. 132) statement that "judgments may not properly reflect underlying beliefs" is supported by others: "The problem is, of course, that mental models may be, or become, inaccurate" (Barr et al., 1992, p. 16). Thus, cognition has been seen as a problem.

Table 28: MOC - Biases Texts

\begin{tabular}{|c|c|c|}
\hline Author(s) & Article Title & Article Content \\
\hline Schwenk (1984) & $\begin{array}{l}\text { Cognitive Simplification Processes in } \\
\text { Strategic Decision-making }\end{array}$ & $\begin{array}{l}\text { Applies cognitive biases, from cognitive psychology and } \\
\text { behavioural decision theory, to a standard strategy } \\
\text { process and suggests further research. }\end{array}$ \\
\hline Barnes (1984) & $\begin{array}{l}\text { Cognitive Biases and Their Impact on } \\
\text { Strategic Planning }\end{array}$ & $\begin{array}{l}\text { Considers cognitive biases and suggests sensitivity } \\
\text { analysis is one way for planners to improve decisions. } \\
\text { Recognizes that producing positive change is difficult. }\end{array}$ \\
\hline $\begin{array}{l}\text { Ireland et al. } \\
\text { (1987) }\end{array}$ & Strategic Formulation Processes & $\begin{array}{l}\text { Hypothesizes that SWOT analyses vary according to } \\
\text { management level and industry, based on cognitive } \\
\text { biases. Demonstrates this in an empirical laboratory } \\
\text { study leading to a recommendation to use group } \\
\text { processes to resolve differences between managers. }\end{array}$ \\
\hline $\begin{array}{l}\text { Haley and Stumpf } \\
\text { (1989) }\end{array}$ & $\begin{array}{l}\text { Cognitive Trails in Strategic Decision } \\
\text { Making }\end{array}$ & $\begin{array}{l}\text { Creates a model that links Jungian types to five cognitive } \\
\text { biases, hypothesizes about the expected behaviours, } \\
\text { and finds the hypotheses are valid through laboratory } \\
\text { simulation. }\end{array}$ \\
\hline Bukszar (1999) & Strategic Bias & $\begin{array}{l}\text { Shows cognitive bias can lead to lack of strategy fit and } \\
\text { suggests managers should be careful about being } \\
\text { certain as it might just be their biases. }\end{array}$ \\
\hline
\end{tabular}




$\begin{array}{lll}\begin{array}{l}\text { Das and Teng } \\ \text { (1999) }\end{array} & \begin{array}{l}\text { Cognitive Biases and Strategic Decision } \\ \text { Processes }\end{array} & \begin{array}{l}\text { Suggests biases (prior knowledge, limited scope, } \\ \text { probabilities, manageability) do not apply uniformly to }\end{array} \\ & \text { five decision making models (rational, avoidance, logical } \\ & \text { incrementalism, political, garbage can). }\end{array}$

These texts, in a variety of ways, integrate biases with some aspect of strategy decision making.

\section{Mental Models}

'Mental models' is the most frequent theme in the MOC articles reviewed. As the texts below show, there is theorizing about what mental models are, and there are techniques proposed for discovering mental models. There is also empirical research that describes actual mental models. These approaches often go beyond consideration of individual mental models to consider the mental models of strategic groups (i.e. groups of individuals who share common views).

For some authors, the challenge with levels of cognition suggests that cognitive maps are useful tools, rather than being representations of the mind. For example, Eden (1992, p. 262) suggests that maps are better at representing knowledge than are other methods, and thus have some utility: "thus the only reasonable claim that can be made of cognitive maps as an artefact ... is that: (1) they may represent subjective data more meaningfully that other models and so have utility for researchers interested in subjective knowledge, and (2) they may act as a tool to facilitate decision-making, problem solving, and negotiation with the context of organization." Spender (1989) also finds that his concept of an industry recipe, this being a way to represent mental states, is limited to being a useful tool.

Table 29: MOC - Mental Models / Strategic Groups Texts

\begin{tabular}{|c|c|c|}
\hline Author(s) & Article Title & Article Content \\
\hline Huff (1982) & $\begin{array}{l}\text { Industry Influences on Strategy } \\
\text { Reformulation }\end{array}$ & $\begin{array}{l}\text { Suggests cognition is important and promotes strategic } \\
\text { frames of industry groups as a future fruitful line of } \\
\text { research. }\end{array}$ \\
\hline Eden (1988) & Cognitive mapping & $\begin{array}{l}\text { Proposes that cognitive mapping be used as a tool for } \\
\text { presenting group-level ideas. Presents computer tools } \\
\text { to do so. }\end{array}$ \\
\hline Porac et al. (1989) & $\begin{array}{l}\text { Competitive Groups as Cognitive } \\
\text { Communities }\end{array}$ & $\begin{array}{l}\text { Proposes that industry group and firm strategies can be } \\
\text { understood through managers' mental models and } \\
\text { demonstrates through qualitative research. }\end{array}$ \\
\hline Spender (1989) & Industry Recipes & $\begin{array}{l}\text { Investigates how industry recipes both enable and } \\
\text { constrain managerial judgment. }\end{array}$ \\
\hline
\end{tabular}




\begin{tabular}{|c|c|c|}
\hline Huff (1990) & Mapping Strategic Thought & $\begin{array}{l}\text { Presents six subjects of general cognitive study } \\
\text { (perception and interpretation, attention, memory, } \\
\text { knowledge representation and learning, problem } \\
\text { solving, social cognition). Presents five mental mapping } \\
\text { techniques. }\end{array}$ \\
\hline $\begin{array}{l}\text { Bougon et al. } \\
\text { (1990) }\end{array}$ & $\begin{array}{l}\text { Identifying Strategic loops: The Self-Q } \\
\text { Interviews }\end{array}$ & $\begin{array}{l}\text { Goes beyond Weick's "I don't know what I mean until I } \\
\text { have said it" to "until I see what I ask myself", that is, } \\
\text { asks interviewees to use introspection. }\end{array}$ \\
\hline Barr et al. (1992) & $\begin{array}{l}\text { Cognitive change, strategic action, and } \\
\text { organizational renewal }\end{array}$ & $\begin{array}{l}\text { Researches why some firms respond to environmental } \\
\text { changes through empirical analysis of letters to } \\
\text { shareholders, with hypotheses and results presented as } \\
\text { organizational mental models. }\end{array}$ \\
\hline Bougon (1992) & Congregate Cognitive Maps & $\begin{array}{l}\text { Reviews different types of cognitive maps and suggests } \\
\text { that a congregate cognitive map underlies all variations. }\end{array}$ \\
\hline Eden (1992) & On the Nature of Cognitive Maps & $\begin{array}{l}\text { Shows cognitive maps show content, not process, as } \\
\text { they do not contain emotion, so cannot predict } \\
\text { behaviour and are, at best, a tool to promote debate. }\end{array}$ \\
\hline $\begin{array}{l}\text { Fiol and Huff } \\
\text { (1992) }\end{array}$ & Maps for Managers & $\begin{array}{l}\text { Suggests that a broad portfolio of cognitive maps is both } \\
\text { possible and required for managers (causal, emphasis, } \\
\text { classification, influence). They are useful for focusing } \\
\text { attention, revealing gaps, and highlighting key factors. }\end{array}$ \\
\hline $\begin{array}{l}\text { Reger and Huff } \\
\text { (1993) }\end{array}$ & Strategic Groups & $\begin{array}{l}\text { Adds a cognitive element to strategic groups and } \\
\text { demonstrates this through a repertory grid analysis of } \\
\text { Chicago banking. }\end{array}$ \\
\hline $\begin{array}{l}\text { Bogner and } \\
\text { Thomas (1993) }\end{array}$ & $\begin{array}{l}\text { The Role of Competitive Groups in } \\
\text { Strategy Formulation }\end{array}$ & $\begin{array}{l}\text { Proposes an integrated model for strategic groups (e.g. } \\
\text { as per Michael Porter's use) and cognitive groups. }\end{array}$ \\
\hline $\begin{array}{l}\text { Hodgkinson and } \\
\text { Johnson (1994) }\end{array}$ & $\begin{array}{l}\text { Exploring the Mental Models of } \\
\text { Competitive Strategists }\end{array}$ & $\begin{array}{l}\text { Through interpretative research in the grocery industry, } \\
\text { shows diversity in individuals' mental models, and } \\
\text { suggests the concept of consensus in a cognitive group } \\
\text { may be flawed. }\end{array}$ \\
\hline Ginsberg (1994) & $\begin{array}{l}\text { Minding the Competition: From } \\
\text { Mapping to Mastery }\end{array}$ & Proposes a socio-cognitive model of competition. \\
\hline
\end{tabular}




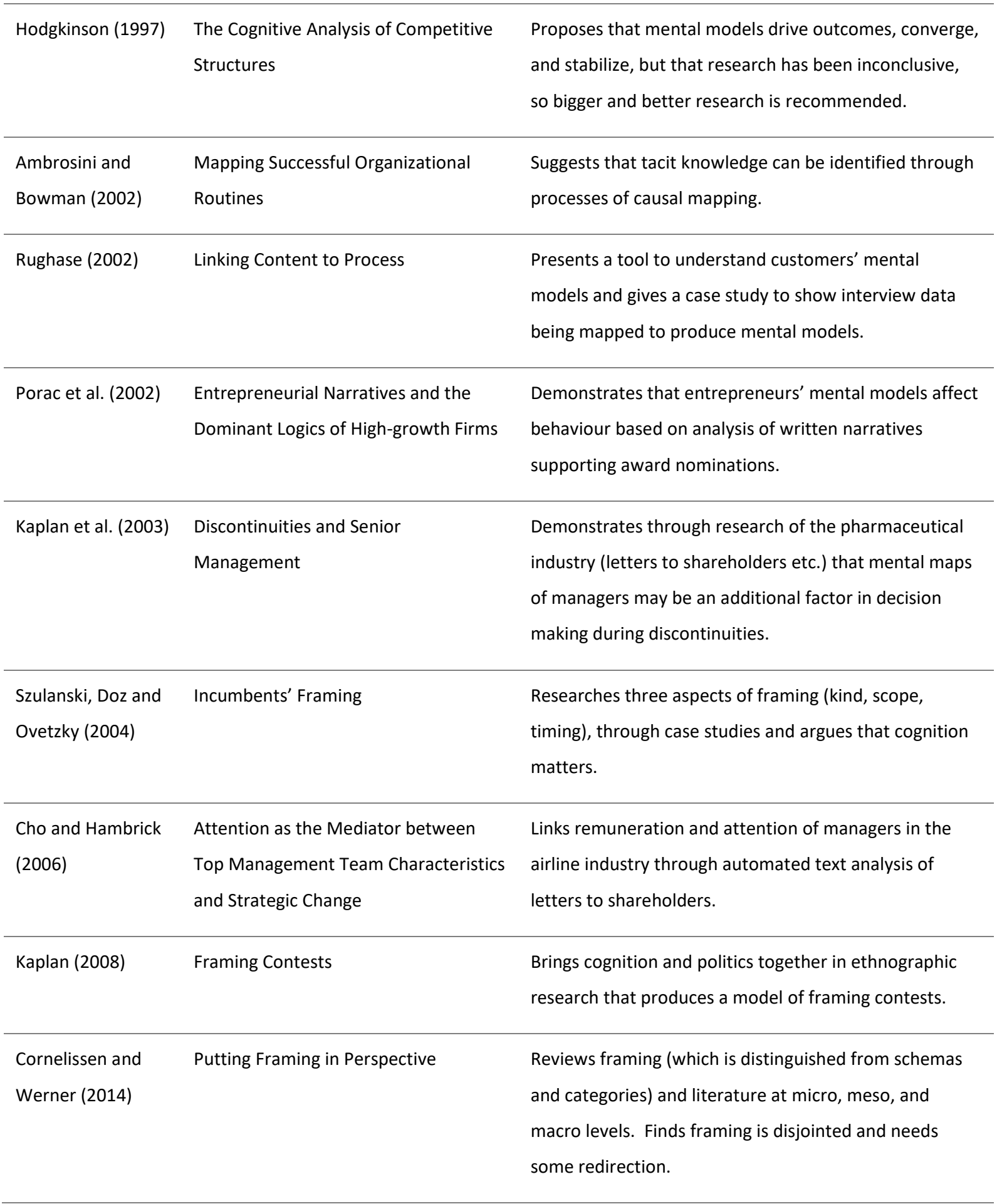

There is a substantial literature that considers mental models. The texts reviewed suggest that researchers build on previous work, more so than in the previous categories of MOC texts. 


\section{Reviews}

The papers below are reviews of the MOC field, often with descriptions of how the field operates and with suggestions as to how to improve the field. For example, Spender and Eden (1998, p. 3) state a basic assumption of MOC: "We assume ... that we are able to gain access to the personal model which the manager has created," Kaplan (2011, p. 665) finds that the field has diffused into other fields: "Rather than managerial cognition becoming its own independent field, cognitive concepts have diffused throughout work in many different managerial fields, leading to a proliferation of terms, concepts, and approaches," and Gavetti and Ocasio (2015, p. xxiii) suggest a way forward: "For us then, one path forward is one in which a behavioural view of strategy premised on representation and an attention-based view of strategy are synthesized."

Table 30: MOC - Review Texts

\begin{tabular}{|c|c|c|}
\hline Author(s) & Article Title & Article Content \\
\hline Walsh (1995) & Managerial and organization cognition & $\begin{array}{l}\text { Reviews MOC based on knowledge structures at varying } \\
\text { levels and suggests various ways forward. }\end{array}$ \\
\hline $\begin{array}{l}\text { Spender and } \\
\text { Eden (1998) }\end{array}$ & $\begin{array}{l}\text { Managerial and Organizational } \\
\text { Cognition: Introduction }\end{array}$ & $\begin{array}{l}\text { Finds } \mathrm{MOC} \text { falling short. There is a need for } \\
\text { understanding of: the mind; relationships between } \\
\text { content/process and behaviour; and knowledge - } \\
\text { choice relationship. Possibilities are networks and the } \\
\text { subconscious. }\end{array}$ \\
\hline $\begin{array}{l}\text { Porac and Thomas } \\
\text { (2002) }\end{array}$ & Managing Cognition and Strategy & $\begin{array}{l}\text { MOC has streams: behavioural decision making; } \\
\text { mapping; decision processes. Suggests that what is } \\
\text { missing is dynamic cognitive structures, and multiple } \\
\text { cognitive structures interacting over time. }\end{array}$ \\
\hline Kaplan (2011) & Research in Cognition and Strategy & $\begin{array}{l}\text { Reviews } 20 \text { years of MOC, based on the article by Porac } \\
\text { et al. (1989) on the Scottish knitwear industry, and finds } \\
\text { MOC has gained legitimacy and defused into multiple } \\
\text { fields. }\end{array}$ \\
\hline $\begin{array}{l}\text { Gavetti and Ocasio } \\
\text { (2015) }\end{array}$ & Cognition and Strategy: Introduction & $\begin{array}{l}\text { Suggests that MOC is diversified, but still } \\
\text { preparadigmatic. Sees that Cyert and March essentially } \\
\text { directed MOC towards behaviourism, but following } \\
\text { Simon leads to more forward-looking cognition. }\end{array}$ \\
\hline
\end{tabular}

These reviews find that MOC is diversified and established, but do not suggest that $\mathrm{MOC}$ has being influential in changing practical behaviour or that it has developed any theoretical positions likely to change behaviour. In fact, the last review of Gavetti and Ocasio (2015) suggests that MOC has been more engaged with describing behaviour than with leading behaviour. 


\section{Knowledge Summary}

The MOC texts reviewed suggest:

- researchers find many ways to think about strategy and cognition

- decision making, biases, and mental models are established ways of perceiving strategy and cognition

- $M O C$ is an established field, but not necessarily with any practical benefits to the business community

So MOC has a lot of knowledge, and that knowledge is varied. Further, that knowledge is often structured in various overarching models of $\mathrm{MOC}$ itself and in specific topical areas. 


\section{Social Effects / Subjectivity}

MOC's few comments regarding practitioners suggest that MOC does not seek to have social effects outside academia and has little influence on how strategist perceive themselves.

The comments of three theorists demonstrate largely abstract treatments of practitioners:

Lyles and Thomas (1988, p. 140) ask whether practitioners know and use the models they research: “Do successful problem formulators understand and use each of the five decision-making models?”

Reger and Huff (1993, p. 105) hope that managers' behaviour aligns with researchers' views of managers: "If groups of firms are 'real' for strategists, then research at the strategic group level is much more important than if groups are only the result of researchers' analytical exercises."

Barnes (1984, p. 135) states, "For strategic planners, the findings reported here pose what may be a difficult challenge: to recognize their own cognitive limitations, ..."

Other authors suggest solutions for practitioners, including working as groups, using mapping tools, and learning cognitive skills:

Ireland et al. (1987, p. 482) suggest 'group working' as a solution: "These findings suggest that an emphasis must be placed on group processes to resolve the differences between the individual managers."

Eden (1988, p. 7) suggests that managers could use mapping tools: "In the practical setting of working with a team of busy managers cognitive mapping is a tool for building interest from all team members in the problem solving activity."

Palich and Bagby (1995, p. 426) suggest that managers can learn cognitive skills: "Unlike personal traits, cognitive traits can be changed. ... if certain aspects of cognition are different for entrepreneurs, or more successful entrepreneurs, these processes can be learned or mastered through programs such as 'frame of reference' training."

These are the few direct references to actual practitioners that were found. Of those found, the high level of abstraction of the discussions suggests limited social effects. The exception found is the recommendation to use mental model mapping techniques. This has had some influence based upon the candidate's own experience, however this now seems to have dissipated. So based on the texts reviewed, MOC has limited social effects and leaves little trace on strategy practitioners. 


\section{Foucauldian Summary}

The MOC texts suggest an established academic field:

Table 31: MOC - Foucauldian Summary

\begin{tabular}{l|l|}
\hline Conditions of Possibility & A belief in scientific process and borrowing from the human sciences \\
\hline Problematization & $\begin{array}{l}\text { The problem is the study of MOC itself, leading to the need to fill gaps, expand } \\
\text { scope, find new approaches, and integrate approaches. }\end{array}$ \\
\hline Knowledge & A broad knowledge of overarching structures, and sub-fields including decision \\
\hline Social Effects & making, biases and mental models \\
\hline Subjectivity & Negligible for strategists \\
\hline
\end{tabular}

\section{Conditions of Possibility}

The literature reviewed suggests that while MOC's own foundations are rarely declared, $\mathrm{MOC}$ is based in scientific method as it aims to accurately represent, measure, and describe human behaviour. MOC borrows from sociology, various forms of psychology, cognitive science, organization studies, and management science.

\section{Problematization}

MOC's problem is MOC, with just a touch of the business world. Within the texts reviewed, some theorists highlight that business world strategists have cognitive challenges, but the majority of theorists find the problem to be the study of MOC itself. So MOC reflects on its own cognitions with an inwards intellectual gaze made apparent in many of the texts studied. As expected in an academic field, MOC's problems lead to further research to fill in gaps, to expand scope, to add approaches, and to integrate approaches.

\section{Knowledge}

As a field that invites multiple approaches from other fields, MOC generates a lot of knowledge. The most prevalent forms relate to mental models and strategic groups, biases, and decision making. A number of other specific topics are addressed and many reviews are undertaken as MOC grapples with itself. 


\section{Social Effects / Subjectivity}

Being an academic field, MOC's influence on the wider world of business strategists is somewhat dependent on its accessibility to that audience. While it has produced tools such as mental maps, these are of minimal influence compared to discourses such as the Classicists reviewed in the previous chapter. Therefore, it is difficult to see MOC having significant social effects outside academia. With this limited reach, how the strategist feels about themselves is unlikely to be much affected.

\section{Summary}

MOC is a broad discourse. The topics of managerial cognition and organizational cognition allow for a multiple of approaches, some of which coalesce into streams such as mental models, biases, and decision making. Having its own Academy of Management division, it has organizational coherence and multiple fora that facilitate a broad range of topics. How well it treats cognition is the subject of the next section. 


\subsection{Treatments of Cognition}

This section analyses $\mathrm{MOC}$ with respect to the Cognitive Heuristic, but first it considers the status of cognition within MOC. This additional analysis is performed because this is the one discourse that is specifically about cognition, and the centrality, or not, of cognition to MOC influences the overall findings and the following research. Hence, the initial consideration is the status of cognition in MOC.

\section{Status of Cognition in MOC}

That the word 'cognition' is part of the MOC title suggests that cognition might be central to MOC. However, while MOC gives cognition some recognition (c.f. the previous Classicist analysis which shows that cognition is ignored by many theorists), cognition being part of the MOC title does not mean that it is the central topic of the discourse. Most of the texts reviewed simply assume cognition, with only a few theorists explicitly stating that cognition is a critical element of strategy, while some others justify cognition by showing that it drives business outcomes.

The few theorists who stress the criticality of cognition to strategy include Barnes (1984) who notes that, "we seem to be overlooking a critical element in the strategy process - the capabilities of planners and decision makings to process and use information" (p. 129); Spender (1989, p. 185) who argues strongly for cognition: “I argue that organizational behaviour is managed, at the most fundamental level, through the ideas adopted by people in the organization;" and Stubbart (1989, p. 327) who is more emphatic: "managerial cognition (thinking) represents a vital 'missing link' in strategy." Another who stresses the importance of cognition is Schwenk (1988).

Six researchers find it necessary to establish links between cognition and strategy/strategic behaviour:

Stubbart (1989, p. 330) states that "Managers take strategic actions mainly for reasons" (he suggests that other causes may be habit or mindlessness).

Thomas et al. (1993) go further than just making a proposition, conducting instead a study that demonstrated that cognition leads to performance: "In response to the fundamental research question of whether there are demonstrable links between sensemaking and variation in organizational performance, the results of this study indicate clearly that there are" (p. 258).

Tripsas and Gavetti (2000, p. 1147) find justification for studying cognition: "The Polaroid story clearly illustrates the importance of managerial cognitive representations..."

Kaplan et al. (2003, p. 227) are somewhat supportive of cognition as a factor of performance: “Our findings are consistent with the hypothesis that managerial sensemaking (recognition and interpretation) of the environment may be an additional explanatory factor in understanding firm actions during periods of technological discontinuity." 
Szulanski et al. (2004, p. 99) are more direct: “Our findings support extant arguments about the impact of framing on the strategy process."

Kaplan (2011, p. 689) finds cognition to be justified as it has been studied: “Cognitive explanations have gained legitimacy and have been analyzed alongside more traditional explanatory factors in strategic management research."

So while cognition is part of the MOC name, the texts reviewed mostly assume cognition, even though some authors do note that cognition is critical to strategy, and others establish a connection between cognition and outcomes. Notwithstanding this lack of explicit priority, cognition is treated, as the following analysis shows.

\section{Types of Abstraction}

Abstractions are often conceptual within MOC, with some operational and phenomenal treatments. These abstractions occur in many different ways, from combining models to inventing new ones. A set of MOC Cognitive Influence Models and Cognitive Hybrid Models (see definitions on page 86) illustrates how MOC abstracts cognition.

\section{Conceptual}

Cognition is modelled conceptually in a variety of intricate and complex ways.

Schwenk (1988) provides a Cognitive Influence Model, shown below, that he proposes to be "an integrative model of cognitions in strategic decision making". The three boxes on the left contain cognitive aspects of humans and modes of human communication. As the title of the diagram, "Strategic problem comprehension", indicates, these human cognitive elements contribute to the development of schemas and the application of schemas to strategic problems. While theoretically plausible, the depiction seems very distant from the actual thinking of individuals and decisions in groups. Although the Cognitive Influence Model conceptually suggests how thought might develop, from the candidate's experience, it is far away from the phenomena of cognition. That is, we do not think like this.

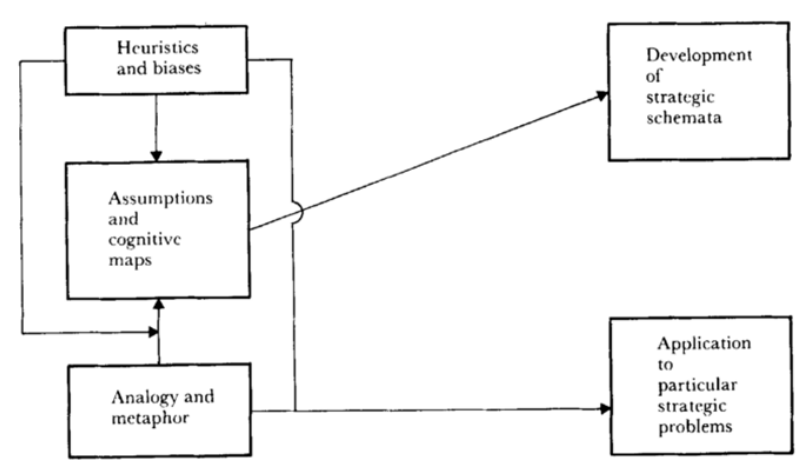

Figure 25: "Strategic problem comprehension", reprinted from The cognitive perspective on strategic decision making (p. 49), by C. R. Schwenk, Journal of Management Studies, 25(1), 1988 (pp. 41-55), Copyright 2007, John Wiley and Sons. 
Barr et al. (1992), with a focus on mental models, present a Cognitive Hybrid Model, shown below, of how mental models change. Like Schwenk above, this is a highly conceptual abstraction, but this model suggests that Learning can be understood as a mixture of influences and actions. The idea that mental models influence what we think of, which then influences how our mental models change is simplistic but useful. But that is the limit of this model and there is no mention of the subconscious.

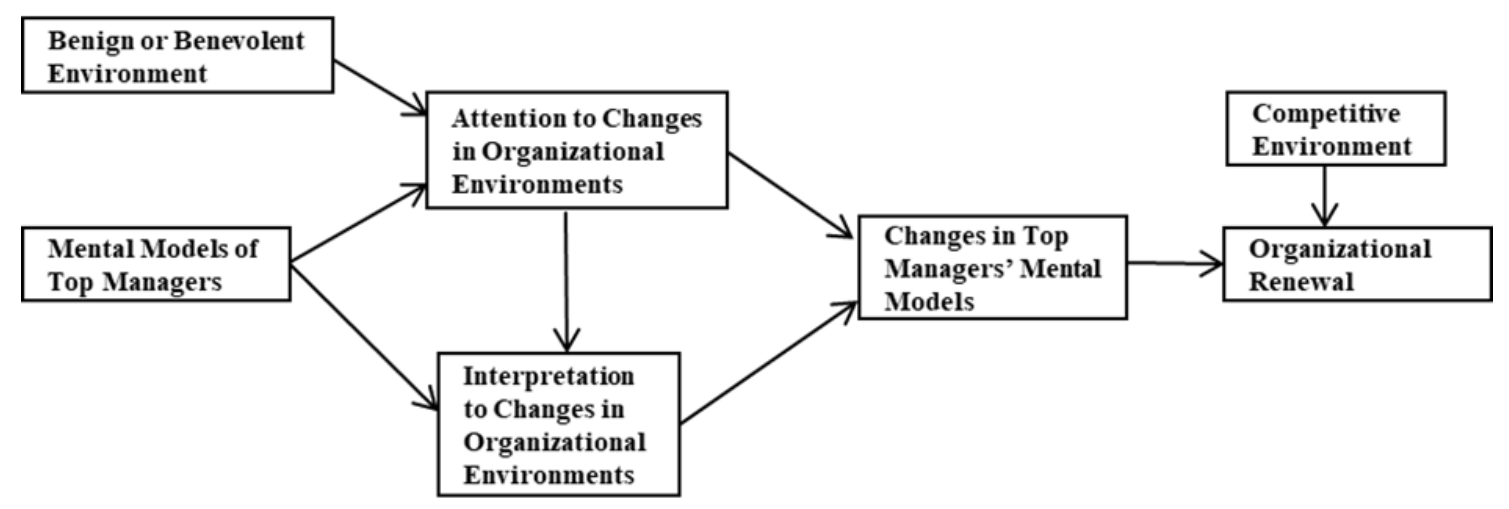

Figure 26: "A cognitive model of organizational renewal", reproduced from Cognitive change, strategic action, and organizational renewal (p. 18), P. S. Barr, J. L. Stimpert, \& A. S. Huff, Strategic Management Journal, 13(S1), 1992 (pp. 15-36), Copyright 1992 by John Wiley \& Sons.

Rindova (1999) presents the Cognitive Influence Model, below, focused on directors' contributions. This model includes structures and environment, but also then suggests that some cognition processes have 'effects' that contain 'processes' such as 'scanning'. The Cognitive Influence Model suggests that a director's participation in a cognitive process has certain outcomes. This is a simplistic behavioural notion, and there is no in-depth consideration of how directors think.

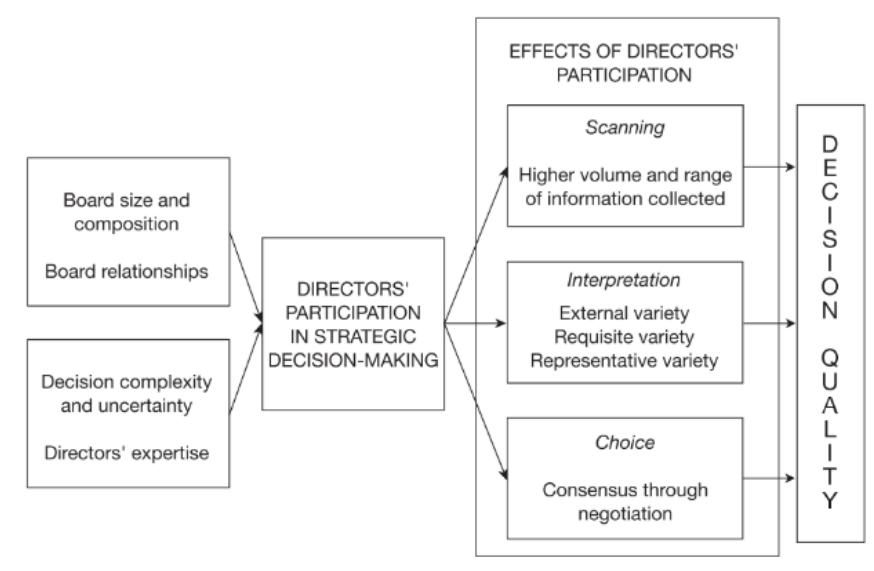

Figure 27: "A model of directors' cognitive contribution to strategic decision making", reprinted from, What corporate boards have to do with strategy: A cognitive perspective (p. 958), by V. P. Rindova, Journal of Management Studies, 36(7), 1999, (pp. 953-975). Copyright Blackwell Publishers Ltd. 1999. 
Kaplan (2008) interprets strategy making as framing contests between actors considered at an organizational level: "I describe the underlying mechanisms in a model of organizational framing contests." The Cognitive Influence Model below is a highly complex mixture of individual cognition, activities, and conceptual entities. But, clearly, it is highly conceptual and not intended to mirror actual cognition in human minds.

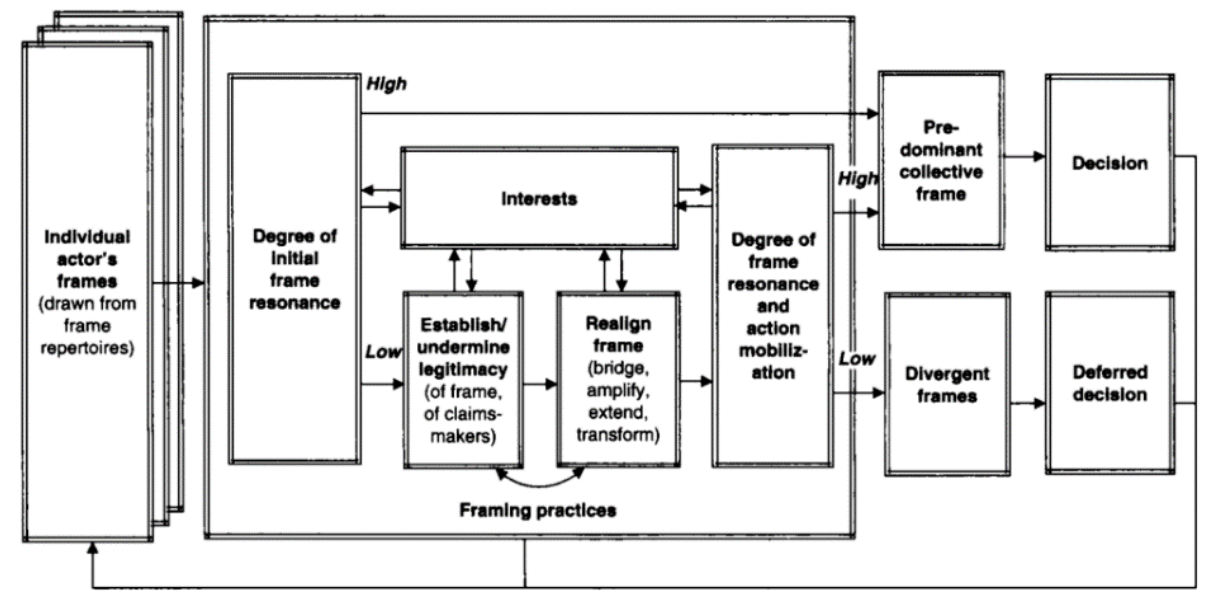

Figure 28: "Framing Contests", reprinted from, Framing contests: strategy making under uncertainty (p. 736), by S. Kaplan, Organization Science, 19(5), 2008, (pp. 729-752), copyright 2008 INFORMS.

Bukszar (1999, p. 109), gets close to the actualities of human thought, but without specifically mentioning aspects of reasoning, memory, judgment etc. In this Cognitive Hybrid Model he comes from a desire to understand bias in strategy and presents a dynamic picture of factors that affect human thought conceived of as bias. Again, the Cognitive Hybrid Model is a high abstraction.

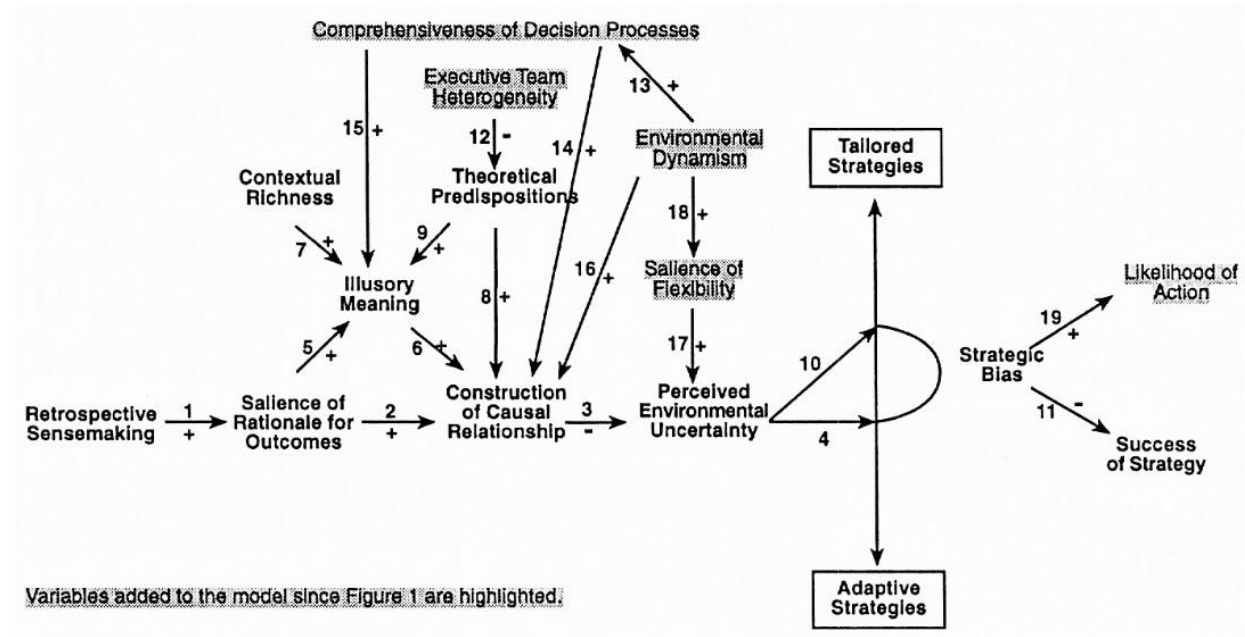

Figure 29: "Model of strategic bias", reprinted from Strategic bias: The impact of cognitive biases on strategy (p. 109), E. Bukszar, Jr, Revue Canadienne des Sciences de l’Administration, 16(2), 1999 (pp. 105-117). Copyright ASAC 1999. 
Rouleau (2005) discusses sensemaking and sensegiving using processes within a knowledge framework in the figure below. In this Cognitive Influence Model, processes such as 'justifying' could be interpreted as being cognitive, but Rouleau means this more as a communication technique. So once again this Cognitive Influence Model is highly abstract.

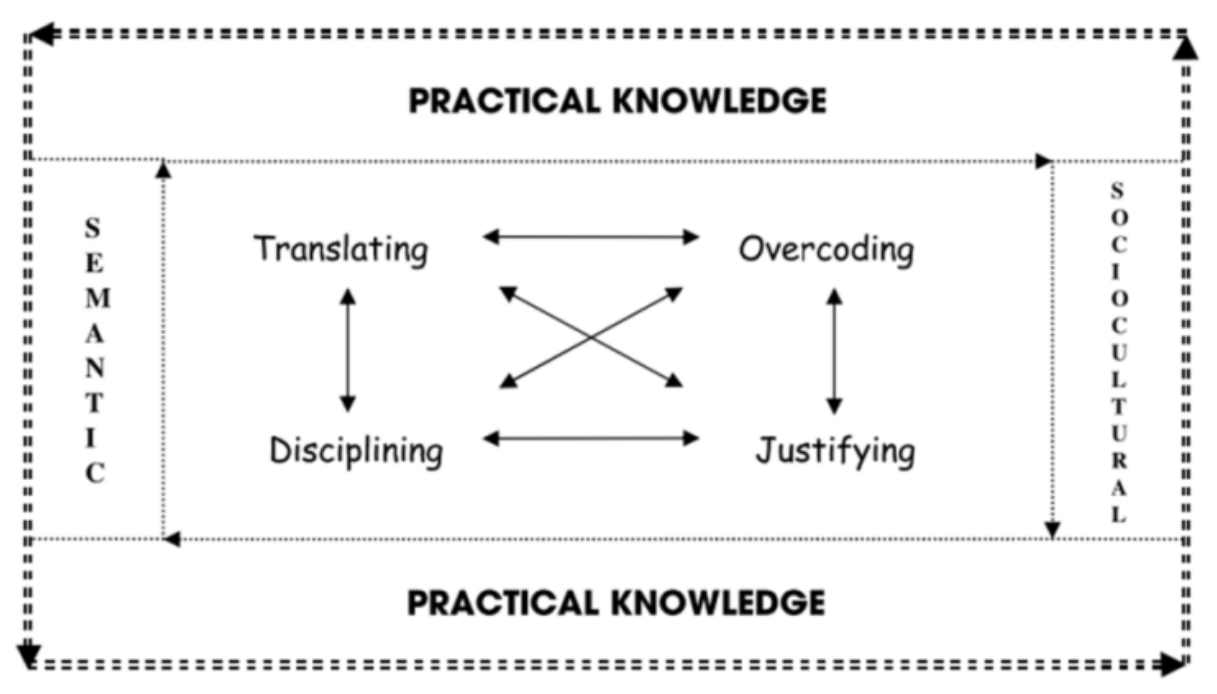

Figure 30: "Strategic sensemaking and sensegiving in practice", reprinted from Micro-practices of strategic sensemaking and sensegiving: How middle managers interpret and sell change every day (p. 1431), by L. Rouleau, Journal of Management Studies, 42(7), 2005, (1413-1441). Copyright Blackwell Publishers Ltd. 1999. Other conceptual abstractions within the texts reviewed are:

- Haley and Stumpf (1989) combine Jungian personality types with biases, but without reference to basic cognition concepts.

- Similarly, at a high level of abstraction, Das and Teng (1999) mix five schools of strategy with four biases and suggest that not all biases apply to all schools.

- El Sawy and Pauchant (1988) abstract strategy formation as triggers, templates, and twitches, but without any strong relationships with cognition.

All of these interpretations illustrate organisational behaviour in some manner. While it can justifiably be claimed that any interpretation must be, in some way, an abstraction, the point to note here is that MOC has many high-level conceptual abstractions. In the candidate's view, these abstractions are gross abstractions that are far from actual experiences of doing strategy. Clearly there is a question of judgment, but these treatments seem to border on the transcendent, and because of this, their utility for strategists may be limited. 


\section{Operational}

Two theorists are found who treat cognition operationally. Van der Heijden and Eden (1998) approach cognition at a high theoretical level as they integrate rationalistic, evolutionary, and processual schools of strategy with a learning loop to build an abstract view of the process of how people learn. In the Cognitive Process Model below, cognitive elements (experience, observation and reflection, formation, testing) make up a learning organization, but it is a very high-level description of what is a complex process.

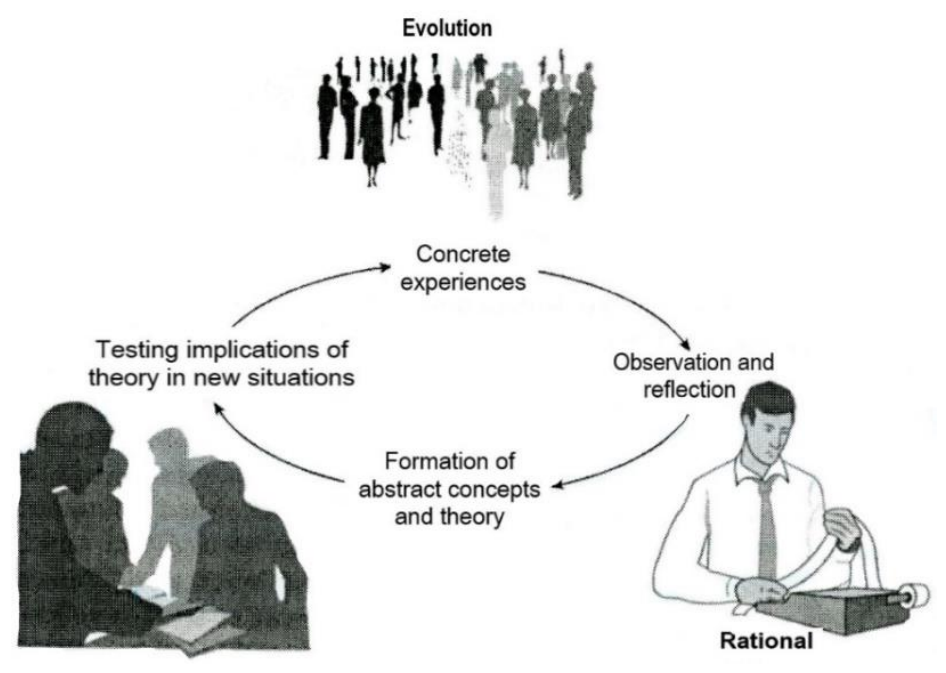

Figure 31: "The learning organization", reproduced from Managerial and organizational cognition: Theory, methods and research (p. 63), edited by K. Van der Heijden, and C. Eden, (1998), The theory and praxis of reflective learning in strategy making (pp. 58-75), by C. Eden \& J.C. Spender, London, United Kingdom: Sage. Copyright Kees van der Heijden and Colin Eden 1998.

Eggers and Kaplan (2013) produce another high-level Cognitive Process Model, below, as they include cognition actions within a traditional model of capability development. The sequence of steps is clear, and they are high-level.

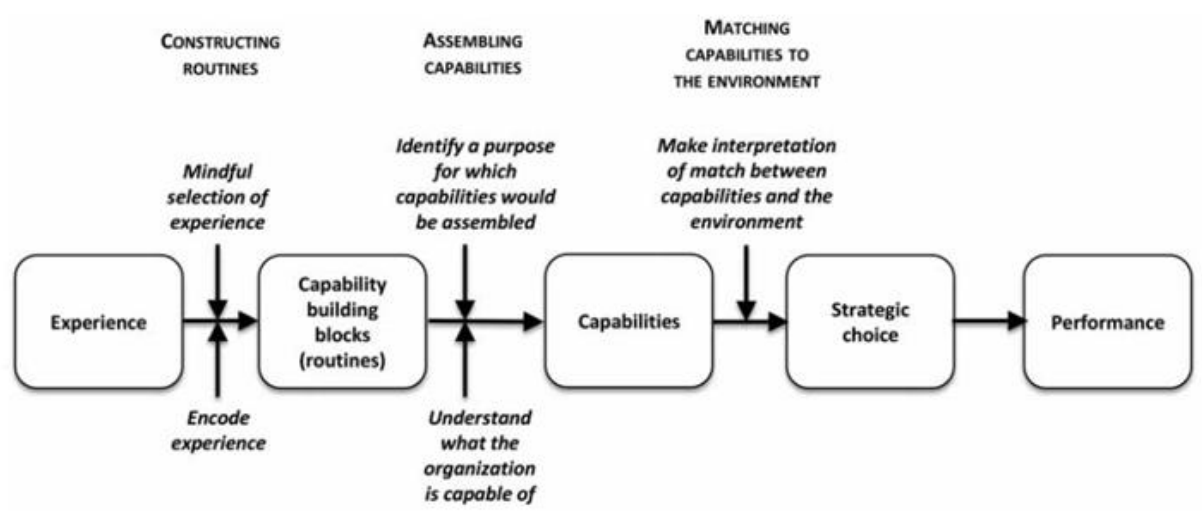

Figure 32: "Cognition and Capabilities - A Linear Model.", reprinted from Cognition and capabilities: A multilevel perspective, J. P. Eggers, \& S. Kaplan, The Academy of Management Annals, 7(1), 2013, (pp. 295-340), Copyright 2013 Academy of Management. 


\section{Phenomenal}

Empirical research treats cognition as a phenomenon (Ambrosini \& Bowman, 2002; Barr et al., 1992; Cho \& Hambrick, 2006; Eggers \& Kaplan, 2009; El Sawy \& Pauchant, 1988; Haley \& Stumpf, 1989; Hall, 2002; Hodgkinson \& Johnson, 1994; Hodgkinson \& Maule, 2002; Huff, 1982; Ireland et al., 1987; Kaplan, 2008; Kaplan et al., 2003; Laamanen \& Wallin, 2009; McKenzie et al., 2009; Nadkarni \& Barr, 2008; Palich \& Bagby, 1995; Porac et al., 1989; Reger \& Huff, 1993; Rouleau, 2005; Rughase, 2002; Spender, 1989; Szulanski et al., 2004; Thomas et al., 1993; Tripsas \& Gavetti, 2000).

There is a broad spectrum of research approaches in these texts (number of texts in brackets):

- input from introspective managers (2)

- ethnographic (2)

- surveys and interviews (12)

- document analysis (6)

- simulation/Artificial Intelligence (3)

At one extreme, introspection is attempted by asking managers to explicitly consider their own minds. Bougon et al. (1990) suggest an approach called Self-Q in which the manager asks themselves what they think, that is, they use introspection: "Self-Q rests on the ... productive principle: How do I know what I think until I see what lask myself' (p. 328). However, in a later study this approach is condemned as being too difficult (Ambrosini \& Bowman, 2002). Such a position is supported by Ireland et al. (1987) who explicitly state that introspection cannot be used. This is based on advice from Argyris and Schön (1974) that a theory in use cannot be simply asked for from a manager, thereby precluding the use of introspection.

At the other extreme managers are not required because computer techniques are used, or documents are simply analyzed. In the middle ground, the researcher interprets either by being directly present or by asking specific questions of managers.

\section{Types of Abstraction Summarized}

The texts reviewed suggest that when MOC treats cognition conceptually and operationally, the treatment is at a high level of abstraction, bordering on the transcendent. While there is utility in any interpretation, the Cognitive Models presented seem to the candidate to be far from actual cognition and therefore of minimal utility.

However, when cognition is treated phenomenally, there is a broader range of levels as some MOC researchers attempt to access cognition directly, while others prefer to abstract away from actual cognitions and use artefacts as proxies for cognition. 


\section{Subject}

The cognifier, that is the thinking subject, is often the individual in MOC even if strategic groups are often discussed. From the perspective of mental models, Huff $(1982$, p. 130) considers mostly group dynamics, but recognizes that such groups are made up of individuals: "members of the same industry 'discipline' share a common world view." From the perspective of biases, Schwenk (1984, p. 114) discusses group consensus, but with a group based on individuals' views. Porac et al. $(1989$, p. 405) expressly recognize the issue of a group mental model as being problematic, and recognize that variations exist between firms and individuals. The authors then go on to research "core beliefs that are shared by many individuals." Stubbart (1989, p. 325) explicitly recognizes the individual nature of cognition: "In a general sense, everyone recognizes that managers think. But what kind of thinkers are thinking managers?" Hodgkinson $(1997$, p. 646) recognizes the individual thinker within industry evolution: “As industries evolve through the various stages of their life cycles, actors' mental models in competitive space become increasingly stable." These examples show how MOC often treats the subject as an individual.

However there are occasional reifications of the company, such as Lyles and Thomas (1988, p. 140) stating that, "as organizations learn, they are likely to develop strong skills in identifying strategic issues and formulating strategic problems." But such reifications of the cognifier are rare in the texts reviewed, with the subject being primarily an individual.

\section{Mind}

From the texts reviewed, MOC's overriding approach is that mind is conscious, with only a few examples of the subconscious being treated. MOC's treatment of bias is less certain, so is discussed separately.

\section{Conscious}

As show in the sections above, Knowledge and Types of Abstractions, there is a focus on conscious processes involving mental models and decision making. The summary of texts and diagrams shows how processes work and what is presented in minds. While these treatments of cognition are the norm in MOC, they are rarely explicitly justified, with only two exceptions: Huff (1990, p. 14) makes it very clear that these mental models are accessible: "I believe that mental maps can also be more than a methodological tool: we can hope to capture something that has the same essential characteristics as thought itself"; and Reger and Huff (1993, p. 106) suggest that specific conscious thought can be found and understood as 'group structures': "Strategists' perceptions of their competitors' strategies will be characterized by a group structure." While these authors are explicit about being able to find and analyse the conscious mind, for the majority of the authors the conscious mind is assumed.

\section{Subconscious}

For those few authors who do consider the subconscious mind, they do so as emotion and tacit knowledge. 
Eden (1992, p. 262) raises the issue of emotion: "The proposition that cognition and behaviour are linked is also problematic because it ignores the role of emotion." Otherwise, emotion is rarely even mentioned in the articles reviewed.

Eden and Spender (1998, p. 4) suggest a broad view of cognition that includes tacit knowledge: "Likewise there has been a widespread appreciation that much of human action is caused by non-conscious predispositions and modes of choice and everyone quotes Polanyi's pithy 'we know more than we say'." Spender (1998, p. 22) in the same volume recognizes tacit knowledge: "Thus an essential dimension of collective mind is that it is both contextualized in a particular field of activity, such as surgery or carrier-deck management, but it is also embedded in practice."

Ambrosini and Bowman (2002) suggest that tacit knowledge is important, search for it, and describe it in causal maps. Rouleau (2005, p. 1437) sees this tacit knowledge being actualized in micro-practices: "It appears that strategic sensemaking and sensegiving processes are made up of a complex set of four micro-practices that middle-managers daily put into action in their interaction with people outside the organization." Kaplan $(2008$, p. 730$)$ starts from practice to discover the nature of some of this knowledge: "This focus on practice led to theoretical insights about the nature of frames and the organizational dynamics through which they shape strategic choices."

This minimal consideration of non-conscious knowledge, such as emotion and tacit knowledge, highlights how much the actual focus is on conscious knowledge.

\section{Bias}

Kahneman (2013) is explicit when he states that human bias "operates automatically and quickly, with little or no effort and no sense of voluntary control" (p. 20). Schwenk (1984), however, finds biases to be conscious when he examines a common bias, 'prior hypothesis', in terms of judgements made over years and of conscious acts. Bukszar (1999, p. 105) focuses on perceptions when he states that "This inflated perception of order may bias strategic management towards strategies designed to take advantage of expected orderliness." Such perceptions are often conscious, so it appears that the concept of bias is not being interpreted as an unconscious act. So while bias may be considered subconscious in psychology, it may be interpreted in MOC as a conscious act.

\section{Mind Summary}

MOC's treatments of the mind are primarily of the conscious mind. Even bias, which was conceived within psychology as being unconscious, is reinterpreted as conscious mind by some theorists. The subconscious is rarely approached, except for some authors who consider emotion and tacit knowledge. 


\section{Thinking Process}

Strategizing is the clear focus in the MOC texts reviewed, with Learning and Designing not being explicitly recognized at all.

As shown above, in the Knowledge section, there is a focus in the decision-making articles and bias articles which concern making 'good' Strategizing decisions. In the Types of Abstraction sections, the Cognitive Models show a Strategizing focus. In the mental models articles, as described below in the next section, the common focus is understanding Context (e.g. environment and the competition) to support Strategizing processes.

Further, in the texts reviewed, instances of knowledge of Strategy itself or of knowledge of Intentions have not been found. In the texts reviewed, MOC has a clear focus on Strategizing. 


\section{Thought Content}

Thought Content is approached directly in empirical studies which focus on Context, especially industry and competition contexts. This Contextual knowledge is expressed as hierarchies, as ideas, and as causal maps. These interpretations are, of course, described using words and phrases. It is not apparent how much of these interpretations are the result of the methodologies employed, and how much they are actual Thought Contents.

\section{Hierarchies}

Porac et al. (1989, p. 407), in an often-cited study of the Scottish knitwear industry, elicit cognitive hierarchies as shown below. These hierarchies, labelled mental models and frames, are essentially what a manager 'knows' the industry as. That is, such hierarchies are seen as representations of cognition. They represent what is ' $i$ ' the mind. Hodgkinson and Johnson (1994) produce similar hierarchies for the United Kingdom's (UK) grocery industry.

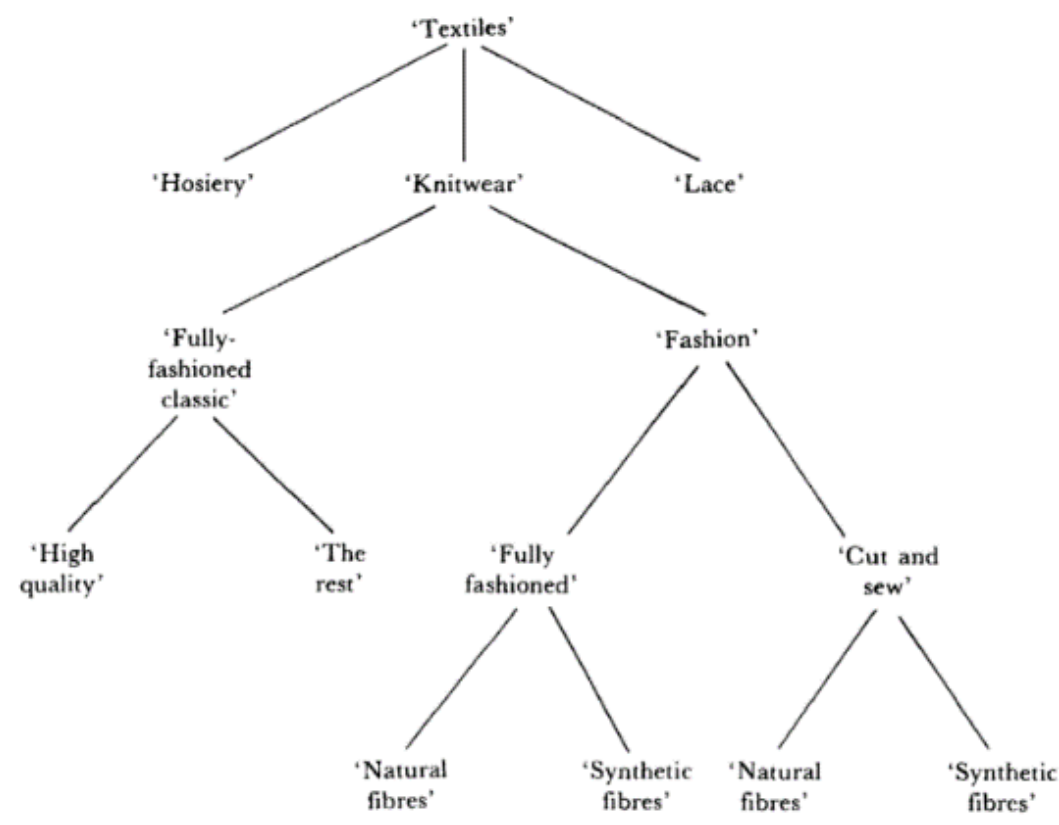

Figure 33: "Elicited 'cognitive taxonomy' of one managing director of a Scottish knitwear firm", reprinted from Competitive groups as cognitive communities: the case of Scottish knitwear manufacturers, by J. F. Porac, $\mathrm{H}$. Thomas, \& C. Baden-Fuller, Journal of Management Studies, 26(4), 1989, (pp. 397-416). Copyright John Wiley and Sons, 2007. 
Ideas

Spender (1989) devotes a book to investigating contextual beliefs in three industries: iron foundries, milk production, and forklift truck rentals. Spender argues that Thought Content, perceived as a set of ideas, drives behaviour: "I argue that organizational behaviour is managed, at the most fundamental level, through the ideas adopted by the people in the organization" (p. 171). Through interpreting interviews, he develops a series of such ideas or 'constructs' as he terms them. In milk production, such Context includes: "Pursuing greater gallonage, expanding the business, awareness of other retailers' positions, improving the rounds, increasing the drop density, evaluating the depot manager, increasing sales per customer, population shifts in the area, concentrating processing throughput, minimising the plant's vulnerability, managing the new technology, developing optimum plant catchment areas, developing a sense of corporate identity and pride, responding to longer term changes" (p. 143). These, as the basis of 'industry recipes', are Thought Content, specifically focusing on Context of the industry.

Porac et al. (2002) also find ideas, as growth logic clusters shown below, in entrepreneurial firms.

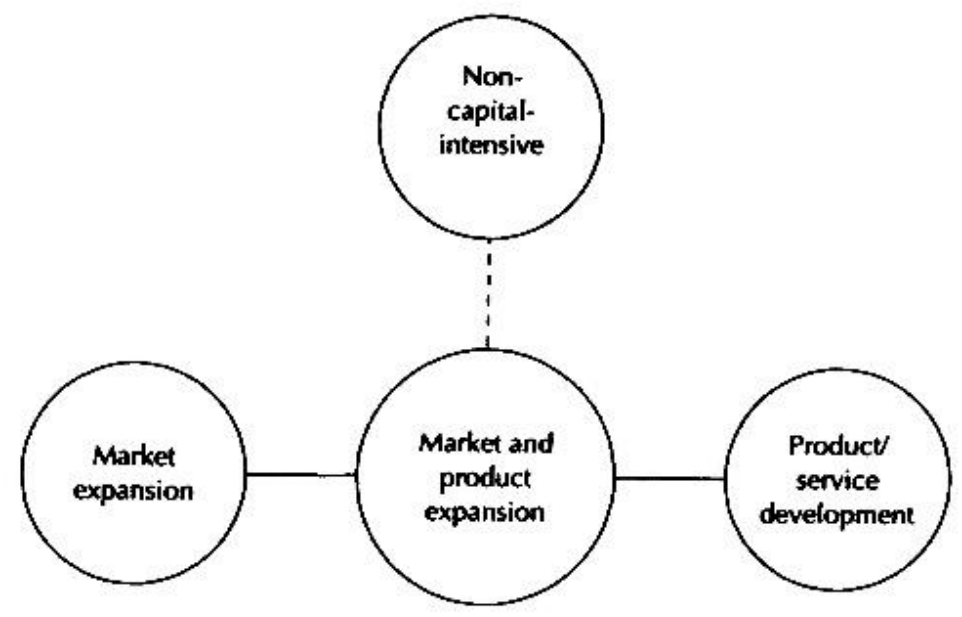

Figure 34: "Growth logic: cluster 2", reprinted from Entrepreneurial narratives and the dominant logics of highgrowth firms (p. 129), by J. F. Porac, Y. Mishina, \& T. Pollock, Mapping strategic knowledge (2002), edited by A. S. Huff \& M. Jenkins, London, United Kingdom: Sage. Copyright Anne Sigismund Huff and Mark Jenkins 2002. 


\section{Causal Maps}

Three other texts present causal maps using varying methodologies to derive them (analysis of company documents, interviews, and a combination of these). All utilize some statistical techniques to show 'representations of thought.' Barr et al. (1992) focus on change within cognitive maps within two railroad organizations, finding links between strategic ideas and performance. Tripsas and Gavetti (2000) similarly perform a longitudinal mapping of ideas for the Polaroid company. Rughase (2002) looks at what customers think as shown in the complex causal map below (p. 57).

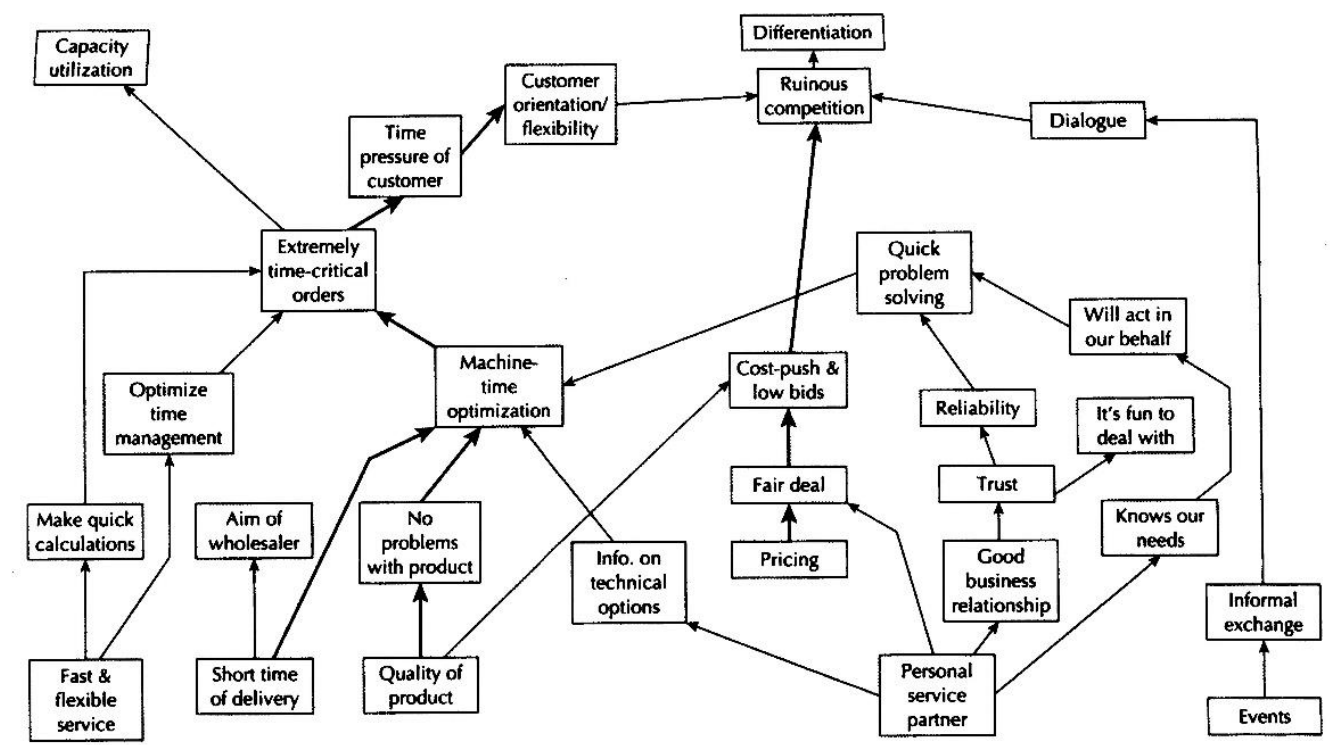

Figure 35: "Customers' causal cognitive map: pattern 1", reprinted from Linking content to process: How mental models of the customer enhance creative strategy processes (p. 57), by O. G. Rughase, Mapping strategic knowledge (2002), (pp. 46-62), edited by A. S. Huff \& M. Jenkins, London, United Kingdom: Sage. Copyright Anne Sigismund Huff and Mark Jenkins 2002.

\section{Thought Content Summarized}

Hierarchies, ideas, and causal maps are presented as 'representations' of what is in the mind, that is, as Thought Content. 


\section{Cognition Summary}

Table 32: Cognitive Summary - MOC

\begin{tabular}{l|l|}
\hline Status & cognition is assumed \\
\hline Type of Abstraction & $\begin{array}{l}\text { conceptual and operational at a distance } \\
\text { phenomenal in a variety of ways }\end{array}$ \\
\hline Subject & individual managers \\
\hline Mind & conscious \\
\hline Thinking Process & Strategizing \\
\hline Thought Content & Context as mental models described as taxonomies, ideas, and causal maps \\
\hline
\end{tabular}

Cognition is assumed by $\mathrm{MOC}$ - explicit consideration of cognition itself is the exception, not the norm. While the word cognition is a part of the title MOC, many MOC theorists simply assume cognition without it ever being a central focus. Some theorists do stress the criticality of cognition and some theorists justify cognition as being a cause of behaviour, but the overriding impression is that cognition is just seen as being there.

When treated, cognition is treated conceptually, operationally, and phenomenally, but always at some distance from the mind. MOC theorists build conceptual models of organizational behaviour that are often highly complex and quite distant from cognition as an everyday event. These abstractions, drawing on organization theory, sociology, and psychology, come in a variety of forms. Operational models are also built, but these tend to be gross generalizations of processes. Empirical research measures the phenomenon of cognition through artefact, and rarely does so directly through introspection.

MOC treats the subject as an individual thinker. While the organization can be reified as an operating entity, parallel abstractions of reifying an organization as a thinking entity rarely occur. Cognition is treated as being conscious. While some theorists consider emotion and tacit knowledge, the predominant focus is on conscious knowledge. MOC's focus is on Strategizing processes. The models reviewed seek to understand how Strategizing processes operate and can be improved. Learning and Designing are rarely mentioned. Thought Content is considered as mental models, focusing on Context, and represented as hierarchies, ideas, and causal maps. Strategy knowledge and Intentions are not considered. 


\subsection{Summary}

Based on the literature reviewed, MOC is an academic discourse, based on scientific method and the human sciences, that spends more time treating MOC itself than the very subjects of strategy - that is the practitioners. After decades of development $\mathrm{MOC}$ has a broad scope, including decision making, mental models, and biases. However, these developments have limited social effects and limited relevance for strategists.

MOC assumes cognition and treats it as an object requiring understanding. MOC focuses on individual managers' conscious Strategizing and Context. Cognition is treated conceptually, operationally, and phenomenally, but always at a distance from cognition itself, and is, at times, significantly adrift from everyday ideas of cognition. With this gap, cognition is often approached through behaviour, and introspection is avoided.

Three provisional insights are suggested:

M1 Academia avoids introspection, preferring to be at least at one remove.

M2 Academia finds cognition to be a problem.

M3 Academia avoids thinking about Design and Learning processes, and Strategy knowledge and Intentions.

\section{Academia Avoids Introspection}

With the influence of psychological behaviourism, this is perhaps not unexpected, but it is surprising to find the lack of significant enquiry into MOC methods for researching cognition. It is also noteworthy that few theorists ever consider the possibility of approaching cognition directly.

\section{Cognition is a Problem}

Certain theorists find cognition to be a problem, while few promote the power of the mind to resolve complex situations. There is some irony in researchers believing that they can understand and promote solutions to the very complex problem of understanding how humans think and behave, but rarely is the strategist seen as having such thinking capabilities; it is the mind of the strategist that is often perceived as the place where problems begin.

\section{Limited Scope}

MOC is one discourse that could be expected to define and research a broad scope of cognition. The texts reviewed suggest that is not the case, but that the scope of $\mathrm{MOC}$ is narrow. This provisional insight, with the other chapters' provisional insights, will be reviewed in final chapters of this thesis, but it is noteworthy how in this one particular academic discourse, the scope of consideration of cognition is so narrow. 
These questions are not raised in MOC itself, which looks inwardly at its own ideology and avoids aspects of the very topic it professes to study. From optimistic beginnings, its energy seems to have dissipated:

$$
\begin{aligned}
& \text { "So the great affair is over but whoever would have guessed } \\
& \text { It would leave us all so vacant and so deeply unimpressed } \\
& \text { It's like our visit to the moon or to that other star } \\
& \text { I guess you go for nothing if you really want to go that far" }
\end{aligned}
$$

Lyrics from Death of a Ladies Man by Phil Spector \& Leonard Cohen, copyright Sony Music Entertainment Canada Inc. 


\section{Chapter 11 - Pop}

With the publication of In Search of Excellence (Peters \& Waterman, 1982) strategy entered the realm of popular management literature. This chapter analyses some well-known and some recent popular texts to develop an understanding of how they treat cognition.

The analysis is structured around two groups of books which are described in the next section. The diagram below shows how the analysis of the two groups (chapter sections 11.1 to 11.2) is split into two, with the first being a Foucauldian analysis of the books to give a Foucauldian perspective to support the second analysis, Treatments of Cognition. This follows the same structure as Chapter 9 - Classical.

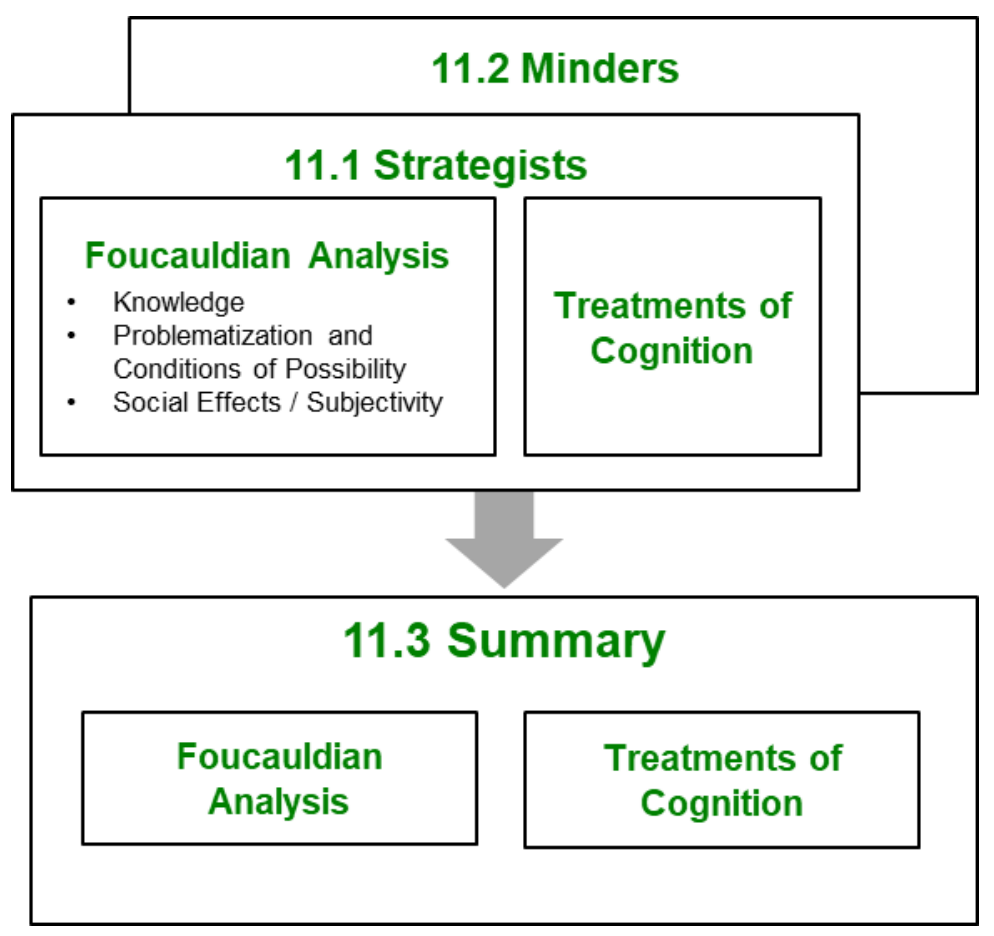

Figure 36: Chapter 11 Structure 


\section{Texts and Groupings}

The Pop texts and their groupings are:

1. Strategists

$\begin{array}{ll}\text { Peters \& Waterman (1982) } & \text { In Search of Excellence } \\ \text { Collins \& Porras (1994) } & \text { Built to Last } \\ \text { Hamel \& Prahalad (1994) } & \text { Competing for the Future } \\ \text { Kim \& Mauborgne (2005) } & \begin{array}{l}\text { Blue Ocean Strategy } \\ \text { Rumelt (2011) }\end{array} \\ \text { Lafley \& Martin (2013) } & \text { Playing to Win }\end{array}$

2. Minders

Ohmae (1983)
Schön (1983)
Argyris (1985)
Senge (1990)
Nonaka \& Takeuchi (1995)

The Mind of the Strategist The Reflective Practitioner Strategy, Change, and Defensive Routines The Fifth Discipline

The Knowledge-Creating Company

\section{Texts}

The eleven selected texts were chosen from the probable lists of 27 Pop texts (see p. 104 for details of this process). Eight of the top ranking ten texts were selected, with Strategy, Change, and Defensive Routines (Argyris, 1985) and The Mind of the Strategist (Ohmae, 1982) being included because of the cognitive content of the texts, and Playing to Win (Lafley \& Martin, 2013) being included as it is a relatively recent strategy text.

\section{Groups}

Based upon an initial reading of the texts, the books were grouped for the following reasons:

\section{Group}

1. Strategists

2. Minders

\section{Description}

Texts with a focus on

strategy, that are well-known, and with authors who are

acknowledged experts.

A parallel series of texts that focus on the mind.

\section{Reasoning}

These texts are highly influential in the business world and cover many common strategy developments of the Pop discourse.

While these may not be as well-known as the Strategists above, they have a following, many of the texts are commonly available, and they have cognitive content. 


\subsection{Strategists}

The target of these strategy texts is the business world. All of them present approaches to business success that are supported by research and/or examples from the business world. However, variations in approach exist: Peters and Waterman stress the treatment of people; Jim Collins and Jerry Porras identify the fundamentals of excellent companies; Gary Hamel and C K Prahalad suggest a way of strategizing for a future changing world; W Chan Kim and Renee Mauborgne prescribe a systematic approach for creating new markets; Richard Rumelt clarifies what good strategy is and provides an approach; and A G Lafley and Roger Martin present a strategy process.

\section{Foucauldian Analysis}

\section{Knowledge}

Tom Peters and Robert Waterman - In Search of Excellence (1982)

Peters and Waterman (1982), within their general review of what makes American companies excellent, find the treatment of people to be the most important attribute of successful companies.

From extensive analyses, they determine eight attributes of excellent companies: 1 . A bias for action, 2. Close to the customer, 3. Autonomy and entrepreneurship, 4. Productivity through people, 5. Hands-on, value driven, 6. Stick to the knitting, 7. Simple form, lean staff, and 8. Simultaneous loose-tight properties (pp. 1315). These eight attributes are each justified by a chapter that includes support for their contentions from other theorists and from examples in the business world. Further, the well-known McKinsey 7-S Framework, with its seven concepts starting with the letter ' $s$ ', is presented, as 'research told us that any intelligent approach to organizing had to encompass and treat as interdependent, at least seven variables" (p. 9).

Besides describing these attributes of excellent companies within the 7-S Framework, the importance of the treatment of people is highlighted as a new theory to supplement current organizational theories: "four prime elements of new theory would include our observations on basic human needs in organizations: (1) people's need for meaning; (2) people's need for a modicum of control; (3) people's need for positive reinforcement ... ; and (4) the degree to which actions and behaviours shape attitudes and beliefs rather than vice versa" (p. 102). This centrality of people is the key message of this book: "the good news comes from treating people decently and asking them to shine, and from producing things that work", "Treating people - not money, machines, or minds - as the natural resource may be the key to it all", and "Without exception, the dominance and coherence of culture proved to be an essential quality of excellent companies" (pp. xxv, 39, 75). 
Jim Collins and Jerry Porras - Built to Last (1994)

Collins and Porras (1994) find that excellent companies are driven by authentic ideologies, and strategy is not important. Through their research, they aimed to discover the fundamental principles of successful companies: "throughout our research we kept looking for underlying times, fundamental principles and patterns that might apply across eras" (p. 17). Visionary companies exhibit these fundamental principles, starting with ideology and drive: "The essence of a visionary company comes in the translation of its core ideology and its own unique drive for progress into the very fabric of the organization - into goals, strategies, tactics, policies, processes, cultural practices, management behaviours, building layouts, pay systems, accounting systems, job design - into everything the company does" (p. 201).

The driving ideology of successful companies is authenticity. This core ideology seems to be beyond comprehension, as it never changes and is above mere management concepts: "It is absolutely essential not to confuse core ideology with culture, strategy, operations, policies, or other noncore practices" (p. 82). Five methods for preserving this ideology are 'big hairy audacious goals', cult-like culture, 'try a lot of stuff and keep what works', home-grown management, and 'good enough never is'. For such companies, strategy is relatively unimportant: "Visionary companies make some of their best moves by experimentation, trial and error, opportunism, and - quite literally - accident" (p. 9).

\section{Gary Hamel and C K Prahalad - Competing for the Future (1994)}

Hamel and Prahalad (1994) present a method for competing in the future that includes concepts such as stretch and core competency management. For them, a changing world of competition requires companies to reinvent themselves through deliberate strategies that involve better thinking. They state that the future will not be the same as the present: "the race to the future occurs in three distinct, overlapping stages: competition for industry foresight and intellectual leadership, competition to foreshorten migration paths, and competition for market position and market share" (p. 45). So in this changing world, a company that wants to lead must be proactive and reinvent the future: "To extend leadership a company must eventually reinvent leadership, to reinvent leadership it must ultimately reinvent its industry, to reinvent its industry it must ultimately regenerate its strategy" (p. 19). Part of this quest is to reinvigorate strategy. Such a reinvigoration of strategy is a matter of building better thinking: "Senior managers must first understand just how competition for the future is different from competition for the present ... We see that competing for the future requires not only a redefinition of strategy, but also a redefinition of top management's role in creating strategy" (p. 30).

Two additional concepts are stretch/leveraging and core competencies. The need for stretch drives a company to leverage of assets. This allows a company to do more with less. Core competencies are fundamental to competing in the future: "a key challenge in competing for the future is to preemptively build the competencies that provide gateways to tomorrow's opportunities, as well as to find novel applications to current core competencies" (p. 197). 
W Chan Kim and Renee Mauborgne - Blue Ocean Strategy (2005)

Kim and Mauborgne (2005) reject previous theorists, change the 'strategic arena', and suggest that new markets can be developed using their own systematic approach and their own tools. The attributes of the excellent companies of Peters and Waterman and the theories of Michael Porter are not enough: "there are no permanently excellent companies, just as there are no permanently excellent industries" ( $p . x)$. Traditional perceptions of the 'strategy arena', these being the 'company' and the 'market', are replaced by the 'strategic move': "the strategic move, and not the company or industry, is the right unit for explaining the creation of blue oceans and sustained high performance" (p. 10). And these moves aim to go beyond the mundane world of competition to find 'blue oceans'.

Such blue oceans present unbridled growth opportunities: "Blue oceans ... are defined by untapped market space, demand creation, and the opportunity for highly profitable growth" (p. 4). Numerous examples are given of the creation of blue oceans (e.g. discount retail, snowboards). Based upon observed patterns of 'value innovation', the book develops a systematic strategy process. The process, even though called value innovation, is all encompassing: "value innovation is more than innovation. It is about strategy that embraces the entire system of a company's activities. Value innovation requires companies to orient the whole system towards achieving a leap in value for both buyers and themselves" (p. 17).

Six Principles of Blue Ocean Strategy are defined. Four are formation principles: reconstruct market boundaries; focus on the big picture, not the numbers; reach beyond existing demand; and get the strategic sequence right. Two are execution principles: overcome key organizational hurdles, and build execution into strategy (p. 21). A systematic approach is key: "managers cannot afford to be riverboat gamblers betting their strategy on intuition or on a random drawing" and "managers need to look systematically across [accepted boundaries] to create blue oceans" (pp. 47,48).

Various tools are presented to support this systematic process, including the 'strategy canvas' that compares a company to its rivals: "The strategy canvas is both a diagnostic and an action framework for building a compelling blue ocean strategy" (p. 25). Value curves are presented within these frameworks and potential options for change are revealed.

\section{Richard Rumelt - Good Strategy Bad Strategy (2011)}

Rumelt (2011) emphatically states what is bad strategy before he provides an in-depth analysis of the nature of strategy, and describes his view of how strategy should be executed through a strategy kernel, strategy heuristics, and strategy tools. He defines bad strategy: "key hallmarks [of bad strategy] ... fluff, the failure to face challenge, mistaking goals for strategy, and bad strategic objectives" (p. 37). These, he states, are all symptoms of a general malaise that is also made apparent through 'long lists' masquerading as strategy, and strategy by template. These are essentially ways of avoiding the real challenge of strategy - that of generating understanding that can then direct actions: "The core of strategy work is always the same: discovering the critical factors in a situation and designing a way of coordinating and focusing actions to deal with these 
factors" (p. 2), and "the term 'strategy' should mean a cohesive approach to an important challenge. ... a strategy is a coherent set of analyses, concepts, policies, arguments, and actions that respond to a high-stakes challenge" (p. 6).

While the development of good strategy involves insight, it has the same nature as a scientific problem. Rumelt sees strategy as being empirical and involving induction: "The process of learning - hypothesis, data, new hypothesis, data, and so on - is called scientific induction and is a critical element of every successful business" (p. 254).

Rumelt describes a structured way of thinking about strategy: “A good strategy has an essential logical structure that I call the kernel. The kernel of a strategy contains three elements: a diagnosis, a guiding policy, and coherent action" (p. 7). In addition he describes a set of general heuristics (leverage, systems thinking, holism, growth, dynamics, and inertia and entropy), and two specific strategy heuristics (proximate objectives and cognitive focus). These heuristics, and a set of tools (lists, his kernel, focusing on the problem, iteration, and practice) are illustrated by numerous examples.

\section{A G Lafley and Roger Martin - Playing to Win (2013)}

Lafley and Martin (2013) describe a strategy process derived from experience in a consumer goods company, Proctor and Gamble. They treat strategy simply as choice: "In short, strategy is choice. More specifically, strategy is an integrated set of choices that uniquely position the firm in its industry so as to create sustainable advantage and superior value relative to competition" (p. 3). Some requirements of good strategy are defined: "[Strategy] requires clear and hard thinking, real creativity, courage, and personal leadership" (p. 6). Also, there are dimensions of strategy which reflect Martin's career with the Monitor Group and the position of Michael Porter: "Ultimately, there are four dimensions you need to think about to choose where to play and how to win: 1. The industry ... 2. Customers ... 3. Relative position ... 4. Competition" (p. 161).

Within these bounds, choice is supported through a framework: "The bad news is that there is no simple algorithm for choice. The good news is that there is a framework that can give you a place to start" (p. 159). This framework is based on questions: "Strategy is the answer to five interrelated questions" (p. 14). These questions form the structure of the book and most of the content: what is your winning aspiration; where will you play; how will you win; what capabilities must be in place; and what management systems are required? Various examples are presented, but the primary examples are from Proctor and Gamble where Lafley was CEO for over ten years.

\section{Commonality}

All the texts, to a degree, are somewhat 'discussion pieces' sharing academic background' a use of anecdotal examples from the business world' and a lack of self-critique. Five of the six texts have at least one author who could be described as an academic, and the sixth, Peter and Waterman's In Search of Excellence, draws 
extensively on academic sources. So while these texts are 'popular' they retain an academic influence in similarity with the strategy discourses analyzed in the two previous chapters.

The use of examples to support propositions is used extensively in all texts. These are often limited to being anecdotal recollections of events or snippets of historical examples of a company's performance in a specific context. No full case studies are presented in the texts, and there is a distinct lack of reasoning and justification for many statements made. Even when texts are based initially on what are stated to be comprehensive industry surveys, they then move easily to the delivery of quite strong propositions that are simply supported by anecdotal examples.

Finally, given the academic backgrounds of most of the authors, some self-critique might be expected, but this is not so. While research based in statistics justifies propositions in some texts, the research methodology is either not expressed or not strongly defended. All authors use limited examples as justification for propositions, without establishing any strong connections between such propositions and behaviour described. Hence, all are open to the critique that they present propositions as being causal, but the behaviour may be only coincidental or correlative. Hence, these texts are more a series of discussion pieces that promote certain propositions, rather than being management science.

\section{Themes}

Two themes are present: a people focus, and a process focus. As described by Kiechel (2010), Peters and Waterman introduced the idea of "the centrality of people to a company's success" (p. 148) and this is shared by two other texts reviewed here, namely Collins and Porras, and Hamel and Prahalad. Collins and Porras (1994) find ideology that works through people to be fundamental to success. Hamel and Prahalad (1994) believe that better human thinking is required before introducing concepts of stretch and core competencies. All three texts find a place for people in their strategy.

Two texts are process oriented. Kim and Mauborgne (2005) promote a systematic process that scans the environment looking for blue oceans. Lafley and Martin (2013) also propose a systematic process, but one resembling product development at Proctor and Gamble. While these processes are executed through people, the authors focus on the process itself.

Rumelt (2011) covers both people and process. The last three chapters of his text are people focused and he includes a number of tools within an overall process of 'diagnosis, policy, action'. 


\section{Problematization}

All the texts find significant problems with strategy:

For Peters and Waterman (1982), strategy's problem is the prevailing rationalistic approach: "The numerative, rationalistic approach ... seeks detached, analytical justification, for all decisions. It is right enough to be dangerously wrong, and it has arguably led us seriously astray"(p. 29).

Collins and Porras (1994) find crumbling edifices of strategy: "Along the way [of our research] we found that many of today's 'new' and 'innovative' management methods aren't really working. ... Widely held myths fell by the dozen. Traditional frameworks buckled and cracked" (p. xiii).

Hamel and Prahalad (1994) see strategy being focused only on the present: "Existing theories of strategy and organization, while providing a solid base for discovery, do not fully answer these questions [of selecting future capabilities]. ... While they provide a scorecard for keeping track of relative competitive advantage, they fail to capture the dynamic of competence building" (p. xi).

Kim and Mauborgne (2005) direct their criticism of strategy squarely at the positioning school, as defined by Michael Porter: "It is conventionally believed that companies can either create greater value to customers at a higher cost or create reasonable value at a lower cost. Here strategy is seen as making a choice between differentiation and low cost"(p. 13).

Rumelt (2011) finds normal strategy simply bad: "Bad strategy ... is an identifiable way of thinking and writing about strategy that has, unfortunately, been gaining ground. Bad strategy is long on goals and short on policy or action. ... It puts forward strategic objectives that are incoherent, and, sometimes, totally impractical. It uses high-sounding words and phrases to hide these failings" (pp. 36-37).

Lafley and Martin (2013) simply find strategy to be confused: "Strategy is a relatively young discipline. ... organizations struggle to define what a strategy is and how to create a useful one; there is no clear, single, pervasive definition of strategy and even less consensus on how to build one" (pp. 2-3).

All the authors, to some extent, highlight the challenge of coping with change and highlight the need to do better. While some are specific, there is a common view of strategy as being an under-developed discipline that is not performing. Given that these texts have been successfully published, the market seems receptive to this style of problem statement. 


\section{Conditions of Possibility}

While not always explicit in their grounding, all texts draw on academic sources and the authors' academic backgrounds. While neither Peters nor Waterman are academics, their text reflects their academic education, especially drawing on sociology, psychology, and cognitive psychology. Collins and Porras indicate that they also draw extensively from such sources, although they do not quote such sources. Hamel and Prahalad are more based upon strategy sources, including Ansoff, Chandler, Porter, and Mintzberg. Kim and Mauborgne and Rumelt give no antecedents, while Lafley and Martin recognize Martin's history with Michael Porter's approach through the Monitor Group. The overriding impression is a series of texts that draw on theory from outside management and strategy, and use such theory as a basis for new strategy approaches.

The three earlier texts (Collins \& Porras, 1994; Hamel \& Prahalad, 1994; Peters \& Waterman, 1982) also reference Japanese competitiveness, as they describe in various ways the attributes of great US corporations or how they should become great in the future.

\section{Social Effects / Subjectivity}

These texts promote variety. Each text has its own individual message.

Peters and Waterman (1982) suggest that we need to focus on how we treat people, potentially leading to more human resources-based approaches to business.

Collins and Porras (1994) find that great companies have authentic ideologies, potentially leading to company introspection and increased visionary activity.

Hamel and Prahalad (1994) introduce the concepts of core competencies and stretch.

Rumelt (2011) highlights the need for thinking.

For Kim and Mauborgne (2005) and Lafley and Martin (2013) executives need to adopt better systematic processes.

These popular texts have social effects. From the candidates' experience during the last 20 years, the usage of concepts such as core competencies, stretch, and 'big hairy audacious goals' derive directly from the texts analyzed.

This can be both empowering and debilitating. For any manager, they have options available to make them instant strategists. For strategists, they can harness the power of these new techniques and add to their professional credibility. For those who oppose the concept of strategy, there is also a literature that tells that strategy is not required, and presumably this means that strategists are redundant too.

Hence, the social effects of the Strategists are varied, and the subjectivity of strategists is also influenced in many and different ways. 
Foucauldian Summary

Table 33: Foucauldian Summary - Strategists

\begin{tabular}{|c|c|c|c|c|c|c|}
\hline & $\begin{array}{l}\text { Peters \& } \\
\text { Waterman }\end{array}$ & $\begin{array}{l}\text { Collins \& } \\
\text { Porras }\end{array}$ & $\begin{array}{l}\text { Hamel \& } \\
\text { Prahalad }\end{array}$ & $\begin{array}{l}\text { Kim \& } \\
\text { Mauborgne }\end{array}$ & Rumelt & $\begin{array}{l}\text { Lafley \& } \\
\text { Martin }\end{array}$ \\
\hline $\begin{array}{l}\text { Conditions of } \\
\text { Possibility }\end{array}$ & \multicolumn{6}{|c|}{$\begin{array}{c}\text { A variety of academic discourses including psychology, cognitive psychology, and } \\
\text { sociology } \\
\text { Japanese competitiveness }\end{array}$} \\
\hline Problematization & \multicolumn{6}{|c|}{ Traditional strategy does not achieve its aims } \\
\hline Knowledge & people & $\begin{array}{l}\text { authentic } \\
\text { ideologies }\end{array}$ & foresight & $\begin{array}{l}\text { systematic } \\
\text { process }\end{array}$ & heuristics & process \\
\hline Social Effects & \multicolumn{6}{|c|}{ A plethora of new techniques, many that focus on aspects of people } \\
\hline Subjectivity & \multicolumn{6}{|c|}{ Everyone can be a strategist } \\
\hline
\end{tabular}

The Pop Strategist texts create new approaches to strategy from similar bases to the Classicists, but do so in a more speculative fashion, relying less on proof and more on inspiration.

Despite the differences, the Strategists' starting position is similar to the Classicists. The unspoken belief in humanity's ability to understand remains firm and is supplemented by various academic disciplines. The problem continues to be traditional strategy, and some Strategists are prepared to be very direct in naming previous theorists whose methods are not sufficiently robust.

The Strategists promote a variety of solutions. Peters and Waterman (1982) recognize the importance of people in excellent American companies. Collins and Porras (1994) find authenticity of ideology to be key and they promote a series of techniques to create and maintain such a single company focus. Hamel and Prahalad (1994) find the changing world to be a threat and suggests that companies need to change to think better. Kim and Mauborgne (2005) recommend an external focus on creating new markets. Rumelt (2011) presents a new model of strategy process. Lafley and Martin (2013) simply present a strategy process based on Proctor and Gamble.

Of these texts, three focus on people, two on systematic process, and one covers both. They all, however, use anecdotal examples to support their positions, and do not share the disciplined thinking that many of the Classicists display. Notwithstanding that, many of the concepts and ideas have social effects and influence the world of the strategist, including both to provide new tools and, at times, to diminish the role of the strategist when strategy is found to be ineffective. 


\section{Cognition}

Four of the six texts simply recognize cognition. The four are Peters and Waterman (1982), Collins and Porras (1994), Kim and Mauborgne (2005), and Lafley and Martin (2013). None of these texts have extensive consideration of cognitive topics, but they do make occasional comments on cognition. The two texts with some focus on cognition are Hamel and Prahalad (1994) who see Strategizing as being a function of the thinking of a manager; and Rumelt (2011) who considers cognition holistically.

\section{Tom Peters and Robert Waterman - In Search of Excellence (1982)}

Peters and Waterman (1982) make a few conceptual, and sometimes contradictory, comments. They label humanity as irrational: "We have argued that man is strikingly irrational" (p. 86), but then, in a more positive vein, treat cognition as a mixture of intuition and process: "Pathfinding is essentially an aesthetic, intuitive process, a design process" (p. 53). There are only a few such remarks, with most of the text focusing on a set of recommended behaviours.

Jim Collins and Jerry Porras - Built to Last (1994)

Collins and Porras (1994) reflect on cognition even less that Peters and Waterman, with only the occasional comment regarding shifts in perspective: "One of the most important steps you can take in building a visionary company is not an action, but a shift in perspective ... But to make good use of [actions] requires first and foremost the right frame of mind" (p. 40).

\section{Gary Hamel and C K Prahalad - Competing for the Future (1994)}

Hamel and Prahalad (1994) treat cognition conceptually, stressing the importance of cognition for Strategizing, and considering the challenges in terms of mental models and foresight. The competition in Competing for the Future is a cognitive competition: "[competition for industry foresight and intellectual leadership] is competition to gain a deeper understanding than competitors of the trends and discontinuities ... In short, it is competition to imagine the future" (pp. 45-46). This competition involves understanding and insight: "what does it take to get to the future first? At a broad level it requires four things, including: (1) an understanding of how competition for the future is different; (2) a process for finding and gaining insight into tomorrow's opportunities" (pp. 21-22).

They recognize that Strategizing is a process involving a group of individual minds: "The brain we have in mind is not the brain of the CEO or strategic planner. Instead it is an amalgamation of the collective intelligence and imagination of managers and employees throughout the company who must possess an enlarged view of what it means to be 'strategic'"' (p. 25).

Hamel and Prahalad focus on mental models. They claim that the longevity of common mental models can be problematic for companies: "The deeply encoded lessons of the past that are passed from one generation to another poses two dangers for any organization. First, individuals may, over time, forget why they believe what they believe. Second, managers may come to believe that what they don't know isn't worth knowing" 
(p. 51). They suggest that there are possible solutions to such problems including, "preserving some genetic variety in a company requires corporate leaders to be very careful about just what and how much of their beliefs and perspectives get institutionalized in the firm's administrative systems" (p. 57), and "Enlarging managerial frames depends, more than anything else, on curiosity and humility" (p. 58).

The authors explicitly state the importance of a 'foresight' that is partially based upon the subconscious. This foresight is a necessary attribute for success: "Although skunk works, intrapreneurship, and thriving on chaos often do yield unexpected new product bonanzas, they aren't substitutes for industry foresight" (p. 79). Such foresight is supported by information, but it rests on imagination: "Industry foresight must be informed by deep insight into trends in lifestyles, technology, demographics, and geopolitics, but foresight rests as much on imagination as on prediction" (p. 82). While they do not explicitly invoke the subconscious, the language of imagination suggests that they perceive foresight as being beyond conscious rationality.

Hamel and Prahalad treat cognition as important and consider it in terms of mental models and foresight. They also touch on specific aspects of cognition, such as imagination, but delve no deeper into cognition. The very recognition of cognitive capabilities is presumably seen to be enough to remind the reader to start thinking better.

\section{W Chan Kim and Renee Mauborgne - Blue Ocean Strategy (2005)}

Kim and Mauborgne (2005) reject the use of cognition, making it clear that intuition is not part of their solution, but then suggesting that culture, as cognition, is important. Intuition is seen as being subconscious and not useful for strategy. All that is required is their systematic process, and intuition is expressly forbidden: "managers cannot afford to be riverboat gamblers betting their strategy on intuition or on a random drawing" (p. 47), and "The process of discovering and creating blue oceans is not about predicting or preempting industry trends. Nor is it a trial-and-error process of implementing wild new business ideas that happen to come across managers' minds or intuition" (pp. 79-80).

But while 'wild thoughts' are out, the authors do recognize that the mind does have some influence in staff engagement: "People's minds and hearts must align with the new strategy so that at the level of the individual, people embrace it of their own accord" (p. 171).

\section{Richard Rumelt - Good Strategy Bad Strategy (2011)}

Rumelt (2011) presents a variety of ideas about cognition in the final three chapters of Good Strategy, Bad Strategy. Cognition is a third section after 1) strategy itself and 2) methods/techniques. In this section Rumelt treats Strategizing conceptually and operationally.

Conceptually, Rumelt finds cognition to be a key issue when he recognizes the importance of cognition, limits to cognition, and the limited capacity of cognition; he finds thinking to be important when he aligns strategy with thinking': "Bad strategy ... is an identifiable way of thinking and writing about strategy that has, unfortunately, been gaining ground" (p. 36). In a Kantian sense, Rumelt finds our knowledge to be uniquely 
human, and not of another world: "anomalies are not in nature but in the mind of the acute observer, revealed by a comparison between the facts and the refined expectations" (p. 249). And while limited in scope, cognition is limited in capacity: "The human mind is finite, its cognitive resources are limited. ... Making a list is a basic tool for overcoming our own cognitive limitations" (pp. 259-260).

Rumelt's subject is the individual: "This personal skill is more important than any one so-called strategy concept, tool, matrix, or analytical framework. It is the ability to think about your own thinking, to make judgments about your own judgments" (p. 267). This comment shows that Rumelt recognizes the ability to work on more than Strategizing, as he recognizes the possibility of Designing, "a number of ways of thinking about thinking that can help you create better strategies" (p. 238). In his recognition of understanding, judgment, and insight, he implicitly also recognizes the subconscious: "dealing with a strategy situation is, in the end, all about making good judgements" (p. 266), and "Conceptual tools may help us get oriented, but, in the end, good ideas just pop into our heads. It's called 'insight'” (p. 267).

But Rumelt also considers operational aspects of cognition such as strategy to be a scientific process: "The problem of coming up with a good strategy has the same logical structure as the problem of coming up with a good scientific hypothesis" (p. 243), and "The process of learning - hypothesis, data, new hypothesis, data, and so on - is called scientific induction and is a critical element of every successful business" (p. 254). He also considers sensemaking within problem solving: "This simplified model of reality [produced by diagnosis] allows one to make sense of the situation and engage in future problem solving" (p. 81).

Rumelt's treatment of strategy is broad and varied. But while there is a significant coverage in three chapters, it is at the level of commentary, and not at the level of guidance or suggested approaches. Guidance comes in the previous chapters as a set of management heuristics. Cognition is important, but it is not part of the solution for good strategy.

A G Lafley and Roger Martin - Playing to Win (2013)

Lafley and Martin (2013) simply recognize that Strategizing involves the mind: "The essence of great strategy is making choices" (p. 46). While they do mention imagination and thinking in general terms, the focus is not on cognition itself, but cognition is included as part of a commentary on general strategy processes. 


\section{Cognition Summary}

\begin{tabular}{|c|c|c|c|c|c|c|}
\hline & $\begin{array}{l}\text { Peters \& } \\
\text { Waterman }\end{array}$ & $\begin{array}{l}\text { Collins } \\
\text { \& Porras }\end{array}$ & $\begin{array}{l}\text { Hamel \& } \\
\text { Prahalad }\end{array}$ & $\begin{array}{l}\text { Kim \& } \\
\text { Mauborgne }\end{array}$ & Rumelt & $\begin{array}{l}\text { Lafley \& } \\
\text { Martin }\end{array}$ \\
\hline Type of Abstraction & - & - & conceptual & - & $\begin{array}{l}\text { conceptual } \\
\text { operational }\end{array}$ & - \\
\hline Subject & - & - & individual & - & individual & - \\
\hline Mind & - & - & $\begin{array}{l}\text { conscious } \\
\text { subconscious }\end{array}$ & - & $\begin{array}{l}\text { conscious } \\
\text { subconscious }\end{array}$ & - \\
\hline Thinking Process & - & - & Strategizing & - & Strategizing & - \\
\hline Thought Content & - & - & Context & - & - & - \\
\hline Summary & - & - & fundamental & $\begin{array}{l}\text { avoid } \\
\text { intuition }\end{array}$ & fundamental & - \\
\hline
\end{tabular}

Of the six texts, three do not treat cognition, while a fourth simply stresses that the authors' systematic process is better than any intuitive mind.

Of the two that treat cognition as being important, Hamel and Prahalad (1994) focus on the future, and attribute success in the future to how we think. Hence, they consider cognition. And for Rumelt (2011), the issue is not change per se, but rather that people think badly. Starting from such a premise, he also considers cognition. Both texts start with problems expressed in cognitive terms, and then provide some treatment of cognition. These treatments: 1) are conceptual and partly operational, 2) see the subject as the individual, 3) implicitly recognize the subconscious, and 4) focus on Strategizing.

Further, they recognize that cognition is fundamental. They include cognition in a strategy text presumably because they believe it has some utility for potential strategists to read about and to consider cognition, and to then make them behave in a more productive manner. However, there is little direction, if any, about how to achieve this using cognitive tools. Cognition is treated as fundamental, but as a 'fundamental aside'.

The Pop Strategists, when they treat cognition, do so in everyday terms. Certainly Hamel and Prahalad and Rumelt delve much more deeply into cognition than the other authors, but this delving is to recognize and comment on cognition, not to explore cognition. 


\section{Strategists Conclusions and Provisional Insights}

The Strategists take strategy forward, adding new strategy process alternatives, and bringing people directly into the strategy discussion. The starting points are similar to the Classicists, these being Enlightenment thinking and academia, but the delivery is more speculative than the Classicists, with propositions often being supported by anecdotal examples, even if there is also broad research of successful companies presented to support the credibility of the text.

In the texts of Peters and Waterman (1982), Collins and Porras (1994), Hamel and Prahalad (1994), and Rumelt (2011) there is a focus on people, whereas the other two texts tend towards more traditional approaches that define strategy processes. However, a people focus in the four texts does not entail a cognitive focus, as only two of the four texts consider cognition in-depth. They are Hamel and Prahalad (1994) who, finding the answer is to be able to think the future, discuss aspects of cognition, and Rumelt (2011) who considers aspects of cognition in some detail, but more as an afterthought to his solution of various heuristics. For these two texts, cognition is 'considered' in everyday language. And that is all. There is no in-depth delving into how cognition might function better, nor any advice other than entreaties to 'think better'.

The above discussion suggests the provisional insight:

P1 A people focus within strategy did not produce cognitive solutions. 


\subsection{Minders}

The Minder texts focus on the mind in a variety of ways. The subconscious comes to the fore through the consideration of tacit knowledge. However, such recognition of a broader cognitive scope does not necessarily translate to cognitive solutions.

\section{Foucauldian Analysis}

\section{Knowledge}

All the Minder texts consider the mind. Kenichi Ohmae, based on Japanese thinking styles, suggests an approach to strategy. Donald Schön focuses on how practitioners practically solve problems. Chris Argyris finds that organizations think defensively and suggests how to change such situations. Peter Senge takes a more global view of how organizations can learn better. Ikujiro Nonaka and Hirotaka Takeuchi focus on the creation of organizational knowledge.

Kenichi Ohmae - The Mind of the Strategist (1983)

Ohmae (1982) presents a description of a strategy process as problem solving, with only a brief discussion of the mind. Based upon his knowledge of Japanese business successes, he suggests a model of competitive strategy that includes four methods of strengthening a competitive position. These methods are paraphrased as use your strengths, exploit weaknesses, disrupt, and innovate (pp. 39-40). Further, he defines a structure for strategy using three concepts starting with ' $c$ ': “In the construction of any business strategy, three main players must be taken into account: the corporation itself, the customer, and the competition" (p. 91).

Within the context of major economic trends and changes to world industry, Ohmae proposes that strategy should be created using both method and intuition. He suggests that everything starts with analysis and asking the right questions: "Analysis is the critical starting point of strategic thinking" (p. 12) and "It is hard to overstate the importance of formulating the question correctly" (p. 17). The analysis starts with phenomena being abstracted, and is followed by creation of a concrete plan: "abstraction followed by movement towards a concrete plan for improvement-is characteristic of the method of solution finding that focuses on critical issues" (p. 21). A key analysis tool is an issue diagram, which provides a useful alternative to simply using intuition: "Rather than recklessly attempting to come up with a solution simply on the basis of experience or intuition, without analyzing these objective factors, the strategic thinker would take a blank sheet of paper and draw up an issue diagram" (p. 22).

\section{Donald Schön - The Reflective Practitioner (1983)}

Schön (1983) focuses on understanding how we actually solve problems in real-world situations. He recognizes two management camps: one based on science, and one based on the art of dealing with uncertainty. He sees the scientific approach as deriving from Positivism and defines it as 'Technical Rationality': "The systematic knowledge base of a profession is thought to have four essential properties. It is 
specialized, firmly bounded, scientific, and standardized" (p. 23). This Technical Rationality is limited in one major aspect: "Technical Rationality depends on agreement about ends. ... A conflict of ends cannot be resolved by the use of techniques derived from applied science" (p. 41). Thus, when ends are not clear, as is often the case, management often fail as they rely on Technical Rationality which is incapable of resolving such messy problems.

To address this issue, Schön aims to bring the camps of art and science together: "Indeed, it may be possible to bring the art of managing into dialogue with management science" (p. 241). His approach is derived from practice: "I offer an approach to epistemology of practice based on a close examination of what some practitioners - architects, psychotherapists, engineers, planners, and managers - actually do" (p. viii). While he doesn't explicitly state a solution, he suggests that through further 'action science' research into reflective practice, we can make efficacious reflective practice the norm: "The extent of our capacity for reciprocal reflection-in-action can be discovered only through an action science which seeks to make what some of us do on rare occasions into a dominant pattern of practice" (p. 354).

\section{Chris Argyris - Strategy, Change, and Defensive Routines (1985)}

Argyris (1985) aims to rid business strategy of the 'negative influence' of 'defensive routines'. These defensive routines are cultural, are learnt early in life, are used for protection, and have negative consequences: "the pathology involved in these defensive routines is created by our culture" (p. 8), "Defensive routines are thoughts and actions used to protect individuals', groups', and organizations' usual way of dealing with reality" (p. 5), "Defensive routines can act to distort reality without our being aware of the distortion. ... How do we know that we are not unknowingly kidding ourselves" (p. 133), and "defensive routines can be acknowledged as one of the most powerful factors that inhibit organizational learning and learning how to learn" (p. 338).

Such defensiveness has multiple layers. Even though most people are aware that defensiveness is occurring, they find it difficult to discuss: "the boss's actions and the subordinates' responses become undiscussable" (p. 6) and "With every conscious distortion of the truth goes a conscious cover-up as well as a cover-up of that cover-up" (p. 8). A behaviour of mixed messages has developed. These behaviours are designed to protect the speaker from the need to take a position and potentially negative political consequences: "we use mixed messages to deal with the difficult problem of autonomy versus control in decentralized organizations" (p. 4).

Argyris defines two models: Model I is the current defensive approach as described above, and Model II is an ideal situation. Model I situations can be 'diagnosed' by a consultant through meeting observations, interviews, and case studies (pp. 133-164). The consultant can then implement a solution by informing the organization: "This [communication back] requires telling the clients (1) that they are behaving in ways that are counterproductive to the organization's effectiveness, (2) that they may be unaware of many of the consequences of such behaviour, (3) that if they are not careful, the defensive routines could come back so powerful they may lose control of the organization" (p. 204).

Peter Senge - The Fifth Discipline (1990) 
The subtitle of Senge (1990) is The Art \& Practice of Learning Organizations. Senge's primary contribution is to suggest that organizations can learn better through the use of systems thinking. He finds that there are many learning disabilities in companies, and he proposes a solution of five disciplines, with systems thinking being the central discipline of the five. The learning disabilities appear to be essentially a lack of awareness, failures of perception, and inconsistent communication. Senge sees an antidote in five new technologies: "Today, I believe, five new 'component technologies' are gradually converging to innovate learning organizations" (p. 6). These 'component technologies' are his five disciplines: systems thinking, personal mastery, mental models, building shared vision, and team learning.

He utilizes systems thinking at multiple levels. At a practical level, he defines reinforcing and balancing systems processes. At a conceptual level, he perceives systems thinking as a way to see wholes: "Systems thinking is a discipline for seeing wholes. It is a framework for seeing interrelationships rather than things, for seeing patterns of change, rather than static "snapshots'" (p. 68), and he sees that underlying structure can be illuminated by systems thinking, "... the art of systems thinking lies in seeing through complexity to the underlying structure generating change" (p. 128). And, most important, he sees systems thinking as the basis of all the disciplines: "systems thinking is the fifth discipline. It is the discipline that integrates the disciplines, fusing them together into a coherent body of theory and practice" (p. 12).

The other four disciplines stress aspects of behaviour that contribute to better outcomes. Companies with employees who have personal mastery learn faster: "People with high levels of personal mastery are more committed. They take more initiative. They have a broader and deeper sense of responsibility in their work. They learn faster" (p. 143). The use of mental models enables a person to be self-critical: "The discipline of working with mental models starts with turning the mirror inward: learning to unearth our internal pictures of the world, to bring them to the surface and hold them rigorously to scrutiny" (p. 9). Shared vision is one that goes beyond bland vision statements to be real shared meaning, while team learning stresses getting results that are truly desired by everyone: "Team learning is the process of aligning and developing the capacity of a team to create the results its members truly desire" (p. 236).

\section{Ikujiro Nonaka and Hirotaka Takeuchi - The Knowledge-Creating Company (1995)}

Nonaka and Takeuchi (1995) find that Japanese business success is based on organizational knowledge creation, and they seek to bring this capability to the Western business world. Based on a comparison of Japanese and Western epistemologies, they present a theory of organizational knowledge creation with organizational implementation guidelines. Bertrand Russell's History of Western Philosophy (Russell, 1961) is the primary source for Western epistemology. The authors find a split in the West: "[In Western epistemology] we encounter two opposing yet complementary traditions. One is 'rationalism' ... The other is 'empiricism"' (Nonaka \& Takeuchi, 1995, p. 21). Japanese society is seen as different: "[The Japanese] see reality in the physical interaction with nature and other human beings. These basic attitudes are clearly different from the prevailing Western view that the thinking self seeks the eternal idea as a detached spectator" (p. 32). The two approaches of the West are seen as tacit and explicit knowledge. The Japanese 
integrate these: "The explanation of how Japanese companies create new knowledge boils down to the conversion of tacit knowledge to explicit knowledge" (p. 11).

A theory is built containing four modes, five conditions, and five phases. The four modes are how tacit and explicit knowledge interact: "four modes of knowledge conversion that are created when tacit and explicit knowledge interact with each other. These four modes - which we refer to as socialization, externalization, combination, and internalization - constitute the 'engine' of the entire knowledge-creation process" (p. 57). The five conditions are: intentions, autonomy, fluctuation and creative chaos, redundancy (information availability), and requisite variety (thinking capacity). The phases are, "The model, which should be interpreted as an ideal example of the process, consists of five phases: (1) sharing tacit knowledge; (2) creating concepts; (3) justifying concepts ; (4) building an archetype; and (5) cross-level knowledge" (p. 84).

Implementing the theory requires a systematic approach that is centered on middle-managers: “What distinguishes the knowledge-creating company is that it systematically manages the knowledge creation process" (p. 125), and "Simply put, knowledge is created by middle-managers, who are often leaders of a team or task force, through a spiral conversion process involving both the top and the front-line employees (i.e., bottom)" (p. 127). That the theory and implementation seem to be somewhat Western may be attributable to the authors' academic education and careers in the United States.

\section{Problematization}

All the theorists find issues with thinking capability either disappearing, being badly taught, or being neglected.

Ohmae (1982) finds that strategic thinking, once natural and instinctive, has disappeared: "Both in Japan and in the West, this breed of natural or instinctive strategist is dying out or at least being pushed to the sidelines in favor of rational, by-the-numbers strategic and financial planners" (p. 3) and "strategic thinking has gradually withered away" (p. 4).

For Schön (1983), the public has lost confidence in the professions: "there are increasing signs of a crisis of confidence in the professions" (p. 4). This loss of confidence is driven by universities failing to teach a holistic approach: "a widening rift between universities, and the professions, research and practice, thought and action" (p. viii).

Argyris (1985) finds a major problem in strategy: "strategy never fulfills its potential" (p. ix). This failure to fulfill is caused by our defensive mindset: "The challenge is to see if we can change the status quo because we live in a society that teaches us to use defensive routines that are contradictory to what we need to create and manage healthy organizations" (p. 8). The approach of Argyris is partly behavioural: he identifies a behaviour, postulates causes, and suggests possible solutions to modify that behaviour. 
Senge (1990) finds that the problem for learning organizations is the diminution of learning capability:

“The problem with talking about 'learning organizations' is that the 'learning' has lost its central meaning in contemporary usage. ... learning has become synonymous with 'taking in information"” (p. 13).

Nonaka and Takeuchi (1995) present the thinking challenge as neglect: "This book calls for a fundamental shift in thinking about what the business organization does with knowledge. ... Knowledge creation by the business organization has been virtually neglected in management studies" (p. viii).

All of the problems are mind problems, but in different forms. For Ohmae, we have lost intuition. For Schön, thought has lost touch with practice. For Argyris, mind is too defensive. For Senge, we need more capability. For Nonaka and Takeuchi, we neglect knowledge. While these all concern the mind, they are all very different expressions of mind problems.

\section{Conditions of Possibility}

As the texts highlight, the USA was preoccupied by a perceived lack of competitiveness when compared to the Japanese economy. To resolve this issue, and also general issues with strategy performance, the texts focus on aspects of the mind in a variety of ways. But none describes their intellectual tradition or clearly identifies the theorists that they base their work upon. Baars (1986) describes a cognitive turn in psychology around 1950, but this is not referenced by any authors. However, cross-referencing is apparent, especially between Schön and Argyris, and later by Senge. Also, scans of bibliographies find texts concerning education, sociology, strategy, and management. It seems likely that these were the seeds for cognitive texts during the 80s and 90s. It is also noted that, given the backgrounds of the authors, both Western and Japanese traditions are drawn upon.

\section{Social Effects / Subjectivity}

These texts confirm the importance of minds, and highlight both negative and positive aspects of mind.

Together these texts promote a view that the human mind is central to our reality. For some the mind is a problem and needs fixing, while for others it has the potential to make us so much better.

For the strategist, it is reassuring that strategy is a discipline requiring skilled thinkers, but it is also daunting because the standard has been raised. As no text provides any in-depth cognitive solutions, strategists will need to rely on basic methodologies or develop their own approaches. 


\section{Summary}

Table 35: Foucauldian Summary - Minders

\begin{tabular}{|c|c|c|c|c|c|}
\hline & Ohmae & Schön & Argyris & Senge & $\begin{array}{l}\text { Nonaka \& } \\
\text { Takeuchi }\end{array}$ \\
\hline $\begin{array}{l}\text { Conditions of } \\
\text { Possibility }\end{array}$ & \multicolumn{5}{|c|}{$\begin{array}{l}\text { Japanese competitiveness } \\
\text { academia including education and sociology } \\
\text { both Western and Japanese traditions }\end{array}$} \\
\hline Problematization & \multicolumn{5}{|c|}{ Poor performance of strategy and firms, based upon poor thinking } \\
\hline Knowledge & $\begin{array}{l}\text { method } \\
3 \mathrm{Cs}\end{array}$ & $\begin{array}{l}\text { technical rationality, } \\
\text { integration }\end{array}$ & $\begin{array}{l}\text { defensive } \\
\text { behaviour }\end{array}$ & five disciplines & $\begin{array}{l}\text { modes } \\
\text { conditions } \\
\text { phases }\end{array}$ \\
\hline Cognition & insightfulness & $\begin{array}{l}\text { reflection-in-action } \\
\text { thinking-in-action }\end{array}$ & a corollary & systems thinking & tacit \\
\hline Social Effects & \multicolumn{5}{|c|}{ The human mind is central to our reality, both as a problem and as potential. } \\
\hline Subjectivity & \multicolumn{5}{|c|}{ More choices, but more things to know } \\
\hline
\end{tabular}

The Minders find challenging circumstances of Japanese competitive superiority over the US. This leads to a contemplation of why the Japanese are better, including how they 'think better'. The authors also draw from academia and their own traditions, both Western and Japanese.

The observable problem is company performance, and the causal problems are variations of poor or missing thinking. While these causal problems have mind in common, they all find different problems ranging from the loss of intuition to poor knowledge creation methods.

The Minders consider the mind, but in quite different ways. Ohmae (1982) invokes the aura of past Japanese master strategists, but his focus is primarily on good process to generate understanding. Schön (1983), when investigating a perceived crisis of trust in poorly performing professionals, finds that we have gone too far towards Technical Rationality, and that we need to recognize the benefits of tacit knowledge and learning in situ. Argyris (1985) finds that we have been programmed from a young age to behave defensively, and that this defensiveness is a major issue in corporate businesses. Senge (1990) is concerned with learning organizations, but his solution is a series of personal skills that are emerging in society, and that he describes as five disciplines, with systems thinking being the primary discipline. Nonaka and Takeuchi (1995) look at the company level, and present a series of frameworks to create knowledge in such environments.

Comparing the five texts shows some intriguing variations. Argyris and Senge are somewhat outliers. Argyris, taking a behavioural approach, finds a problem but does little more than suggest that defensiveness can be resolved by informing companies when they behave badly. Senge builds grand structures around a single heuristic, systems thinking, but does little more than to suggest that companies need to be 'truer' (e.g. have 'real' visions, rather than 'bland' visions). 
The other three texts, two deriving from Japanese experience, explicitly consider the conscious and the subconscious, primarily in terms of tacit knowledge. They give examples of the benefits of integrating tacit and explicit knowledge, and suggest that this is the way forward for business. However, after stating a conceptual position on mind, both Japanese texts tend to promote methods and models that are distinctly Western. Initial forays into the Japanese mind give way to Western style thinking. Schön, however, is the standout, as he proposes cognitive solutions. His interpretation of cognition, based on reflecting-in-action and knowing-in-action, illuminates thinking. Schön suggests that his approach could be operationalized, but searches of texts have not revealed that this has occurred within strategy.

Together, the texts represent a movement to present the mind as being central to strategy. These are wellknown and well-cited texts, and hence they are likely to have had social effects. This may include confusion about whether mind is the problem or the solution. For the strategist, they provide another perspective on strategy, but possibly one that strategists need to develop themselves, rather than being a solution ready to be adopted. 


\section{Cognition}

The five texts treat cognition very differently: Ohmae (1982) makes passing comments only, Schön (1983) builds a theoretical framework on top of cognition, Argyris (1985) treats cognition as a side issue to behaviour, Senge (1990) solves cognitive issues through systems thinking, and Nonaka and Takeuchi (1995) find knowledge in our bodies as much as in our minds.

Kenichi Ohmae - The Mind of the Strategist (1983)

The title The Mind of the Strategist might suggest a focus on cognition, but Ohmae (1982) makes few observations about cognition. He presents cognition conceptually, considers insight and rational thinking in Strategizing, and finds that insight is beyond conscious thought.

His few comments include that cognitive capability is something we all have: "Creativity, mental productivity, and the power of strategic insight know no national boundaries. Fortunately for all of us, they are universal" (p. 277). Regarding Strategizing, this insight and rational thinking are both required: "[The true strategist] has a more reliable recipe for success: the combination of analytical method and mental elasticity that I call strategic thinking" (p. 35).

This ability to be both insightful and analytical is recognized as being learnable and a way of life: "In short, creativity cannot be taught but it can be learned" (p. 270) and "[Drafting of a strategy] represents the expression of an attitude to life" (p. 79). "Great strategies, ... originate in insights that are beyond the reach of conscious analysis" (p. 4). So while Ohmae does not use the term subconscious, he clearly sees cognition as being beyond mere rational thought. And, as in other Japanese arts, such insightfulness can be developed in the individual.

Donald Schön - The Reflective Practitioner (1983)

Schön (1983), as is implicit in the title of his text The Reflective Practitioner, focuses on human cognition. He seeks to describe a way of thinking about thinking that will improve our performance, especially in the professions. He treats cognition conceptually, operationally, and phenomenally.

Conceptually, epistemology is considered as artistry. This art is not explicit, but can be learnt: "If the art is not invariant, known, and teachable, it appears nonetheless, at least, for some individuals, to be learnable" (p. 18). This artistry is what we use when ends are not clear: "Let us search, instead, for an epistemology of practice implicit in the artistic, intuitive processes which some practitioners do bring to situations of uncertainty, instability, uniqueness, and value conflict" (p. 49). While no philosophical basis is given for this epistemology, Schön is seeking to go beyond the limited knowledge of what he terms Technical Rationality.

Schön provides examples of numerous workplace phenomena to support the definition of operational cognitive processes, and names two operational Thinking Processes of knowing-in-action and reflection-inaction. Knowing-in-action is similar to tacit knowledge: "[The practitioner's] knowledge-in-action tends to 
become increasingly tacit, spontaneous, and automatic, thereby conferring upon him and his clients the benefits of specialization" (p. 60). Schön sees such knowing-in-action as being 'within' practice itself, although this may be more a literary device that a metaphysical proposition: "It seems right to say that our knowing is in our action. Similarly, the workaday life of the professional depends on tacit knowing-in-action” (p. 49). Reflection-in-action is a form of reasoning that occurs in the moment, and something we can understand through common-sense or introspection: "If common sense recognizes knowing-in-action, it also recognizes that we sometimes think about what we are doing" (p. 54). Reflection-in-action is key to Schön's study as he sees it to be the underlying technique of good thinking and worthy of being utilized more extensively.

Schön uses these core concepts to discuss other activities. He suggests that we use reflection-in-action when experimenting: "When the practitioner reflects-in-action in a case he perceives as unique, paying attention to phenomena and surfacing his intuitive understanding of them, his experimenting is at once exploratory, move testing, and hypothesis testing" (p. 147). He extends the concepts to a form of iteration with a situation: "He shapes the situation, in accordance with his initial appreciation of it, the situation 'talks back,' and he responds to the situation's back talk. In a good process of design, this conversation is reflective. In answer to the situation's back-talk, the designer reflects-in-action" (p. 79).

As the quotations above indicate, Schön has a focus on tacit knowledge. He does not explicitly state that this is subconscious, but clearly he sees such knowledge as being beyond conscious: "I begin with the assumption that competent practitioners normally know more than they can say" (p. viii).

Schön builds an operational framework of cognition in a professional context. His comments are primarily general, but he does specifically consider Strategizing in a chapter in which he discusses the art of managing. He rarely approaches cognition directly but creates his own super-structure upon cognitive terms. From this he draws his inferences, conclusions, and suggestions.

\section{Chris Argyris - Strategy, Change, and Defensive Routines (1985)}

For Argyris (1985), cognition is a corollary to a behaviour problem. When Argyris mentions cognition, it is to do with defensive routines in a general sense. He finds that reason is programmed, even though we may be able to reason better.

Like Schön, Argyris treats cognition in multiple ways. Conceptually, he recognizes that cognition can be both useful and problematic: "the processes that the human mind uses to help us make sense of the world may be the same ones that help us get into trouble" (p. xi), and "Thus the key features of defensive reasoning are the unawareness of the inferences being made, the lack of testing of those inferences publicly, combined with the certainty than none of this is happening" (p. 76). Human reasoning capability could be useful, but we are programmed to think poorly: "We are taught to act counterproductively in the name of being humane, thoughtful and civilized"(p. xi), and "Defensive routines exist in most organizations. The routines most dangerous to organizational learning and effectiveness are those that are used in the name of support, concern, strength, humanism, and realism. These ideas are culturally taught and accepted to be true" (p. xi). 
Operationally, it is possible to engage in productive reasoning and migrate to hard reasoning: "Underlying understanding and action is reasoning. The reasoning required for effective leadership is productive reasoning" (p. 353), and "Organizations are increasingly managed through the use of sophisticated information science systems that require tough reasoning. ... However, also involved in the defensive routines taught by our culture is ... soft reasoning. ... our instincts are to use soft reasoning to deal with ... threat. The soft reasoning ... will be rationalized as a result of caring thoughtfulness" (pp. 8-9). Here Argyris associates defensive routines with our programmed soft reasoning, whereas he would prefer open reasoning that is factual.

Argyris' text is based on analysis of various phenomena within work situations. While it is written 20 to 30 years after the purported rejection of behaviourism, his work has a distinctive behaviourist feel. He spends much time describing behaviour and inferring rationales for this behaviour. His approach is not strictly behaviourism in the mould of Skinner and Watson, who forbid any theorizing of cognitive processes, but it does align with that of Tolman who does allow such theorizing and conjecture.

\section{Peter Senge - The Fifth Discipline (1990)}

Senge (1990) treats cognition conceptually, as a problem that he solves.

Whilst his focus is on general cognition of the individual rather than Strategizing processes, he recognizes learning is cognitive, sees humans as being flawed, and suggests that his five disciplines will resolve learning difficulties. Senge recognizes that cognition is human: "Real learning gets to the heart of what it means to be human" (p. 14), and that learning involves a cognition change: "The most accurate word in Western culture to describe what happens in a learning organization is [metanoia] ... and it means a shift of mind" (p. 13). The learning that Senge considers is general learning, and not specifically the Learning process of strategy as defined in this thesis.

He suggests that knowledge can be 'right' and that many humans fail to perceive correctly. Such failures are due to a lack of sensing capability, deceiving ourselves, and flawed mental models: "Personal vision comes from within. ... Most adults have little sense of real vision" (p. 147), "[Commitment to the truth] means a relentless willingness to root out the ways we limit or deceive ourselves from seeing what is, and to continually challenge our theories of why things are the way they are" (p. 159), and "Contemporary research shows that most of our mental models are systematically flawed" (p. 203). Senge considers that people are the problem.

Senge suggests that his disciplines will provide relief for learning organizations at multiple levels. The disciplines will solve the learning issues: "The five disciplines of the learning organization can, I believe, act as antidotes to [the seven] learning disabilities" (p. 26), especially as systems thinking will make us think better: "Systems thinking is a discipline for seeing wholes. It is a framework for seeing interrelationships rather than things, for seeing patterns of change, rather than static 'snapshots'" (p. 68). With the other four disciplines, systems thinking enables the mind to perceive reality and shape the future: "[the five disciplines] are concerned with a mind shift from seeing parts to seeing wholes, from seeing people as helpless reactors to 
seeing them as active participants in shaping their reality, from reacting to the present to creating the future" (p. 69).

Senge's solution goes further to harness the subconscious: "Implicit in the practice of personal mastery is another dimension of the mind, the subconscious. It is through the subconscious that all of us deal with complexity. What distinguishes people with high levels of personal mastery is they have developed a higher level of rapport between their normal awareness and their subconscious" (p. 13), and "Systems thinking may hold a key to integrating reason and intuition. Intuition eludes the grasp of linear thinking, with its exclusive emphasis on cause and effect that are close in time and space. The result is that most intuitions don't make "sense" - that is, they can't be explain in terms of linear logic" (p. 13).

Besides finding ways to harness the subconscious, Senge suggests that we may find the 'core mental models of organization': "Eventually, what will accelerate mental models as a practical management discipline will be a library of 'generic structures' used throughout an organization" (p. 204). Perhaps having solved some significant problems of management, it is unsurprising that Senge goes further by invoking transcendent power: "A shared vision is not an idea. It is not even an important idea such as freedom. It is ... a force in people's hearts, a force of impressive power. ... People begin to see it as if it exists. Few, if any, forces in human affairs are as powerful as shared vision" (p. 206).

Ikujiro Nonaka and Hirotaka Takeuchi - The Knowledge-Creating Company (1995) Nonaka and Takeuchi (1995) treat cognition operationally as a very generalized process, and treat knowledge conceptually as tacit knowledge and part of the body.

Like many other authors, cognition is not a focus of their text, but more a concept upon which other structures are built. They define the status of knowledge itself: "In this book we take knowledge as the basic unit of analysis for explaining human behavior" (p. viii). While their subject is often the organization, they see cognition as being of the individual: "In a strict sense, knowledge is created only by individuals" (p. 59).

As shown in the Cognitive Process Model below, cognitive concepts are part of their knowledge creation process. While this model is operational, it is a very abstract and stylized view of how knowledge is formed. It may have some utility for defining processes, but as a representation of cognition, it is more transcendent than operational. 


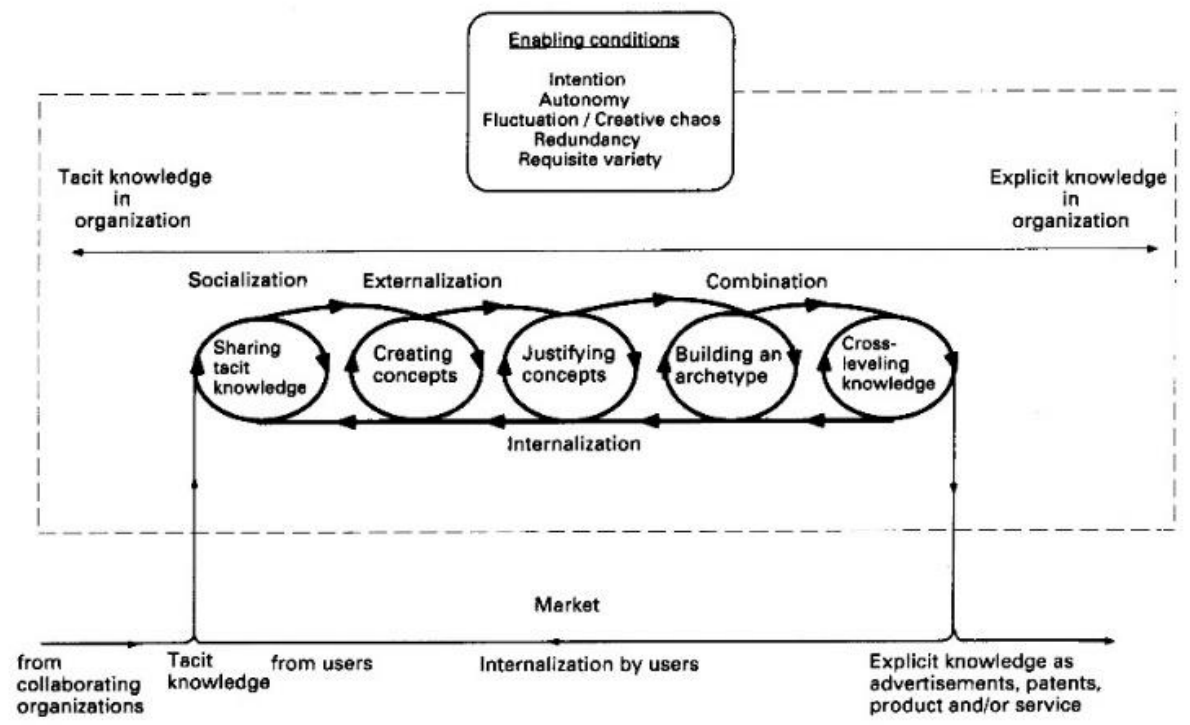

Figure 37: "Five-phase model of the organizational knowledge-creation process", reprinted from (1995). The Knowledge-Creating Company (p. 84), by I. Nonaka, \& H. Takeuchi, 1995, New York, NY: Oxford University Press. Copyright 1995 by Oxford University Press.

Tacit knowledge is conceptually aligned with the subconscious. Firstly, tacit knowledge is found to be one of two forms: "The cornerstone of our epistemology is the distinction between tacit and explicit knowledge" (p. 56). Tacit knowledge is found to be key and to be partly subconscious: "[Japanese companies] view knowledge as being 'primarily' tacit - something not easily visible and expressible. ... Subjective insights, intuitions, and hunches fall into this category of knowledge. Furthermore, tacit knowledge is deeply rooted in an individual's action and experience, as well as in the ideals, values, and emotions he or she embraces" (p. 8).

For Nonaka and Takeuchi, knowing is a complex process that involves the body: "To know something is to create its image or pattern by tacitly integrating particulars. In order to understand the pattern of the meaningful whole, it is necessary to integrate one's body with the particulars. This indwelling breaks the traditional dichotomies between mind and body, reason and emotion, subject and object, and knower and known" (p. 60). Or put more directly, "Like a child learning to eat, walk, and talk, [Japanese managers] learn with their minds and bodies" (p. 10). So for Nonaka and Takeuchi, the flow between tacit and explicit knowledge is the key dynamic, and tacit knowledge seems to be more highly prized that explicit knowledge. 
Table 36: Cognitive Summary - Minders

\begin{tabular}{|c|c|c|c|c|c|}
\hline & Ohmae & Schön & Argyris & Senge & $\begin{array}{l}\text { Nonaka \& } \\
\text { Takeuchi }\end{array}$ \\
\hline Type of Abstraction & conceptual & $\begin{array}{l}\text { conceptual } \\
\text { operational } \\
\text { phenomenal }\end{array}$ & $\begin{array}{l}\text { conceptual } \\
\text { operational } \\
\text { phenomenal }\end{array}$ & conceptual & $\begin{array}{l}\text { conceptual } \\
\text { operational }\end{array}$ \\
\hline Subject & individual & individual & individual & individual & individual \\
\hline Mind & $\begin{array}{l}\text { conscious } \\
\text { subconscious }\end{array}$ & $\begin{array}{l}\text { conscious } \\
\text { subconscious }\end{array}$ & conscious & $\begin{array}{l}\text { conscious } \\
\text { subconscious }\end{array}$ & $\begin{array}{l}\text { conscious } \\
\text { subconscious }\end{array}$ \\
\hline Thinking Process & Strategizing & general & general & general & \\
\hline Thought Content & - & - & - & - & - \\
\hline Summary & insightfulness & $\begin{array}{l}\text { reflection-in-action } \\
\text { thinking-in-action }\end{array}$ & an aside & $\begin{array}{l}\text { systems } \\
\text { thinking }\end{array}$ & tacit \\
\hline
\end{tabular}

The texts take quite different approaches to cognition. Ohmae (1982) and Nonaka and Takeuchi (1995) find tacit knowledge and its integration with explicit knowledge to be fundamental to Japanese success and recommended for the West. The contributions of Schön (1983) and Senge (1990) are similar, in that their conceptual ideas (reflection-in-action and system thinking) are based upon the concept of cognition, but Schön goes much further into in-depth consideration of cognition. Argyris (1985) is quite different, as he treats cognition as a corollary to behaviour.

All texts consider cognition conceptually, even if these comments are not in-depth. The main exception is Schön, who delves deeply into cognition conceptually, operationally, and phenomenally. He takes positions of what cognition is, how it functions, and uses examples to illustrate his points. Argyris and Nonaka and Takeuchi consider cognition operationally, but only at a high level of abstraction, while Argyris also researches cognition phenomenally.

All texts treat the subject as the individual.

All texts, with the exception of Argyris, consider the subconscious. It is least important for Senge who focuses on a specific form of systems thinking, but for the other three, the subconscious and how it is utilized is a primary concern. However, beyond such recognition, only Schön suggests any way forward outside the common methods and prescriptions of management literature. His approach is to develop, through action science, a reflection-in-action mental process that becomes the norm, rather than the exception.

Ohmae specifically considers Strategizing, while the other authors take a more general view, as their texts are not just focused on strategy but have a broader management view. What strategists think, in terms of Strategy, Context, and Intentions, is not considered explicitly by any of the authors. 
These texts start with concerns with mind, and with an acceptance that mind can be rationally understood. It is simply assumed that mind is reasonable. In the absence of any prevailing orthodoxy of mind, the authors develop five different approaches to cognition.

While four texts treat cognition, they do so sparingly, albeit that the subconscious is highlighted through discussions and tacit knowledge and insight. Schön (1983) is the standout, as he does not revert to standard methodological prescriptions, but devotes his text to cognition. However, his text does not appear to be influential in strategy itself. Highly quoted texts that cite Schön (1983) are primarily education and sociology text, with only one strategy text, Nonaka and Takeuchi (1995), that is reviewed in this chapter.

\section{Minder Conclusions and Provisional Insights}

The Minders provide a cognitive perspective on strategy. They find that strategy thinking is problematic and suggest a variety of ways to improve the situation. This is in marked contrast to other discourses, which often ignore or pay little attention to cognition.

A significant variation is also that the subconscious is recognized, primarily as tacit knowledge. These texts, unlike others, not only recognize the subconscious, but perceive it as being on a par with, or more important than, the conscious mind. However, no theorist offers advice on how to utilize the subconscious better, focusing instead on normal methodological approaches with some cognitive aspects. Schön is the exception, but his in-depth cognitive analysis is primarily descriptive, and does not advance to cognitive solutions.

These conclusions raise two provisional insights:

P2 Cognition was once briefly treated seriously by strategy.

P3 Even when strategy treats cognition seriously, solutions are not cognitive. 


\subsection{Summary}

The Pop texts find problems that must be resolved. There are many solutions proposed, often based upon a central idea. Within these problem and solution definitions, cognition is approached deeply by only one author. Whole industries are created through various concepts, even if these are not necessarily generative of good strategy.

\section{Foucauldian Analysis}

Table 37: Pop Foucauldian Summary

\begin{tabular}{|c|c|c|}
\hline & Strategists & Minders \\
\hline \multirow[t]{2}{*}{ Texts } & $\begin{array}{l}\text { Peters \& Waterman (1982) } \\
\text { Collins \& Porras (1994) } \\
\text { Hamel \& Prahalad (1994) } \\
\text { Kim \& Mauborgne (2005) } \\
\text { Rumelt (2011) } \\
\text { Lafley \& Martin (2013) }\end{array}$ & $\begin{array}{l}\text { Ohmae (1983) } \\
\text { Schön (1983) } \\
\text { Argyris (1985) } \\
\text { Senge (1990) } \\
\text { Nonaka \& Takeuchi (1995) }\end{array}$ \\
\hline & \multicolumn{2}{|c|}{ Japanese competitiveness } \\
\hline $\begin{array}{l}\text { Conditions of } \\
\text { Possibility }\end{array}$ & $\begin{array}{l}\text { Academic discourses, including psychology, } \\
\text { cognitive psychology, and sociology }\end{array}$ & $\begin{array}{l}\text { Academia discourses including education } \\
\text { and sociology } \\
\text { Western and Japanese traditions }\end{array}$ \\
\hline Problematization & $\begin{array}{l}\text { Traditional strategy does not achieve its } \\
\text { aims }\end{array}$ & $\begin{array}{l}\text { Poor performance, based upon poor } \\
\text { thinking }\end{array}$ \\
\hline Knowledge & $\begin{array}{l}\text { - people } \\
\text { - authentic ideologies } \\
\text { - foresight } \\
\text { - systematic process } \\
\text { - heuristics } \\
\text { - strategy process }\end{array}$ & $\begin{array}{l}\text { - } \text { method, } 3 \text { Cs } \\
\text { - } \text { reflect-in-action, thinking-in-action } \\
\text { - defensive behaviour } \\
\text { - } \text { systems thinking } \\
\text { - tacit knowledge }\end{array}$ \\
\hline Social Effects & A plethora of new approaches & Mind raised, but forgotten \\
\hline Subjectivity & $\begin{array}{l}\text { Everyone can be a strategist } \\
\text { The strategist's role becomes more complex }\end{array}$ & No long-term influence \\
\hline
\end{tabular}

\section{Conditions of Possibility}

Three conditions of possibility stand out: heightened competition, underlying academic foundations, and an acceptance of cognition as a topic. The Japanese challenge to US business from the 1980s onwards is wellknown and is clearly a condition reflected in these texts from the 1980s and 1990s. 
Most of the authors have academic backgrounds and the content often reflects their underlying academic ideas from management science, sociology, and psychology. However, the need to explicitly recognize such traditions is no longer apparent for these texts.

Cognition is central to the Minders. That a cognitive turn happened in psychology may contribute to this renewed interest in cognition. Potentially, developments in education may have been the catalyst for management interest in the mind.

\section{Problematization}

For the Strategists, strategy and management are themselves the problem whereas, for the Minders, performance is suffering due to sub-optimal thinking. The Strategists both cast aspersions on previous authors, and use case examples of business failures to show that strategy is a problem. They have little problem finding the need for some intervention. The Minders vary somewhat, with Ohmae and Nonaka and Takeuchi finding that an issue is that Western thinking is not as good as Japanese thinking, while Schön sees a problem with professional conduct, and Argyris sees a general problem with people's defensive attitudes. Senge takes a different approach, finding organizational learning to be sub-optimal.

A common thread is a relatively relaxed attitude to defining the problem. The authors, predominantly from academia, do not exert any real effort to provide any defendable proof of a problem. Anecdotal case examples are often the starting point for propositions and speculations, without any in-depth analysis that attempts to pin-point problems, even if there is some in-depth analysis by some to identify the solutions (e.g. Peters and Waterman's identification of excellent attributes, Collins and Porras' identification of fundamental principles of success).

\section{Knowledge}

An overriding impression of these texts is a strong central idea and speculative propositions. All of these texts have a strong central idea such as the treatment of people, fundamental principles, authentic ideology, systematic process, tacit knowledge, defensive routines, systems thinking, or learning organizations. These texts are not written to be comprehensive. Compared to the Classical period, the authors seek to promote specific perspectives on strategy, rather than to find holistic solutions.

Like the problematizations made without significant detail, propositions are made without significant justification other than numerous anecdotal examples from the past to support such propositions. The whole discourse seems to be speculative in the sense that single ideas are expanded into broader methodologies, but with limited consideration of the full context of the management and strategy world. 


\section{Social Effects / Subjectivity}

Whereas the Classical texts suggest an expanding discipline with some common basis, Pop texts present a variety of distinct approaches. From the candidate's experience, some have had great effects, such as the expansion of Human Resources departments that Peters and Waterman (1982) likely contributed to, and the concepts of stretch and competencies made explicit in Hamel and Prahalad (1994). Others, especially the Minders, have not had long-term influence. Systems thinking and reflecting-in-action may be concepts that people remember, but they do not seem to be significant in the field of strategy now.

Pop makes everyone into a strategist. Whereas the strategist previously could claim some arcane knowledge, Pop strategy makes strategy simple, requiring no specific knowledge. For strategists, there are a plethora of new techniques to support their perceived role, but also some would now see the strategist's role as irrelevant. The whole of strategy becomes confused, making the strategist's role obscure and strategy itself ambiguous. No longer are there some general processes to follow, but, from the candidate's experience, corporates can choose to follow a guru and adopt their framework.

\section{Foucauldian Summary}

The Strategists and the Minders are found in similar periods, but their influences are quite different. While they may share similar conditions of possibility and problematizations, the Strategists created ideas that have endured for longer than the Minders.

$\begin{array}{ll}\begin{array}{l}\text { Conditions of Possibility } \\ \text { Problematization }\end{array} & \begin{array}{l}\text { Academia and Japanese competitiveness } \\ \text { Knowledge }\end{array} \\ \text { Methods based upon central ideas, and cognitive for the Minders } \\ \text { Social Effects } & \begin{array}{l}\text { The people approach that influences Human Resources, and a number of } \\ \text { methodologies }\end{array} \\ \text { Subjectivity } & \text { A generalist becomes a strategist }\end{array}$




\section{Cognition}

\section{By Cognitive Heuristic}

Table 38: Pop Cognitive Summary

\begin{tabular}{|c|c|c|}
\hline & Strategists & Minders \\
\hline Texts & $\begin{array}{l}\text { Peters \& Waterman (1982) } \\
\text { Collins \& Porras (1994) } \\
\text { Hamel \& Prahalad (1994) } \\
\text { Kim \& Mauborgne (2005) } \\
\text { Rumelt (2011) } \\
\text { Lafley \& Martin (2013) }\end{array}$ & $\begin{array}{l}\text { Ohmae (1983) } \\
\text { Schön (1983) } \\
\text { Argyris (1985) } \\
\text { Senge (1990) } \\
\text { Nonaka \& Takeuchi (1995) }\end{array}$ \\
\hline $\begin{array}{l}\text { Cognition } \\
\text { Summary } \\
\text { by } \\
\text { Text }\end{array}$ & $\begin{array}{l}- \\
\text { cognition is fundamental } \\
\text { avoid intuition } \\
\text { cognition is fundamental } \\
-\end{array}$ & $\begin{array}{l}\text { insightfulness } \\
\text { reflection-in-action, thinking-in-action } \\
\text { a corollary to behaviour } \\
\text { systems thinking } \\
\text { tacit knowledge }\end{array}$ \\
\hline $\begin{array}{l}\text { Type of } \\
\text { Abstraction }\end{array}$ & $\begin{array}{l}\text { conceptual } \\
\text { operational }\end{array}$ & $\begin{array}{l}\text { conceptual } \\
\text { operational } \\
\text { phenomenal }\end{array}$ \\
\hline Subject & \multicolumn{2}{|c|}{ individual } \\
\hline Mind & conscious & conscious and subconscious \\
\hline Thinking Process & \multicolumn{2}{|c|}{ Strategizing } \\
\hline Thought Content & \multicolumn{2}{|c|}{ rarely considered, but if so as Context } \\
\hline
\end{tabular}

Based on these groupings, there are some clear differences in treatments of cognition, but also some similarities. The similarities are the subject being the individual, the thinking process being Strategizing, and thought content being rarely considered.

The primary difference is the level of treatments of cognition. The Strategists either ignore cognition or simply recognize it, and, in one case, Kim and Mauborgne (2005) reject the use of the cognitive capability of intuition. The exceptions are Hamel and Prahalad (1994) who devote one chapter to industry foresight and Rumelt (2011) who devotes three chapters to cognition, but neither text proposes any cognitive solutions for strategy.

However, the Minders, as the name suggests, take cognition seriously. Of the five, Argyris (1985), who takes a behavioural approach to strategy, does not delve deeply into cognition. Senge (1990) also does not go to any depth, but he promotes a particular thinking framework - systems thinking - throughout his text.

The others consider tacit knowledge, two from a Japanese perspective, but without going into any depth (Nonaka \& Takeuchi, 1995; Ohmae, 1982), and Schön (1983) who devotes his whole text to a consideration of 
cognition. Such considerations of tacit knowledge are beyond conscious thinking, and while the theorists rarely use the term subconscious, tacit knowledge is clearly a form of the subconscious.

In respect of levels of abstraction, all treatments include conceptual discussions of the nature of cognition. The Minders and one Strategist, Rumelt, develop operational process definitions. Schön and Argyris derive their theories from phenomena, and Schön goes further when he delves into the phenomena of detailed thinking processes.

The key standout text is Schön (1983) who builds his edifice of knowing-in-action and reflection-in-action on top of basic cognitive concepts, and remains at that level of abstraction throughout his text. Other Pop texts also build processes, but Schön goes further to suggest that we can proactively change thinking processes and that this needs further research. So he too, like other theorists, does not promote specific cognitive solutions.

\section{Provisional Insights}

A series of provisional insights were gained in each sub-discourse analysis. These are used as a starting point to these provisional insights, which in turn will be considered with other discourses in Chapter 13 - Findings (p. 271):

P1 A people focus within strategy did not produce cognitive solutions.

P2 Cognition was once briefly treated seriously by strategy.

P3 Even when strategy treats cognition seriously, solutions are not cognitive.

\section{A People Focus Does Not Equate to Cognitive Solutions}

The Strategists, especially Peters and Waterman (1982), highlight the contribution that people make to business performance and the need to treat people well. However, a people focus does not necessitate cognitive solutions. Issues of core ideology and foresight may be raised, but this does not entail that a theorist must describe solutions in cognitive terms.

\section{Cognition Was Once Treated Seriously}

Cognition was once treated seriously, especially in the work of Schön (1983), and to a lesser extent in the works of Argyris (1985), and Senge (1990). But, as Kiechel (2010) notes, the people movement that he attributed to have started with Peters and Waterman (1982) has lost momentum in strategy. A brief flourish in interest in mind seems to have concluded in the 1990s, but strategy appears to have lost a people focus, and hence the opportunity to go further to thinking about minds.

\section{In-depth Treatment of Cognition does not Entail Cognitive Solutions}

The Minders show that theorists can discuss the mind at length, but this does not mean that they will promote any cognitive techniques. One could expect some ideas of how to develop foresight that involve more than procedural approaches. One could expect some way of developing thinking-in-action that involves mind skills. These are not present in the literature reviewed. 


\section{Summary}

These final words cannot summarize the variety of Pop discourse, but some observations can be made. Within Pop, the Strategists raised people to the top of the strategy pyramid, but these people simply needed to be treated better. The Minders raised the issue of mind, and contributed conceptual frameworks and buzz words to strategy, but did not create a cognitive turn in strategy. Pop has broadened the field, but it is no cognitive game changer, as per the provisional insights:

P1 A people focus within strategy did not produce cognitive solutions.

P2 Cognition was once treated seriously by strategy.

P3 Even when strategy treats cognition seriously, solutions are not cognitive.

"Somewhere over the rainbow the bluebirds fly birds fly over the rainbow why then oh why can't I?"

Lyrics from Over the Rainbow by Yip Harburg and Harold Arlen, copyright Sony/ATV Music Publishing LLC 


\section{Chapter 12 - Strategy as Practice}

"The agenda is to find out more about the work of strategizing and how strategists learn to do it"

(Whittington, 1996, p. 734)

"[The traditional perspective] has no answer to the practitioner's question 'how should I best decide?"”

(Hendry, 2000, p. 963)

"With the 'practical' so strongly implied in our field's title, making practice better should surely be a central part of our research endeavour"

Whittington (2010).

Strategy as Practice ("SaP") is a well-defined discourse with precedents, a beginning, a body of work and a formal organization. As is commonly acknowledged in the literature reviewed, SaP was preceded by the Process School. As the result of a 'Practice Turn' in the 1970s, SaP evolved out of this Process School. SaP has a beginning in the work of the key theorists Richard Whittington and Paula Jarzabkowski. SaP became an established field which is institutionalized in an international organization of over 3,000 scholars (www.s-asp.org) and has gained an accepted structure and approach through ongoing research articles, special journal editions, handbooks, and undergraduate texts.

This chapter follows the same structure as Chapter 10 - Managerial and Organizational Cognition: initially the resource material selection is defined, then the discourse is considered in Foucauldian terms, followed by a consideration of treatments of cognition, and finally a summary is presented.

12.1 Foucauldian Analysis

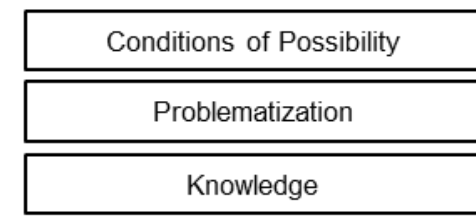

Social Effects / Subjectivity

SaP uses the terms 'micro' and 'practice' interchangeably, and also uses the term 'macro'. This thesis follows the same practices.
12.2 Treatments of Cognition

\subsection{Summary}

Figure 38: Chapter 12 Structure 


\section{Articles and Books}

An initial search yielded 49 texts which were checked for relevance leading to the selection of 44 texts (41 journal articles and 3 books) that were reviewed for SaP.

An initial decision was made to focus on journal articles as these are the standard publication in academic fields, and only to include other types of texts if they have relevant content. The two main sources of texts were 1) search engines, and 2) two Cambridge handbooks of SaP.

Google Scholar and the Victoria University of Wellington library search engines were used to find texts. Searches were made for:

- highly cited articles that referenced variants of 'strategy as practice'

- highly cited authors that the candidate was familiar with (e.g. Jarzabkowski and Whittington).

The first and second editions of The Cambridge Handbook of Strategy as Practice (Golsorkhi, Rouleau, Seidl \& Vaara, 2010c, 2015) provided a rich source of references, especially in the introductory chapters, which include appendices of example papers. As these appendices included many papers that were not specifically SaP, a manual search was required. This involved an initial identification of likely papers, followed by paper retrieval and checking of abstracts.

These two methods yielded 44 texts that were clearly SaP, of which 41 are papers. Of these, nine were found in The Cambridge Handbook of Strategy as Practice (five in the first edition, four in the second edition). The three books were strategy as practice: an activity based approach (Jarzabkowski, 2005), Strategy as Practice: Research Directions and Resources (Johnson, Langley, Melin \& Whittington, 2007b), and Strategy Practices: Texts and Cases (Paroutis, Heracleous \& Angwin, 2013). The first is a concise definition of the SaP field and hence is very relevant. The second has two parts - a first part of three chapters that discuss SaP itself and a second part of illustrative papers. The first part is reviewed in this thesis, and hence the text is considered to be a book. The third book is a later redescription of SaP itself.

While no claim is made that this list is representative of SaP, the texts cover 21 years of scholarship and includes many, if not all, of the principal theorists in the field. Hence, it has a useful coverage of the discipline and the potential to illustrate a variety of different treatments of cognition. 


\subsection{Foucauldian Analysis}

This Foucauldian analysis finds an established and developing field that focuses on practice, is based upon scientific method, borrows extensively from other fields, and finds issues with strategy itself. It is also selfcritical, finding issues with SaP itself and opportunities for development. Being a narrow academic field, its social effects are likely to be limited and to have minimal influence on strategists.

\section{Conditions of Possibility}

SaP has a scientific focus based on the knowable. The Practice Turn (Nicolini, 2012; Schatzki, Cetina \& von Savigny, 2001) and the Process School (Mintzberg, 1987; Pettigrew, 1992) are starting points, as they both introduce a focus on practice. However, many other underlying theories are invoked and enable multiple treatments of practice.

\section{Scientific Basis}

As with MOC, SaP is an academic field. This analysis finds that SaP, like MOC, rarely states its ontological and epistemological bases. For SaP, the exceptions appear to be when SaP is being justified as an approach. In such cases, the scientific basis of SaP is explicitly stated. In an early article, Chia $(2004$, p. 29) finds that SaP brings 'realism': “[The practice-based approach] injects a much-needed degree of realism into academic theorizing." Jarzabkowski (2004, p. 530) finds theoretical robustness: "strategy as practice is a topic for serious academic endeavour, being both theoretically robust and practically relevant," while Johnson, Langley, Melin and Whittington (2007a, p. 6) see that SaP can be convincing if systematic: "If Strategy as Practice is to influence either or both the academic world and the world of management, it has to be based on sound and convincing academic inquiry offering the kinds of systematic data and guidance expected now in contemporary teaching and, especially, research." Vaara and Whittington (2012, p. 286) neatly summarize the scientific basis as a special capacity to understand: "Practice-based analyses of organizations are becoming increasingly widespread in the management disciplines because of their special capacity to understand how organizational action is enabled and constrained by prevailing organizational and societal practices."

\section{The Process School}

The Process School is recognized as a precedent to SaP with positive effects: "We are strongly sympathetic to this process turn in the strategy field" (Johnson et al., 2003, p. 10). This includes recognizing the Process School's contribution towards opening the black box of the organization, its humanizing of the field, and its legitimizing small sample studies, and that "strategy process research ... seeks to capture the internal reality of organizations 'in flight'” (Chia \& MacKay, 2007, p. 220).

\section{Practice Turn}

As the term indicates, SaP is about practice. This is reflected in many of the foundational articles: "In recent years social scientists have been scrutinizing the practices of scientists, accountants and architects. Now it is 
the turn of the strategists" (Whittington, 1996, p. 732), "This attention to people's actual activity follows a broader 'practice' turn in social theory since the 1980s" (Whittington, 2003, p. 118), and "Strategy as practice is part of a broader practice turn in contemporary social theory and the management sciences over the past 20 years. ... More recently, the practice turn has entered the strategy field" (Jarzabkowski, 2005, p. 2).

\section{Broadening Basis}

While practice was the initial rallying point, a broadening theoretical basis is also apparent: "Strategy-aspractice, in common with much other organization theory, draws from the meta-theoretical principles of sociology, social psychology, anthropology, and ethnomethodology, among others, to understand the construction of activity within organizations" (Jarzabkowski, Balogun \& Seidl, 2007, p. 20). Examples of theoretical positions and methodologies used within SaP are: Communications Theory (Fenton \& Langley, 2011), Personal Construct Theory and Repertory Grid (Wright, Paroutis \& Blettner, 2013), Actor Network Theory (Chapman, Chua \& Mahama, 2015), Critical Management Studies (Blom \& Alvesson, 2015), Maclntyre's moral philosophy (Tsoukas, 2017), ethnographical studies (Samra-Fredericks, 2003), and narrative analysis (Beech \& Johnson, 2005).

\section{Practice Treatments Variants}

How practice is treated is a reflection of the conditions of possibility, and SaP has some startling variants. When the SaP field was forming, many invocations simply reflected the practice turn as organizational activity: "we should examine strategy not as something a firm has, but something a firm does" (Jarzabkowski, 2004, p. 529). Whittington (2007) is very specific in his view that practice is to be viewed sociologically: "when we place this practice under the 'sociological eye', we immediately take on a comprehensiveness of vision that obliges us to draw from both sides of the dichotomies between Process and the rest." For Vaara and Whittington (2012, p. 285) this means that social practice takes precedence: "strategy is enabled and constrained by prevailing organizational social practices." Paroutis et al. (2013, p. 12) find that practice is behaviour at an individual level: "We showed that the strategy-as-practice perspective fundamentally moves away from modernist and positivist views of strategy that focus on the macro scale of organizational activity towards a more micro-level, humanistic, behavioral, interpretative approach to strategy making and execution." At another extreme, practice becomes being-in-the-world: "From a Heideggerian phenomenological perspective, strategizing, namely the process of forming thematic awareness, is a distinctive moment of being-in-the world that comes about when people step back from immediate practical tasks and reflect on an entity in a detached manner" (Tsoukas, 2010, p. 59).

\section{Summary}

$\mathrm{SaP}$, with a scientific basis and the Process School and the Practice Turn as precedents, borrows from a variety of fields to broaden its basis and treats practice in many ways, including organizational activity, social practices, individual behaviour, and being-in-the-world. From this perspective, SaP can be seen as a rich field with broad conditions of possibility. 


\section{Problematization}

SaP finds concerns with strategy itself; a need for academic progress; and, quite differently, a questioning of the lack of a sound basis for SaP. In the literature reviewed, cognition itself is rarely seen as being a problem.

\section{Strategy Concerns}

SaP finds concerns with strategy. These concerns are expressed: as a general issue with strategy; specifically as a lack of focus on practice; and with respect to Mintzberg's denial of explicit strategy. Whittington (2003, p. 122) provides a succinct and powerful critique of the general strategy field: "If looking for practical advice on how best to do [strategy work], I turn not to the leading journals of strategy and organization - I find little there." Others support this general contention: "concern over the gap between the theory of what people do and what people actually do" (Jarzabkowski, 2004, p. 539), and "a general unease with the way that strategy research has developed over the last three decades" (Jarzabkowski et al., 2007, p. 6).

These general concerns are articulated as specific concerns about a lack of consideration of people's actual practices: "What both the action and the interpretative approaches lack is a conceptualization that can take account of the practitioner's experience of intentional decision making as an instrumental aspect of the decision process" (Hendry, 2000, p. 963), and "the process approach ... does not go far enough in attending to the actual micro-practices and everyday routines of strategy formation" (Chia, 2004, p. 29).

For some, this is explicitly because such practices were deemed by Mintzberg to provide no research utility: "Rather than using their observations as the starting point for an exploration of the ways in which decisions and actions are related ... Mintzberg and Waters take it as a cue to dismiss decisions altogether as 'getting in the way' of and serving no useful purpose in the analysis of organizational action" Hendry (2000), and "For Mintzberg, why bother to explore the actual roles, adaptions and impacts of planning in practice, if strategic plans are typically not realized in organizational outcomes? For the sociologist, this indifference is the equivalent of ignoring marriage simply because so many partnerships end in disappointment or divorce" (Whittington, 2007, p. 1581).

\section{A Need for Academic Progress}

For many researchers, no problem is explicitly stated, and SaP's imperative is to expand the field with more theoretical approaches or by filling in research gaps. Expansion is prevalent in compendia. Such texts seem not to require a statement problem for each article, but instead to encourage the expression of new views and possibilities (Chapman et al., 2015; Fenton \& Langley, 2011; Grand, Rüegg-Stürm \& Von Arx, 2010; Langley \& Lusiani, 2015; Orlikowski, 2010; Tsoukas, 2017; Whittington, 2010).

Gap filling is most noticeable in empirical research (Beech \& Johnson, 2005; Hodgkinson, Whittington, Johnson \& Schwarz, 2006; Laine \& Vaara, 2007; Maitlis \& Lawrence, 2003; Mantere, 2005, 2008; Marabelli, Newell \& Galliers, 2015; Regnér, 2003; Samra-Fredericks, 2003; Sillince \& Mueller, 2007; Vaara et al., 2004). 


\section{SaP Itself}

$\mathrm{SaP}$, as with MOC, finds itself to be a general problem and, in a somewhat ironic fashion, finds itself specifically problematic because it is limited to individual practices and does not consider macro practices. The general issues are a lack of clarity:

"To sustain the momentum of [SaP], we argue here that more secure theoretical grounding, both philosophically and methodologically, is needed to further clarify and differentiate the practice perspective from the strategy process research agenda" (Chia \& MacKay, 2007, pp. 218-219).

"The strategy as practice approach has adopted an unclear and contradictory definition of practice" (Carter, Clegg \& Kornberger, 2008, p. 90).

The scope of SaP is found to be too narrow, and needs to expand to consider the broader social and organizational contexts:

"Connecting the micro-level more explicitly to the larger picture can now offer a variety of pay-offs. There is of course the scientific benefit of a more holistic understanding of strategy praxis, ... linking strategy praxis to a larger picture offers a more substantial basis for theoretical claims" (Seidl \& Whittington, 2014, p. 1407).

"there has been concern in some of the literature that Strategy Process and Practice research will remain only marginally valuable for scholars and practitioners if it cannot offer insight into how lowerlevel processes and practices ... connect to broader organizational-level processes and outcomes" (Kouamé \& Langley, 2018, p. 560).

This SaP scope issue challenges the very basis of SaP. To extend to a macro view, the straightforward SaP concept of studying practices must now extend to developing organizational and societal perspectives. The challenge, to simply examine just what people do, is now to understand how social systems operate.

\section{Cognition}

In only two cases does the literature reviewed reference cognition. A need is found to go beyond cognitive maps, and a need is found to include emotion: "strategy researchers need to move beyond the static analysis of actor's cognitive maps to a deeper understanding of what lies behind the actions of strategists as they engage with particular strategy practices in their praxis" (Hodgkinson \& Clarke, 2007, p. 20); and "emotions have not yet found a forceful way into the field of strategy as practice" (Brundin \& Liu, 2015, p. 632).

\section{Summary}

From the literature reviewed, SaP does not find any new problems with strategy itself, but finds the need to consider practice. Once established, SaP finds opportunities to expand and fill gaps, and also critiques itself. 


\section{Knowledge}

In order to analyze SaP knowledge, texts are categorized in themes, and then summarized within themes.

\section{Themes}

Being SaP, the texts reviewed have a strong practice focus and lack the clear variety of topics that MOC has (e.g. biases, decision processes, and mental models). So, to provide some structure, texts are categorized instead by the style of the text, these being:

$\begin{array}{ll}\text { Foundational } & \text { Five early texts on SaP and micro-strategy } \\ \text { Theoretical } & \text { Texts that focus on theoretical concerns with SaP itself } \\ \text { Empirical } & \text { Empirical research that has some theoretical content } \\ \text { Reviews } & \text { These texts look at the history and development of SaP }\end{array}$

The texts reviewed are all journal articles (including articles from compendia), except for three books, which are clearly indicated.

\section{Foundation}

Four articles and one book are foundation texts for $\mathrm{SaP}$, and recognize the Practice Turn and the new beginnings of studying strategy as practice. The first three articles are: a brief statement of the concept; a discourse approach; and a micro-strategy approach. The fourth article consolidates the SaP agenda, and a book by Jarzabkowski (2005) presents a comprehensive SaP framework.

Table 39: SaP - Foundation Texts

\begin{tabular}{|c|c|c|}
\hline Author(s) & Title & Content \\
\hline Whittington (1996) & Strategy as Practice & $\begin{array}{l}\text { Introduces SaP and suggests that social science has } \\
\text { considered various professions as a social practice, and } \\
\text { that it is time to consider strategy in the same way. }\end{array}$ \\
\hline Hendry (2000) & $\begin{array}{l}\text { Strategic decision making, discourse, } \\
\text { and strategy as social practice }\end{array}$ & $\begin{array}{l}\text { Finds that decision making theories (rational, action, } \\
\text { and interpretative) do not consider practitioners' } \\
\text { experiences and recommends treating decision making } \\
\text { as discourse, this being a social practice. }\end{array}$ \\
\hline $\begin{array}{l}\text { Johnson et al. } \\
\text { (2003) }\end{array}$ & $\begin{array}{l}\text { Micro strategy and strategizing: } \\
\text { Towards an activity-based view }\end{array}$ & $\begin{array}{l}\text { Promotes a micro-activity-based approach, addressing } \\
\text { shortcomings in resource-based theory, institutional } \\
\text { theory, diversification, and structural design; and finds } \\
\text { that changing business environments need different } \\
\text { solutions. }\end{array}$ \\
\hline
\end{tabular}




\begin{tabular}{|c|c|c|}
\hline Whittington (2003) & $\begin{array}{l}\text { The work of strategizing and } \\
\text { organizing: for a practice perspective }\end{array}$ & $\begin{array}{l}\text { In line with the practice turn in organizational and } \\
\text { social theory, proposes six sets of empirical research } \\
\text { questions: where and how is strategy done, who does } \\
\text { strategy, what skills are required, what are common } \\
\text { tools/techniques, how is strategy organized, and how } \\
\text { is strategy communicated and consumed? }\end{array}$ \\
\hline Jarzabkowski (2005) & $\begin{array}{l}\text { Strategy as Practice: an activity based } \\
\text { approach }\end{array}$ & $\begin{array}{l}\text { A book, based upon a previous article (Jarzabkowski, } \\
\text { 2003), that introduces core concepts of practice, }\end{array}$ \\
\hline Book & & $\begin{array}{l}\text { practices, and practitioners; an activity-based view; } \\
\text { and a research context. }\end{array}$ \\
\hline
\end{tabular}

\section{Theoretical}

$\mathrm{SaP}$, starting from a single central idea of practice, does not initially specify a theoretical basis. In the articles reviewed, SaP fills this gap through the examination of three disciplines: sociology, philosophy, and psychology. Sociology provides many possible alternative supporting frameworks, as shown in the list below. Philosophy provides a different context within which to debate the underlying basis of SaP. Psychology provides a further context, and one that can potentially include a focus on cognition.

\section{Sociological}

SaP finds potential in a number of different sociological concepts including adaptive and recursive behaviour, micro/macro distinctions, social constructionism, structuration theory, habitus, critical realism, narrative, critical management studies, and actor network theory. These are all suggested as approaches that will allow SaP to be more effective.

Table 40: SaP - Theoretical / Sociological Texts

\begin{tabular}{|c|c|c|}
\hline Author(s) & Title & Content \\
\hline $\begin{array}{l}\text { Jarzabkowski } \\
\text { (2004) }\end{array}$ & $\begin{array}{l}\text { Strategy as practice: recursiveness, } \\
\text { adaptation, and practices-in-use }\end{array}$ & $\begin{array}{l}\text { Develops a Social Theory Framework, based on prior } \\
\text { research, and suggests extensions to SaP to generate } \\
\text { not only knowledge of specific strategy events, but also } \\
\text { knowledge of adaptive and recursive behaviour. }\end{array}$ \\
\hline $\begin{array}{l}\text { Jarzabkowski and } \\
\text { Wilson (2006) }\end{array}$ & $\begin{array}{l}\text { Actionable strategy knowledge: a } \\
\text { practice perspective }\end{array}$ & $\begin{array}{l}\text { Finds the position school and capability theory to be } \\
\text { inadequate, and suggests that high velocity theory and } \\
\text { complex ecosystem theory illustrate the potential for } \\
\text { researching use of knowledge artefacts in practice. }\end{array}$ \\
\hline
\end{tabular}




\begin{tabular}{|c|c|c|}
\hline Whittington (2006) & $\begin{array}{l}\text { Completing the practice turn in } \\
\text { strategy research }\end{array}$ & $\begin{array}{l}\text { Sees SaP as being incomplete and proposes a } \\
\text { framework for integrating research into intra- } \\
\text { organizational and extra-organizational activities. }\end{array}$ \\
\hline Whittington (2007) & $\begin{array}{l}\text { Strategy practice and the strategy } \\
\text { process }\end{array}$ & $\begin{array}{l}\text { Finds, from a sociological perspective, that SaP is much } \\
\text { broader than the process strategy approach as it } \\
\text { includes praxis, practices, practitioners, and profession. } \\
\text { Suggests that SaP could be extended to include } \\
\text { connections and relationships, embeddedness, ironies, } \\
\text { problems, and continuities. }\end{array}$ \\
\hline Grand et al. (2010) & $\begin{array}{l}\text { Constructivist epistemologies in } \\
\text { Strategy as Practice research }\end{array}$ & $\begin{array}{l}\text { Considers how three types of constructivist } \\
\text { epistemologies shape SaP research, and concludes that } \\
\text { SaP research should consider the interaction of } \\
\text { researchers and strategists, understand the constructed } \\
\text { nature of strategy, reflect on the constructed nature of } \\
\text { the SaP programme, and understand construction and } \\
\text { deconstruction of concepts and processes. }\end{array}$ \\
\hline Whittington (2010) & $\begin{array}{l}\text { Giddens, structuration theory and } \\
\text { Strategy as Practice }\end{array}$ & $\begin{array}{l}\text { Considers the use of Gidden's structuration theory, in } \\
\text { comparison to Bourdieu's habitus and Bhaskar's Critical } \\
\text { Realism, finds structuration used in eight SaP empirical } \\
\text { studies, and identifies the future potential to consider } \\
\text { strategy as an institution. }\end{array}$ \\
\hline $\begin{array}{l}\text { Fenton and } \\
\text { Langley (2011) }\end{array}$ & $\begin{array}{l}\text { Strategy as Practice and the Narrative } \\
\text { Turn }\end{array}$ & $\begin{array}{l}\text { Promotes the use of narrative in SaP, and recommends } \\
\text { seven narrative approaches: practice, practitioners, } \\
\text { praxis, strategy texts, narrative infrastructure, } \\
\text { metaconversation, and coherence. }\end{array}$ \\
\hline $\begin{array}{l}\text { Paroutis et al. } \\
\text { (2013) } \\
\text { Book }\end{array}$ & Practicing strategy: Text and cases & $\begin{array}{l}\text { Provides an overview of SaP in a book aiming to be used } \\
\text { as a post-graduate SaP textbook. }\end{array}$ \\
\hline $\begin{array}{l}\text { Seidl and } \\
\text { Whittington (2014) }\end{array}$ & $\begin{array}{l}\text { Enlarging the strategy-as-practice } \\
\text { research agenda: towards taller and } \\
\text { flatter ontologies }\end{array}$ & $\begin{array}{l}\text { Presents a case for the use of various sociological } \\
\text { schema to broaden SaP's scope from a narrow focus on } \\
\text { micro-events to consider macro issues. }\end{array}$ \\
\hline $\begin{array}{l}\text { Blom and Alvesson } \\
\text { (2015) }\end{array}$ & $\begin{array}{l}\text { A critical perspective on strategy as } \\
\text { practice }\end{array}$ & $\begin{array}{l}\text { Finds that many theoretical approaches are adopted } \\
\text { within SaP with little justification, and then promotes } \\
\text { critical management studies as a future approach. }\end{array}$ \\
\hline
\end{tabular}




\begin{tabular}{|c|c|c|}
\hline $\begin{array}{l}\text { Chapman et al. } \\
\text { (2015) }\end{array}$ & $\begin{array}{l}\text { Actor-network theory and strategy as } \\
\text { practice }\end{array}$ & $\begin{array}{l}\text { Presents actor-network theory as a useful approach for } \\
\text { SaP, as demonstrated by studies of accounting practices. }\end{array}$ \\
\hline $\begin{array}{l}\text { Langley and Lusiani } \\
\text { (2015) }\end{array}$ & Strategic planning as practice & $\begin{array}{l}\text { A survey of strategy planning research, using a } \\
\text { framework of production, text, and consumption, that } \\
\text { finds a focus on production, and suggests that SaP } \\
\text { needs to consider planning as a dynamic practice, have } \\
\text { a political dimension, and link planning and action. }\end{array}$ \\
\hline $\begin{array}{l}\text { Kouamé and } \\
\text { Langley (2018) }\end{array}$ & $\begin{array}{l}\text { Relating microprocesses to macro- } \\
\text { outcomes in qualitative strategy } \\
\text { process and practice research }\end{array}$ & $\begin{array}{l}\text { Finds three strategies for linking microprocesses and } \\
\text { macro-outcomes in SaP and Process Strategy } \\
\text { (correlation, progression, and instantiation) and } \\
\text { suggests these can be effectively used together in } \\
\text { hybrid approaches. }\end{array}$ \\
\hline
\end{tabular}

\section{Philosophical}

Philosophy provides a perspective from which to view practice. These articles are somewhat speculative, taking high-level philosophical positions, but without attempting to create any comprehensive ontoepistemological positions.

Table 41: SaP - Philosophical Texts

\begin{tabular}{|c|c|c|}
\hline Author(s) & Title & Content \\
\hline $\begin{array}{l}\text { Clegg, Carter and } \\
\text { Kornberger (2004) }\end{array}$ & $\begin{array}{l}\text { Get Up, I feel like being a strategy } \\
\text { machine }\end{array}$ & $\begin{array}{l}\text { Reaffirms the practice side of SaP, and suggests that } \\
\text { further SaP development will require a focus on: power, } \\
\text { professional identity, non-human actors, ethics, } \\
\text { language, and institutions. }\end{array}$ \\
\hline $\begin{array}{l}\text { Chia and MacKay } \\
\text { (2007) }\end{array}$ & $\begin{array}{l}\text { Post-processual challenges for the } \\
\text { emerging strategy-as-practice } \\
\text { perspective }\end{array}$ & $\begin{array}{l}\text { Suggests that SaP needs to go beyond simple } \\
\text { consideration of processes, as in the process school, by } \\
\text { adopting a Heideggerian-inspired approach that goes } \\
\text { beyond the individual to discover the inner sense of } \\
\text { strategizing. }\end{array}$ \\
\hline Orlikowski (2010) & $\begin{array}{l}\text { Practice in research: Phenomenon, } \\
\text { perspective and philosophy }\end{array}$ & $\begin{array}{l}\text { Suggests that SaP research can be considered as three } \\
\text { modes: as phenomenon (understanding actual events), } \\
\text { as perspective (using theoretical models), and as } \\
\text { philosophy (practice is reality plus less extreme } \\
\text { variants). }\end{array}$ \\
\hline
\end{tabular}


Tsoukas (2017) Strategy and virtue: Developing strategy-as-practice through virtue ethics

\author{
Suggests that SaP should be extended through the \\ addition of a value ethics perspective, thus highlighting: \\ an underlying moral dimension, illuminating morally- \\ charged decision making, and shedding light on agency \\ as judgment.
}

\section{Psychological}

Three articles consider SaP from a psychological standpoint. The initial article is speculative, as it promotes a high-level cognitive framework, while the other two raise the possibility that SaP might consider emotion and cognition.

Table 42: SaP - Psychological Texts

\begin{tabular}{|c|c|c|}
\hline Author(s) & Title & Content \\
\hline Hodgkinson and & Exploring the cognitive significance of & Promotes the use of a cognitive framework which \\
\hline Clarke (2007) & organizational strategizing & $\begin{array}{l}\text { contrasts practitioners' analytic and intuitive styles } \\
\text { within SaP, as a technique for observation of practices. }\end{array}$ \\
\hline $\begin{array}{l}\text { Brundin and Liu } \\
\text { (2015) }\end{array}$ & The role of emotions in strategizing & $\begin{array}{l}\text { Finds that emotion is rarely considered in SaP research, } \\
\text { and recommends a stronger focus on emotion. }\end{array}$ \\
\hline Tsoukas (2010) & $\begin{array}{l}\text { Practice, strategy making, and } \\
\text { intentionality }\end{array}$ & $\begin{array}{l}\text { Finds that while SaP addresses problems recognized by } \\
\text { the Process School, it does not allow for deliberate } \\
\text { action. Proposes a Heideggerian inspired onto- } \\
\text { epistemological framework that includes tacit } \\
\text { understanding, explicit awareness, and thematic } \\
\text { awareness, and caters for both emergent strategy and } \\
\text { deliberate strategizing. }\end{array}$ \\
\hline
\end{tabular}

\section{Empirical}

As the name suggests, SaP studies practice. As with much empirical work, the articles tend to start with statements of the theoretical basis of the research and the theoretical propositions made. The articles then follow a similar pattern of data acquisition (e.g. surveys, interviews) and then apply both qualitative and quantitative techniques to generate a series of predominantly sociological statements and conclusions. 
Table 43: SaP - Empirical Texts

\begin{tabular}{|c|c|c|}
\hline Author(s) & Title & Content \\
\hline $\begin{array}{l}\text { Maitlis and } \\
\text { Lawrence (2003) }\end{array}$ & Orchestral manoeuvres in the dark & $\begin{array}{l}\text { Presents a longitudinal case study of an orchestra, } \\
\text { describing strategizing in a Cognitive Hybrid Model } \\
\text { based on discourse and politics, and makes a series of } \\
\text { general propositions about the efficacy of strategizing in } \\
\text { certain situations, based on the example of the } \\
\text { orchestra. }\end{array}$ \\
\hline Regnér (2003) & Strategy creation in the periphery & $\begin{array}{l}\text { Delivers a longitudinal study of four multinational } \\
\text { companies that finds strategy making at the centre to } \\
\text { be more deductive, while strategy making in the } \\
\text { periphery to be more inductive. }\end{array}$ \\
\hline $\begin{array}{l}\text { Samra-Fredericks } \\
\text { (2003) }\end{array}$ & $\begin{array}{l}\text { Strategy as lived experience and } \\
\text { strategists' everyday efforts to shape } \\
\text { strategic direction }\end{array}$ & $\begin{array}{l}\text { Combines ethnography and } \\
\text { ethnomethodology/conversation analysis in an } \\
\text { empirical study and finds six relational-rhetorical skills } \\
\text { that an effective strategist exhibited. }\end{array}$ \\
\hline Vaara et al. (2004) & Strategies as discursive constructions & $\begin{array}{l}\text { Executes a Critical Discourse Analysis of the airline } \\
\text { industry that distinguishes five types of distinctive } \\
\text { discursive practices (e.g. problematizations of } \\
\text { traditional strategies, naturalization of alliance } \\
\text { strategies). }\end{array}$ \\
\hline $\begin{array}{l}\text { Beech and Johnson } \\
\text { (2005) }\end{array}$ & $\begin{array}{l}\text { Discourses of disrupted identities in } \\
\text { the practice of strategic change }\end{array}$ & $\begin{array}{l}\text { Analyses a company undergoing significant change using } \\
\text { narrative techniques to show how the dynamics of } \\
\text { individuals' identities influence and change strategy } \\
\text { outcomes, especially at the micro level. }\end{array}$ \\
\hline Mantere (2005) & $\begin{array}{l}\text { Strategic practices as enablers and } \\
\text { disablers of championing activity }\end{array}$ & $\begin{array}{l}\text { Researches strategic champions, rather than strategists, } \\
\text { through grounded research to suggest that such } \\
\text { champions are both constrained and enabled by access } \\
\text { to recursive practices and adaptive practices. }\end{array}$ \\
\hline $\begin{array}{l}\text { Hodgkinson et al. } \\
\text { (2006) }\end{array}$ & $\begin{array}{l}\text { The role of strategy workshops in } \\
\text { strategy development processes }\end{array}$ & $\begin{array}{l}\text { Determines, based on survey research, that strategy } \\
\text { workshops are useful, based upon discursive rather than } \\
\text { analytical approaches, and are elitist. }\end{array}$ \\
\hline $\begin{array}{l}\text { Laine and Vaara } \\
\text { (2007) }\end{array}$ & Struggling over subjectivity & $\begin{array}{l}\text { Executes a Critical Discourse Analysis, drawing on } \\
\text { Foucauldian concepts, that demonstrates how }\end{array}$ \\
\hline
\end{tabular}


practitioners use discourse to influence subjectivities, and how this has a central role in strategizing.

\begin{tabular}{|c|c|c|}
\hline $\begin{array}{l}\text { Sillince and } \\
\text { Mueller (2007) }\end{array}$ & $\begin{array}{l}\text { Switching strategic perspective: The } \\
\text { reframing of accounts of responsibility }\end{array}$ & $\begin{array}{l}\text { Studies strategy development qualitatively over time, } \\
\text { and finds that accountability is reframed throughout a } \\
\text { project by different levels of management. }\end{array}$ \\
\hline Mantere (2008) & $\begin{array}{l}\text { Role expectations and middle manager } \\
\text { strategic agency }\end{array}$ & $\begin{array}{l}\text { Finds, in a qualitative study, eight enabling conditions of } \\
\text { middle-manager strategic agency (e.g. narration form } \\
\text { top managers, resource allocation, trust) and suggests } \\
\text { that these can be proactively managed to produce } \\
\text { better outcomes. }\end{array}$ \\
\hline $\begin{array}{l}\text { Wright et al. } \\
\text { (2013) }\end{array}$ & $\begin{array}{l}\text { How useful are the strategic tools we } \\
\text { teach in business schools? }\end{array}$ & $\begin{array}{l}\text { Executes an empirical study using Repertory Grid } \\
\text { analysis, based on Kelly's Personal Construct Theory, } \\
\text { and finds that practitioners use tools for a variety of } \\
\text { reasons including that of promoting diverse thinking. }\end{array}$ \\
\hline $\begin{array}{l}\text { Marabelli et al. } \\
\text { (2015) }\end{array}$ & $\begin{array}{l}\text { The role of power and materiality in } \\
\text { healthcare improvement initiatives }\end{array}$ & $\begin{array}{l}\text { Finds power and materiality to be core aspects of } \\
\text { strategic practice, with materiality exhibiting its own } \\
\text { agency. }\end{array}$ \\
\hline
\end{tabular}

\section{Reviews}

A number of reviews of SaP have been identified. These reviews align with the Foundation articles, as they promote the primacy of practice.

Table 44: SaP - Review Texts

\begin{tabular}{lll} 
Author(s) & Title & Content \\
\hline $\begin{array}{l}\text { Whittington et al. } \\
\text { (2003) }\end{array}$ & Taking strategy seriously & $\begin{array}{l}\text { Suggests, based upon the example of the Enron failure, } \\
\text { that academia needs to develop better systematic } \\
\text { research, be more critical of its own work, and work } \\
\text { closer with practitioners. }\end{array}$ \\
\hline $\begin{array}{l}\text { Jarzabkowski et al. } \\
\text { (2007) }\end{array}$ & $\begin{array}{l}\text { Strategizing: The challenge of a } \\
\text { practice perspective }\end{array}$ & $\begin{array}{l}\text { Finds that SaP has usefully advanced strategy research, } \\
\text { and suggests five areas for further development. }\end{array}$ \\
\hline $\begin{array}{l}\text { Johnson et al. } \\
\text { (2007a) }\end{array}$ & $\begin{array}{l}\text { Strategy as practice: Research } \\
\text { Book }\end{array}$ & $\begin{array}{l}\text { Re-establishes the basis of SaP, discusses practical } \\
\text { theories, and considers how to perform research in } \\
\text { SaP. }\end{array}$
\end{tabular}




\begin{tabular}{|c|c|c|}
\hline Carter et al. (2008) & Strategy as Practice? & $\begin{array}{l}\text { Critiques SaP and finds that SaP is naïve, that } \\
\text { researching practice is not new, and that SaP could be } \\
\text { usefully extended. }\end{array}$ \\
\hline $\begin{array}{l}\text { Jarzabkowski and } \\
\text { Spee (2009) }\end{array}$ & $\begin{array}{l}\text { Strategy-as-practice: A review and } \\
\text { future directions for the field }\end{array}$ & $\begin{array}{l}\text { Finds gaps in research, based on mapping research } \\
\text { onto a } 3 \times 3 \text { matrix with axes of praxis and practitioners; } \\
\text { analyses the treatment of practice and suggests future } \\
\text { research opportunities; and finds types of strategy } \\
\text { outcomes are defined (from personal to institutional) } \\
\text { and there is research potential in this conceptual } \\
\text { space. }\end{array}$ \\
\hline $\begin{array}{l}\text { Golsorkhi, } \\
\text { Rouleau, Seidl and } \\
\text { Vaara }(2010 a)\end{array}$ & $\begin{array}{l}\text { Introduction: What is strategy as } \\
\text { practice? }\end{array}$ & $\begin{array}{l}\text { Summarises the status of SaP and finds multiple fields } \\
\text { contributing to a rich discipline, though there is } \\
\text { potential to broaden the thinking of researchers. }\end{array}$ \\
\hline $\begin{array}{l}\text { Vaara and } \\
\text { Whittington (2012) }\end{array}$ & $\begin{array}{l}\text { Strategy-as-Practice: taking social } \\
\text { practices seriously }\end{array}$ & $\begin{array}{l}\text { Reviews SaP and recommends five directions for } \\
\text { development: agency considered within a web of } \\
\text { practices, a macro-institutional view, more focus on } \\
\text { emergence, material objects, and increased critical } \\
\text { analysis. }\end{array}$ \\
\hline
\end{tabular}

\section{Knowledge Summary}

\begin{tabular}{|c|c|}
\hline Foundational & Initial texts that establish the SaP field and its core structures. \\
\hline Theoretical & $\begin{array}{l}\text { Expands the SaP field by drawing on sociology, philosophy, and } \\
\text { psychology. }\end{array}$ \\
\hline Empirical & $\begin{array}{l}\text { Researches strategy behaviour to generate predominantly sociological } \\
\text { conclusions. }\end{array}$ \\
\hline
\end{tabular}

Reviews $\quad$ Finds SaP to be useful but requiring extension and enrichment.

SaP produces much knowledge. It is now a well-established field, with theoretical development and empirical research. It is based upon practice, but borrows from sociology, philosophy, and psychology. When borrowing from these other fields, the discourse questions the centrality of practice itself. This suggests that SaP is not so much a discourse with a strong central theoretical basis, but that SaP is based upon social bonds between similarly minded academics. 


\section{Social Effects / Subjectivity}

SaP promotes the view of strategy being practice, but its limited academic audience suggests that its social effects and its influence on strategists themselves is likely to be limited.

With a strong focus on practice, even though SaP often uses a trio of practice, praxis and practitioners, the strategist is very much a vehicle for activities, not the central body. Chia and MacKay (2007) explicitly dismiss the strategist: "it is the unconsciously acquired practice-complexes that generate the possibilities for strategy, not so much individual consciousness and intentionality" (p. 232).

Comments finding a space for the strategist are very limited in SaP. Whittington (2006) does suggest that strategists do have a role to play: "By reflecting on experience, practitioners are able to adapt existing practices; by exploiting plurality, they are sometimes able to synthesize new practices; by taking advantage of openness, they may be able to introduce new practitioners and new practices altogether" (p. 620). Jarzabkowski and Whittington (2008) also find that SaP may effect strategists: "strategy-as-practice may, therefore, be influential in enabling practitioners to better understand their own actions, to reflect on strategic implications, and to potentially reconstruct activity in light of these reflections" (p. 283).

In the SaP literature reviewed the strategist predominantly executes practices, and these social practices are presumably often derived from the strategy methods of the day. The strategist is thus implied to be an unthinking actor, performing the strategist's duty according to the social script.

So if SaP has social effects, it will be to promote practice over the practitioner. But the social effects of SaP on the world of strategy is likely to be minimal, and so similarly, for the strategist, SaP will not affect how they view their own subjectivity. 


\section{Foucauldian Summary}

The SaP texts show an established and developing field:

Table 45: SaP - Foucauldian Summary

\begin{tabular}{|c|c|}
\hline Conditions of Possibility & $\begin{array}{l}\text { A belief in scientific method, the Practice Turn, the Process School, and } \\
\text { borrowing from the human sciences }\end{array}$ \\
\hline Problematization & $\begin{array}{l}\text { Strategy itself, a lack of consideration of practice within strategy, the need to fill } \\
\text { SaP academic gaps, and the underlying basis of SaP }\end{array}$ \\
\hline Knowledge & $\begin{array}{l}\text { A field of study centred upon practice, with theoretical development and } \\
\text { empirical research, and its own review literature }\end{array}$ \\
\hline Social Effects & Limited, as the focus is practice, not practitioners \\
\hline Subjectivity & Limited, but minimizes the importance of the strategist \\
\hline
\end{tabular}

\section{Conditions of Possibility}

SaP, premised on a belief in scientific method, is born out of the Practice Turn and the Process School. Strategy can be understood, and this is achieved initially by investigating practice. Later, this initial narrow focus on practice as events is broadened, as the conditions of possibility draw from other disciplines and see practice as being organizational activity, social practices, individual behaviour, and being-in-the-world.

\section{Problematization}

Like all other discourses reviewed in this thesis, SaP raises a concern with the efficacy of strategy. This is a general concern, and is also found specifically to be a lack of consideration of practice as typified by Mintzberg's emergent strategy that simply occurs, thereby obviating the need to understand strategy in practice. Beyond these problems with strategy, SaP both finds a need for academic development and finds itself an issue. For academic development, this is simply business as usual, as SaP fills gaps in theory and empirical research. For SaP itself, some theorists find that SaP needs to go beyond practice to organizational and societal outcomes, somewhat questioning the very concept of SaP. With this strong focus on practice and its extensions, it is not surprising that cognition is rarely seen as a problem within SaP.

\section{Knowledge}

The knowledge that SaP creates is firmly focused on practice. A series of foundation articles establish practice as the central topic, and subsequent review articles intensify this single focus. Within the discourse itself, many theoretical articles, drawing on sociology, philosophy, and psychology, seek to extend the study of SaP beyond simply practice. A positive take on this would see this as an enrichment of SaP, whereas a less forgiving view may see this as a discourse without a strong onto-epistemological basis searching for some 
support. A series of empirical studies based on standard qualitative and quantitative techniques make a series of propositions, primarily sociological in nature. These studies focus on practice behaviours and have some cognitive aspects which are covered in some depth in the next section.

$\mathrm{SaP}$ is an academic field, but lacks a strong enduring conceptual basis. While it started as a focus on practice, the literature reviewed shows that SaP has developed divergent streams of theoretical development and empirical research. That it exists and has some vibrancy may be more a reflection of a strong social bond between like-minded academics than a discourse based on a well-developed and evolving central set of concepts.

\section{Social Effects / Subjectivity}

SaP does not have much impact on the mainstream strategy analyzed. Further, while SaP considers practice, practices, and practitioners, the focus is not on the practitioner who is simply part of the materiality that supports practice. If there are any social effects of SaP, it would be to deny the strategists personal utility, and to find them consumed by what they cannot control. Obviously, this would not raise the strategist up, but may minimize the strategist's value.

\section{Summary}

This thesis, based on the literature reviewed, finds SaP to be born out of the Process School with the aid of a catalyst of the Practice Turn. Strategy is found to be problematic, and the absence of practice within strategy is noted. This initial starting point, of moving from gross processes to the micro events of practice is, at times, directly questioned and there is a broadening of the underlying conditions of possibility of SaP to accommodate more and broader approaches to strategy. With such an unresolved basis, it is difficult to predict how SaP, as a discourse, will deliver useful applications to strategy. No doubt, there will be useful instances of research within SaP, but its underlying lack of conceptual coherence suggests that, as a discourse, it has little to offer beyond providing convenient academic fora. 


\subsection{Treatments of Cognition}

The SaP literature, with a strong focus on the micro, activities and practices, has few treatments of cognition. Hence, this analysis is more about how SaP does not treat cognition, or how it only mildly treats cognition.

Because of the lack of cognitive treatments, this analysis does not follow the structure of the Cognitive Heuristic used for the other discourses analyzed, as some sections would have virtually no content, thus making the analysis somewhat meaningless. Instead, the four themes defined on page 243 are followed to show how different themes of texts treat and, as importantly, don't treat cognition.

\section{Texts}

The four types of texts defined in the Knowledge analysis above, foundational, theoretical, empirical, and review, are repeated as a framework for this section.

\section{Foundation}

The Foundation texts recognize cognition, but their main focus is to establish the micro as a research topic. Whittington (1996), in what is likely to have been the first SaP article, recognizes cognition, but specifies that $\mathrm{SaP}$ is about the practice: "Thus the practice perspective is concerned with managerial activity, how managers 'do strategy'” (p. 732).

Hendry (2000) identifies three schools of strategy, paraphrased as: rational process; action focus/emergence; and post-event sensemaking. He proposes a fourth, a discourse approach to practice. So while there are problems with other approaches, Hendry does not turn to cognition; he turns instead to discourse as a form of practice: "we have argued for an integrating conceptualization of strategic decisions as elements of a social discourse that is itself the most prominent feature of strategy as a social practice" (p. 971).

Johnson et al. (2003) find that strategy has a limited macro-level focus and illustrate these failings through consideration of the resource-based view, institutional theory, and empirical research into diversification and structure. They also find that the Process School has humanized strategy, but still is based on the macro. The authors propose an alternative approach that investigates practice to understand strategy: "Just what do managers have to do to make a difference and what is their impact?" (p. 16).

Whittington (2003) makes no mention of cognition, but suggests the study of actual work, roles, skills, tools, organization, and communication. Jarzabkowski, in her foundational text Strategy as Practice (Jarzabkowski, 2005), focuses on practitioners, practice, and practices, and only in one instance recognizes cognition as part of strategizing: "Strategy as practice is thus concerned with the detailed aspects of strategizing: how strategists think, talk, reflect, act, interact, emote, embellish and politicize" (p. 3). 
Table 46: Cognitive Summary - SaP Foundation Texts

\begin{tabular}{l|l|}
\hline Type of Abstraction & conceptually recognize cognition, but focus on practice \\
\hline Subject & individual managers \\
\hline Mind & - \\
\hline Thinking Process & Strategizing \\
\hline Thought Content & - \\
\hline
\end{tabular}

These Foundation texts focus on the micro. There is an occasional mention of cognition, but their purpose is to establish practice as the basis of SaP. The subject is the individual manager, the practitioner. Mind is not raised as a subject. There are no discussions of Design or Learning processes, and the practices considered are Strategizing. Thought content is not considered.

\section{Theoretical}

Theoretical texts that have cognitive content are discussed below. Those without any relevance are not considered. As in previous Foucauldian analysis in this chapter, theoretical texts are considered under the headings of Sociological, Philosophical, and Psychological.

\section{Sociological}

These texts have a common theme, that of seeking to extend practice in sociological directions. Whittington (2006), Whittington (2010), and Kouamé and Langley (2018) explicitly extend to the macro, while others suggest general social approaches that support and extend the scope of SaP (Blom \& Alvesson, 2015; Fenton \& Langley, 2011; Grand et al., 2010; Jarzabkowski, 2004; Jarzabkowski \& Wilson, 2006; Whittington, 2007). For most theorists, cognition is treated as being a mind that contains practice, with the exception being Grand et al. (2010) who promote a social constructionist SaP research programme that has a basis of 'concepts held in minds'.

Whittington (2006) proposes a Strategizing model to complete the practice turn in strategy by integrating intra and extra-organizational levels of strategy. Practitioners exist and "By reflecting on experience, practitioners are able to adapt existing practices" (p. 621). 


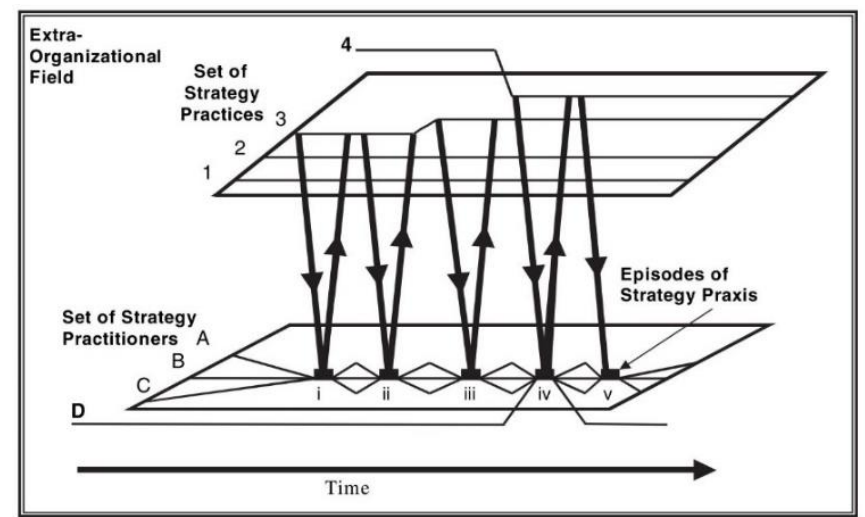

Figure 39: "Integrating Praxis, Practices and Practitioners", reprinted from Completing the practice turn in strategy research (621), by R. Whittington, Organization Studies, 27(5), 2006, (pp. 613-634). Copyright 2006 SAGE Publications.

In this integration of the micro and the macro, Whittington does not consider cognition directly, even if it is implicit in practice, praxis, and practitioners.

Whittington (2010) suggests that Giddens' structuration theory is a useful research approach for SaP. He finds it to have advantages over Bourdieu's habitus and Bhaskar's critical realism. The opportunity for Giddens' structuration is "in order to understand the larger social structures" (p. 109). Cognition is found in discussions of agency, but it is not a focus in such a social framework comparison.

Kouamé and Langley (2018) aim to link the micro and the macro through three perspectives of correlations, progressions, and instantiations. They explicitly recognize cognitive elements of micro-processes: "We define microprocesses here as individual or collective processes and activities taking place at a lower level than organizational level. These might include activities of individuals and groups. such as framing ..., issue-selling ..., conversations ..., and other forms of interaction, as well as psychological processes such as managerial cognition ... and emotion" (p. 561).

This is the limit of treatments of cognition - simply used as descriptive elements within broader definitions of social processes. The study does not go deeper into cognition, as it stays at a behavioural level: "We draw on a corpus of qualitative process and practice studies to develop and illustrate three micro-macro linking strategies" (p. 559). Cognition is not treated as conscious and subconscious thinking processes, but is conceptualized and used, sparingly, as a building block for other structures.

Jarzabkowski (2004) builds a link between recursive and adaptive behaviour. From a recursive perspective, following Bourdieu, she finds that "Practice comprises social order residing both in people's minds and in the habitus" (p. 532). The mind is where practice 'resides'. She goes further to state, "At the level of the actor, the problem is largely a psychological one arising from individual cognition" (p. 532). So, in the recursive world, the mind holds practices and is a problem. From an adaptive perspective, learning is a social event: 
"New practice does not come from external sources, but from participating in the social process of problemsolving within that community" (pp. 536-537). Jarzabkowski then defines nine practice-based research questions, for example, "What characteristics of the within-firm context, such as power, structure, culture, and diversity, might be associated with more adaptive or more recursive uses of particular management practices?" (p. 549). These questions have a specifically behavioural aspect as Jarzabkowski concludes: "we may develop a link between practice and firm behaviour by analyzing the tendencies towards recursive or adaptive use of practices and the impact this has upon strategic action over time" (p. 552). So while cognition is momentarily recognized as being part of practice and as being a problem, this SaP approach is primarily about understanding behaviour as practices.

Jarzabkowski and Wilson (2006) find strategy to be unable to cope with environmental velocity (the speed of modern change) and knowledge intensity (the breadth of knowledge required to be assimilated). They claim that neither the positioning school theory nor capability-building theory are solutions, while High Velocity Theory and Complexity Theory have more potential. A practice epistemology is proposed to break with highly rational approaches and instead consider strategy knowledge used in specific contexts and "for analyzing strategy knowledge in action" (p. 348). So knowledge is recognized but the focus is on researching practice.

Whittington (2007) considers the relationship between the Process School and SaP. He finds that with SaP, strategy under the sociological eye is far broader than the Process School, as it could extend to "social connections and relationships, embeddedness, irony, problematized notions of performance and a respect for continuity" (p. 1575). But still strategy is not a cognitive process: "Under the sociological eye, strategy is another thing that people do" (p. 1584).

Grand et al. (2010) delve deeply into different forms of social constructionism and treat cognition as a social phenomenon. They promote a constructionist approach and the cognition they are interested in involves both researchers and practitioners: "In the perspective of constructivist epistemologies, strategy research would focus on the creation, construction, translation, and transformation of strategy concepts and strategizing practices. Thereby it is important to study their self-evident, unquestioning nature. ... Strategy and strategizing practices are the result of continuous (re-)construction, through the creative activities of the actors and the researchers involved, and through interactions between actors and researchers" (p. 71). For these theorists, cognition, as part of social constructionism, is important, even if it is not a primary focus.

Fenton and Langley (2011) suggest a narrative extension of SaP. They recommend seven narrative approaches: practice, practitioners, praxis, strategy texts, narrative infrastructure, metaconversation, and coherence. These extensions do not include cognition, but are frameworks that researchers may find useful.

Seidl and Whittington (2014) consider strategy sociologically without mention of cognition. They argue strongly for an expansion to macro phenomena: "we argue for progress in strategy-as-practice research through more effective linking of 'local' strategizing activity with 'larger' social phenomena" (p. 1407). 
Blom and Alvesson (2015) suggest how critical management studies can be applied to SaP. They propose extending SaP to include strategy as power, diffusion of strategic management, irrationalities and nonrationalities of strategic management, the consequences and performativity of strategic management, and anti-strategerialism (p. 416). There is no mention of cognition. In a similar way, Chapman et al. (2015) promote action network theory as an extension to SaP, again without mention of cognition. Langley and Lusiani (2015) consider planning as practice, utilizing a framework of production, text, and consumption. Again, this is wholly without cognition.

All of these sociological texts consider how to make SaP more effective by extending its scope, primarily by use of frameworks and techniques that are either recognized as sociology or are expressed in sociological terms. Coupled with SaP's inherent focus on practice, there is no need to raise the priority of cognition. When cognition is recognized, it is within the context of practice, and not considered as an object of study.

\section{Philosophical}

Four of the articles reviewed approach SaP from philosophical positions, but without a focus on the mind. Clegg et al. (2004) find Cartesian dualism to be the source of the ills of strategy; Chia and MacKay (2007) and Orlikowski (2010) take Heideggerian existential positions and suggest that mind is less important; and Tsoukas (2017) finds morality to be the issue.

Clegg et al. (2004) "argue that strategic planning and its fallacies are best understood in terms of the domain assumptions of Cartesian philosophy" (p. 21). They suggest that Descartes' distinction between mind and matter is repeated in management literature as a distinction between strategy and operations, and can be identified as seven fallacies. They make recommendations for extension of practice, but without suggesting any epistemology to replace Cartesian dualism. So, even though the problem is formulated using the mind/body distinction, perceptions of cognition are not raised, as practice is still the focus.

Chia and MacKay (2007) find the need for an ontology of practice: "Ontological priority is accorded to the immanent logic of practice rather than to actors and agents" (p. 219). This approach draws on Chia's previous work considering theorists such as Heidegger and Dreyfus (Chia, 2004). The concept of a power outside the mind is made clear by the use of the word 'purposive': “Actions may therefore be purposive without there necessarily being an overall purpose in mind" (Chia \& MacKay, 2007, p. 235). Only the practitioner is required for performing the act - the mind is not. Practice holds the purpose, alienating the practitioner's mind.

Orlikowski (2010) considers SaP in terms of three modes of engagement: phenomenology, organizational rationality, and existentiality. It is suggested that SaP can either focus on the phenomena of practice, can create theories of organizational practice, or can treat strategy 'as' practice. These relate only to the mind of the researcher: there is no mention of the mind of the practitioner.

Tsoukas (2017) suggests that a moral dimension of strategy remains unexplored. Based on the moral philosophy of Alasdair Maclntyre, he redefines key aspects of SaP. Much of practice is driven by morality that 
is embedded within practice. Even though such practices involve mind, it is claimed that habits (or acquired morality) are what drives action: "what practitioners do is shaped by the habits of thinking, feeling, and desiring that have been formed within their practices" (p. 328).

These four philosophical texts apply different philosophical perspectives to SaP to suggest how the study of practice can be taken forward. Cognition is found to be present, but not central.

\section{Psychological}

Three articles have been reviewed that consider SaP from a psychological standpoint. Hodgkinson and Clarke (2007) and Brundin and Liu (2015) suggest respectively a cognitive framework and the inclusion of emotion in SaP research. Tsoukas (2010) however, goes further to promote, based on an Heideggerian ontoepistemology, the active study of cognition.

To understand what lies behind actions, Hodgkinson and Clarke (2007, p. 20) propose going beyond static cognitive-maps, to employ a conceptual cognitive framework when engaging in SaP research. They propose a "basic typology of contrasting cognitive strategies and styles" (Figure 37 below) and suggest this as an extension to SaP research techniques.

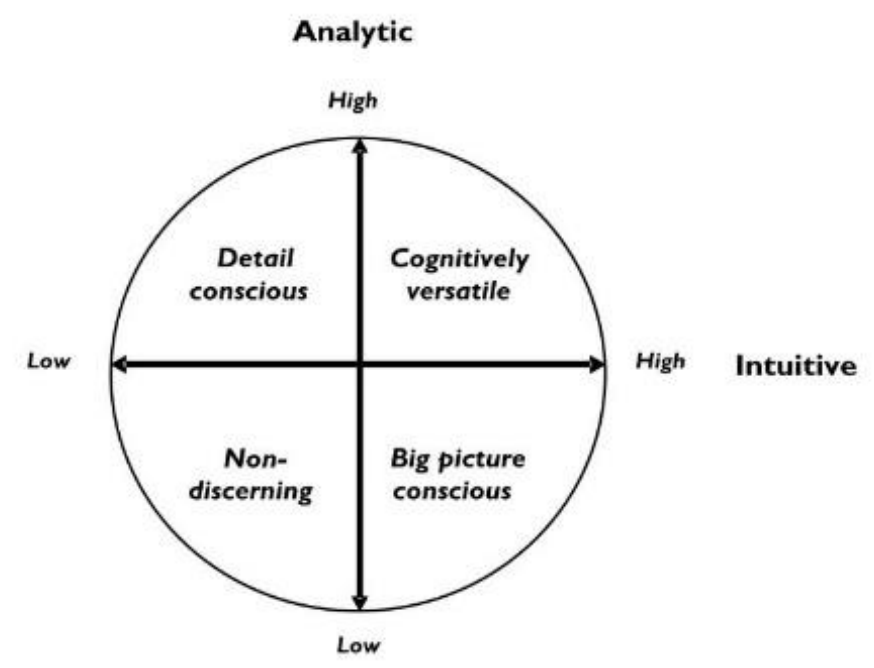

Figure 40: "Basic typology of contrasting cognitive strategies and style", reprinted from Exploring the cognitive significance of organizational strategizing: A dual-process framework and research agenda (261), by G. P. Hodgkinson, \& I. Clarke, Human Relations, 60(1), 2007, (pp. 243-255). Copyright 2007 The Tavistock Institute. Brundin and Liu (2015) conceptually raise the issue of emotion, and recommend emotion as an area of study. They find emotion mentioned in 13 articles and that "emotions have not yet found a forceful way into the field of strategy as practice" (p. 632).

The article by Tsoukas (2010) could have been included in the previous Philosophical section above, but is included here as it also considers the psychology of mind. Based upon an Heideggerian onto-epistemology, Tsoukas proposes three types of coping: practical, deliberate, and detached. The latter involves developing thematic awareness, or ideas: “From a Heideggerian phenomenological perspective, strategizing, namely the 
process of forming thematic awareness, is a distinctive moment of being-in-the world that comes about when people step back from immediate practical tasks and reflect on an entity in a detached manner, seeking to identify its property in abstracto. How thematic awareness develops, with what results, is a fascinating topic to study from a practice perspective" (Tsoukas, 2010, p. 59). Tsoukas explicitly recognizes the concept of cognition and suggests that the study of cognition should be part of the SaP agenda.

These three psychological texts treat cognition as being important. Hodgkinson and Clarke (2007, p. 20) see practitioners' cognitive styles as an important aspect of research, Brundin and Liu (2015) suggest the study of emotion, and Tsoukas (2010) recommends studying thematic awareness, or subconscious knowledge.

\section{Theoretical Treatments of Cognition}

Table 47: Cognitive Summary - SaP Theoretical Texts

\begin{tabular}{l|l|}
\hline Type of Abstraction & conceptually - psychological texts \\
\hline Subject & individual managers \\
\hline Mind & $\begin{array}{l}\text { conscious mind } \\
\text { subconscious mind - psychological texts }\end{array}$ \\
\hline Thinking Process & Strategizing \\
\hline Thought Content & - \\
\hline
\end{tabular}

The theoretical texts vary. The sociological and philosophical texts analyzed here recognize cognition, but do so as part of the overall context of SaP. The psychological texts treat cognition as conceptually important and recommend a variety of ways of including it in future research. In addition, they recognize the subconscious. 


\section{Empirical}

Twelve empirical studies from 2003 to 2015 are the subject of this section. The studies include both large comprehensive longitudinal studies and shorter single survey studies, they cover a variety of business scenarios, and research many different topics.

The studies start with cognitively-derived data but rarely express conclusions in cognitive terms. Being empirical, they start by considering strategy phenomenally and, to do so, measure the cognitive ideas of managers through interviews, surveys, and analysis of documents. At times, the documents analyzed are interpretations by others such as press reports and company documents, and hence the research is interpretations of interpretations. They then make operational and conceptual propositions about practices. Only in two instances are such propositions cognitive (Regnér, 2003; Wright et al., 2013).

As one might expect for SaP, these analyses lead to statements or conclusions which are practice focused. So while these articles start from some form of interpretation of cognition, their outcomes are not necessarily cognitive:

- Maitlis and Lawrence (2003) build an operational model of strategizing.

- Regnér (2003) categorizes styles of strategizing in different parts of large organizations.

- Samra-Fredericks (2003) makes functional propositions about skills and knowledge.

- Vaara et al. (2004) discern discursive practices.

- Beech and Johnson (2005) find changing identity dynamics in times of strategic change.

- Mantere (2005) compares recursive and adaptive strategy behaviours.

- Mantere (2008) investigates role expectancy of middle-managers.

- Hodgkinson et al. (2006) develop ideas about workshop practices.

- Laine and Vaara (2007) discern practices that managers undertake to control and resist strategy.

- Sillince and Mueller (2007) investigate roles of managers during strategy and how they change.

- Wright et al. (2013) investigate practices that utilize strategic tools.

- Marabelli et al. (2015) show how power and material objects are used in practice. 
Based on observation and interviews, Maitlis and Lawrence (2003) build an operational framework of organizational strategizing that includes cognitive elements. They developed the Cognitive Hybrid Model below "Figure 1 (p. 124). The authors recognize that the model is a simplification, "episodes of strategizing often happen in a non-linear manner, involving loops back from one stage to a previous stage and causal links that run in both directions" (p. 123).

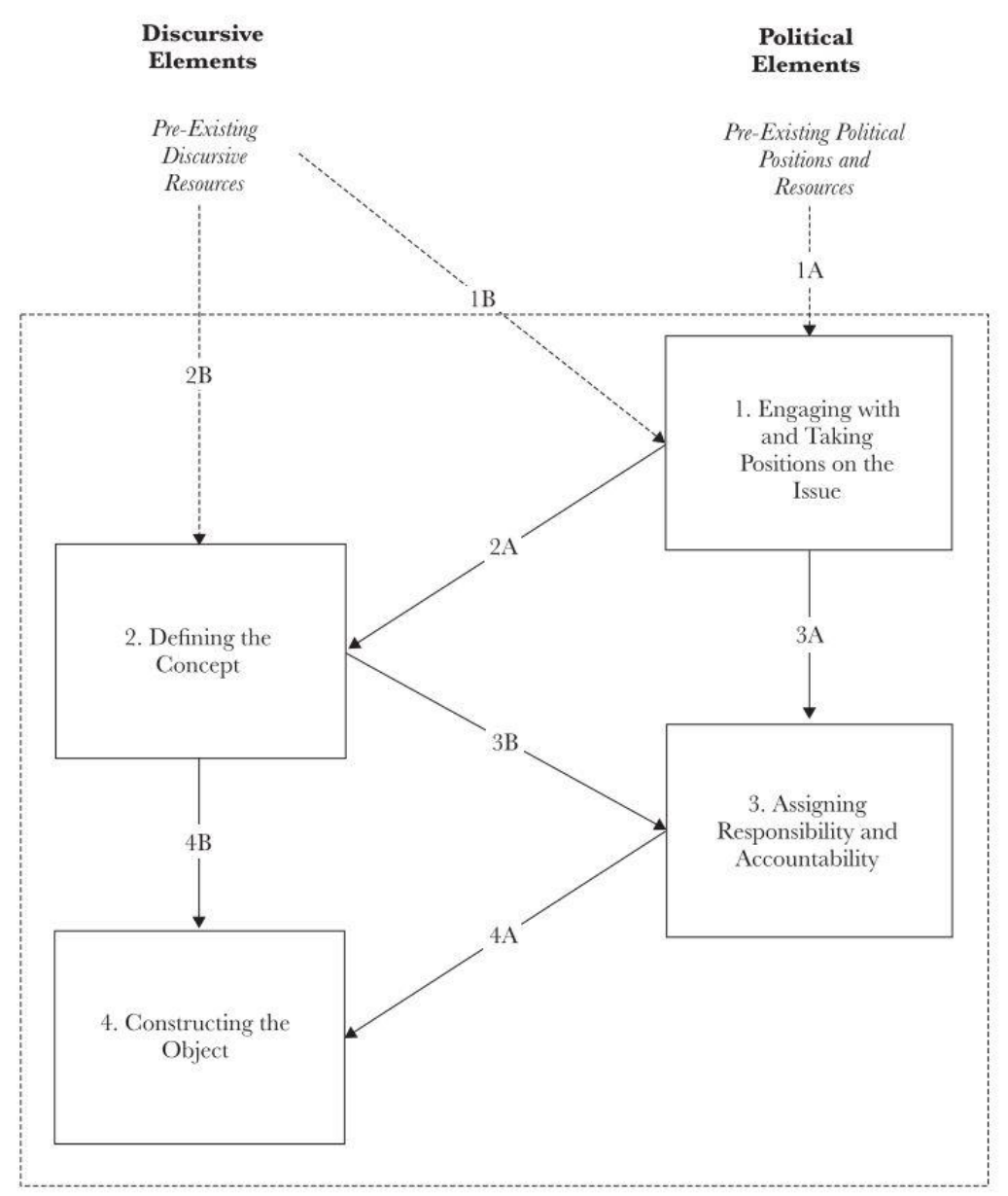

Figure 41: "An episode of organizational strategizing", reprinted from Orchestral manoeuvres in the dark: Understanding failure in organizational strategizing (p. 124), by S. Maitlis, \& T. B. Lawrence, Journal of Management Studies, 2003, 40(1), (pp. 109-139). Copyright Blackwell Publishing Ltd. 2003.

When discussing the model, they justify it through general cognitive propositions. For example: "An episode of strategizing will be more likely to fail when the key actors do not interpret the issue as relevant to the situation" (p. 126). This pertains to the dotted line $1 \mathrm{~A}$ in this Cognitive Process Model. So effects of cognition are recognized, but within a larger process model that presents the principle findings. This Cognitive Process Model is highly conceptual, and borders on the transcendent - strategy practice has been abstracted to four boxes.

Regnér (2003) considers reason. From a series of interviews he concludes that, within large organizations, central bodies tend to deductive thinking, while the periphery tend to inductive reasoning. He aims to 
understand activity, understanding, and outcomes through this process, but notes that, "Another limitation of the study might be a lack of sophisticated psychology techniques in order to discover more detailed differences in sensemaking and knowledge structures over time" (pp. 79-80). Here he is recognizing the very limited treatment of cognition by his study, and possibly within SaP itself. But his conclusions are cognitively expressed as a way of thinking in different scenarios.

To avoid the limitations of interviews, Samra-Fredericks (2003) undertook an ethnographic study that recorded and then analyzed strategy conversations. This analysis aims to connect 'talk' and 'outcomes', but this is difficult: "To account for the linkages between strategists' talk and the outcomes ... is challenging primarily because the human activity across time and space is so rich, dynamic and complex" (p. 151). Samra-Fredericks simplifies this issue through a qualitative analysis that identifies six relational-rhetorical skills of a successful strategist. These skills are cognitively-based around perception, communication, and reasoning, but are not expressed in such a way. Instead, they are expressed as behaviours in business contexts.

Vaara et al. (2004) utilize Critical Discourse Analysis to delve into strategy micro-practices. Their starting point is that "Intuitively, we all know that strategies are discursive constructions" (p. 1) and hence they seek and find discursive practices. They do not find cognitive processes. Beech and Johnson (2005) research identity dynamics using narrative analysis, leading to such conclusions as "The tough outsider wants to change his identity: the hero wants to be a different kind of hero" (p. 38). Both these approaches are essentially social.

Mantere (2005) explores a social aspect of strategy, namely what enabling conditions make people strategy champions. Semi-structured interviews asked respondents how they conducted strategy and what they thought strategy to be. Through grounded research, Mantere identifies a series of adaptive and recursive practices that have enabled and constrained strategy championing. While the interviews may have revealed some practitioner thinking, the paper fulfills the aim of identifying practices. In a later paper, Mantere (2008) does a similar study focusing on middle managers. Conditions that enable middle-manager strategizing include contextualization, resource allocation, trust, and inclusion. While contextualization borders on mind, the primary focus is on behaviour and activities.

When considering strategy workshops through analysis of survey data, Hodgkinson et al. (2006) find a number of common behaviours, such as use of tools and preparation time. They do not delve into how the people actually create strategy as a team: "We do not claim to understand the dynamics of such workshops" (p. 20), simply focusing on conclusions about effective processes for strategy workshops.

Laine and Vaara (2007) approach SaP from a Foucauldian perspective, focusing on subjectivity. Subjectivity is "understood as a discursively constructed sense of identity and social agency in specific contexts" (p. 30). Through analysis of texts, observations, and interviews within a single company, the authors illustrate how political strategy struggles are driven by discourses and subjectivities. This application of Foucauldian ideas differs significantly to the approach in this thesis, as for Laine and Vaara, the effect of subjectivity is a form of 
functionalism. So while the underlying analysis inherently looks at how staff in the firm think about strategy, the results are expressed in functional terms.

Sillince and Mueller (2007) similarly research a political strategy struggle, but from the perspective of reframing of accounts of responsibility: "we argue that responsibility is important for researching strategy-aspractice because it is a site of agency of individuals within the formation-implementation interface" (p. 158). The study considers ideas and events over time, concluding that reframing occurs, but is not well researched.

Wright et al. (2013) investigate the use of strategy tools using Personal Construct Theory and Repertory Grid analysis. These techniques are seen as essential to understanding what people think: "Without any understanding of these interconnected dualities [that give managers internal construct systems], researchers lack critical insights into the cognitive building blocks at the individual level, which gives rise to group-level and organizational patterns of likes or dislikes regarding the use of strategic tools" (p. 98). To achieve some insights into practices, cognition is measured scientifically and, from statistical analysis, they conclude that "managers think in dualities (often paradoxically) and have a preference for multiple-tools-in-use, tools that provide different perspectives, peripheral vision, connected thinking, simultaneously help differentiate and integrate complex issues, and guide the thinking process" (p. 92). These conclusions are cognitively expressed and based on survey data obtained from 12 students at the completion of a 14-week strategy tools course.

Marabelli et al. (2015) consider power and materiality, finding that both have effects: "it is evident that power and materiality, combined, promote changes through everyday strategizing process" (p. 13). The authors find no space for conscious thought, finding innate objects to be drivers of strategy.

Table 48: Cognitive Summary - SaP Empirical Texts

\begin{tabular}{l|l|}
\hline Type of Abstraction & $\begin{array}{l}\text { phenomenally at the source of research data } \\
\text { conceptually by two texts (inductive/deductive thinking, thoughts about } \\
\text { strategy tools) }\end{array}$ \\
\hline Subject & individual managers \\
\hline Mind & conscious mind \\
\hline Thinking Process & Strategizing \\
\hline Thought Content & - \\
\hline
\end{tabular}

The table above represents the most common findings. While two texts express conclusions conceptually in a cognitive way (Regnér, 2003; Wright et al., 2013), these are exceptions. While not explicitly stated in the analyses above, the subject is the individual manager, there is little mention of the subconscious, little mention of Design or Learning processes, and little mention of Thought Content. 


\section{Reviews}

The five reviews analyzed below examine the state of SaP. While they question aspects of SaP, they continue to reinforce the primacy of practice over all other aspects of strategy, including cognition.

In Taking Strategy Seriously (Whittington et al., 2003) the authors find strategy failed in the 2001 Enron failure and suggest solutions that would put strategy back on track. The authors are clear that strategy should be treated as practice: "Taking strategy seriously therefore involves examining and assessing strategy as a social practice with a wider constituency and wider repercussions than those of particular organizations" (p. 397).

In an early review of SaP, Jarzabkowski et al. (2007) make it clear that cognition is a result of practices, not the other way around. She states that it is practices that provide the cognitive resources that we use: "The use of ... practices is intrinsically connected to 'doing' because they provide the behavioural, cognitive, procedural, discursive and physical resources through which multiple actors are able to interact in order to socially accomplish collective activity" (p. 9). Given the primacy of practice, more empirical research is recommended.

In a review of SaP, Johnson et al. (2007a) make it very clear that, in their view, cognition is not part of SaP: “Within the 'process field' one response in the 1980s and 1990s that sought a more rigorous base of understanding the role of individuals with regard to strategy was work on managerial cognition. ... However, the problems such research faced and faces in relation to the management of strategy take us back to reasons for the practice-based view that we take. A good deal of the early research on managerial cognition attended to how managers make sense of strategic issues... There are several problems here. First, it cannot be assumed that, because an individual or individuals make sense of a situation or problem in a given way, that can be taken as a sufficient explanation for what they do. ... Second, ... strategies are rarely developed by an individual, they are developed by groups of people" (pp. 11-12). So the authors believe that researching cognition is problematic because individual cognition cannot be linked directly to individual action, and because strategy is a group process.

Carter et al. (2008) challenge what they see as the narrowness and naivety of SaP. They request a broadening of perspective: "To understand practice, we regard it as important to engage with issues of power, reality construction, symbolic order, actor networks and language games" (p. 96).

Jarzabkowski and Spee (2009) review SaP using a 3x3 matrix with axes of levels of praxis and types of practitioner. Cognition does not feature in this framework, and the authors further note a lack of consideration of cognition: "there has been little empirical work on intangible embodied strategy practices, such as strategy know-how, motivations, emotions and intent" (p. 83).

Golsorkhi et al. (2010a) emphasize that SaP is about the doing of strategy and note that, "the practice approach breaks with methodological individualism by emphasizing that activities need to be understood as enabled or constrained by the prevailing practices in the field in question" (p. 3). Clearly, practice takes priority over the cognition of individuals. 
Vaara and Whittington (2012) repeat the same position on methodological individualism and also assert the primacy of practice: "strategy is enabled and constrained by prevailing organizational social practices" (p. 285).

Table 49: Cognitive Summary - SaP Review Texts

\begin{tabular}{l|l|}
\hline Type of Abstraction & conceptually, cognition is treated as subservient to practice \\
\hline Subject & - \\
\hline Mind & - \\
\hline Thinking Process & Strategizing \\
\hline Thought Content & - \\
\hline
\end{tabular}

These reviews are consistent in conceptually positioning practice as the primary driver of strategy, and in stating what SaP should focus on. While cognition is recognized, it is not central to strategy from a SaP perspective. 


\section{Cognition Summary}

The four categories vary in their treatment of cognition:

Table 50: SaP Treatments of Cognition by Category

\begin{tabular}{|c|c|}
\hline Foundation & $\begin{array}{l}\text { A strong focus is on establishing practice as the object of study, and hence } \\
\text { cognition is only recognized as an element within a general context. }\end{array}$ \\
\hline Theoretical & $\begin{array}{l}\text { The sociological papers do not promote a cognitive approach, except for Grand et } \\
\text { al. (2010) who find cognition to be important for social constructionism, but not as } \\
\text { a focus of research. The philosophical articles are not in the Kantian tradition of } \\
\text { mind as a central element to be understood. Rather, philosophy provides another } \\
\text { theoretical possibility for engaging with practice. The psychological articles } \\
\text { promote a conceptual cognitive framework and the study of cognition. }\end{array}$ \\
\hline Empirical & $\begin{array}{l}\text { The core data is cognitive phenomena from surveys, interviews, press reports, etc. } \\
\text { This is then used to find various conclusions and premises which are not cognitively } \\
\text { based, but tend towards sociological propositions. } \\
\text { Exceptionally, Regnér (2003) considers cognition conceptually by distinguishing } \\
\text { inductive and deductive thinking, and Wright et al. (2013) consider cognition } \\
\text { conceptually as thoughts about strategy tools. }\end{array}$ \\
\hline Review & $\begin{array}{l}\text { These articles are consistent in promoting a practice focus that does not include } \\
\text { cognition. }\end{array}$ \\
\hline
\end{tabular}

So in SaP, Foundation and Review texts have little focus on cognition. Theoretical texts just recognize cognition, except for three psychological texts that recommend the study of aspects of cognition. The Empirical papers are partially cognitive because the practices they research involve practitioners whose behaviours are often discovered through cognitive means. Unsurprisingly for a discourse titled Strategy as Practice, the focus is not on cognition, but is on practice. 
Table 51: Cognitive Summary - SaP

\begin{tabular}{|l|l|}
\hline Type of Abstraction & $\begin{array}{l}\text { conceptually - by psychological texts and by two empirical texts } \\
\text { phenomenally - by empirical research }\end{array}$ \\
\hline Subject & individual managers \\
\hline Mind & primarily conscious \\
\hline Thinking Process & Strategizing \\
\hline Thought Content & - \\
\hline
\end{tabular}

For 39 out of the 44 texts, cognition is either simply recognized or not mentioned at all, the subject is the individual manager, when considered mind is conscious mind, the focus is on Strategizing, and thought content is rarely discussed.

Of the other five texts, the three psychological texts within the Theoretical group are by definition cognitive. These texts all present ideas about cognition: that is, how it might be defined and areas that could be studied. They do not indicate a movement within SaP, but simply a variation as to how SaP might be extended.

Of the other two empirical texts, Regnér (2003) is a comprehensive longitudinal study that examines four realworld companies and presents ideas about deductive and inductive thinking. The other, Wright et al. (2013), is more a laboratory experiment, where twelve students are the data source for propositions about how strategists think about strategy tools. While Wright et al. (2013) is cognitive, Regnér (2003) is a more substantive paper.

In summary, there are instances of cognition but these are few. Only one, Regnér (2003), seems to be a study undertaken with some belief in the value of studying cognition. 


\subsection{Summary}

$\mathrm{SaP}$ is born out of a movement towards practice. In a bid to evade the supposed emptiness of bland theory, SaP aims to 'get real' by looking at actual activities. Very quickly it finds a need to enrich itself with supplementary theories and reach for connection to the macro, in order to be able to make some relevant generalizations that may appeal to practitioners.

With practice being the central focus of SaP, in most texts reviewed cognition is simply recognized as being part of SaP's context of practice, praxis, and practitioner. Cognition is considered in contextual terms, except for empirical texts which treat cognition phenomenally as the source of data. The subject is treated as the individual manager, the mind is primarily the conscious mind, the focus is on Strategizing process, and thought content is not considered. Like the Minders within Pop, SaP has a few texts in which cognition is given some focus, but the priority is clearly practice.

So SaP stays true to its own dictate by treating strategy as practice and, while doing so, it does not treat strategy as cognition. With such a strong focus, SaP could be seen as going beyond treating practice 'as' a perspective on strategy, to suggesting that strategy 'is' practice.

With SaP being a field with a tight focus on practice, there are limited provisional insights from this discourse (the first also occurs in the MOC analysis):

S1 Academia avoids thinking about Design and Learning processes, and Strategy knowledge and Intentions.

S2 Strategy research has found 'practice' to be an easier path to progress than 'cognition'

The first provisional insight is detailed in MOC. For the second, it seems clear that SaP is based upon a concern with strategy in general, and with the lack of a focus on practice in particular. The advent of the Practice Turn is perceived as a precedent to the establishment of SaP, which seems to have easily assumed that if other strategy approaches are wrong, then the practice approach must be right.

It is rather tempting to suggest that the influence of psychological behaviourism has influenced such research choices, but this cannot be easily demonstrated, if at all. Instead, it can be noted that practice may well be another name for behaviour. 
In a recent review (Blom \& Alvesson, 2015, p. 416), SaP appears to have come full circle, as these authors promote the study of five theoretical areas of strategy: strategy as power, diffusion of strategic management, irrationalities and non-rationalities of strategic management, the consequences and performativity of strategic management, anti-strategerialism. From a simple idea about focusing on doing, rather than on broad theories, SaP may have returned to the place it aims to avoid.

“I can't get no satisfaction, I can't get no satisfaction

'cause I try and I try and I try and I try

I can't get no, I can't get no"

Lyrics from (I Can't Get No) Satisfaction by Keith Richards and Michael Jagger, copyright Abkco Music Inc 


\section{Chapter 13 - Findings}

This chapter brings together all of the findings from chapters 9-12.

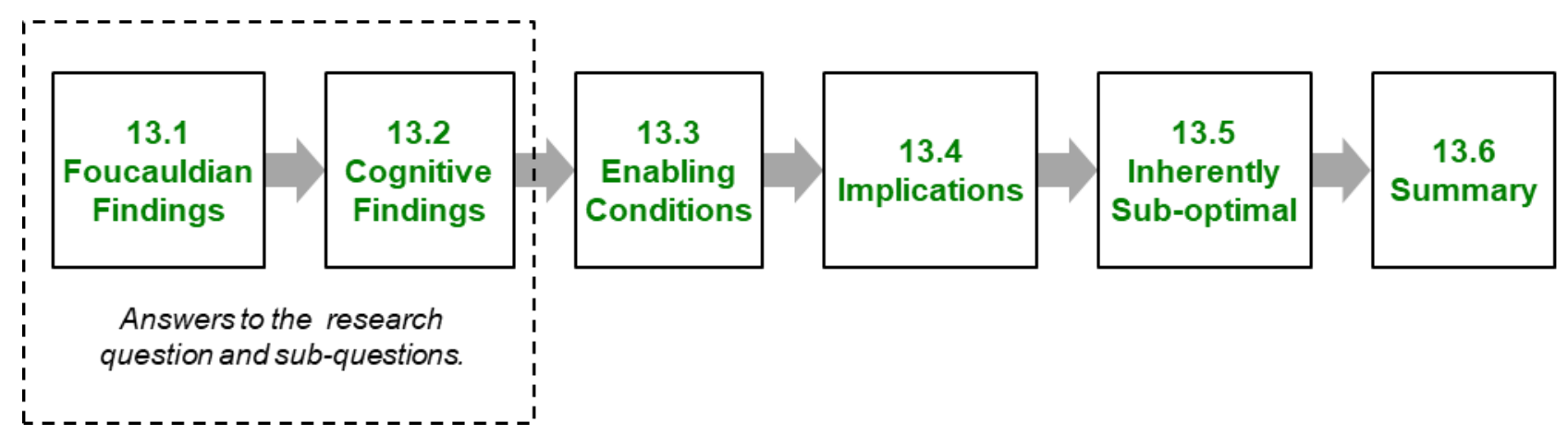

Figure 42: Chapter 13 Structure

As shown in the figure above, the chapter starts with two sections that answer the research question (13.2) and sub-questions (13.1). These sections utilize the same structures used within chapters 9-12; that is, findings in 13.1 are presented within the Foucauldian framework, and findings in 13.2 are presented using the Cognitive Heuristic. Additionally, in 13.2 the provisional insights found in each discourse analysis chapter are synthesized and contribute to answering the research question.

However, simply answering the research question is not the end of the findings, as a number of propositions are made regarding the enabling conditions of strategy's treatment of cognition, the implications for strategy's treatment of cognition, and strategy being inherently sub-optimal. These three sections are based on observations made throughout the thesis and the candidate's own knowledge and experience. Hence, they are an extrapolation of the research executed to answer the research questions, but they are supported by reasoned arguments and by material identified during the research process.

In these three sections, 13.3 suggests enabling conditions for strategy's treatment of cognition, 13.4 presents a series of implications for strategy's treatment of cognition, and 13.5 presents an argument suggesting that strategy's sub-optimal performance is inherent in contemporary strategy. 


\subsection{Foucauldian Findings}

The Foucauldian analyses of chapters 9-12 are summarized in this section. Initially, detailed findings are shown to give an overall impression of the interpretations discerned. This is followed by a discussion of findings within the Foucauldian framework. The summary of these analyses is then represented as answers to the research sub-questions.

\section{Detailed Foucauldian Findings}

The following table shows the predominant themes discerned during discourse analyses. It is not a summary, nor is it a generalization of each of the discourses - the table shows themes that occur in multiple texts within each discourse.

Table 52: Detailed Foucauldian Findings

\begin{tabular}{|c|c|c|c|c|}
\hline & Classical & MOC & Pop & SaP \\
\hline & \multicolumn{4}{|c|}{ - Enlightenment Thinking and a Scientific Approach applies to all discourses } \\
\hline $\begin{array}{l}\text { Conditions of } \\
\text { Possibility }\end{array}$ & $\begin{array}{l}\text { - business experience } \\
\text { - } \text { sociology } \\
\text { - management science } \\
\text { - operations research } \\
\text { - organizational studies } \\
\text { - industrial economics } \\
\text { - mathematics }\end{array}$ & $\begin{array}{l}\text { - } \text { scientific method } \\
\text { - psychology } \\
\text { - cognitive science } \\
\text { - sociology } \\
\text { - organizational theory } \\
\text { - management science }\end{array}$ & $\begin{array}{l}\text { - psychology } \\
\text { - cognitive psychology } \\
\text { - sociology } \\
\text { - management science } \\
\text { - education theory } \\
\text { - Japanese traditions } \\
\text { - Japanese competition }\end{array}$ & $\begin{array}{l}\text { - Process School } \\
\text { - Practice Turn } \\
\text { - human sciences }\end{array}$ \\
\hline Problematization & $\begin{array}{l}\text { - lack of theory } \\
\text { - lack of tools } \\
\text { - firm performance }\end{array}$ & - MOC itself & $\begin{array}{l}\text { - strategy does not } \\
\text { achieve its goals } \\
\text { - poor thinking } \\
\text { - firm performance }\end{array}$ & $\begin{array}{l}\text { - bad theory lacks } \\
\text { practice } \\
\text { - SaP itself }\end{array}$ \\
\hline Knowledge & $\begin{array}{l}\text { - } \text { executive ability } \\
\text { - } \text { marketing } \\
\text { - } \text { economic models } \\
\text { - } \text { planning methods } \\
\text { - } \text { analytical tools } \\
\text { - } \text { structure } \\
\text { - corporate planning } \\
\text { - } \text { scenario planning } \\
\text { - change management }\end{array}$ & $\begin{array}{l}\text { - decision theory } \\
\text { - biases } \\
\text { - mental models } \\
\text { - strategic groups }\end{array}$ & $\begin{array}{l}\text { - people are important } \\
\text { - strategy fundamentals: } \\
\text { - excellence } \\
\text { - competence } \\
\text { - stretch } \\
\text { - systems thinking } \\
\text { - strategy methods } \\
\text { - reflect-in-action } \\
\text { - tacit knowledge } \\
\text { - defensive behaviour }\end{array}$ & $\begin{array}{l}\text { - practice theories } \\
\text { - empirical research }\end{array}$ \\
\hline $\begin{array}{l}\text { Social Effects/ } \\
\text { Subjectivity }\end{array}$ & $\begin{array}{l}\text { - discipline created } \\
\text { - multiple options } \\
\text { - a strategist role } \\
\text { created }\end{array}$ & $\begin{array}{l}\text { - limited effects } \\
\text { - little bearing on } \\
\text { strategists }\end{array}$ & $\begin{array}{l}\text { - a plethora of } \\
\text { approaches } \\
\text { - everyone can be a } \\
\text { strategist }\end{array}$ & $\begin{array}{l}\text { - limited effects } \\
\text { - } \text { strategists are } \\
\text { unimportant }\end{array}$ \\
\hline
\end{tabular}




\section{Findings Within the Foucauldian Framework}

The discussions below include the presentation of findings in graphical form to illuminate differences and trends among the mainstream strategy discourses (on the left) and the academic strategy discourses (on the right), plus the earlier strategy discourses (the top two) and the later strategy discourses (the bottom two). This approach is varied for knowledge which takes a time scale approach.

\section{Conditions of Possibility}

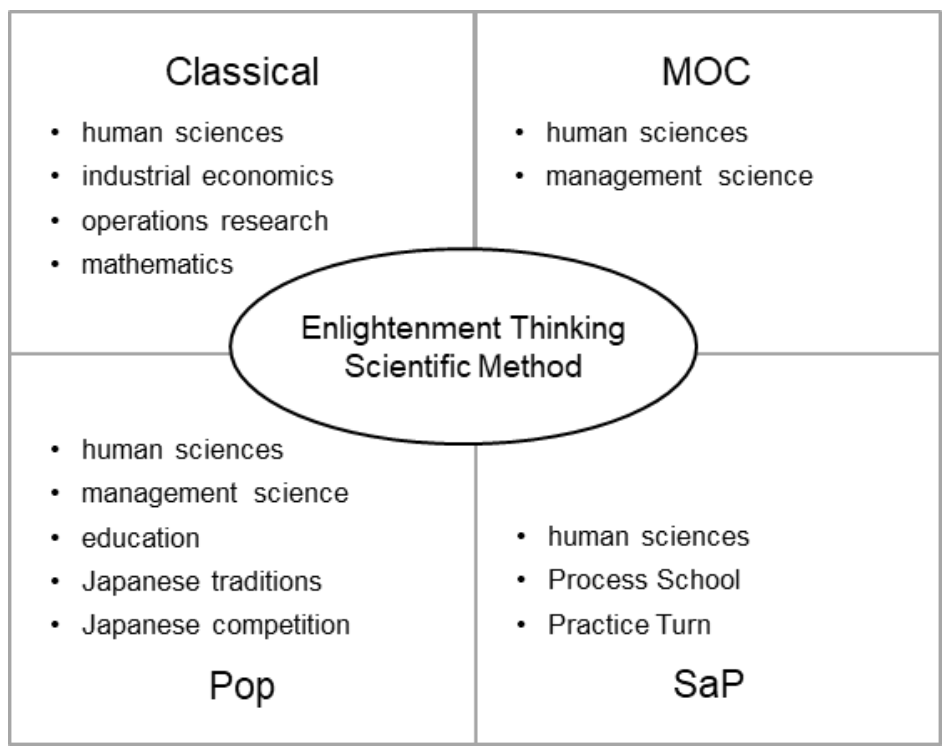

Figure 43: Conditions of Possibility Summarized

Conditions of possibility that underlie treatments of strategy are our core thinking models and societal circumstances.

Our core thinking models are primarily based upon Enlightenment thinking, often expressed as scientific method. Such Enlightenment thinking is expressed in various human sciences that pervade strategy, namely: sociology, management science, organizational studies, economics, psychology, and cognitive science. These disciplines consistently feed into strategy over a long period. This consistency of influences is only interrupted by one major point of inflection, that being the 'Practice Turn' that is recognized within SaP as the catalyst for that discourse.

Within all these thinking models there is a noticeable lack of strong onto-epistemological starting positions. While there are some momentary examples of philosophy in $\mathrm{MOC}$ and $\mathrm{SaP}$, nowhere is there found a questioning of, or a definition of, an ontology or an epistemology appropriate to support the study of human strategy. The Enlightenment approach, which leads to scientific approaches, is simply assumed to be valid. Even in business strategy, which appears to be highly complex, uniquely human and cognitive, there is little consideration of any onto-epistemological basis. 
Societal circumstances are rarely explicitly identified in the strategy discourses reviewed, with the exception of increasing economic pressure in the USA resulting from the Japanese economic rise during the 1980s-90s.

The figure above shows variations among the discourses. What is shown, and should be expected, is that later discourses have more to draw upon. So, in summary, the conditions of possibility for business strategy are common Enlightenment thinking and scientific trends observable in many other disciplines.

\section{Problematization}

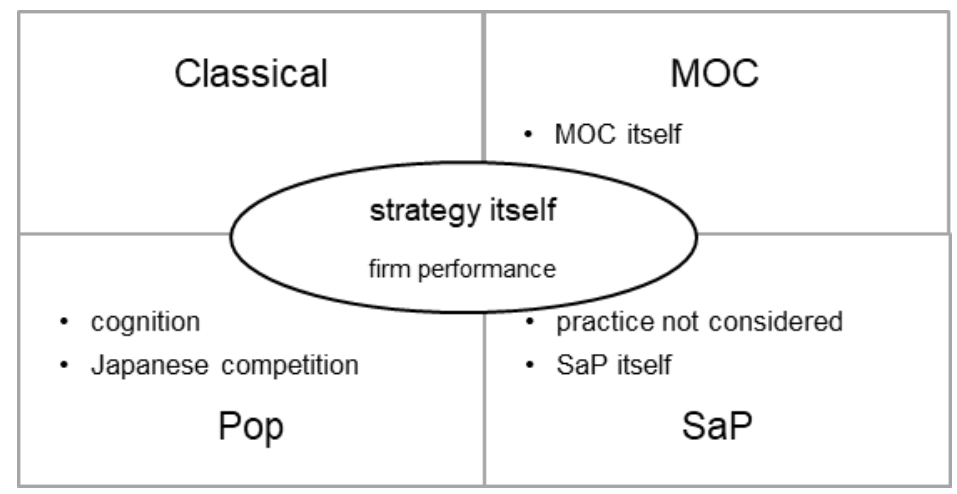

Figure 44: Problematization Summarized

The problem is mainly strategy itself! Performance is often cited as an issue, but the common theme is a lack of good theory and methods that enable human beings to do good strategy. It is only the Minders, within the Pop discourse, that find cognition to be the problem.

For Classical and Pop, the problem is a general malaise. The Classicists, being the first, find a lack of theory and tools. For some, this is expressly the lack of planning techniques and methods. For Pop, the Strategists find previous strategy theory to be ineffective, and a new version required. The Minders take a different position, and find cognitive issues, but these do not lead to any cognitively-based solutions. Instead, they propose methodological solutions, without any specifically cognitive features, to solve cognitive limitations.

MOC and SaP find the problem to be academia itself. MOC does so in a typically academic way, finding: an initial gap in accepted theory, the scope of MOC to be limited and in need of expansion, approaches which are limited and need to be enriched, and a lack of integration of approaches. SaP explicitly finds the lack of consideration of practice to be a starting point, and then critiques its own discipline in a similar academic manner as MOC.

The figure above shows some variety among the four discourses, but these really are no more than variations on the central theme of 'strategy is the problem'.

When they are described, problems are general. They are rarely seen as one major issue that needs to be resolved, such as the quest to find Higgs Boson in quantum mechanics. Instead, problems are expressed conceptually as general issues within strategy itself. This also applies when the problem is business 
performance, as issues are expressed as general assertions that competition gets harder and there is a need for better strategy.

So problems are rarely expressed either as a need to fix an agreed and specific issue or as a specific area of performance. So most texts take the approach of inventing a new strategy approach. There are methods that build on other theoretical foundations, so business strategy finds itself with a multitude of different discourse elements, instead of an evolving solution to a set of core problems.

So, for business strategy, while the problem varies, problematizations focus on strategy itself, and predominantly the perceived need is for more strategy.

\section{Knowledge}

Strategy is filled with knowledge. It seems to breed knowledge and rarely, if ever, does it discard knowledge. The texts reviewed include planning, corporate strategy, structure, marketing, tools, change management, scenarios, mental models, strategic groups, biases, competencies, stretch, fit, disciplines, frameworks, practice, praxis, practitioners, and blue oceans - to name just a few. Strategy simply expands and rarely rationalizes itself. Without a limiting onto-epistemological basis many varieties of strategy are possible, and there are many who are prepared to promote different perspectives on strategy.

The four discourses examined contribute in different fashions. A very high-level view of these contributions is:
1930s-1960s
1970s
1980s
1990s
2000s
2010s

Classical
structure, methods, planning, scenarios
MOC
mental models, biases, decision-making
Pop
fundamentals, methods, disciplines, people
SaP
practice

Figure 45: Knowledge Summarized

The forms of knowledge vary as shown in Table 52: Detailed Foucauldian Findings (p. 272). Academically, it includes both conceptual theorizing and empirical research. In Classical and Pop, knowledge can take many forms, including historical context and methods. Historical context can be presented as case studies, often derived from the direct experience of an author, and it can also be the result of academically based research. 
Table 52 shows that mainstream strategy discourses (Classical and Pop) provide the majority of strategy knowledge. Even though these mainstream discourses are often based upon academic work, academia itself ( $\mathrm{MOC}$ and $\mathrm{SaP}$ ) do not contribute greatly to knowledge, whereas mainstream discourses generate many more themes of strategy knowledge.

In summary, in business strategy knowledge structures are many and varied, and often new ideas are introduced in mainstream strategy discourses.

\section{Social Effects / Subjectivity}

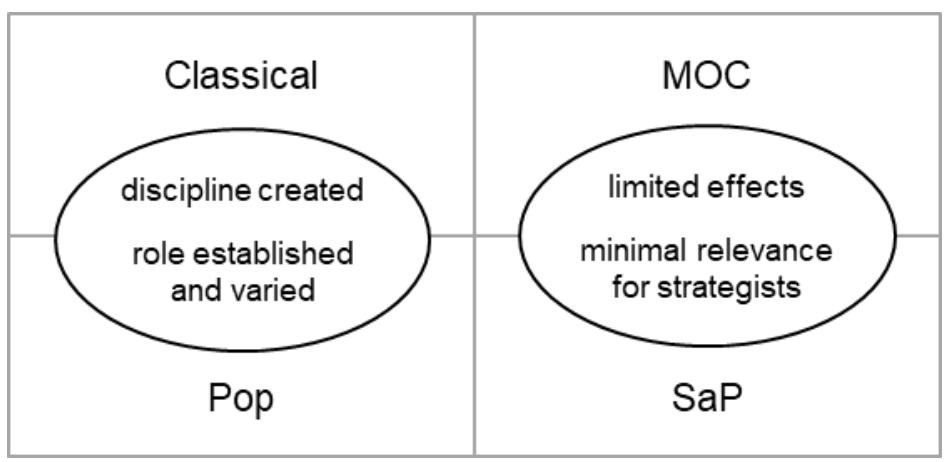

Figure 46: Social Effects/Subjectivity Summarized

Classical and Pop have clearly had a significant social effect on business strategy, as they have established and expanded the strategy discourse. MOC and SaP have had less effect in business communities, other than providing some frameworks and tools that can be utilized in strategy processes.

Classical and Pop have created and, to a degree, maintain the role of the strategist. With such a broad array of strategy approaches, the strategist is not tightly defined. Instead, the strategist has a plethora of possible tools, but also, depending on context, has the challenge of understanding them all. MOC and SaP could make this more difficult for the strategist, as they see strategists as being subservient to social structures and practices. However, given their limited social effects, such concepts do not seem to have diminished the standing of strategists in business communities.

Strategy has created its own unique and expanding discipline, with a need for skilled strategists. 


\title{
Summary
}

The above analyses are summarized as:

Table 53: Foucauldian Summary

\begin{tabular}{ll}
\hline $\begin{array}{l}\text { Conditions of } \\
\text { Possibility }\end{array}$ & $\begin{array}{l}\text { The conditions of possibility are Enlightenment thinking and scientific trends } \\
\text { observable in many other disciplines. }\end{array}$ \\
\hline $\begin{array}{l}\text { Problematization } \\
\text { Problematizations focus on strategy itself and predominantly the perceived need } \\
\text { is for more strategy. }\end{array}$ \\
\hline Knowledge & $\begin{array}{l}\text { Knowledge structures are many and varied. } \\
\text { Social Effects and }\end{array}$ \\
Subjectivity & $\begin{array}{l}\text { Strategy has created its own unique and expanding discipline. This includes a } \\
\text { need for skilled strategists, despite some academic discourses minimizing the } \\
\text { relevance of strategists. }\end{array}$
\end{tabular}

\section{Research Sub-questions}

As described on page 53, the research sub-questions are derived from the Foucauldian framework utilized.

The Foucauldian findings above are represented below as answers to the sub-questions.

The four sub-questions and answers are:

1. Under what conditions does business strategy operate?

\begin{abstract}
Business strategy operates in a culture of Enlightenment thinking, conveyed through human sciences. Without its own strong philosophical basis, it borrows from other disciplines.
\end{abstract}

2. What problems does business strategy Business strategy finds itself to be the major problem, that is, try to solve? it does not have the ability to do strategy well. A secondary issue is business performance.

3. What type of knowledge does business Business strategy produces much knowledge over a broad strategy create? range, with many methods and models.

4. What social effects does business strategy have and how does this make Business strategy creates its own expanding field and establishes a profession to utilize it and carry it forward. strategists feel about themselves?

Through science-based approaches, strategy creates itself and finds itself to be a problem. It creates many solutions, but these mostly only lightly touch on the mind. 


\subsection{Cognitive Findings}

The cognitive findings are presented in four sections: findings are presented based on the Cognitive Heuristic, the provisional insights are summarized, the provisional insights are synthesized, and finally these inputs lead to the research question being answered.

\section{Findings by Cognitive Heuristic}

A common finding is that cognition is treated superficially or not at all by much of strategy. This finding is repeated throughout this thesis, and is explicitly restated here to avoid the reader assuming that the summary of treatments presented here indicates widespread attention by strategy to cognition - this is not the case.

\section{Type of Abstraction}

Strategy treats cognition conceptually, operationally, and phenomenally. In the texts reviewed, the most predominant treatment is conceptual, and this is often stated in everyday cognitive terms such as perception, reason, understanding, and learning. In most strategy, these conceptual discussions do not go beyond the simple recognition that cognition is part of strategy.

MOC, especially, and the other discourses treat cognition operationally, as they define various Cognitive Models. These all have high degrees of generalisation, in which strategy is depicted as a number of distinct material and cognitive steps which can be measured and implemented. The models rarely consider issues such as how strategy reason occurs, or how strategy insights are created. When treated conceptually and operationally, cognition could be almost any mechanical or administrative process. Such treatments are not mindful, and often they are almost mindless.

MOC and SaP treat cognition phenomenally, as human endeavours are their raw data, and practitioners' cognitive appreciations of such activity are the starting point of their research. Such phenomena are acquired through many methods including interviews, surveys, and observation. Once obtained, the cognitive element of the research is typically dropped as research proceeds to sociological propositions and conclusions.

Two texts stand out as they treat cognition more deeply. Even though he does not propose any cognitivelybased solutions, van der Heijden (1996) aims to introduce methods that produce specific cognitive results. Schön (1983) does delve deeply into cognition from multiple levels of abstraction, but then he does not go further to incorporate cognition into any solution.

So cognition is abstracted in multiple ways, but is treated like any other physical or human phenomenon and often at a high level of abstraction. Techniques such as introspection, that would make strategy's treatment of cognition mindful, are notably absent. In only a few cases is the term introspection ever used, and it appears as if psychological behaviourism from the early $20^{\text {th }}$ century, that bars such direct treatments of cognition, still has an influence. 


\section{Subject}

Rarely is the firm reified as the subject, and when it is, it often appears to be more of a linguistic device than a genuine proposition that the mind of the firm exists. Generally, the subject is predominantly seen as an individual, and discussed as such or as groups of people. While there is a tendency to default to the 'topmanagement team', there are also occasions when discussions go wider to consider other participants.

\section{Mind}

Strategy is conscious of the conscious, and only at times does it venture to peer into the subconscious. Besides the occasional call to include emotion, the principle foray into the subconscious is through the Minders in the Pop discourse who stress the existence and power of tacit knowledge (this is also highlighted in SaP, in philosophical papers that consider a Heideggerian approach). Schön (1983) and Senge (1990) go somewhat further to speculate on the subconscious, but such speculation seems to be a finishing point rather than the start of a 'cognitive moment' in strategy.

\section{Thinking Process}

Strategy focuses on Strategizing - not on Learning nor on Designing. All the discourses researched focus on Strategizing, or the actual act of creating strategy. There is almost no discussion about how an organization may design its own strategy process, nor about how individuals and groups might learn about strategy. Strategy sees only the process directly in front of it and struggles to find processes behind the act of Strategizing.

\section{Thought Content}

In the discourses examined, Thinking Process has much more focus than does Thought Content. Thought Content is primarily focused on Context, as demonstrated by MOC building descriptive market frameworks (mental models, frames), and some Classical and Pop authors developing models as an aid to understanding markets. In addition to a lack of focus on Learning and Designing processes, there is almost no focus on Strategy knowledge. It appears that what people know about strategy is relatively unimportant. Further, no examples of the consideration of Intentions were found. Intentions, of course, can be recorded in material forms, as well as held cognitively. But, even within this broader scope, the idea that Intentions are part of strategy seems to hold little sway.

In summary, current business strategy focuses on Thought Content of market Context, and aligns with the Strategizing process that operates on such contextual knowledge. 


\section{Summary}

Table 54: Cognitive Summary

\begin{tabular}{ll}
\hline Type of & - conceptual abstractions are common, using everyday terms \\
Abstraction & - operational models of processes are found and are usually gross generalizations \\
& - phenomenal data is the basis of much research, but the conclusions are sociological \\
& - contemplation of reason is very limited (e.g. induction, deduction, abduction) \\
\hline Subject & - the thinking subject is the individual manager \\
\hline Mind & - mind is primarily considered as conscious mind \\
\hline Thinking Process & - there is a strong focus on Strategizing over Learning and Designing \\
\hline Thought Content & - not often considered \\
& - when considered, it is primarily as strategy Context \\
& - little focus on Strategy knowledge or strategy Intentions \\
\hline
\end{tabular}

The research question asks, "How does business strategy treat cognition?"

As the table above shows, this thesis has revealed themes in the literature reviewed. The structure of the Cognitive Heuristic highlights the limited scope of current treatments of cognition. While cognition is conceptually discussed, operational interpretations are often high-level abstractions, and phenomenal treatments simply aim to create data for sociological reasoning, rather than to delve deeply into the mind using such techniques as introspection. Strategy is consistent in treating the subject as the individual manager, but in the majority of texts reviewed only the conscious part of the manager's mind is seen as important. Finally, cognitive processes and thought are limited to Strategizing and Context respectively. There is almost no appreciation of Learning and Designing processes, and no contemplation of Strategy knowledge and strategy Intentions.

The conclusions from the texts reviewed are that strategy does not recognize the importance of cognition, and on the rare occasions it does, such treatments are at arm's length and within a limited scope. 


\section{Provisional Insights}

A series of provisional insights were identified when each of the four discourses were analyzed. These are listed below (note M3 and S1 are the same insight found in the analysis of different discourses):

Table 55: Provisional Insights

\begin{tabular}{lll} 
Discourse & Provisional Insight \\
\hline Classical & C1 & Cognition, even when recognized as important, is not part of strategy solutions. \\
\cline { 2 - 3 } & C2 & Treatment, or non-treatment, of cognition is independent of strategy approach. \\
\hline C3 & Practitioners are more likely to treat cognition seriously than academics. \\
\hline Pop & P1 & A people focus within strategy did not produce cognitive solutions. \\
\hline P2 & Cognition was once briefly treated seriously by strategy. \\
\hline P3 & Even when strategy treats cognition seriously, solutions are not cognitive. \\
\hline M1 & Academia avoids introspection, preferring to be at least at one remove. \\
\hline M2 & Academia finds cognition to be a problem. \\
\hline M3 & Academia avoids thinking about Design and Learning processes, and Strategy knowledge \\
& and Intentions. \\
\hline SaP & Academia avoids thinking about Design and Learning processes, and Strategy knowledge \\
& \begin{tabular}{l} 
and Intentions. \\
\hline S2
\end{tabular} & Strategy research has found 'practice' an easier path to progress than 'cognition' \\
\hline
\end{tabular}




\section{Synthesized Insights}

The provisional insights above have been synthesized into six insights. As explained below, while insights were gained in analyses of particular discourses, the themes were often found in multiple discourses. The only exception was provisional insight C3, which suggests a different pattern between mainstream and academic discourses. However, this provisional insight is not consistent throughout the discourses and hence C3 does not contribute to any synthesized insight.

Table 56: Insights

\begin{tabular}{|c|c|c|}
\hline Insight & & $\begin{array}{l}\text { Contributing } \\
\text { Provisional Insight }\end{array}$ \\
\hline Insight One & treatments of cognition are random & $\mathrm{C} 2$ \\
\hline Insight Two & treatments of cognition are narrow & M3, S1 \\
\hline Insight Three & cognition is perceived as a problem & $\mathrm{M} 2$ \\
\hline Insight Four & cognition is not studied directly & $\mathrm{M} 1, \mathrm{~S} 2$ \\
\hline Insight Five & strategy solutions are not cognitive & $\mathrm{C} 1, \mathrm{P} 1, \mathrm{P} 3$ \\
\hline Insight Six & cognition was central for only a brief period & $\mathrm{P} 2$ \\
\hline
\end{tabular}

\section{Insight One - Treatments of cognition are random}

Although initially revealed in the Classical texts reviewed, overall there are no discernible patterns that suggest particular approaches to cognition by strategy are predictable. The most common treatments are either no treatment or a simple recognition of cognition - these cannot be predicted by the discourse itself, by the conditions of possibility, or by any other aspect of a particular text. The only exception is the Minders who, by definition, treat cognition.

It appears that an author's treatment of cognition is based on an author's own predilections. There is no compulsion to mention cognition, and cognition is not seen as a central element of strategy. In this respect, cognition is currently treated as an optional extra for strategy.

\section{Insight Two - Treatments of cognition are narrow}

As suggested by the academic discourses, and confirmed in the Cognitive Heuristic findings, current treatments of cognition are narrow, and principally focus on the conscious mind and Strategizing processes. The unconscious mind is rarely considered, broader processes of Designing and Learning processes are not core to strategy discourses, and Thought Contents about Strategy and Intentions are not studied in the literature reviewed. This overwhelming narrowness is likely to pervade all of strategy. 


\section{Insight Three - Cognition is perceived as a problem}

A prevalent view in the academic discourses reviewed, and supported in mainstream discourses, is that cognition is a problem. Far from being the critical capability that sets humans apart and provides the opportunity to develop sophisticated understanding, reasoning, and intentions, the mind is a problem that needs to be fixed.

\section{Insight Four - Cognition is Not Studied Directly}

As indicated by SaP's adherence to the study of practice, academic discourses that set the tone for strategy research do not use introspection; they prefer to study behaviour.

\section{Five - Strategy solutions are not cognitive}

It is apparent in both mainstream discourses and in academic discourses that, even when cognition is treated seriously, this does not translate into cognitive solutions. Current solutions are primarily methods and processes, rather than guidelines for more effective utilization of the mind. While solutions will involve concepts that must be thought about and achieved through cognitively driven actions of practitioners, these solutions are not expressed in cognitive terms.

\section{Insight Six - Cognition was central for only a brief period}

As exemplified by Schön (1983) in the Pop strategy discourse, cognition was once seen as being central to strategy. But web searches and the lack of a continuing literature suggest that this view was only current in a period from circa 1980-1990. There are no indications that Schön's influence goes any further or that any following theorists take up his ideas with any seriousness. This situation is confirmed by the candidate's own experiences, and suggests that strategy found the cognitive path to be too challenging compared with more approachable and available paths, such as practice. 


\section{Research Question Answered}

Application of the Cognitive Heuristic in analyses of the four strategy discourses finds that strategy tends not to treat cognition, and when it does, such treatments are at arm's length and within a limited scope.

This is confirmed and extended through the insights developed:

- treatments of cognition are random

- treatments of cognition are narrow

- cognition is perceived as a problem

- cognition is not studied directly

- strategy solutions are not cognitive

- cognition was central for only a brief period

So strategy:

- operates at the level of concept and operations, thereby avoiding the in-depth phenomena of the mind

- limits contemplation of mind to the conscious and avoids engaging with the subconscious

- avoids reflective thinking, which would promote consideration of Designing and Learning processes

- focuses on the immediacy of behavioural Context in front of it, thereby avoiding contemplation of knowledge of Strategy itself and the holding of Intentions

- finds cognition to be a problem that needs to be resolved and fixed rather than embraced

- other than a brief period circa 1980-90, avoids studying cognition directly, and avoids including cognition in solutions.

So the answers to the research question of "How does business strategy treat cognition?" are:

Strategy ignores cognition or recognizes cognition as an isolated side issue.

Even when cognition's importance is recognized, strategy solutions are not cognitive.

When cognition is considered, its treatment is limited, scientific, and simplistic.

Specific cognitive elements that are rarely mentioned are:

the subconscious, Learning and Designing processes, and Thought Contents of Strategy and Intentions. 


\subsection{Conditions Enabling Such Treatments}

The reasons for such treatments of cognition by strategy have been alluded to throughout this thesis and in these findings. These are made explicit here as five contributing conditions to strategy's treatment of cognition:

1. mind is no longer the centre of our world

2. looking inwards is uncomfortable

3. understanding cognition is inherently difficult

4. the humanities lack a conceptual basis that admits mind

5. strategy has alternatives to cognition

\section{Mind is no longer the centre of our world}

Mind is not perceived as a capability to direct the world - it is something to be manipulated and is no longer central.

Our concept of mind has changed over the centuries, from a simple process, to a virtue, to a disease, and to something malleable. Intuition, for example, started as a mechanical process. According to Aristotle and Kant, intuition was simply a process for getting sensory perceptions into the mind in order for reason to then take over. Intuition did not have any magic in and of itself. During the Age of Reason, intuition became part of the wonderful abilities of homo sapiens. With the rise of humanism, when the great minds could understand and control the world, part of this was the ability of intuition to make great leaps.

However, such an exalted position for the mind did not last. Psychological behaviourism, from the early $20^{\text {th }}$ century, explicitly suggests that mind should be avoided. This still has ramifications - mind never fully recovered in psychology, even though a cognitive turn occurred around the mid-20 ${ }^{\text {th }}$ century (Baars, 1986). This turn was not a return, but a partial turn. Cognitive psychology, one key outcome of the cognitive turn, finds intuition to be a problem because it is biased! This concept of 'failed mind' seems to be readily accepted, as it aligns to Judaic-Christian concepts of sin and the implicit wickedness of humanity. Perhaps we are receptive to such messages, notwithstanding a brief period of Enlightenment, as we have been conditioned by more than 2,000 years of history to believe that we are inherently flawed.

And, from thinking our minds are flawed, we go on to assume that minds are not the source of our power. Humanity seems to be in a mode of simple 'mind maintenance', rather than aiming to optimize the workings of the mind. Within strategy, this loss of faith in our ability to think our way to a better life in the Western World supports the treatment of cognition as an isolated side issue. 


\section{We find looking inward uncomfortable}

Suggesting why we do not embrace introspection is highly speculative as it requires understanding of how people think and feel about their own consciousness. However, as mental illness is currently a significant public issue, one can posit that we live in an age in which the mind is perceived as being prone to disease and we have learnt through the psychoanalysts that mind has its demons. It is quite thinkable that the current age finds looking inward to be very uncomfortable.

\section{Understanding cognition is inherently difficult}

Personal experience, the discourse analyses above, and the advent of Artificial Intelligence (Al), support the contention that cognition is not easy to understand. When one delves into one's own mind, it does not seem a straightforward process (at least to this candidate). It seems that mind is a complex subject and that the use of introspection is difficult.

It is readily apparent, through the analyses in this thesis, that while some texts stress the importance of cognition, they never venture in. Given strategy's penchant for exploiting theoretical bases from other disciplines, such reticence is likely to be based upon the inherent complexity of cognition. Just as it is challenging for individuals, strategy discourses have also found it difficult to delve deeply into cognition.

And now we try to build machine-based cognitions using Artificial Intelligence. The investment and interest in $\mathrm{Al}$ is astounding, and dwarfs that within strategy academia. For example, the kaggle.com website lists a number of Al competitions. On 2 June 2019, there were 11,397 entries that aimed to determine, through $\mathrm{Al}$, what type of people were most likely to survive the Titanic catastrophe ("Titanic: Machine learning from disaster," 2019). It seems that we find it easier to build an artificial mind, rather than to focus on the human variety that sits atop our shoulders.

So delving into the mind appears to be difficult and has been avoided, and we have found alternatives. All these observations support the contention that understanding cognition is inherently difficult.

\section{The humanities lack a conceptual basis that allows for mind}

It is problematic to think of mind because of a lack of a supportive philosophy, the lack of words to speak about cognition, the limitations of scientific thinking, and the failure to hold fast to our own beliefs.

\section{The lack of a philosophy that admits a sophisticated cognition}

Platonic concepts of ideals and materiality pervade philosophy. For the humanities, without a stated ontoepistemology, a series of similar dichotomies arise, such as theory/practice and strategy/implementation. Within such dichotomies there is a semblance of mind, but it is only one object of study, a single layer of cognition that holds a series of messages. It is not a reciprocal process that works on itself, nor does the subject, such as the researcher, contemplate that they them self may have a mind. Through this received, but 
unstated onto-epistemology, humanities such as strategy are unable to think of cognition as the primary aspect of study. Accordingly, a sophisticated cognition cannot be admitted within the dichotomy, because it does not fit.

\section{The lack of a sophisticated cognitive language}

William James suggests that we lack a language to discuss cognition: "This absence of a special vocabulary for substantive facts hinders the study of all but the very coarsest of [sensations]" (James, 1890/1950b, p. 195). He goes on to state, "It is hard to focus our attention on the nameless, and so there results a certain vagueness in the descriptive parts of most psychologies" (p. 195).

It is questionable whether there has been much advancement since William James because the current language of cognition resembles that which has been used for centuries. And it further appears that there is a lack of combinations of such words to produce any conceptual sophistication. As shown in Chapter 4-A Review of Treatments of Cognition, a relatively unsophisticated Cognitive Heuristic had to be created because no suitable variety was apparent in the literature reviewed. While there is language for basic cognitive functions, there is still a lack of a suitable language that can consider more complex cognitive scenarios.

\section{Default scientific thinking limits treatments of cognition}

The sophistication of mind is not sufficiently predictable for science. Such science is often concerned with description; that is, it is concerned with understanding and describing things as they are. For strategy, this can be seen in Cognitive Models that describe observed strategy processes in highly simplistic terms, and which then go on to prescribe how strategy should be performed based upon these descriptions. This hard science is a pale imitation of the strengths, capabilities, and vagrancies of cognitive processes, and thus is inherently limited when dealing with cognition.

\section{The implications of social constructionism are ignored}

Business strategy implicitly, and at times explicitly, adopts a sociological epistemology of social constructionism, where independent mind is recognized. However, in academia, this is often followed by statistical analysis, based on data derived from interviews and surveys, that is more aligned to a form of determinism, such as environmental determinism (see Social Constructionism and Environmental Determinism, page 24, for a description of how this thesis interprets these terms). An example is MOC, in which both approaches can co-exist in a single article. The use of such positivistic techniques essentially reduces mind to a variable and thereby limits the scope and depth of any cognitive appreciation. 


\section{Strategy has easier alternatives}

For strategy in particular, there are alternatives that allow cognition to be avoided. Mainstream strategy simply adopts low levels of reasonableness, while academia sits comfortably with abstract empiricism. These two habitual approaches allow cognition to be avoided.

\section{Mainstream assertion of truths}

In much of Pop strategy authors simply assert 'truths', and then describe examples to support their assertions. Often there is not even any pretence of justifying concepts. Considering that options for expressing ideas include assertion, description, demonstration, theorization, validation, justification, and proof, it seems that, within strategy, both authors and readers have decided that just assertion and description are necessary and sufficient. A good example is "The Myth of the Great Idea" (Collins \& Porras, 1994, pp. 23-27). The authors use the examples of HP, Sony, and Wal-Mart to support their proposition that great ideas are not the genesis of successful companies, but there is no contemplation of context and reasoning is entirely replaced by bold assertion. Clearly, this assertion is highly speculative, but this does not trouble the authors and, because these books are read, presumably it doesn't trouble the readers either. The analyses of other texts support this contention. The approach of justifying a rule by an example seems to be well established. So it appears that the standard of reasonability for mainstream texts is relatively low. With such a low standard there is no need to take on the hard problems of strategy, and so much easier to take the position that anything goes.

\section{Academic strategy research defaults to abstract empiricism}

Burrell and Morgan (1979) describe the use of abstract empiricism as when "a highly nomothetic methodology is used to test a theory which is based upon an ontology, an epistemology and a theory of human nature of a more subjectivist kind" (p. 105). While the theorist may profess to base their work on an ontology or epistemology that recognizes cognition, the actual methodology may expressly avoid cognition or minimize its influence. Such an approach of looking for patterns in human behaviour and finding them seems well established, especially in SaP empirical studies. So, with an accepted approach of abstract empiricism, academic strategy research simply has no imperative to consider cognition. 


\section{Summary}

This section describes conditions that enable strategy's treatment of cognition:

1. Mind, once the great human capability, is no longer exalted, and hence strategy is not obliged to pay homage.

2. The current age, beset with mental problems and a belief in the demons of the mind, finds looking inwards uncomfortable, if not dangerous.

3. Cognition is not easy to understand. Strategy does not assume such a task, as presumably it is the role of other disciplines, such as psychology, to lead the development of cognitive understanding.

4. There is no conceptual basis that easily admits a sophisticated cognition. There is a lack of a suitable philosophy and of a language, and scientific thinking cannot cater for a sophisticated mind.

5. Strategy, provided with the two alternatives of mainstream assertion of 'truths' and academic abstract empirical, finds no compulsion to dive into the depths of the mind. 


\subsection{Strategy Implications}

Enabling conditions for strategy's treatment of cognition are presented above. Beyond these understandings of what conditions and historical accidents may have produced this state of denial of cognition, there are also implications for contemporary strategy practice. The implications of strategy's treatment of cognition are:

- strategy is methodological

- strategy has limited scope

- strategy underperforms.

\section{Strategy is methodological}

Strategy is largely methodological because it is based on science. The researcher, as the detached observer, seeks to describe and predict behaviour. The strategist is recommended to adopt a similar strategy to the researcher. It seems that many of the designers of strategy processes are academics who have simply created strategy processes in their own likeness. It seems that the strategy frameworks of practitioners are scientific because they are based on academic research programmes.

Further, these strategy frameworks are often systematic. Strategy is rarely, if ever, presented as a series of techniques and open questions into which strategists must plunge into in order to devise their own way forward. The systematic nature of strategy processes is inherent in the very definitions of process, and at times this is explicitly stated. For example Kim and Mauborgne (2005) state that "managers need to look systematically across [accepted boundaries] to create blue oceans" (p. 48). As a result, current strategy is a method - it is not a use of mind.

\section{Strategy has limited scope}

As illustrated in the detailed discourse analyses of this thesis, the methodologies practised have very limited scope. Consideration of strategy process rarely goes beyond Strategizing, into the realms of Designing and Learning. Similarly, consideration of strategy rarely goes beyond Context, to Strategy and Intentions.

\section{Strategy underperforms}

As this thesis shows, strategy finds itself to be a problem. This aligns with and perhaps explains the popular cynicism about the effectiveness of current strategy process. This candidate's own poll of business-people finds that strategy is not held in the same esteem as are law and accountancy, that is as a discipline that can reliably produce results. Rather, it is more seen to be like Information Technology, an area where language is confusing, and results are hard to obtain. Strategy itself reinforces this view as each new wave of ideas negatively critiques previous strategy approaches. 


\subsection{Inherently Limited to Sub-optimality}

The starting point for the proposition that strategy is sub-optimal is that strategy is primarily cognitive. That is, strategy is primarily the use of the mind to develop ideas and concepts, and to hold those in the mind as intentions that drive future behaviours - mind comes before behaviour.

The question now becomes one of strategy discourses being well equipped to consider cognition as the central aspect of strategy? MOC has the word 'cognition' in its title but has limited focus on cognition. While there is consideration of bias and mental models, it is limited to descriptive techniques and there are no cognitive strategy solutions. These descriptive techniques are used to understand behaviour. In a similar fashion, SaP is explicit in not considering mind, because it studies a form of behaviour, namely practice.

Mainstream strategy discourses take a lead from human sciences. While cognition may be seen as being structurally important, mainstream strategy has no tools that enable it to delve into the workings of the mind. When authors do consider mind, they simply provide a commentary on mind. Such commentaries are just adjuncts to actual proposed methodological solutions that are based on scientific principles inherited from other disciplines.

Guilford (1939) provides a perspective on the human sciences. In an introductory psychology text, he states the expectations of sciences: "Like other sciences, psychology aims to understand its subject matter so well, with emphasis on the human individual, that we are able to predict and control human actions" (p. 19). While such an approach reflects a prevailing psychological behaviourism, which may have utility when trying to predict and control humanity, its utility for business strategy is questionable.

If business strategy is cognitive, and such cognition is more than simply aiming to predict and control, then business strategy will be limited by such behaviouristic human science approaches. Essentially, strategy is inherently sub-optimal for the purposes of making the mind more efficacious.

The proposition this thesis presents here is that, given that strategy is accepted as being cognitive, strategy discourses deriving from human sciences will inherently be sub-optimal as they have no potential to view mind in any way other than in a behavioural fashion. 


\subsection{Summary}

Consider the following quote being made in 2020 to describe the planet's response to various social and environmental challenges: "If we can imagine an anthropological report about homo sapiens written by extraterrestrial scientists from a more advanced civilization, we can assume that humanity's inability to solve its psychological, social, and ecological problems or to provide answers to basic cosmological questions ... would lead to the conclusions that homo sapiens is a species capable of very limited robot-reactivity and that Intelligent Life has not yet evolved on this planet."

But this quote is from Leary $(1977$, p. 2). While Leary's text, Exo-psychology, primarily aims to justify the use of certain mind-altering drugs in so far as they are a necessary tool to develop insightful control of the body, he also raises the pertinent question of 'how well do we think?'

This thesis also considers the efficacy of thinking, but not thinking in general. Instead, it looks at thinking from a business strategy perspective. This thesis finds strategy to be treating cognition in a limited fashion:

- Strategy ignores cognition or recognizes cognition as an isolated side issue.

- Even when cognition's importance is recognized, strategy solutions are not cognitive.

- When cognition is considered, its treatment is limited, scientific, and simplistic.

- Specific cognitive elements that are rarely mentioned are: the subconscious, Learning and Designing processes, and Thought Contents of Strategy and Intentions.

Three additional findings from the research are:

1. Conditions that enable strategy's treatment of cognition as described above are that mind is no longer the centre of our world, looking inwards is uncomfortable, understanding cognition is inherently difficult, the humanities lack a conceptual basis that admits mind, and strategy has alternatives to cognition.

2. There are implications for strategy: it is methodological, it is limited, and it underperforms.

3. Strategy is inherently limited to being sub-optimal for the cognitive nature of its very subject, that is, business strategy. 
So the Foucauldian analyses (13.1 Foucauldian Findings, p. 272) show, from the reviewed texts, a discipline called business strategy that draws predominantly from human sciences, that has created itself as an accepted discipline with many different styles and different shapes, and that finds itself to be the problem that requires more strategy.

The cognitive analyses find this problem to be that cognition is missing. They show that cognition is not treated as being central to business strategy but is treated as an aside. They further suggest that the problem business strategy has is linked to the very scientific basis of contemporary business strategy, because such a basis cannot allow cognition to be central to strategy. The human sciences that could enable business strategy to delve deeply into cognition may have been present in the time of the Minders (see 11.2 Minders), but this influence was only temporary. As a result, business strategy is now stuck in a non-cognitive bind, in which cognition - its central element - cannot be approached directly and therefore can only be treated as an aside.

Based upon the premise that business strategy is a human cognitive process, this thesis finds that the fundamental problem for contemporary business strategy is that its Enlightenment scientific basis does not allow it to treat cognition as its central element of strategy, and therefore business strategy is, and will continue to be, sub-optimal.

"How you gonna win, when you ain't right within?"

From Doo Wop (That Thing), by Lauryn Hill / Lauryn N. Hill, @ Sony/ATV Music Publishing LLC 


\section{Part Three - Recommendations}

"Sometimes, though, perhaps we should try to reinvent the wheel

- in this case a revealing and useful theory on strategy and strategizing"

(Blom \& Alvesson, 2015).

Part Two finds that business strategy is sub-optimal and limited. This thesis now makes a series of recommendations for reinvention as shown in the figure below:

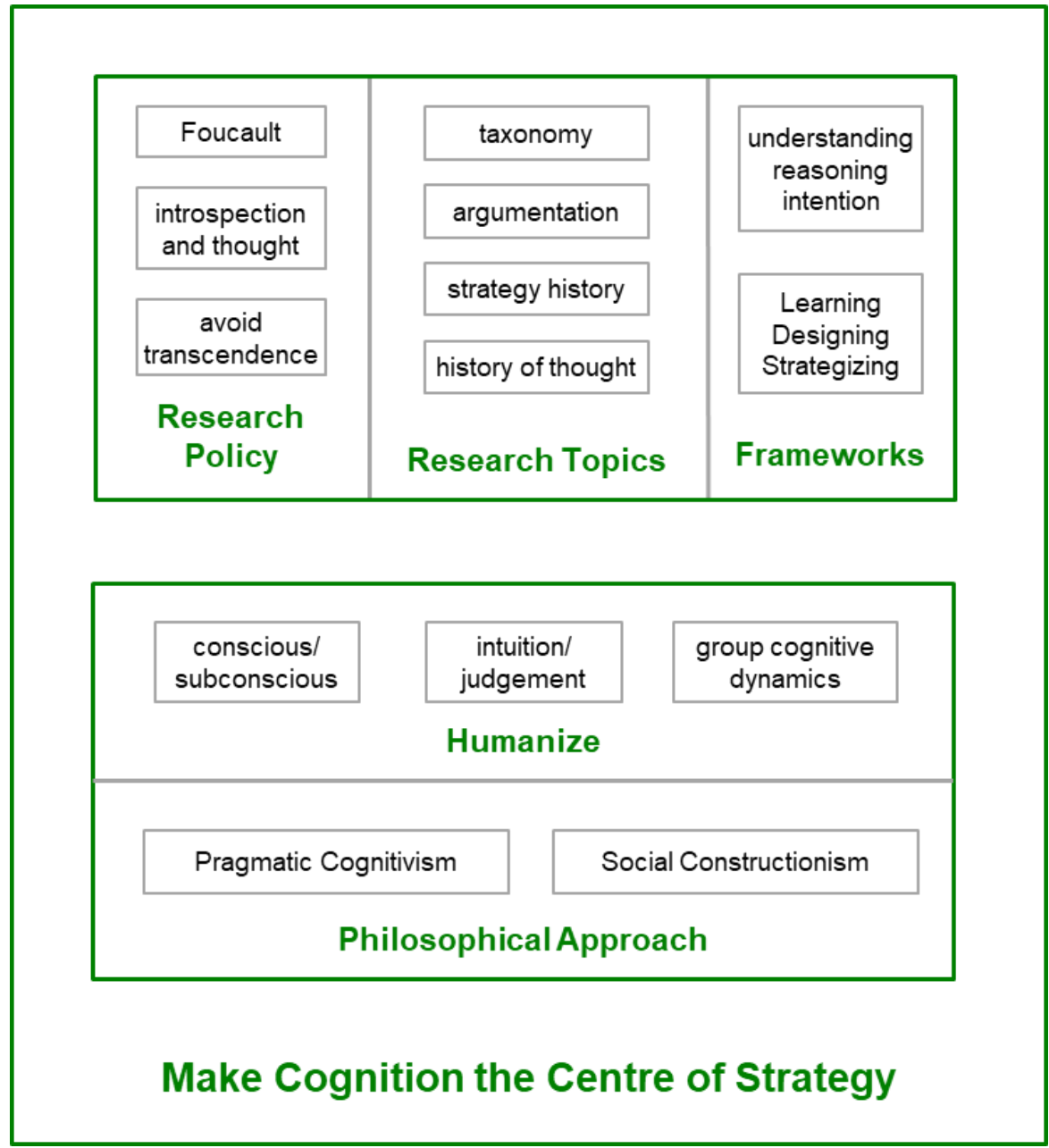

Figure 47: Part Three Structure 


\section{Make Cognition the Centre of Strategy}

This thesis recommends making cognition the central focus of business strategy. Such a fundamental change of emphasis will entail new ways of perceiving strategy, developing strategy, and executing strategy.

\section{Current Status}

There are many approaches to strategy which are represented by many methods and theories. As Part Two established, strategy is sub-optimal because it is not structured to consider cognition, the central element of strategy. This structure is embedded in strategy discourses which are made up of artefacts and interpretations in minds. Both the changing of artefacts and the changing of minds are possible.

\section{A Cognitive Turn for Business Strategy}

The basis is a cognitive turn in how we judge and think about strategy. This turn does not demand that other forms of strategy, such as methods, scientific-based studies, behavioural studies, and experience-based advice are abandoned. However, this turn does require that other forms of strategy are interpreted as subservient to cognition, and recommends the development of a cognition-centred business strategy.

To achieve such a turn, it is recommended that Pragmatic Cognitivism (see 3.3 Pragmatic Cognitivism, p. 13) be adopted as an epistemology that allows us to think about thinking, and to consider the full implications of a world of interpretations. Once mind can be comprehended, strategy can be humanized through recognition of the mind as an enabling condition of our existence, and not as a problem to be resolved.

Such a cognitive turn gives rise to recommendations for research policies, specific research topics and the use of frameworks developed in this thesis. These are examples of potential future directions, but the adoption of a cognitive epistemology and the humanizing of strategy are the two strategies that are the cornerstones of more efficacious strategy discourses.

\section{A Cognitive Return}

While this is a cognitive turn for strategy, it is somewhat a cognitive return for psychology and human sciences. The recommendation for strategy is to consider mind to be central to human endeavours, as was established by William James (1890/1950a, 1890/1950b) in the late nineteenth century. This is not necessarily reflected in current human sciences, because even though there was a mid-twentieth century cognitive revolution as described by Baars (1986), the influence of psychological behaviourism still seems to be prevalent in sciencebased methods used for much of the research in the human sciences. Therefore, these recommendations are not simply to draw more from contemporary psychology, but to treat cognition in a manner more akin to the style of William James. 


\section{Philosophical Approach}

Two philosophical recommendations are made. Firstly, setting mind at the centre of strategy discourses will only occur if strategy is based upon an epistemology that allows mind to be thought. Therefore, the use of Pragmatic Cognitivism is recommended. Secondly, the implications of a fully developed social constructionism confirms the inherently human nature of strategy and has implications for the treatment of strategy. Therefore it is recommended that the implications of social constructionism are recognized.

\section{Adopt Pragmatic Cognitivism as an epistemology that allows mind to be thought}

An epistemology allows thoughts to be thought. Especially for strategy, in which mind is central, an epistemology that does not have a place for mind itself has very limited applicability. Therefore, the recommendation is to adopt Pragmatic Cognitivism (p. 13) as the epistemology that supports mind. As illustrated in this thesis, Pragmatic Cognitivism can be built upon to yield frameworks and guidelines that implicitly include cognition. Such frameworks and guidelines have utility for the way strategy is thought, taught, researched, and practiced.

\section{Recognize the implications of social constructionism}

In 3.7 Social Constructionism and Environmental Determinism (p. 24), the alignment of social constructionism and Pragmatic Cognitivism was recognized. This is now developed further as an opportunity to consider the implications of social constructionism for strategy, in order to shed further light on strategy.

Social constructionism's starting point, as defined in The Social Construction of Reality (Berger \& Luckmann, 1966 ) is the premise that 'reality' as we know it is constructed in human minds (this aligns fully with Pragmatic Cognitivism). What Berger and Luckmann do not develop further is the influence of time, one of Pragmatic Cognitivism's triad of space, time, and cognition. When time is considered, it seems likely that any particular two social realities in time may relate to another time through commonalities of interpretations, but because interpretations are in the mind, the possibility of finding hard relationships between any two interpretations is highly problematic. Hence, the application of scientific analysis and prediction to social reality held in minds would be foolhardy.

The exclusion of such overly scientific approaches would have significant and positive implications for the manner in which business strategy is thought about and presented. Instead of dictating methodologies, strategy would provide contexts for minds to find ways forward. If the mind is accorded the ability to judge, potentially more efficacious ways to think strategy will be forthcoming. 


\section{Humanize}

Humans are inherent to business strategy. Making business strategy recognize humanity is recommended by actively acknowledging both the conscious and the subconscious mind, reinstating judgment and intuition, and considering group cognitive processes.

\section{Recognize the conscious and the subconscious mind}

While it cannot be conclusively proven that the subconscious mind contributes to business strategy, even the most superficial introspection of one's own mind processes suggests that not all our thoughts and ideas are the result of conscious processes. Accordingly the subconscious may be a very important source of strategy capability. The intent is not to debate the relative merits here, but to recommend that a cognitive approach to strategy should include cognisance of both the conscious and the subconscious mind.

This thesis has demonstrated that the subconscious mind is rarely considered by business strategy discourses. Such an imbalance suggests that strategy is likely to be significantly sub-optimal, and that processes should be designed to utilize both minds. How to do this is a very pertinent question, but without deliberate intent, it is unlikely that we will ever be optimized to use the full capability of the mind when doing strategy.

\section{Reinstate judgement and intuition}

If it is accepted that business strategy involves choice, there is a clear need for some way to decide what to do. It is recommended that judgement and intuition are reinstated as being core to deciding. This thesis finds that judgment and intuition are recognized, but that such recognition is not the norm, except for the Minders who, to varying degrees, recognize tacit knowledge as intuition and judgment.

It is recommended that judgement and intuition be considered to be central to business strategy. This is not to suggest that strategy tools are obsolete, but to suggest that these tools be thought of as being channelled through minds with judgemental and intuitive capabilities.

\section{Consider group cognitive processes}

The intent here is not to reify group cognition, but is to recommend that strategy seeks to optimize the cognitive capabilities of groups. This can include seeking outcomes such as:

1. shared perceptions of cognitive capabilities

2. a common view of cognitively based strategy processes

3. shared understandings of business context.

Clearly the third outcome is already an objective that much strategy aspires to. However, the idea of a strategy group sharing a conception of the capabilities of the mind and a view of how to use their minds is not. 


\section{Research Policy}

These three recommendations are for Michel Foucault to be used as a theorist again for research into strategy research, for a fundamental change in research methods to use introspection and to focus on thought content, and for strategy research to become more disciplined by avoiding transcendence.

\section{Michel Foucault as a theorist}

This thesis demonstrates that the theories and work of Michel Foucault can be the basis of a methodology for studying strategy discourses. While the final efficacy will be judged by readers, from the candidate's perspective, the methodology was a useful choice because:

- the methodology aligns with the candidate's epistemology

- the methodology could be operationalized

- the research yielded results that could be consolidated

- the research questions were answered.

For the second point, the approach of surveying Foucault and selecting useful Foucauldian concepts for this thesis was found to be very advantageous once fully completed. That a slight restructure was required during the actual research process suggests that more work beforehand could have been appropriate, but that may simply be the benefit of hindsight. However, the candidate acknowledges that more in-depth understanding of Foucault's work earlier in the process would have been useful.

Another observation is that Foucault's work should come with a general warning about the dangers of emulation. While Foucault has a significant following and is considered to be a leading scholar, his literary style, appropriate to a French intellectual in a certain time period, is not necessarily appropriate to a thesis in a New Zealand university in the third millennium. While the candidate did not attempt to emulate Foucault's style directly, a tendency to be speculative as Foucault often appears to be, even though he is rarely criticized for it, resulted in the need for some reworking at times.

Given the completion of this thesis and the candidate's own perceptions of this process, the work of Michel Foucault is recommended as a basis for future strategy research. 


\section{Introspection and Thought}

As this thesis shows, based upon the literature, business strategy does not use introspection as a tool to look into the mind, and rarely considers what is thought. It is recommended that this changes if strategy is to become more useful to strategists.

Introspection, proposed by William James at the beginning of the $20^{\text {th }}$ century, looks into the mind. This seems to be an essential tool if researchers are going to understand what people think. The challenge is, as the early psychologists found, that defining any standards of measurement is difficult but, if one accepts that strategy is a human pursuit instead of a scientific voyage of discovery, introspection simply adds to the richness of the journey.

It seems surprising that very little research has studied what people know about strategy. There are empirical studies, often based on surveys, regarding tools, but there does not appear to be many in-depth analyses into what people know about strategy, let alone what they feel about strategy. In order to progress strategy, the strategy context - that is the minds of the strategists - would be a useful starting point.

This is a very broad recommendation. Any implementation would have significant hurdles but continuing to ignore both the most direct channel to the mind and the information in the mind would appear to indicate an acceptance that business strategy will continue to be sub-optimal.

\section{Avoid Transcendence}

As defined in Chapter 3 - Epistemology, the transcendent is the space beyond the conceptual. Such excesses seem easy for strategy to fall into, as the object of study includes human cognitive capabilities for which we lack descriptive techniques, and which hence tend to be conceptualized and, subsequently, reified beyond the conceptual to the transcendent. Once they are transcendent, they are free to roam and fill minds, but with little prospect of any pragmatic outcomes.

The epistemological distinction between the conceptual and the transcendent is an essential heuristic that should be applied to research. That the application of such a heuristic is an act of judgement does not diminish the utility of the distinction but places it within the gambit of human cognition. 


\section{Research Topics}

\section{A Cognitive Taxonomy for Strategy}

The language of strategy and the language of cognition may limit the capacity of strategy to be cognitive.

Strategy has many terms and, perhaps due to the cognitive nature of strategy, these terms can be ambiguous. For example the terms aim, goal, and objective describe concepts that may be held in the mind, but the actual interpretation of each term can vary widely. The language of cognition, with terms such as reason, intuition, feeling, comprehension, consciousness, and understanding, are everyday usage, and while well-known, they do not provide a detailed view of mind. It may be that cognition language has only needed to support the description of behaviour and therefore lacks sophistication. A useful research task may be to understand the effects of language on strategy and cognition, and determine whether a more advanced taxonomy is possible.

\section{Teach cognitive methods of argumentation}

As strategy often involves social processes, a knowledge of how humans discuss ideas may be useful. The general movement away from classical education to functional education means that we do not have a vocabulary that categorizes methods of argument. Such terms as a minore ad maius (from the smaller to the greater), argumentum a contrario (true because nothing contrary), ab origine (from an origin), argumentum ad consequentiam (true based on the consequences), argumentum ad hominem (against the person), argumentum ex silentio (given no other theory), non sequitur (it does not follow), and reductio ad absurdum (reduction to the absurd) suggest that previous civilizations had sophisticated language to describe the ways we think and present ideas. In contemporary times, we even lack a clear understanding of logical terms, such as induction, deduction, and abduction. For strategy, where understanding and reasoning are so crucial, a study of previous approaches to argumentation may yield useful tools for the executives of today.

\section{Strategy History}

While this thesis has covered over 80 years of strategy, there is a significant literature and specific areas of strategy, such as the resource-based view, that have not been researched. There is a clear opportunity to extend this current research over a broader range of strategy literature, and possibly to investigate different aspects of strategy.

\section{History of Thought}

Michel Foucault died before he could complete his research of sexuality from the earliest recorded times. In his quest he traces how humankind think about sexuality in different epochs. It would be an equally or more challenging task to trace how humankind thought about thought. Such an undertaking may have utility in a world where the concept of thought itself seems to be under threat from the concept of 'fake news' leading to changes in the dynamics of power and knowledge, and technologies such as artificial intelligence that attempt to replicate a mind in a machine. 


\section{Frameworks}

Two frameworks developed in this thesis are recommended for use by strategists and researchers.

\section{Adopt a strategy heuristic of understanding, reasoning, and intentions}

To focus strategy on the mind, a heuristic of understanding, reasoning, and intentions is recommended. Such a categorization is as arbitrary as, and has some commonality with, process models such as Analyse, Plan, Implement, and Control. However, it is recommended as a better alternative because it fits with and focuses on our minds.

Key abilities of our minds are the ability to comprehend, the ability to make determinations, and the ability to maintain a desire to make our future. The words understanding, reasoning, and intentions are a relatively unemotive collection of gerunds and nouns that encapsulate these aspects of human behaviour within business strategy. They can be utilized both as a way of structuring process and as criteria for process. In the latter case, any proposed strategy process can be measured by its likely contribution to this framework. In the former case, strategy could be specifically structured to use such a framework.

Of the three elements of this strategy heuristic, intention is especially noteworthy because of the lack of any consideration by strategy. While studies exist of failures to achieve stated strategies, the cognitive process of intending, or holding intentions, has not been a topic of study. Indeed, using the verb 'intending' seems somewhat out of place when discussing strategy, but surely the very success of strategy is dependent on keeping intentions in mind?

\section{A strategy heuristic of Learning, Designing, and Strategizing}

This heuristic has proven to be useful when analyzing strategy discourses and is further recommended as a useful way to comprehend strategy. While arbitrary, it does have the utility of introducing the real possibilities of Learning about strategy and the process of Designing a Strategizing process.

By considering Learning one invites the questioning of what one knows, what one could learn, how one can learn, and where one can learn. This might be a useful starting point to strategy for an executive. Designing a Strategizing process could be informed by company context and by strategy knowledge. The likely number of combinations of both are, of course, infinite. However, understanding the status of a company (maturity, risk profile, strategy knowledge), and the style of dialogue at a point in time (e.g. emotive, political, technical, economic etc.), are useful starting points for the application of judgment and knowledge, with the aim of finding a Strategizing approach that has utility. Based upon the above Learning and Designing processes, Strategizing would become a cognitively-focused activity designed for cognitive ends. It would be designed for the current state of the company, and it would often change from one strategy iteration to the next strategy iteration. A strategy process would never be set in stone but would be a living process that evolves with a company. These evolutions could include the form of each strategy episode, the interval between episodes, and take account of changes in circumstances between episodes. 


\section{Recommendations in a Wider Context}

These recommendations are not to 'fix' business strategy - they are to reconceive business strategy as a human activity that involves choice. Business strategy, a cognitive phenomenon that moves forward in time, is reconceived as something that minds can judge and determine, not as behaviours amenable to proofs and forecasts. This is different from most approaches as there are no guarantees - there are only interpretations that may provide useful guidelines when judging.

This thesis highlights how business strategy discourses endeavour to use sometimes inappropriate scientific methods to understand the past, in order to then present how strategy should be developed for the future. That this knowledge is perceived as being problematic suggests that it either needs to be fixed or another approach taken. These recommendations, taken together, are another approach.

The recommendations suggest that business strategy should reflect the cognitive aspect of humans doing strategy through thought. Seen this way, business strategy should aim to find useful descriptions and structures that enable more efficacious human understanding, reasoning, and judgment.

For example, a strategist who judges their firm's level of knowledge of strategy and its ability to design strategy, based upon a core desire to improve the firm's understanding, reasoning, and intentions, and who is cognisant of the power of the subconscious mind, the use of intuition, and how groups may function together, is well placed to determine what to do next. This what to do next is not based on a formulaic prescription - it is based upon a judgement of the context of the firm and the context of the strategist. The strategist does not ask 'what methodology should I employ?', but asks 'where are we and how are we today?'. The strategist can then judge what to do next, and this may and probably will be something that has never been done that way before. Of course, it may be a variation upon a common theme or it may also be a new direction. But it will be 'whatever comes to mind'.

Such a new approach, which is effectively a 'reinstatement of mind', does not rely on proofs derived from past performance and lacks any guarantee as no guarantee can be had - mind, the most basic human condition, is currently not fully knowable through science. So, pragmatically, we should simply aim to use mind as best we can. Pragmatic Cognitivism and the heuristics derived from it enable such a forward thinking approach.

The challenge then becomes to find interpretations that have utility, instead of to find the right answer. That is, 'how can we think about thinking to enable us to think better?' 


\section{Conclusion}

This thesis answers the question "How does business strategy treat cognition?" In business strategy, a most mindful activity of directing commercial interests, it finds that cognition is currently treated overwhelmingly as a side issue. The assertion is made that business strategy is sub-optimal because it avoids the very thing that is central to its being - cognition.

To create the opportunity for business strategy to perform better, this chapter recommends a cognitive turn for business strategy based on:

- a mindful philosophical basis for strategy

- the humanizing of strategy.

Further recommendations are made for:

- a research policy based on Foucault and cognitive elements

- future research topics

- the use of cognitive frameworks.

The cognitive turn is the priority. Strategy needs an epistemology that admits mind, and strategy needs to be humanized. The further recommendations provide future options that have arisen from the research of this thesis. While they have value and potential, they are subordinate to the cognitive turn that places cognition at the centre of business strategy.

While putting mind back into strategy will not be an easy task, it might be worth it.

And I hope that you are having the time of your life

But think twice

That's my only advice

Lyrics from Crazy by Brian Joseph Burton, Gian Pero Reverberi, Gianfranco Reverberi, and Thomas Decarlo Callaway, (C) Warner Chappell Music, Inc., Universal Music Publishing Group, Downtown Music Publishing, BMG Rights Management, Sony/ATV Music Publishing LLC, Kobalt Music Publishing Ltd. 


\section{Chapter 14 - References}

The 25 most influential business management books. (2016). Retrieved from http://content.time.com/time/specials/packages/completelist/0,29569,2086680,00.html

Ackoff, R. L. (1970). A concept of corporate planning. New York, NY: Wiley-Interscience.

Alvesson, M., \& Sköldberg, K. (2009). Reflexive methodology: New vistas for qualitative research (2nd ed.). London, United Kingdom: Sage.

Ambrosini, V., \& Bowman, C. (2002). Mapping successful organizational routines. In A. S. Huff \& M. Jenkins (Eds.), Mapping strategic knowledge (pp. 19-45). London, United Kingdom: Sage.

Andrews, K. R. (1971). The Concept of Corporate Strategy. Homewood, IL: Dow Jones-Irwin.

Andrews, T. (2012). What is social constructionism. Grounded theory review, 11(1), 39-46.

Ansoff, H. I. (1965). Corporate strategy: An analytic approach to business policy for growth and expansion. New York, NY: McGraw-Hill Book Company.

Argyris, C. (1985). Strategy, change, and defensive routines. Boston, MA: Pitman Publishing.

Argyris, C. (2005). Double-loop learning in organizations: A theory of action perspective. Great minds in management: The process of theory development, 261-279.

Argyris, C., \& Schön, D. A. (1974). Theory in practice: Increasing professional effectiveness. San Francisco, CA: Jossey-Bass.

Aristotle. (circa 350 BC/1986). De Anima (On the Soul) (H. Lawson-Tancred, Trans.). London, United Kingdom: Penguin Books.

Aronson, E., Wilson, T. D., Akert, R. M., \& Sommers, S. R. (2013). Social Psychology (9th ed.). Boston, NY: Pearson.

Ashby, W. R. (1956). An introduction to cybernetics. New York, NY: John Wiley and Sons.

Baars, B. J. (1986). The cognitive revolution in psychology. New York, NY: The Guilford Press.

Barnard, C. I. (1938). The functions of the executive. Cambridge, MA: Harvard University Press.

Barnes, J. H. (1984). Cognitive biases and their impact on strategic planning. Strategic Management Journal, 5(2), 129-137.

Barney, J. B. (2001). Resource-based theories of competitive advantage: A ten-year retrospective on the resource-based view. Journal of management, 27(6), 643-650.

Barr, P. S., Stimpert, J. L., \& Huff, A. S. (1992). Cognitive change, strategic action, and organizational renewal. Strategic Management Journal, 13(S1), 15-36.

Beech, N., \& Johnson, P. (2005). Discourses of disrupted identities in the practice of strategic change: The mayor, the street-fighter and the insider-out. Journal of Organizational Change Management, 18(1), 31-47.

Benjamin Jr, L. T. (2014). A brief history of modern psychology (2nd ed.): Wiley \& Sons Ltd.

Berger, P. L., \& Luckmann, T. (1966). The social construction of reality: A treatise in the sociology of knowledge.

Bermúdez, J. L. (2010). Cognitive science: An introduction to the science of the mind. Cambridge, United Kingdom: Cambridge University Press.

The best business books ever. (2012). New York, NY: Basic Books. 
Bhaskar, R. (1993/2008). Dialectic: The pulse of freedom. Oxon, United Kingdom: Routledge.

Blom, M., \& Alvesson, M. (2015). A critical perspective on strategy as practice. In D. Golsorkhi, D. Seidl, E. Vaara, \& L. Rouleau (Eds.), Cambridge handbook of strategy as practice (2nd ed., pp. 405-428). Cambridge, United Kingdom: Cambridge University Press.

Bogner, W. C., \& Barr, P. S. (2000). Making Sense in Hypercompetitive Environments: A Cognitive Explanation for the Persistence of High Velocity Competition. Organization Science, 11(2), 212-226.

Bogner, W. C., \& Thomas, H. (1993). The Role of Competitive Groups in Strategy Formulation: A Dynamic Integration of Two Competing Models. Journal of Management Studies, 30(1), 51-67.

Bougon, M. G. (1992). Congregate cognitive maps: a unified dynamic theory of organization and strategy. Journal of Management Studies, 29(3), 369-387.

Bougon, M. G., Baird, N., Komocar, J. M., \& Ross, W. (1990). Identifying strategic loops: The self-Q interviews. In A. S. Huff (Ed.), Mapping strategic thought (pp. 327-354). Chichester, United Kingdom: John Wiley and Sons.

Braddon-Mitchell, D., \& Jackson, F. (2007). The philosophy of mind and cognition (2nd ed.). Malden, MA: Blackwell Publishing.

Brundin, E., \& Liu, F. (2015). The role of emotions in strategizing. In D. Golsorkhi, D. Seidl, E. Vaara, \& L. Rouleau (Eds.), Cambridge handbook of strategy as practice (2 ed., pp. 632-646). Cambridge, United Kingdom: Cambridge University Press.

Bryman, A., \& Bell, E. (2003). Business research methods (3rd ed.). Oxford, United Kingdom: Oxford University Press.

Bukszar, E., Jr. (1999). Strategic bias: The impact of cognitive biases on strategy. Revue Canadienne des Sciences de l'Administration, 16(2), 105-117.

Burrell, G., \& Morgan, G. (1979). Sociological paradigms and organisational analysis. Farnham, United Kingdom: Ashgate.

Butler-Bowdon, T. (2010). 50 Success Classics: Winning Wisdom for Work \& Life from 50 Landmark Books. (n.p.): Nicholas Brealey Publishing.

Carter, C., Clegg, S., \& Kornberger, M. (2008). Strategy as practice? Strategic Organization, 6(1), 83-99.

Chandler, A. D. (1962). Strategy and structure: chapters in the history of the industrial enterprise. Cambridge, MA: MIT press.

Chapman, C. S., Chua, W. F., \& Mahama, H. (2015). Actor-network theory and strategy as practice. In D. Golsorkhi, D. Seidl, E. Vaara, \& L. Rouleau (Eds.), Cambridge handbook of strategy as practice (2 ed., pp. 265-280). Cambridge, United Kingdom: Cambridge University Press.

Chia, R. (2004). Strategy-as-practice: Reflections on the research agenda. European Management Review, 1(1), 29-34.

Chia, R., \& MacKay, B. (2007). Post-processual challenges for the emerging strategy-as-practice perspective: Discovering strategy in the logic of practice. Human Relations, 60(1), 217-242.

Cho, T. S., \& Hambrick, D. C. (2006). Attention as the Mediator Between Top Management Team Characteristics and Strategic Change: The Case of Airline Deregulation. Organization Science, 17(4), 453-469.

Christensen, C. M. (1997). The innovator's dilemma: when new technologies cause great firms to fail. Boston, MA: Harvard Business Review Press.

Clegg, S., Carter, C., \& Kornberger, M. (2004). 'Get up, I feel like being a strategy machine'. European Management Review, 1(1), 21-28. 
Collins, J. C., \& Porras, J. I. (1994). Built to last: Successful habits of visionary companies. New York, NY: HarperBusiness.

Cornelissen, J. P., \& Werner, M. D. (2014). Putting Framing in Perspective: A Review of Framing and Frame Analysis across the Management and Organizational Literature. The Academy of Management Annals, 8(1), 181-235. doi:10.1080/19416520.2014.875669

Covert, J., \& Sattersten, T. (2011). The 100 best business books of all time. New York, NY: The Penguin Group.

Cropley, A. (2006). In Praise of Convergent Thinking. Creativity Research Journal, 18(3), 391-404. doi:10.1207/s15326934crj1803_13

Das, T. K., \& Teng, B.-S. (1999). Cognitive Biases and Strategic Decision Processes: An Integrative Perspective. Journal of Management Studies, 36(6), 757-778. doi:10.1111/1467-6486.00157

De Wit, B., \& Meyer, R. (2010). Strategy: Process, content, context: An international perspective (4th ed.). Andover, United Kingdom: Cengage Learning.

Derrida, J. (1967/1997). Of Grammatology (G. C. Spivak, Trans.). Baltimore, MA: The John Hopkins University Press.

Descartes, R. (1641/1986). Meditations on First Philosophy. Cambridge, United Kingdom: Cambridge University Press.

Dreyfus, H. L., \& Rabinow, P. (1983). Michel Foucault: Beyond structuralism and hermeneutics (2nd ed.). Chicago, IL: University of Chicago Press.

Easterby-Smith, M., Thorpe, R., \& Jackson, P. (1991). Management Research (4th ed.). Longon, United Kingdom: SAGE Publications Ltd.

Eden, C. (1988). Cognitive mapping. European Journal of Operational Research, 36(1), 1-13.

Eden, C. (1992). On the nature of cognitive maps. Journal of Management Studies, 29(3), 261-265.

Eden, C., \& Spender, J.-C. (Eds.). (1998). InManagerial and organizational cognition: theory, methods and research. London, United Kingdom: Sage.

Eggers, J. P., \& Kaplan, S. (2009). Cognition and renewal: Comparing CEO and organizational effects on incumbent adaptation to technical change. Organization Science, 20(2), 461-477.

Eggers, J. P., \& Kaplan, S. (2013). Cognition and capabilities: A multi-level perspective. The Academy of Management Annals, 7(1), 295-340.

El Sawy, O. A., \& Pauchant, T. C. (1988). Triggers, templates and twitches in the tracking of emerging strategic issues. Strategic Management Journal, 9(5), 455-473.

Epistemology. (n.d.) dictionary.com. Retrieved from https://www.dictionary.com/browse/epistemology?s=t, Date Accessed: 08 January 2020

Fairclough, N. (2013). Critical discourse analysis: The critical study of language (2nd ed.). Oxon, United Kingdom: Routledge.

Faulkner, D. O., \& Campbell, A. (Eds.). (2003). InThe Oxford handbook of strategy: a strategy overview and competitive strategy. Oxford, United Kingdom: Oxford University Press.

Fenton, C., \& Langley, A. (2011). Strategy as practice and the narrative turn. Organization Studies, 32(9), 11711196.

Fiol, C. M., \& Huff, A. S. (1992). Maps for managers: where are we? Where do we go from here? Journal of Management Studies, 29(3), 267-285. 
Fletcher, K. E., \& Huff, A. S. (1990). Argument mapping. In A. S. huff (Ed.), Mapping strategic thought (pp. 355402). Chichester, United Kingdom: John Wiley and Sons.

Foucault, M. (1961/1988). Madness and civilization. New York, NY: Vintage Books.

Foucault, M. (1964/1990). Nietzsche, Freud, Marx. In G. L. Ormiston \& A. D. Schrift (Eds.), Transforming the hermeneutic context: From Nietzsche to Nancy (pp. 59-67). Albany, NY: State University of New York Press.

Foucault, M. (1969/2010). The archaeology of knowledge. New York, NY: Vintage Books.

Foucault, M. (1976/1990). The history of sexuality, volume I: An introduction. New York, NY: Vintage Books.

Foucault, M. (1984/1990). The use of pleasure, volume 2 of the history of sexuality. New York, NY: Vintage Books.

Foucault, M. (1994). The birth of the clinic. New York, NY: Vintage Books.

Foucault, M. (1995). Discipline and punishment (2nd ed.). New York, NY: Vintage Books.

Freedman, L. (2013). Strategy: a history. New York: Oxford University Press.

Gardner, H. (2008). The mind's new science: A history of the cognitive revolution. New York, NY: Basic Books.

Gavetti, G., \& Ocasio, W. (2015). Introduction. In G. Gavetti \& W. Ocasio (Eds.), Cognition and Strategy (Vol. 32, pp. xi-xxiv). Bingley, United Kingdom: Emerald Group Publishing.

Ginsberg, A. (1989). Construing the business portfolio: a cognitive model of diversification. Journal of Management Studies, 26(4), 417-438.

Ginsberg, A. (1994). Minding the competition: From mapping to mastery. Strategic Management Journal, 15(S1), 153-174.

Golsorkhi, D., Rouleau, L., Seidl, D., \& Vaara, E. (2010a). Introduction: What is strategy as practice? In D. Golsorkhi, D. Seidl, E. Vaara, \& L. Rouleau (Eds.), Cambridge handbook of strategy as practice (pp. 120). Cambridge, United Kingdom: Cambridge University Press.

Golsorkhi, D., Rouleau, L., Seidl, D., \& Vaara, E. (2010b). What is strategy-as-practice?

Golsorkhi, D., Rouleau, L., Seidl, D., \& Vaara, E. (Eds.). (2010c). InCambridge Handbook of Strategy as Practice. Cambridge, United Kingdom: Cambridge University Press.

Golsorkhi, D., Rouleau, L., Seidl, D., \& Vaara, E. (Eds.). (2015). InCambridge Handbook of Strategy as Practice (2nd ed.). Cambridge, United Kingdom: Cambridge University Press.

Goold, M., \& Campbell, A. (1987). Strategies and styles: The role of the centre in managing diversified corporations. Oxford, United Kingdom : Basil Blackwell Ltd.

Grand, S., Rüegg-Stürm, J., \& Von Arx, W. (2010). Constructivist epistemologies in Strategy as Practice research. In D. Golsorkhi, D. Seidl, E. Vaara, \& L. Rouleau (Eds.), Cambridge handbook of strategy as practice (pp. 63-78). Cambridge, United Kingdom: Cambridge University Press.

Grønhaug, K., \& Falkenberg, J. S. (1998). Success attributions within and across organizations. In C. Eden \& J. Spender (Eds.), Managerial and organizational cognition: Theory, methods, and research (pp. 93-107). London, United Kingdom: Sage.

Guilford, J. P. (1939). General pyschology. New York, NY: D. Van Nostrand Company, Inc.

Guilford, J. P. (1959). Three faces of intellect. American Psychologist, 14(8), 469-479. doi:10.1037/h0046827

Gutting, G. (2005). Introduction Michel Foucault: A user's manual. In G. Gutting (Ed.), The Cambridge Companion to Foucault (2nd ed., pp. 1-28). Cambridge, United Kingdom: Cambridge University Press. 
Haley, U. C., \& Stumpf, S. A. (1989). Cognitive trails in strategic decision-making: Linking theories of personalities and cognitions. Journal of Management Studies, 26(5), 477-497.

Hall, R. I. (2002). Gaining understanding in a complex cause-effect policy domain. In A. S. Huff \& M. Jenkins (Eds.), Mapping strategic knowledge (pp. 89-111). London, United Kingdom: Sage.

Hamel, G., \& Prahalad, C. K. (1994). Competing for the future. Boston, MA: Harvard Business School Press.

Hammer, M., \& Champy, J. (2001). Reengineering the corporation: A manifesto for business revolution: Nicholas Brealey.

Heidegger, M. (1926/2008). Being and time (J. Macquarrie \& E. Robinson, Trans.). New York, NY: HarperCollins.

Heil, J. (2013). Philosophy of mind: A contemporary introduction (3rd ed.). New York, NY: Routledge.

Henderson, B. D. (1979). Henderson on corporate strategy. Cambridge, MA: Abt Books.

Hendry, J. (2000). Strategic decision making, discourse, and strategy as social practice. Journal of Management Studies, 37(7), 955-978.

Hernes, T. (2014). A process theory of organization. Oxford, United Kingdom: Oxford University Press.

Hindle, T. (2008). Guide to management ideas and gurus (Vol. 42). London, United Kingdom: The Economist.

Hodgkinson, G. P. (1997). The cognitive analysis of competitive structures: A review and critique. Human Relations, 50(6), 625-654.

Hodgkinson, G. P., \& Clarke, I. (2007). Exploring the cognitive significance of organizational strategizing: A dualprocess framework and research agenda. Human Relations, 60(1), 243-255.

Hodgkinson, G. P., \& Johnson, G. (1994). Exploring the mental models of competitive strategists: The case for a processual approach. Journal of Management Studies, 31(4), 525-552.

Hodgkinson, G. P., \& Maule, A. J. (2002). The individual in the strategy process: insights from behavioural decision research and cognitive mapping. In A. S. Huff \& M. Jenkins (Eds.), Mapping strategic knowledge (pp. 196-219). London, United Kingdom: Sage.

Hodgkinson, G. P., Whittington, R., Johnson, G., \& Schwarz, M. (2006). The role of strategy workshops in strategy development processes: Formality, communication, co-ordination and inclusion. Long Range Planning, 39(5), 479-496.

Hofer, C. W., \& Schendel, D. (1980). Strategy formulation: Analytical concepts: West Publ.

Hofstede, G. (2001). Culture's consequences: Comparing values, behaviors, institutions and organizations across nations. Thousand Oaks, CA: Sage.

Hrebiniak, L. G., \& Joyce, W. F. (1985). Organizational adaptation: Strategic choice and environmental determinism. Administrative Science Quarterly, 336-349.

Huff, A. S. (1982). Industry influences on strategy reformulation. Strategic Management Journal, 3(2), 119-131.

Huff, A. S. (Ed.) (1990). InMapping strategic thought. Chichester, United Kingdom: John Wiley \& Sons.

Huff, A. S., \& Jenkins, M. (Eds.). (2002). InMapping strategic knowledge. London, United Kingdom: SAGE.

Husserl, E. (1913/2001). Logical Investigations (2nd ed.). Oxon, United Kingdom: International Library of Philosophy.

Husserl, E. (1913/2014). Ideas 1. Indianapolis, IN: Hackett Publishing Company.

Ireland, R. D., Hitt, M. A., Bettis, R. A., \& De Porras, D. A. (1987). Strategy formulation processes: Differences in perceptions of strength and weaknesses indicators and environmental uncertainty by managerial level. Strategic Management Journal, 8(5), 469-485. 
James, W. (1890/1950a). The principles of psychology (Vol. 1). New York, NY: Dover Publications Inc.

James, W. (1890/1950b). The principles of psychology (Vol. 2). New York, NY: Dover Publications Inc.

James, W. (1907/1975). Pragmatism and The meaning of truth. Cambridge, MA: Harvard University Press.

James, W. (1912/1996). Essays in radical empiricism. Lincoln, NE: University of Nebraska Press.

Jarzabkowski, P. (2003). Strategic practices: An activity theory perspective on continuity and change. Journal of Management Studies, 40(1), 23-55.

Jarzabkowski, P. (2004). Strategy as practice: recursiveness, adaptation, and practices-in-use. Organization Studies, 25(4), 529-560.

Jarzabkowski, P. (2005). Strategy as practice: An activity based approach. London, United Kingdom: Sage.

Jarzabkowski, P., Balogun, J., \& Seidl, D. (2007). Strategizing: The challenges of a practice perspective. Human Relations, 60(1), 5-27.

Jarzabkowski, P., \& Spee, A. P. (2009). Strategy-as-practice: A review and future directions for the field. International Journal of Management Reviews, 11(1), 69-95.

Jarzabkowski, P., \& Whittington, R. (2008). A strategy-as-practice approach to strategy research and education. Journal of Management Inquiry, 17(4), 282-286.

Jarzabkowski, P., \& Wilson, D. C. (2006). Actionable strategy knowledge: A practice perspective. European Management Journal, 24(5), 348-367.

Johnson, G., Langley, A., Melin, L., \& Whittington, R. (2007a). Strategy as practice: Research directions and resources. Cambridge, United Kingdom: Cambridge University Press.

Johnson, G., Langley, A., Melin, L., \& Whittington, R. (Eds.). (2007b). InStrategy as practice: research directions and resources. Cambridge, United Kingdom: Cambridge University Press.

Johnson, G., Melin, L., \& Whittington, R. (2003). Micro strategy and strategizing: Towards an activity-based view. Journal of Management Studies, 40(1), 3-22.

Johnson, G., \& Scholes, K. (1984). Exploring corporate strategy. Englewood Cliffs, NJ: Prentice/Hall International.

Johnson, G., \& Scholes, K. (2002). Exploring corporate strategy (6th ed.). Harlow, United Kingdom: Pearson Education.

Jung, C. J. (1968). The archetypes and the collective unconscious (2nd ed.). Princeton, NJ: Princeton University Press.

Kahneman, D. (2013). Thinking, fast and slow. New York, NY: Farrar, Straus, and Giroux.

Kant, I. (1781/1991). Critique of pure reason (N. K. Smith, Trans.). Basingstoke, United Kingdom: Macmillan Press Ltd.

Kanter, R. M. (1983). The change masters. New York, NY: Simon and Schuster.

Kaplan, S. (2008). Framing Contests: Strategy Making Under Uncertainty. Organization Science, 19(5), $729-752$.

Kaplan, S. (2011). Research in cognition and strategy: reflections on two decades of progress and a look to the future. Journal of Management Studies, 48(3), 665-695.

Kaplan, S., Murray, F., \& Henderson, R. (2003). Discontinuities and senior management: Assessing the role of recognition in pharmaceutical firm response to biotechnology. Industrial and Corporate Change,

12(2), 203-233. 
Kiechel, W. (2010). The lords of strategy: The secret intellectual history of the new corporate world. Boston, Mass: Harvard Business Press.

Kim, J. (2011). Philosophy of mind (3rd ed.). Boulder, CO: Westview Press.

Kim, W. C., \& Mauborgne, R. (2005). Blue ocean strategy: How to create uncontested market space and make competition irrelevant. Boston, MA: Harvard Business Press.

Kouamé, S., \& Langley, A. (2018). Relating microprocesses to macro-outcomes in qualitative strategy process and practice research. Strategic Management Journal, 39(3), 559-581.

Laamanen, T., \& Wallin, J. (2009). Cognitive Dynamics of Capability Development Paths. Journal of Management Studies, 46(6), 950-981.

Lafley, A. G., \& Martin, R. L. (2013). Playing to win: how strategy really works. Boston, MA: Harvard Business Review Press.

Laine, P.-M., \& Vaara, E. (2007). Struggling over subjectivity: A discursive analysis of strategic development in an engineering group. Human Relations, 60(1), 29-58.

Lampel, J., Ghoshal, S., Mintzberg, H., \& Quinn, J. B. (2014). The strategy process: Concepts, contexts, cases (5th ed.). Harlow, United Kingdom: Pearson Education.

Langley, A., \& Lusiani, M. (2015). Strategic planning as practice. In D. Golsorkhi, D. Seidl, E. Vaara, \& L. Rouleau (Eds.), Cambridge handbook of strategy as practice (2 ed., pp. 547-563). Cambridge: Cambridge University Press.

Learned, E. P., Christensen, C. R., Andrews, K. R., \& Guth, W. D. (1965). Business policy: Text and cases. Homewood, IL: RD Irwin.

Levitt, T. (1962). Innovation in marketing: New perspectives for profit and growth. New York, NY: McGraw-Hill.

Lyles, M. A., \& Schwenk, C. R. (1992). Top management, strategy and organizational knowledge structures. Journal of Management Studies, 29(2), 155-174.

Lyles, M. A., \& Thomas, H. (1988). Strategic problem formulation: biases and assumptions embedded in alternative decision-making models. Journal of Management Studies, 25(2), 131-145.

Lyotard, J.-F. (1984). The postmodern condition: A report on knowledge (Vol. 10). Minneapolis, MN: University of Minnesota Press.

Maitlis, S., \& Lawrence, T. B. (2003). Orchestral manoeuvres in the dark: Understanding failure in organizational strategizing. Journal of Management Studies, 40(1), 109-139.

Managerial and Organizational Cognition Division - Domain Statement. (2018). Retrieved from http://moc.aom.org/index.php/about

Mantere, S. (2005). Strategic practices as enablers and disablers of championing activity. Strategic Organization, 3(2), 157-184.

Mantere, S. (2008). Role expectations and middle manager strategic agency. Journal of Management Studies, 45(2), 294-316.

Mantzavinos, A. (2016). Hermeneutics. The Stanford Encyclopedia of Philosophy. Fall 2016. Retrieved from https://leibniz.stanford.edu/friends/members/preview/hermeneutics/

Marabelli, M., Newell, S., \& Galliers, R. D. (2015). The role of power and materiality in healthcare improvement initiatives: A strategy-as-practice perspective. Thirty Sixth International Conference on Information Systems.

March, J. G., \& Simon, H. A. (1958). Organizations. New York, NY: John Willey \& Sons, Inc. 
Maturana, H. (2002). Autopoiesis, structural coupling and cognition: A history of these and other notions in the biology of cognition. Cybernetics \& Human Knowing, 9(3-4), 5-34.

McCrae, R. R. (1987). Creativity, divergent thinking, and openness to experience. Journal of Personality and Social Psychology, 52(6), 1258-1265. doi:10.1037/0022-3514.52.6.1258

McKenny, J. L., \& Keen, P. G. W. (1974). How managers' minds work. Harvard Business Review, 53(3), 79-90.

McKenzie, J., Woolf, N., van Winkelen, C., \& Morgan, C. (2009). Cognition in strategic decision making. Management Decision, 47(2), 209-232.

Miller, J. (2000). The passion of Michel Foucault. New York, NY: Simon \& Schuster.

Mintzberg, H. (1987). Crafting strategy. Harvard Business Review, 65(4), 66-74.

Mintzberg, H. (1994). Rise and fall of strategic planning. Harlow, United Kingdom: Pearson Education.

Mintzberg, H., Ahlstrand, B., \& Lampel, J. (1988). Strategy safari: A guided tour through the wilds of strategic management. New York, NY: Free Press.

Nadkarni, S., \& Barr, P. S. (2008). Environmental context, managerial cognition, and strategic action: an integrated view. Strategic Management Journal, 29(13), 1395-1427.

Neisser, U. (1967/2014). Cognitive Psychology. New York, NY: Psychology Press.

Nicolini, D. (2012). Practice theory, work, and organization: An introduction. Oxford, United Kingdom: Oxford University Press.

Nonaka, I., \& Takeuchi, H. (1995). The Knowledge-Creating Company. New York, NY: Oxford University Press.

Noonan, J. (2008). Ontology. In L. M. Given (Ed.), The SAGE Encyclopaedia of Qualitative Research Methods (Vol. 2, pp. 577-581). Thousand Oaks, CA: SAGE.

O’Farrell, C. (2005). Michel Foucault. London, United Kingdom: SAGE.

O’Leary, Z. (2014). The essential guide to doing your research project. London, United Kingdom: Sage.

Ohmae, K. (1982). The Mind of the Strategist. New York, NY: McGraw-Hill Book Company.

Ontology. (n.d.) dictionary.com. Retrieved from https://www.dictionary.com/browse/ontology?s=t, Date Accessed: 08 January 2020

Orlikowski, W. J. (2010). Practice in research: Phenomenon, perspective and philosophy. In D. Golsorkhi, D. Seidl, E. Vaara, \& L. Rouleau (Eds.), Cambridge handbook of strategy as practice (pp. 23-33). Cambridge, United Kingdom: Cambridge University Press.

Palich, L. E., \& Bagby, D. R. (1995). Using cognitive theory to explain entrepreneurial risk-taking: Challenging conventional wisdom. Journal of Business Venturing, 10(6), 425-438.

Palmer, R. R., Colton, J., \& Kramer, L. S. (2007). A history of the modern world (10th ed.). New York, NY: McCraw-Hill.

Pareto, V. (1935). The mind and society (Vol. 1): Рипол Классик.

Paroutis, S., Heracleous, L., \& Angwin, D. (2013). Practicing strategy: text and cases. London, United Kingdom: Sage.

Parsons, T. (1951). The Social System.

Penrose, E. T. (1959/1966). The theory of the growth of the firm. Oxford, England: Oxford Basil Blackwell.

Peteraf, M. A. (1993). The cornerstones of competitive advantage: a resource-based view. Strategic Management Journal, 14(3), 179-191. 
Peters, T. J., \& Waterman, R. H. (1982). In search of excellence: Lessons from America's best-run companies. New York, NY: Harper \& Row.

Pettigrew, A. M. (1992). The character and significance of strategy process research. Strategic Management Journal, 13(S2), 5-16.

Pettigrew, A. M., Thomas, H., \& Whittington, R. (Eds.). (2002). InHandbook of strategy \& management. London, United Kingdom: Sage.

Popular Business Strategy Books. (2016). Retrieved from https://www.goodreads.com/shelf/show/businessstrategy

Porac, J. F., Mishina, Y., \& Pollock, T. (2002). Entrepreneurial narratives and the dominant logics of high-growth firms. In A. S. Huff \& M. Jenkins (Eds.), Mapping strategic knowledge (pp. 112-136). London, United Kingdom: Sage.

Porac, J. F., \& Thomas, H. (2002). Managing cognition and strategy: Issues, trends and future directions. In A. M. Pettigrew, H. Thomas, \& R. Whittington (Eds.), Handbook of strategy and management (pp. 165181). London, United Kingdom: Sage.

Porac, J. F., Thomas, H., \& Baden-Fuller, C. (1989). Competitive groups as cognitive communities: the case of scottish knitwear manufacturers. Journal of Management Studies, 26(4), 397-416. doi:10.1111/j.14676486.1989.tb00736.x

Porter, M. E. (1979). On competition. Boston, MA: Harvard Business School Press.

Porter, M. E. (1985). Competitive strategy. New York, NY: Free Press.

Porter, S. E., \& Robinson, J. C. (2011). Hermeneutics: An introduction to interpretive theory. Grand Rapids, MI: William B. Eerdmans Publishing.

Powell, T. C., Lovallo, D., \& Fox, C. R. (2011). Behavioral strategy. Strategic Management Journal, 32(13), 13691386.

Quinn, J. B. (1980). Strategies for change: logical incrementalism: R.D. Irwin.

Ramberg, B., \& Gjesdal, K. (2005). Hermeneutics. Winter 2014. Retrieved from http://plato.stanford.edu/archives/win2014/entries/hermeneutics/

Reger, R. K., \& Huff, A. S. (1993). Strategic groups: A cognitive perspective. Strategic Management Journal, $14(2), 103-123$.

Regnér, P. (2003). Strategy creation in the periphery: Inductive versus deductive strategy making. Journal of Management Studies, 40(1), 57-82. doi:doi:10.1111/1467-6486.t01-1-00004

Rindova, V. P. (1999). What corporate boards have to do with strategy: A cognitive perspective. Journal of Management Studies, 36(7), 953-975.

Rorty, R. (1989/1999). Contingency, irony, and solidarity. Cambridge, United Kingdom: Cambridge University PRess.

Rorty, R. (1992). Twenty five years after. In R. Rorty (Ed.), The linguistic turn: Essays in philosophical method. Chicago, IL: The University of Chicago Press.

Rorty, R. (Ed.) (1967/1992). InThe linguistic turn: Essays in philosophical method. Chicago, IL: The University of Chicago Press.

Rouleau, L. (2005). Micro-practices of strategic sensemaking and sensegiving: How middle managers interpret and sell change every day. Journal of Management Studies, 42(7), 1413-1441. 
Rughase, O. G. (2002). Linking content to process: How mental models of the customer enhance creative strategy processes. In A. S. huff \& M. Jenkins (Eds.), Mapping strategic knowledge (pp. 46-62). London, United Kingdom: Sage.

Rumelt, R. P. (2011). Good strategy/bad strategy: The difference and why it matters. New York, NY: Crown Business.

Russell, B. (1961). The history of western philosophy. London, United Kingdom: Unwin Hyman.

Rust, J., \& Golombok, S. (1999). Modern Psychometrics (2nd ed.). London, United Kingdon: Routledge.

Samra-Fredericks, D. (2003). Strategizing as lived experience and strategists' everyday efforts to shape strategic direction. Journal of Management Studies, 40(1), 141-174. doi:10.1111/1467-6486.t01-100007

Sartre, J.-P. (1992/1975). Being and nothingness. New York, NY: Washington Square Press.

Schatzki, T. R., Cetina, K. K., \& von Savigny, E. (Eds.). (2001). InThe practice turn in contemporary theory. Oxon, United Kingdom: Routledge.

Schön, D. A. (1983). The reflective practitioner: How professionals think in action. New York, NY: Basic Books.

Schwenk, C. R. (1984). Cognitive simplification processes in strategic decision-making. Strategic Management Journal, 5(2), 111-128.

Schwenk, C. R. (1988). The cognitive perspective on strategic decision making. Journal of Management Studies, 25(1), 41-55.

Schwenk, C. R. (1989). Linking cognitive, organizational and political factors in explaining strategic change. Journal of Management Studies, 26(2), 177-187.

Seidl, D., \& Whittington, R. (2014). Enlarging the strategy-as-practice research agenda: towards taller and flatter ontologies. Organization Studies, 1407-1421.

Senge, P. M. (1990). The fith discipline: The art and practice of the learning organization. New York, NY: Doubleday.

Shields, C. (2016). Aristotle's Psychology. The Stanford Encyclopedia of Philosophy. Winter 2016. Retrieved from https://leibniz.stanford.edu/friends/members/view/aristotle-psychology/a4/

Sillince, J., \& Mueller, F. (2007). Switching strategic perspective: The reframing of accounts of responsibility. Organization Studies, 28(2), 155-176.

Simon, H. A. (1997). Administrative behavior: A study of decision-making processes in administrative organization (4 ed.). New York, NY: The Free Press.

Spender, J. (1998). The dynamics of individual and organizational knowledge. In C. Eden \& J. Spender (Eds.), Managerial and organizational cognition (pp. 13-39). London, United Kingdom: Sage.

Spender, J., \& Eden, C. (1998). Introduction Managerial and organizational cognition (pp. 1-12). London, United Kingdom: Sage.

Spender, J. C. (1989). Industry Recipes: An enquiry into the nature and sources of management judgement. London, United Kingdom: Basil Blackwell.

Steiner, G. A. (1979). Strategic Planning. New York, NY: The Free Press.

Stone, L. (2008). Epistemology. In L. M. Given (Ed.), The SAGE Encyclopaedia of Qualitative Research Methods (Vol. 1, pp. 264-268). Thousand Oaks, CA: SAGE.

Strategy \& Competition. (2016). Amazon Best Sellers. Retrieved from https://www.amazon.com/Best-SellersBooks-Strategy-Competition/zgbs/books/2553\#1 
Stubbart, C. I. (1989). Managerial cognition: A missing link in strategic management research. Journal of Management Studies, 26(4), 325-347.

Szulanski, G., Doz, Y., \& Ovetzky, Y. (2004). Incumbents' framing: three established companies respond to the internet. Advances in Strategic Management, 21, 77-106.

Thomas, J. B., Clark, S. M., \& Gioia, D. A. (1993). Strategic sensemaking and organizational performance: Linkages among scanning, interpretation, action, and outcomes. Academy of Management Journal, $36(2), 239-270$.

Tikkanen, H., Lamberg, J.-A., Parvinen, P., \& Kallunki, J.-P. (2005). Managerial cognition, action and the business model of the firm. Management Decision, 43(6), 789-809.

Titanic: Machine learning from disaster. (2019). Retrieved from https://www.kaggle.com/c/titanic

Tripsas, M., \& Gavetti, G. (2000). Capabilities, cognition, and inertia: Evidence from digital imaging. Strategic Management Journal, 21(10/11), 1147-1161.

Tsoukas, H. (2010). Practice, strategy making and intentionality: a Heideggerian onto-epistemology for Strategy as Practice. In D. Golsorkhi, D. Seidl, E. Vaara, \& L. Rouleau (Eds.), Cambridge handbook of strategy as practice (pp. 47-62). Cambridge, United Kingdom: Cambridge University Press.

Tsoukas, H. (2017). Strategy and virtue: Developing strategy-as-practice through virtue ethics. Strategic Organization, 16(3), 323-351.

Tversky, A., \& Kahneman, D. (1974). Judgment under uncertainty: Heuristics and biases. Science, 185(4157), 1124-1131.

Vaara, E., Kleymann, B., \& Seristö, H. (2004). Strategies as discursive constructions: The case of airline alliances. Journal of Management Studies, 41(1), 1-35.

Vaara, E., \& Whittington, R. (2012). Strategy-as-practice: Taking social practices seriously. The Academy of Management Annals, 6(1), 285-336.

van der Heijden, K. (1996). Scenarios: the art of strategic conversation. Chichester, United Kingdom: John Wiley $\&$ Sons.

van der Heijden, K., \& Eden, C. (1998). The theory and praxis of reflective learning in strategy making. In C. Eden \& J. Spender (Eds.), Managerial and organizational cognition: Theory, methods and research (pp. 58-75). London, United Kingdom: Sage.

Walsh, J. P. (1995). Managerial and organizational cognition: Notes from a trip down memory lane. Organization Science, 6(3), 280-321.

Watson, J. B. (1913). Psychology as the behaviorist views it. Psychological Review, 20(2), 158-177.

Weick, K. E. (1979). The social psychology of organizing (2nd ed.). New York, NY: McGraw-Hill.

Weick, K. E. (1995). Sensemaking in organizations. Thousand Oaks, CA: Sage.

Wernerfelt, B. (1984). A resource-based view of the firm. Strategic Management Journal, 5(2), 171-180.

Whittington, R. (1996). Strategy as practice. Long Range Planning, 29(5), 731-735.

Whittington, R. (2003). The work of strategizing and organizing: for a practice perspective. Strategic Organization, 1(1), 117-125.

Whittington, R. (2006). Completing the practice turn in strategy research. Organization Studies, 27(5), 613-634.

Whittington, R. (2007). Strategy practice and strategy process: Family differences and the sociological eye. Organization Studies, 28(10), 1575-1586. 
Whittington, R. (2010). Giddens, structuration theory and Strategy as Practice. In D. Golsorkhi, D. Seidl, E. Vaara, \& L. Rouleau (Eds.), Cambridge handbook of strategy as practice (pp. 109-126). Cambridge, United Kingdom: Cambridge University Press.

Whittington, R., Jarzabkowski, P., Mayer, M., Mounoud, E., Nahapiet, J., \& Rouleau, L. (2003). Taking strategy seriously: Responsibility and reform for an important social practice. Journal of Management Inquiry, 12(4), 396-409.

Wiener, N. (1954). The Human use of human beings: Cybernetics and society (Revised ed.). Boston, MA: Houghton Mifflin.

Wittgenstein, L. (1921/1974). Tractatus logico-philosophicus (D. F. Pears \& B. F. McGuiness, Trans.). London, United Kingdom: Routledge Classics.

Wolff, R. P. (1963). Kant's theory of mental activity: a commentary on the transcendental analytic of the critique of pure reason. Cambridge, MA: Harvard University Press.

Wolff, R. P. (2016). Kant, Critique of Pure Reason, Robert Paul Wolff Lectures 1-9. [Video File]. Retrieved from https://www.youtube.com/watch?v=d In2PQS60\&t=5s

Wright, R. P., Paroutis, S. E., \& Blettner, D. P. (2013). How useful are the strategic tools we teach in business schools? Journal of Management Studies, 50(1), 92-125.

Wundt, W. M. (1874/1910). Principles of physiological psychology (2nd English ed.). Frome, United Kingdom: Butler \& Tanner. 